\begin{abstract}
UNIVERSIDADE DE SÃO PAULO
FACULDADE DE MEDICINA DE RIBEIRÃO PRETO

DEPARTAMENTO DE NEUROCIÊNCIAS E CIÊNCIAS DO COMPORTAMENTO PROGRAMA DE PÓS-GRADUAÇÃO EM SAÚDE MENTAL
\end{abstract}

Tatiana luriko Kawasaki Nakabayashi

CARACTERIZAÇÃO DO PADRÃO DE SOLICITAÇÕES PSIQUIÁTRICAS EM UM HOSPITAL GERAL: ESTABILIDADE E MUDANÇAS EM UM PERÍODO DE 30 ANOS DE UM SERVIÇO DE INTERCONSULTA

RIBEIRÃO PRETO - SP 
TATIANA IURIKO KAWASAKI NAKABAYASHI

CARACTERIZAÇÃO DO PADRÃO DE SOLICITAÇÕES PSIQUIÁTRICAS EM UM HOSPITAL GERAL: ESTABILIDADE E MUDANÇAS EM UM PERÍODO DE 30 ANOS DE UM SERVIÇO DE INTERCONSULTA

Tese apresentada à Faculdade de Medicina de Ribeirão Preto da Universidade de São Paulo para a obtenção do título de Doutorado em Ciências Médicas.

Área de concentração: Saúde Mental

Orientador: Prof. Dr. José Alexandre de Souza Crippa

RIBEIRÃO PRETO - SP 
AUTORIZO A REPRODUÇÃO E DIVULGAÇÃO TOTAL OU PARCIAL DESTE TRABALHO, POR QUALQUER MEIO CONVENCIONAL OU ELETRÔNICO, PARA FINS DE ESTUDO E PESQUISA, DESDE QUE CITADA A FONTE.

FICHA CATALOGRÁFICA

Nakabayashi, Tatiana luriko Kawasaki

Caracterização do padrão de solicitações psiquiátricas em um hospital geral: estabilidade e mudanças em um período de 30 anos de um serviço de Interconsulta, 2012.

$214 p$.

Tese de Doutorado apresentada à Faculdade de Medicina de Ribeirão Preto da Universidade de São Paulo, 2012. Área de concentração: Saúde Mental. Orientador: José Alexandre de Souza Crippa.

1. Interconsulta psiquiátrica. 2. Hospital geral. 3. Padrões de uso. 4. Diagnósticos psiquiátricos. 
Nome: NAKABAYASHI, Tatiana luriko Kawasaki

Título: Caracterização do padrão de solicitações psiquiátricas em um hospital geral: estabilidade e mudanças em um período de 30 anos de um serviço de Interconsulta.

Tese apresentada à Faculdade de Medicina de Ribeirão Preto da Universidade de São Paulo para a obtenção do título de Doutorado em Ciências Médicas. Área de concentração: Saúde Mental

Aprovado em:

\section{Banca examinadora}

Prof. Dr.

Instituição: Assinatura:

Prof. Dr.

Instituição: Assinatura:

Prof. Dr. Instituição: Assinatura:

Prof. Dr. Instituição: Assinatura:

Prof. Dr. Instituição: Assinatura: 
Dedico este trabalho à minha amada família, Vaildo, Igor, Luana, Ivan, João Paulo, Sandro e, em especial à minha mãe, Sayuri, por tudo o que passamos juntas e por cada palavra de amor que sempre me confortou, me fortaleceu e me incentivou a ir além. Sem ela, este estudo não teria sido concretizado. 


\section{AGRADECIMENTOS}

Ao meu orientador, Prof. Dr. José Alexandre de Souza Crippa pela disponibilidade em me orientar, pela oportunidade e pela compreensão nos momentos em que mais precisei.

Aos professores do Programa de Pós-Graduação em Saúde Mental da Faculdade de Medicina de Ribeirão Preto, em especial ao Prof. Dr. Antonio Waldo Zuardi, ao Prof. Dr. Jaime Eduardo Cecílio Hallak e à Prof ${ }^{a}$. Dra. Sonia Regina Loureiro.

À Coordenação de Aperfeiçoamento de Pessoal de Nível Superior - CAPES, e à Fundação de Amparo à Pesquisa do Estado de São Paulo - FAPESP, pela ajuda financeira.

Às funcionárias Ivana Geraldo Cintra Faria, Selma Pontes e Júnia Adriano Wiezel, pela prontidão em me ajudar.

Aos colegas mestrandos e doutorandos do Programa de Pós-Graduação em Saúde Mental da Faculdade de Medicina de Ribeirão Preto, em especial ao Marcos Hortes, pelas disciplinas e discussões compartilhadas ao longo de todos esses anos, e também à Karen Aguirres Guerra, pela parceria na pesquisa no Hospital Universitário da Universidade Federal de Santa Catarina.

Ao Grupo de Interconsultas do Instituto de Psiquiatria do Hospital das Clínicas da Faculdade de Medicina da Universidade de São Paulo, em especial ao Prof. Dr. Renério Fráguas Jr, por ter me acolhido e me dado a preciosa oportunidade de participar das discussões semanais do grupo.

Aos irmãos que a vida me presenteou, João Paulo Basso Alves e Sandro Rodrigues Gontijo, pela companhia incondicional, pelo carinho e compreensão que ofereceram nos momentos mais difíceis e pelas inúmeras experiências que compartilhamos.

Às queridas amigas Ana Luisa Trevisam Martins, Ana Vilela Mendes, Carolina Meneses Gaya, Danielle Chaves Gomes de Oliveira e lla Linares, pelo apoio e pelas doces palavras e conselhos.

Aos meus companheiros de infância, Lylian Sanchez Oliveira, Taynã Malaspina e Valter Hugo Muniz Tenório Silva, pela torcida ao longo de toda a minha vida. 
À minha querida família de Ribeirão Preto, Sonia Zanon, Natalia, Dona Jandira, seu Ézio e, em especial, à Julia Zanon, pelo meu segundo lar.

Aos amigos que me incentivaram ao longo desta jornada de cinco anos, Adriana Azevedo, Alana Martins, Alzira Uemura, Bruno Pastorello, Bruno Rossi, Cintia Lopes Soares, Clarissa Trzesniak, Ederson Stahl Soares e Gisele Alves Constancia, Fabio Scorsolini Comin, Fernando Cassiolato de Freitas, Gisele Cabral, Halina Teixeira Lima, Hemil Uechi e Cristina Uechi, Henrique Serpa, Khallil Taverna Chaim, Maiana Eid, Marcia Luciano, Mariana Bellini, Milena Maretti, Monique Marcomini Massoneto, Paola Eid, Priscila Previato, Renato Capellari, Roberta e Paulo, Solang Taverna.

Aos meus tios e tias, Aida, Ana e Celso, Ester e Marlei, Fatinha, Íris, Kiko e Wagner, Meri, Nico e Ju, Regina e Rose, por me proporcionarem tanta alegria nos encontros familiares que me ajudou a seguir nesta jornada.

Aos meus primos, Auana, Danilo, Diego e Cibele, Gabriel, Ingrid, Larissa e Michael, Lucas e Roberta, Neuza e Simone, Priscila, Renata e Ricardo, Thiago e Caroline, Thula e Rafael e, em especial, ao Kawan e à Yaskara, por estarem comigo em todos os momentos, inclusive, em feriados que passamos trabalhando - guardo todos os lembretes espalhados pelos documentos com muito carinho.

Aos meus padrinhos, Paulo e Sandra, pelos inúmeros abraços tão acolhedores.

À tia Silvana, pelas palavras de incentivo, pelas conversas e conselhos, pelo cuidado e carinho, e pelos cafés.

À minha amada afilhada, Giulia, pela sua ternura que por tantas vezes aqueceu meu coração.

E aos meus pais, Vaildo e Sayuri, irmãos, Igor e Luana, e cunhado, Ivan, pelo exemplo de amor, de união e de força, especialmente nos momentos em que as dificuldades superavam as expectativas, meus sinceros agradecimentos. 


\title{
RESUMO
}

\begin{abstract}
NAKABAYASHI, T.I.K. Caracterização do padrão de solicitações psiquiátricas em um hospital geral: estabilidade e mudanças em um período de $\mathbf{3 0}$ anos de um serviço de Interconsulta. 2012. 214f. Tese (Doutorado) - Faculdade de Medicina de Ribeirão Preto, Universidade de São Paulo, Ribeirão Preto, 2012.
\end{abstract}

A Interconsulta Psiquiátrica é considerada por muitos pesquisadores como sendo a área prática e aplicada da Medicina Psicossomática, de conhecimento concernente à investigação da interação entre fatores biológicos e psicossociais no desenvolvimento, curso e resultado de todas as doenças. A prevalência de transtornos psiquiátricos em hospitais gerais pode variar de 20 a $40 \%$ entre pacientes internados, porém uma reduzida parcela é assistida pela Interconsulta e consequentemente recebe tratamento psiquiátrico. Sendo assim, o presente estudo teve por objetivos: a) obter informações dos dados sociodemográficos dos pacientes e seus históricos em saúde mental (tratamentos anteriores e tentativa de suicídio); b) analisar o uso do serviço de Interconsulta Psiquiátrica, tais como as clínicas solicitantes, função dos profissionais solicitantes, motivos de solicitação, tempo de internação dos pacientes assistidos, tempo de solicitação do $\mathrm{PI}$ e de sua resposta, e o número de atendimentos realizados; c) descrever os diagnósticos clínicos e psiquiátricos dos pacientes avaliados através dos critérios estabelecidos pela CID-10; d) analisar intervenções farmacoterapêuticas e não medicamentosas, tais como as condutas sugeridas pelo interconsultor, profissionais solicitados durante a internação, as medicações psicotrópicas em uso e prescritas; e) caracterizar aspectos relacionados aos médicos clínicos, aos profissionais de saúde e aos interconsultores; e f) avaliar a qualidade estrutural da solicitação psiquiátrica realizada pelo profissional clínico e a resposta dada pelo interconsultor. Para tanto, foi realizada uma análise retrospectiva de todas as solicitações consecutivas realizadas entre janeiro de 1981 a dezembro de 2010 para a Psiquiatria do Serviço de Interconsulta em Saúde Mental do Hospital das Clínicas da Faculdade de Medicina de Ribeirão Preto da Universidade de São Paulo assim como a consulta dos prontuários de todos os pacientes assistidos pelo serviço para obter outras informações. Foram realizadas 4882 solicitações psiquiátricas e a taxa de encaminhamento variou de 0,7 a $1,1 \%$. Dados sociodemográficos dos pacientes que foram atendidos com mais frequência relacionados ao sexo, cor e/ou etnia, estado civil, com quem os pacientes residiam (somente para os homens), situação laboral (somente para as mulheres), escolaridade e procedência tenderam a permanecer relativamente estáveis ao longo dos anos. As mulheres apresentaram idade média menor que os homens e foram atendidos com mais frequência: homens e mulheres casados (e mais homens solteiros quando comparados com as mulheres), homens que residiam com seus pais e mulheres que residiam com seus cônjuges e filhos, homens afastados de seus trabalhos e mulheres responsáveis pelos cuidados da casa, e também pacientes de ambos os sexos com idades entre 21 e 50 anos, pacientes caucasianos, pacientes procedentes do estado de São Paulo e 
pacientes com escolaridade até ensino fundamental completo. As mulheres foram mais frequentemente assistidas pelo serviço de Interconsulta Psiquiátrica ao longo de todos os anos, assim como ficaram menos tempo internadas e também tiveram solicitações psiquiátricas realizadas em um menor intervalo de tempo após a admissão hospitalar. Em trinta anos, a Clínica Médica Geral foi a clínica que mais realizou solicitações psiquiátricas, o motivo de solicitação mais frequente foi a presença de sintomas psiquiátricos e o tempo de internação dos pacientes assistidos pela Interconsulta foi maior quando comparado aos pacientes internados no hospital de modo geral. Os transtornos neuróticos, somatoformes e relacionados ao estresse foram os diagnósticos psiquiátricos mais comuns entre as mulheres e homens atendidos pelo SISMen, seguido pelos transtornos de humor e transtornos mentais orgânicos nas mulheres e transtornos mentais orgânicos e transtornos devido ao uso de substâncias nos homens. Já em relação ao diagnóstico clínico, foram atendidos com mais frequência mulheres com doenças endócrinas, metabólicas e nutricionais e homens com doenças infecciosas e parasitárias; e casos de múltiplas comorbidades clínicas se tornaram mais frequentes com o passar dos anos. As principais condutas sugeridas pelos interconsultores foram: atendimento individual, orientação à equipe e prescrição de psicofármacos para ambos os pacientes, permanecendo frequentes ao longo dos anos, com destaque para um aumento progressivo de casos em que medicações psicotrópicas foram prescritas a partir de meados dos anos 90 . E com o passar dos anos, os planos de tratamento se tornaram mais complexos e abrangentes e houve um aumento progressivo no número de encaminhamentos para atendimento psiquiátrico ambulatorial. Em relação à qualidade estrutural das solicitações psiquiátricas e das respostas dadas pelos interconsultores, ambas foram consideradas aceitáveis ou boas na maioria dos casos, sendo um indicativo positivo na qualidade de comunicação entre os profissionais. Pode-se dizer que este foi o primeiro estudo longitudinal a analisar consecutivamente trinta anos e também toda a população assistida por um serviço de Interconsulta Psiquiátrica.

Palavras-chave: Interconsulta psiquiátrica, hospital geral, padrões de uso, diagnósticos psiquiátricos. 


\begin{abstract}
NAKABAYASHI, T.I.K. Referral pattern of requests in a general hospital: stability and change over a period of $\mathbf{3 0}$ years of consultation-liaison service. 2012. 214s. Tese (Doutorado) - Faculdade de Medicina de Ribeirão Preto, Universidade de São Paulo, Ribeirão Preto, 2012.
\end{abstract}

Consultation-liaison Psychiatry is considered by many researchers as the practical and applied area of psychosomatic medicine, which is an area of knowledge concerning the investigation of the interaction between biological and psychosocial factors in the development, course and outcome of all diseases. The prevalence of psychiatric disorders in general hospitals range from 20 to $40 \%$ of hospitalized patients, but a small portion is assisted by the consultation-liaison and consequently receives psychiatric treatment. Considering this background, this study aimed: a) to obtain information about sociodemographic characteristics of patients and their mental health history (previous treatment and attempted suicide); b) to analyze the referral patterns of consultation-liaison psychiatry, such as referral sources, reasons for referral, length of stay, lagtime and other; c) to describe clinical and psychiatric diagnoses according by ICD-10; d) to analyze pharmacotherapeutic and non-drug interventions; e) to describe aspects related to physicians, health professionals and psychiatrists; and f) to analyze the structural quality of the request made by the physicians and psychiatrists. For this purpose, it was performed a retrospective analysis of all consecutive referrals made between January 1981 and December 2010 to consultation-liaison psychiatry of Hospital das Clínicas da Faculdade de Medicina de Ribeirão Preto da Universidade de São Paulo as well as the review of medical charts of all patients assisted by the service. 4882 referrals were made and consultation rate ranged from 0.7 to $1.1 \%$. Sociodemographic characteristics related to sex, color or ethnicity, marital status, patients who lived (for men), employment status (for women), education and origin tended to remain relatively stable over the years. Women had a lower average age than men and were seen more frequently: married men and women (and more single men compared with women), men who lived with their parents and women who lived with their spouses and children, and also patients of both sexes aged between 21 and 50 years, caucasian patients and patients from the state of Sao Paulo. Women were more often assisted by the consultation-liaison service over the years and the length of stay and lagtime were lower than men. In thirty years, internal medicine was the most frequent referral source, presence of psychiatric symptoms was the common reason for referral and the length of stay of patients assisted by consultation-liaison psychiatry was higher compared to those admitted to the hospital in general. The main clinical diagnoses for women and men were endocrine, nutritional and metabolic, cardiovascular diseases and infectious and parasitic diseases and cases with multiple morbidities have become more frequent over the years. One third of patients were diagnosed with neurotic disorders, stress related and somatoform disorders in women and men, 
followed by mood disorders and organic mental disorders in women, and organic mental disorders and due to substance use in men. The main interventions were individual therapy, guidelines for staff and prescription of psychotropic drugs for women and men. There was a increase in the number of referrals to outpatient psychiatric care. Psychiatric referrals and responses by psychiatrist were considered acceptable or good in most cases, a positive indicative on the quality of communication between professionals. This was the first longitudinal study to examine thirty years consecutively and also the entire population assisted by Consultation-liaison Psychiatry.

Keywords: Consultation-liaison psychiatry, referral patterns, general hospital, psychiatric diagnoses. 


\section{LISTA DE TABELAS}

\begin{tabular}{l|l} 
Tabela 1.1 & Fases do desenvolvimento da Interconsulta Psiquiátrica.
\end{tabular}

Tabela 1.2 Estudos desenvolvidos na década de 80 a respeito do funcionamento dos serviços de Interconsulta, características das amostras atendidas, comparações entre períodos, grupos de pacientes e entre serviços.

Tabela 1.3 Estudos prospectivos e multicêntricos a respeito dos serviços de Interconsulta Psiquiátrica.

Tabela 4.1 $\quad$ Frequência das variáveis com mais ausência de informação antes do uso dos protocolos de registro e depois da implementação dos mesmos.

Tabela 4.2 Número de solicitações realizadas ao serviço de Interconsulta Psiquiátrica, número de internações totais realizadas no HCFMRP-USP e taxas de encaminhamento entre janeiro de 1981 a dezembro de 2010.

Tabela 4.3 Números e frequências das solicitações psiquiátricas realizadas aos pacientes do sexo feminino e masculino entre janeiro de 1981 a dezembro de 2010.

Tabela 4.4 Números e frequências das faixas etárias e da cor/etnia dos pacientes do sexo feminino atendidos entre janeiro de 1981 a dezembro de 2010.

Tabela 4.5 Números e frequências das faixas etárias e da cor/etnia dos pacientes do sexo masculino atendidos entre janeiro de 1981 a dezembro de 2010.

Tabela 4.6 Estado civil e com quem ou onde moravam as mulheres atendidas pelo serviço de Interconsulta Psiquiátrica entre janeiro de 1981 a dezembro de 2010.

\begin{tabular}{l|l} 
Tabela 4.7 & Estado civil e com quem ou onde moravam os homens atendidos pelo
\end{tabular} serviço de Interconsulta Psiquiátrica entre janeiro de 1981 a dezembro de 2010. 
Tabela 4.9 Situação laboral dos homens atendidas pelo serviço de Interconsulta Psiquiátrica entre janeiro de 1981 a dezembro de 2010.

Tabela 4.10 Nível de escolaridade das mulheres atendidas pelo serviço de Interconsulta Psiquiátrica entre janeiro de 1981 a dezembro de 2010.

Tabela 4.11 Nível de escolaridade dos homens atendidos pelo serviço de Interconsulta Psiquiátrica entre janeiro de 1981 a dezembro de 2010.

Tabela 4.12 Cidade de procedência das mulheres atendidas pelo serviço de Interconsulta Psiquiátrica entre janeiro de 1981 a dezembro de 2010.

Tabela 4.13 Cidade de procedência dos homens atendidos pelo serviço de Interconsulta Psiquiátrica entre janeiro de 1981 a dezembro de 2010.

Tabela 4.14 Antecedentes em tratamento psiquiátrico e histórico de tentativas de suicídio das mulheres atendidas pelo serviço de Interconsulta Psiquiátrica entre janeiro de 1981 a dezembro de 2010.

Tabela 4.15 Antecedentes em tratamento psiquiátrico e histórico de tentativas de suicídio dos homens atendidos pelo serviço de Interconsulta Psiquiátrica entre janeiro de 1981 a dezembro de 2010.

Tabela 4.16 Clínicas que solicitaram atendimento às mulheres internadas no HCFMRP-USP entre janeiro de 1981 a dezembro de 2010.

Tabela 4.17 Clínicas que solicitaram atendimento aos homens internados no HCFMRP-USP entre janeiro de 1981 a dezembro de 2010.

Tabela 4.18 Especialidades da Clínica Médica que solicitaram atendimento às mulheres internadas no HCFMRP-USP entre janeiro de 1981 a dezembro de 2010.

Tabela 4.19 Especialidades da Clínica Médica que solicitaram atendimento aos homens internados no HCFMRP-USP entre janeiro de 1981 a dezembro de 2010.

Tabela 4.20 Função do profissional solicitante do PI aos pacientes internados no HCFMRP-USP entre janeiro de 1981 a dezembro de 2010. 
Tabela 4.21 Motivos alegados pelos profissionais clínicos para a avaliação psiquiátrica dos pacientes do sexo feminino internados entre janeiro de 1981 a dezembro de 2010.

Tabela 4.22 Motivos alegados pelos profissionais clínicos para a avaliação psiquiátrica dos pacientes do sexo masculino internados entre janeiro de 1981 a dezembro de 2010.

Tabela 4.23

Hipóteses diagnósticas psiquiátricas dadas pelos profissionais para os pacientes do sexo feminino atendidos pelo serviço de Interconsulta Psiquiátrica entre janeiro de 1981 a dezembro de 2010.

Tabela 4.24 Hipóteses diagnósticas psiquiátricas dadas pelos profissionais para os pacientes do sexo masculino atendidos pelo serviço de Interconsulta Psiquiátrica entre janeiro de 1981 a dezembro de 2010.

Tabela 4.25 Médias e medianas do tempo de internação (período decorrido entre a data de admissão no hospital e a data da alta hospitalar) dos pacientes do sexo feminino e do sexo masculino que tiveram solicitação psiquiátrica entre janeiro de 1981 a dezembro de 2010.

Tabela 4.26 Médias e medianas do tempo de solicitação (período decorrido entre a data de admissão no hospital e a data da solicitação psiquiátrica) dos pacientes do sexo feminino e do sexo masculino que tiveram solicitação psiquiátrica entre janeiro de 1981 a dezembro de 2010.

Tabela 4.27 Frequências das solicitações psiquiátricas atendidas em até 48 horas após seu recebimento e posterior a esse prazo.

Tabela 4.28 Médias e medianas do tempo de reposta (período decorrido entre a data da solicitação psiquiátrica e a data da resposta) dos pacientes do sexo feminino e do sexo masculino que tiveram solicitação psiquiátrica entre janeiro de 1981 a dezembro de 2010.

Tabela 4.29 Médias e medianas do número de atendimentos realizados pelo interconsultor para os pacientes do sexo feminino e do sexo masculino que tiveram solicitação psiquiátrica entre janeiro de 1981 a dezembro de 2010. 
Tabela 4.30 Médias e medianas gerais do tempo de internação (período decorrido entre a data de admissão no hospital e a data da alta hospitalar) e do tempo de solicitação (período decorrido entre a data de admissão no hospital e a data da solicitação psiquiátrica) de acordo com as faixas etárias dos pacientes dos sexos feminino e masculino que tiveram solicitação psiquiátrica entre janeiro de 1981 a dezembro de 2010.

Tabela 4.31 Médias e medianas gerais do tempo de internação (período decorrido entre a data de admissão no hospital e a data da alta hospitalar) e do tempo de solicitação (período decorrido entre a data de admissão no hospital e a data da solicitação psiquiátrica) de acordo com as clínicas solicitantes dos pacientes dos sexos feminino e masculino que tiveram solicitação psiquiátrica entre janeiro de 1981 a dezembro de 2010.

Tabela 4.32 Médias e medianas do tempo de internação (período decorrido entre a data de admissão no hospital e a data da alta hospitalar) das clínicas do HCFMRP-USP e dos pacientes que tiveram solicitação para atendimento psiquiátrico do SISMen no ano de 2010.

Tabela 4.33 Motivos de solicitação psiquiátrica e as médias e medianas do tempo de solicitação (período decorrido entre a data de admissão no hospital e a data da solicitação psiquiátrica).

Tabela 4.34 Médias e medianas gerais do tempo de internação (período decorrido entre a data de admissão no hospital e a data da alta hospitalar) e do tempo de solicitação (período decorrido entre a data de admissão no hospital e a data da solicitação psiquiátrica) de acordo com os diagnósticos clínicos dos pacientes dos sexos feminino e masculino que tiveram solicitação psiquiátrica entre janeiro de 1981 a dezembro de 2010.

Tabela 4.35 Médias e medianas gerais do tempo de internação (período decorrido entre a data de admissão no hospital e a data da alta hospitalar) de acordo com os diagnósticos psiquiátricos dos pacientes do sexo feminino e do sexo masculino que tiveram solicitação psiquiátrica entre janeiro de 1981 a dezembro de 2010.

Tabela 4.36 Diagnósticos clínicos segundo a CID-10 dos pacientes do sexo feminino atendidos pelo serviço de Interconsulta Psiquiátrica entre janeiro de 1981 a dezembro de 2010.

Tabela 4.37 Diagnósticos clínicos segundo a CID-10 dos pacientes do sexo masculino atendidos pelo serviço de Interconsulta Psiquiátrica entre janeiro de 1981 a dezembro de 2010. 
Tabela 4.38 Diagnósticos clínicos específicos dos pacientes de ambos os sexos atendidos pelo serviço de Interconsulta Psiquiátrica entre janeiro de 1981 a dezembro de 2010.

Tabela 4.39 Diagnósticos psiquiátricos segundo a CID-10 dos pacientes do sexo feminino atendidos pelo serviço de Interconsulta Psiquiátrica entre janeiro de 1981 a dezembro de 2010.

Tabela 4.40 Diagnósticos psiquiátricos específicos segundo a CID-10 dos pacientes do sexo feminino atendidos pelo serviço de Interconsulta Psiquiátrica entre janeiro de 1981 a dezembro de 2010.

Tabela 4.41 Diagnósticos psiquiátricos segundo a CID-10 dos pacientes do sexo masculino atendidos pelo serviço de Interconsulta Psiquiátrica entre janeiro de 1981 a dezembro de 2010.

Tabela 4.42 Diagnósticos psiquiátricos específicos segundo a CID-10 dos pacientes do sexo masculino atendidos pelo serviço de Interconsulta Psiquiátrica entre janeiro de 1981 a dezembro de 2010.

Tabela 4.43 Frequências dos principais diagnósticos clínicos encontrados nos pacientes com diagnósticos psiquiátricos entre janeiro de 1981 a dezembro de 2010.

Tabela 4.44 Ideação suicida detectada pelo interconsultor nos pacientes de ambos os sexos atendidos pelo serviço de Interconsulta Psiquiátrica entre janeiro de 1981 a dezembro de 2010.

Tabela 4.45 Condutas sugeridas pelo interconsultor para os pacientes do sexo feminino avaliadas entre janeiro de 1981 a dezembro de 2010.

Tabela 4.46 Condutas sugeridas pelo interconsultor para os pacientes do sexo masculino avaliados entre janeiro de 1981 a dezembro de 2010.

Tabela 4.47 Planos de tratamentos e o número de condutas sugeridas para os pacientes de ambos os sexos avaliados entre janeiro de 1981 a dezembro de 2010.

Tabela 4.48 Profissionais solicitados pelo interconsultor para os pacientes do sexo feminino avaliados entre janeiro de 1981 a dezembro de 2010. 
Tabela 4.49 Profissionais solicitados pelo interconsultor para os pacientes do sexo masculino avaliados entre janeiro de 1981 a dezembro de 2010.

Tabela 4.50 Medicações em uso antes da avaliação do interconsultor, medicações suspensas e prescritas após a avaliação dos pacientes do sexo feminino avaliados entre janeiro de 1981 a dezembro de 2010.

Tabela 4.51 Medicações em uso antes da avaliação do interconsultor, medicações suspensas e prescritas após a avaliação dos pacientes do sexo masculino avaliados entre janeiro de 1981 a dezembro de 2010.

Tabela 4.52 Encaminhamentos dos pacientes do sexo feminino propostos pelo interconsultor após a alta hospitalar.

Tabela 4.53 Encaminhamentos dos pacientes do sexo masculino propostos pelo interconsultor após a alta hospitalar.

Tabela 4.54 Frequências dos casos em que o profissional solicitante informou o paciente a respeito da consulta do psiquiatra interconsultor e dos casos em que o paciente recebeu alta hospitalar sem o conhecimento do psiquiatra interconsultor.

Tabela 4.55 Legibilidade da solicitação psiquiátrica escrita pelo profissional clínico e a legibilidade da resposta escrita pelo interconsultor para os pacientes de ambos os sexos atendidos pelo serviço de Interconsulta Psiquiátrica entre janeiro de 1981 a dezembro de 2010.

Tabela 4.56 Uso de siglas para a identificação dos diagnósticos clínicos nas solicitações psiquiátricas escritas pelos profissionais clínicos para os pacientes de ambos os sexos atendidos pelo serviço de Interconsulta Psiquiátrica entre janeiro de 1981 a dezembro de 2010.

Tabela 4.57 Registro do nome do profissional clínico, manifestação por escrito de sua expectativa por atendimento na solicitação psiquiátrica e a identificação do interconsultor responsável pelo atendimento do caso.

Tabela 4.58 Aspectos gerais da solicitação psiquiátrica feita pelo profissional clínico e de sua resposta escrita feita pelo interconsultor. 


\section{LISTA DE FIGURAS}

\begin{tabular}{l|l} 
Figura 4.1 & Principais clínicas que solicitaram atendimento a pacientes do sexo
\end{tabular} feminino internados no HCFMRP-USP entre janeiro de 1981 a dezembro de 2010.

Figura 4.2 $\quad$ Principais clínicas que solicitaram atendimento a pacientes do sexo masculino internados no HCFMRP-USP entre janeiro de 1981 a dezembro de 2010.

Figura 4.3 $\quad$ Principais especialidades da Clínica Médica que solicitaram avaliação psiquiátrica a pacientes do sexo feminino em trinta anos de serviço de Interconsulta Psiquiátrica no HCFMRP-USP.

\begin{tabular}{l|l} 
Figura 4.4 & Principais especialidades da Clínica Médica que solicitaram avaliação
\end{tabular} psiquiátrica a pacientes do sexo masculino em trinta anos de serviço de Interconsulta Psiquiátrica no HCFMRP-USP.

Figura 4.5 $\quad$ Principais diagnósticos psiquiátricos dos pacientes do sexo feminino internados no HCFMRP-USP entre janeiro de 1981 a dezembro de 2010.

\begin{tabular}{l|l} 
Figura 4.6 & Principais diagnósticos psiquiátricos dos pacientes do sexo masculino
\end{tabular} internados no HCFMRP-USP entre janeiro de 1981 a dezembro de

2010.

\begin{tabular}{l|l} 
Figura 4.7 & Confirmações diagnósticas pelos interconsultores das hipóteses de
\end{tabular} transtornos devido ao uso de substâncias levantadas pelos profissionais solicitantes.

Confirmações diagnósticas pelos interconsultores das hipóteses de transtornos neuróticos, somatoformes e relacionados ao estresse levantadas pelos profissionais solicitantes.

Figura 4.8

Figura 4.9 Confirmações diagnósticas pelos interconsultores das hipóteses de esquizofrenia, transtornos esquizotípicos e delirantes levantadas pelos profissionais solicitantes. 
Figura 4.10 Confirmações diagnósticas pelos interconsultores das hipóteses de transtornos orgânicos mentais levantadas pelos profissionais solicitantes.

Figura 4.11 Confirmações diagnósticas pelos interconsultores das hipóteses de transtornos de personalidade e do comportamento adulto levantadas

pelos profissionais solicitantes.

Figura 4.12 Confirmações diagnósticas pelos interconsultores das hipóteses de transtornos do humor levantadas pelos profissionais solicitantes.

Figura 4.13 Principais condutas sugeridas pelo interconsultor aos pacientes do sexo feminino entre janeiro de 1981 a dezembro de 2010.

Figura 4.14 Principais condutas sugeridas pelo interconsultor aos pacientes do sexo masculino entre janeiro de 1981 a dezembro de 2010.

Figura 4.15 Principais medicações prescritas ou com doses reajustadas pelo interconsultor após a visita aos pacientes do sexo feminino entre janeiro de 1981 a dezembro de 2010.

\begin{tabular}{l|l} 
Figura 4.16 & Principais medicações prescritas ou com doses reajustadas pelo in-
\end{tabular} terconsultor após a visita aos pacientes do sexo masculino entre janeiro de 1981 a dezembro de 2010. 


\section{LISTA DE ABREVIATURAS E SIGLAS}

CEBRID Centro Brasileiro de Informações sobre Drogas Psicotrópicas

CID-10 | Classificação Estatística Internacional de Doenças e Problemas relacionados à Saúde, $10^{\underline{a} \text { revisão }}$

ECLW European Consultation-Liaison Workgroup for General Hospital Psychiatry and Psychosomatics

HCFMRP-USP $\mid$ Hospital das Clínicas da Faculdade de Medicina de Ribeirão Preto da Universidade de São Paulo

HIV Vírus da imunodeficiência humana

HU-UFSC $\mid$ Hospital Universitário Professor Polydoro Ernani de São Thiago da Universidade Federal de Santa Catarina

IBGE Instituto Brasileiro de Geografia e Estatística

MINI Mini International Neuropsychiatric Interview

OMS $\mid$ Organização Mundial da Saúde

PI Pedido de Interconsulta

\begin{tabular}{l|l} 
PRISMe & Protocolo de Registro de Interconsulta em Saúde Mental
\end{tabular}

SAMe $\quad$ Serviço de Arquivo Médico

\begin{tabular}{l|l} 
SENAD & Secretaria Nacional Antidrogas
\end{tabular}

SISMen Serviço de Interconsulta em Saúde Mental

SUS Sistema Único de Saúde 
TMC $\mid$ Transtornos Mentais Comuns

UE Unidade de Emergência

UETDI Unidade Especial de Terapia de Doenças Infecciosas

UIPHG $\quad$ Unidade de Internação Psiquiátrica em Hospital Geral

\begin{tabular}{l|l} 
UNIFESP & Universidade Federal de São Paulo
\end{tabular}

USP Universidade de São Paulo 


\section{SUMÁRIO}

1. INTRODUÇÃO

1.1. Assistência psiquiátrica no hospital geral: aspecto histórico

1.2. Prevalência de transtornos mentais nas populações

1.3. Estudos a respeito da Interconsulta Psiquiátrica 35

2. OBJETIVOS

2.1. Geral 40

2.2. Específicos

3. MÉTODO

3.1. Caracterização do local de estudo 43

3.2. Procedimento de coleta e registro dos dados 45

3.2.1. Amostra

3.2.2. Registro dos dados e análise das solicitações psiquiátricas 46

3.3. Procedimento de análise dos dados 51

3.4. Aspectos éticos

\section{RESULTADOS}

4.1. Taxas de encaminhamento

4.2. Caracterização sociodemográfica e histórico em Saúde Mental dos pacientes

4.2.1. Caracterização sociodemográfica 56

4.2.2. Histórico em Saúde Mental

4.3. Uso do serviço de interconsulta psiquiátrica 65

4.3.1. Clínicas solicitantes 65

4.3.2. Funções dos profissionais solicitantes

4.3.3. Motivos para solicitação psiquiátrica 72

4.3.4. Tempo de internação 75

4.3.5. Tempo de solicitação 76

4.3.6. Tempo de resposta 
4.3.7. Número de atendimentos realizados

4.3.8. Tempo de internação, tempo de solicitação e outros achados

4.3.8.1. Tempo de internação, de solicitação e faixa etária 79

4.3.8.2. Tempos de internação, de solicitação e clínicas solicitantes 80

4.3.8.3. Tempo de solicitação e motivos dos Pls 81

4.3.8.4. Tempos de internação, de solicitação e diagnósticos clínicos 82

4.3.8.5. Tempo de internação e diagnósticos psiquiátricos 83

4.4. Diagnósticos clínicos, diagnósticos psiquiátricos e ideação suicida

4.4.1. Diagnósticos clínicos 84

4.4.2. Diagnósticos psiquiátricos 88

4.4.3. Diagnósticos clínicos, diagnósticos psiquiátricos e outros achados

4.4.4. Concordância entre hipóteses e diagnósticos psiquiátricos 96

4.4.5. Ideação suicida 102

4.5. Planos de tratamento e medicações psicotrópicas 103

4.5.1. Planos de tratamento 103

4.5.2. Medicações psicotrópicas 108

4.5.3. Encaminhamentos 112

4.6. Aspectos relacionados aos profissionais de saúde e aos interconsultores 114

4.7. Qualidade estrutural do PI e de sua resposta

\section{DISCUSSÃO}

5.1. Taxas de encaminhamento

5.2. Caracterização sociodemográfica e histórico em saúde mental dos pacientes 129

5.3. Uso do serviço de interconsulta psiquiátrica 136

5.4. Diagnósticos clínicos, diagnósticos psiquiátricos e ideação suicida 153

5.5. Planos de tratamento e medicações psicotrópicas 163

5.6. Aspectos relacionados aos profissionais de saúde e aos interconsultores 167

5.7. Qualidade estrutural do PI e de sua resposta 169 
1. Protocolo de Registro de Interconsulta em Saúde Mental - PRISMe 195

2. Aprovação pelo Comitê de Ética em Pesquisa do HCFMRP-USP 197

3. Termo de Dispensa 198

ARTIGO PUBLICADO RELACIONADO À TESE 


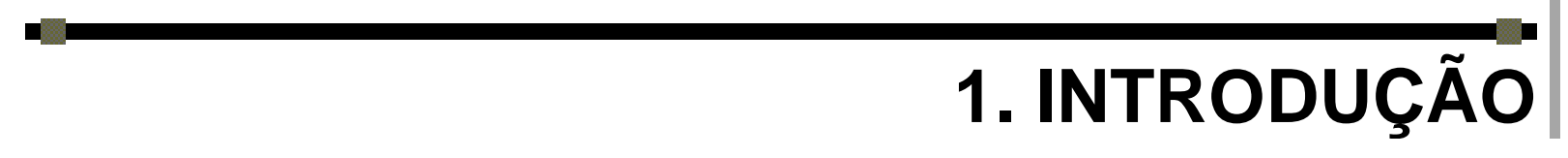




\subsection{ASSISTÊNCIA PSIQUIÁTRICA NO HOSPITAL GERAL:} ASPECTO HISTÓRICO

Na Idade Média, indivíduos considerados "loucos" e que se mostravam violentos ou inconvenientes, eram privados da convivência social e conduzidos aos hospitais gerais, cadeias ou casas para pobres. Segundo Foucault (1986, apud DALGALARRONDO, 1990, p.19), os hospitais gerais dessa época eram instituições desprovidas de caráter médico, podendo ser consideradas um recurso misto de exclusão social, de caridade e de assistência espiritual. Os indivíduos que adentravam nos hospitais, muitas vezes marginalizados sociais, eram diagnosticados e encaminhados para instituições afastadas dos grandes centros urbanos caso fossem considerados ameaça para a ordem social, promovendo uma reclusão indiscriminada da loucura - época esta denominada por Foucault de "O Grande Enclausuramento".

Não diferente do contexto mundial, no Brasil do início do século XIX, os "loucos" eram conduzidos aos porões das Santas Casas de Misericórdia e prisões públicas (FIGUEIREDO, 1996) e, em 1852, foi inaugurado o primeiro hospício brasileiro, instalado no Rio de Janeiro.

A loucura se tornou objeto de domínio do discurso médico-científico apenas em meados do século XVIII e início do século XIX, com as conquistas científicas nas áreas de conhecimento acerca da anatomia patológica, da microbiologia e da bioquímica (FOUCAULT, 1972/1997, apud VECHI, 2004, p.490). Começou, então, a instaurar uma mudança no paradigma da época: as doenças mentais passaram a serem consideradas doenças com base em alterações fisiológicas do cérebro e os 
aspectos psicológicos e sociais do indivíduo não eram cogitados.

No século XX, com a psicanálise de Freud, houve uma remodelagem do olhar clínico sob o indivíduo. Começou-se a questionar a visão organicista proposta pela medicina e a concepção de um adoecer psíquico começou a ser implementada na prática e nas pesquisas médicas. E foi também nesta época que emergiram críticas a respeito dos maus tratos e das condições precárias dos hospícios (DALGALARRONDO, 1990).

Foi apenas no final da $2^{\underline{a}}$ Guerra Mundial que propostas alternativas ao enclausuramento dos doentes mentais em hospícios se fortaleceram, pois a experiência de internações psiquiátricas curtas de militares e a rapidez com que os mesmos se recuperavam e retornavam à guerra se mostrou muito promissor.

Foi então que as Unidades de Internação Psiquiátrica em Hospital Geral (UIPHGs) e os serviços de Interconsulta Psiquiátrica se estabeleceram como uma alternativa terapêutica oferecendo um serviço com planejamento terapêutico e de reabilitação, abordagens psicoterápicas, além de internações breves como tentativa de combate à dimensão segregadora e estigmatizante da conduta psiquiátrica até então vigente (BOTEGA, 2006). Desta forma, a idéia principal dessa proposta era possibilitar o tratamento com o mínimo distanciamento do indivíduo de sua comunidade de origem.

O crescimento numérico das UIPHGs foi um fenômeno mundial, sendo mais significativo nos países da América do Norte e Europa, e também acompanhado por um decréscimo de leitos e internações em hospitais psiquiátricos. Foi apenas na década de 50 que foi discutida a necessidade de UIPHGs no Brasil, sendo, em 1954, instaladas UIPHGs no Hospital das Clínicas da Faculdade de Medicina da Universidade da Bahia, pela iniciativa do Prof. Nelson Pires, no Hospital dos Comerciários de 
São Paulo, pelo Dr. Laertes Fernão e, em 1957, no Hospital Pedro II da Faculdade de Medicina da Universidade Federal de Pernambuco (DALGALARRONDO, 1990). Esta prática foi amplamente difundida pelo país nas décadas seguintes.

Em relação à Interconsulta Psiquiátrica, esta foi considerada por muitos pesquisadores como sendo a área prática e aplicada da chamada "Medicina Psicossomática" (ROGERS; FRICCHIONE; REICH, 1999, apud ALI et al., 2006; LIPOWSKI, 2002, apud ALI et al., 2006). Segundo Lipowski (2002, apud ALI et al., 2006), entende-se por "Medicina Psicossomática" uma área de conhecimento concernente à investigação da interação entre fatores biológicos e psicossociais no desenvolvimento, curso e resultado de todas as doenças. Sendo assim, a Interconsulta Psiquiátrica teve um papel estratégico na integração e interação entre a Psiquiatria e as outras clínicas médicas dentro do hospital geral, introduzindo à Medicina Geral elementos da Psicologia Médica, Psicologia Social, Psicanálise e Antropologia Médica, e favorecendo, assim, o aparecimento de um novo modelo de assistência, de pesquisa e de formação de profissionais da saúde. Originalmente, o termo "psicossomático" foi criado por Heinroth em 1918, a fim de referir-se ao modelo psicológico e neurofisiológico e às influências da mente no corpo, sendo o homem considerado em seu caráter holístico (BOTEGA, 2006).

De acordo com Ali et al. (2006), o desenvolvimento da Interconsulta Psiquiátrica pode ser dividido em quatro fases: i) preliminar; ii) organização e pioneirismo; iii) desenvolvimento, que inclui desenvolvimento conceitual e de crescimento; e iv) consolidação (Tabela 1.1). 
Tabela 1.1 - Fases do desenvolvimento da Interconsulta Psiquiátrica.

\begin{tabular}{|c|c|}
\hline FASES & ACONTECIMENTOS \\
\hline Preliminar & $\begin{array}{l}\text { Antes de } 1900 \text { a } 1930 \\
\text { Novo papel do hospital e das práticas médicas } \\
\text { Primeira Guerra Mundial } \\
\text { 1902: primeira unidade de internação psiquiátrica em hospital geral (Albany Hospital) } \\
\text { 1929: primeiro estudo clínico publicado sobre Interconsulta Psiquiátrica }\end{array}$ \\
\hline Organização / Pioneirismo & $\begin{array}{l}1930 \text { a } 1950 \\
\text { Primeiros estudos sobre custo/benefício } \\
\text { 1953: fundação da Academy of Psychosomatic Medicine } \\
\text { Inauguração de diversos serviços de Interconsulta com diferentes modelos }\end{array}$ \\
\hline Desenvolvimento & $\begin{array}{l}1950 \text { a } 1980 \\
\text { Período de pós Segunda Guerra Mundial }\end{array}$ \\
\hline Conceitual & $\begin{array}{l}1960 \text { a } 1975 \\
\text { Estudos, publicações e eventos relacionados à Interconsulta Psiquiátrica }\end{array}$ \\
\hline Crescimento & $\begin{array}{l}1975 \text { a } 1980 \\
\text { Aumento no número de serviços de Interconsulta Psiquiátrica } \\
\text { Mais programas de treinamento e modelos de funcionamento de Interconsulta Psiquiátrica }\end{array}$ \\
\hline Consolidação & $\begin{array}{l}1980 \text { até o presente } \\
\text { Debate entre consultoria psiquiátrica e psiquiatria de ligação } \\
\text { Redução dos serviços de Interconsulta e reavaliação dos objetivos } \\
\text { Enfermagem psiquiátrica } \\
\text { Investigação do custo-efetividade dos serviços de Interconsulta Psiquiátrica }\end{array}$ \\
\hline
\end{tabular}

Baseado em Ali et al. (2006)

Ao longo dos anos, pôde-se identificar um aumento na valorização desse tipo de assistência psiquiátrica nos hospitais gerais. Muitos países começaram a investir na formação de psiquiatras especializados em Interconsulta, oferecendo estágios na área e ampliando o conhecimento através de pesquisas e eventos científicos. A importância desse investimento reside no fato de que há uma elevada morbidade psiquiátrica em pacientes internados em hospitais gerais e em atendimentos na atenção primária, além do aumento da população idosa e aumento da frequência de transtornos mentais, das doenças crônicas e distúrbios psicossociais e psiquiátricos associados. Além disso, este tipo de assistência acompanhou o movimento de valorização da "humanização" dos hospitais, da qualidade de vida e da adesão dos 
pacientes ao tratamento (BOTEGA, 2006).

No Brasil, no início da década de 1980, essa mudança no panorama da atenção psiquiátrica foi reforçada pelos movimentos em defesa dos direitos civis e diversos programas nacionais de saúde mental foram implementados. Atualmente, a assistência psiquiátrica no hospital geral, em sua maioria, inclui não só as unidades de internação e a Interconsulta Psiquiátrica, como também o serviço de emergência e $o$ atendimento ambulatorial.

Segundo Shavitt, Busatto Filho e Miguel Filho (1989), entende-se por Interconsulta Psiquiátrica sensu lato a atuação de um psiquiatra juntamente com profissionais de outras especialidades. Dentro desta área, existem duas modalidades de interação entre os profissionais: a consultoria, que consiste na atuação do psiquiatra na avaliação e indicação de tratamento para pacientes que estão sob cuidados de outros especialistas, sendo o contato episódico e em resposta a uma solicitação específica do serviço; e a psiquiatria de ligação, que diz respeito ao psiquiatra que é membro da equipe médica e cuja participação é contínua. Assim, preocupações com a relação entre equipe assistencial, paciente e instituição também costumam ser aspectos relevantes em seu trabalho.

Portanto, o foco de atuação do interconsultor está centrado em quatro vertentes: (i) no médico; (ii) no paciente; (iii) na relação médico-paciente e (iv) na relação médico-instituição. O objetivo último do trabalho em Interconsulta:

\footnotetext{
"é melhorar a qualidade da atenção ao paciente, auxiliando na provisão de cuidados a todos os aspectos envolvidos na situação de estar doente e hospitalizado. Outros objetivos podem ser também destacados, tais como modificar a estrutura assistencial centrada na doença para uma forma de trabalho centrada no paciente, valorizar o papel da relação médico-paciente, aprofundar o estudo da situação do doente e dos profissionais nas instituições assistenciais, bem como aproximar a psiquiatria das outras especialidades médicas" (BOTEGA, 2006, p.25).
} 
As palestras de Isaac Luchina (psicanalista argentino, com produções literárias em 1977 e 1979) e suas participações em eventos científicos e em grupos de formação de interconsultores contribuíram muito para o desenvolvimento de uma cultura acerca da implementação do serviço de Interconsulta no Brasil. E, em 1977, iniciou-se o primeiro serviço de Interconsulta profissionalizante no programa de residência médica oferecido pelo Departamento de Psiquiatria e Psicologia Médica da Escola Paulista de Medicina (BOTEGA, 2006).

\subsection{PREVALÊNCIA DE TRANSTORNOS MENTAIS NAS POPULAÇÕES}

Muitos estudos acerca da freqüência e da distribuição dos transtornos mentais na população em geral foram desenvolvidos ao longo dos anos. Porém, a falta de critérios diagnósticos mais definidos e a ausência de instrumentos padronizados limitaram o avanço deste campo de pesquisa até a segunda metade do século $X X$. Notou-se também que pouco foi estudado acerca da prevalência de transtornos psiquiátricos em cidades com menor desenvolvimento urbano e populacional.

Segundo Lima (2004), os estudos iniciais sobre a prevalência apresentaram resultados que variaram de 1 a 50\% devido às diferenças metodológicas. Contudo, achados comuns entre esses estudos foram que, apesar das "alterações psicopatológicas serem frequentes nas comunidades, estas não se distribuíam aleatoriamente e apenas uma pequena minoria de casos chegava aos profissionais de saúde mental" (LIMA, 2004, p.5). 
Tais achados motivaram o aprimoramento de metodologias de pesquisa e começaram as ser utilizadas escalas estruturadas e entrevistas, além da criação de projetos de pesquisa de âmbito nacional - como o projeto organizado pelo National Institute of Mental Health abrangendo populações de regiões norte-americanas com 270 a 420 mil habitantes. Neste estudo, foram utilizados critérios diagnósticos baseados no DSM-III e uma entrevista padronizada, revelando uma prevalência de transtornos mentais por volta de 15\% (DALGALARRONDO, 1990; LIMA, 2004).

Outros estudos que utilizaram os critérios diagnósticos do DSM-III e DSM-IIIR, encontraram prevalências entre 15,4 a 36,0\% nos países da América do Norte, América Latina e Europa (REGIER et al., 1988; KESSLER et al., 1994; VEGA et al., 1998; KESSLER et al., 2001; NARROW et al., 2002; PARADA et al., 2002; VINCENTE et al., 2006) e, no Brasil, entre 15,2 a 45,6\% (BUSNELLO; PEREIRA; KNAPP, 1992; ALMEIDA-FILHO et al., 1997; ANDRADE et al., 1999).

Bijl et al. (2003) analisaram a prevalência de transtornos mentais em cinco países diferentes (Alemanha, Canadá, Chile, Estados Unidos e Holanda), com populações representativas e acima de 15 anos, de acordo com os critérios do DSMIV. Encontraram prevalências que variaram entre 17,0 (Chile) e 29,1\% (Estados Unidos); sendo 4,9 a $11,9 \%$ para transtornos do humor, 5,0 a $17,0 \%$ para transtornos ansiosos e 5,2 a 11,5\% para uso de substâncias psicoativas.

Outro estudo que contou com a participação de 14 países foi o desenvolvido pela Organização Mundial da Saúde, OMS (WORLD MENTAL HEALTH SURVEY CONSORTIUM, 2004). Os países participantes foram: Alemanha, Bélgica, China, Colômbia, Espanha, Estados Unidos, França, Holanda, Itália, Japão, México, Nigéria, República do Líbano e Ucrânia; e as prevalências variaram de 4,3 (na China) a 26,4\% (nos Estados Unidos), com amplitude inter-quartil de 9,1 (Alemanha) a 16,9\% 
(República do Líbano), de acordo com os critérios estabelecidos pelo DSM-IV.

No Brasil, Morgado e Coutinho (1985) investigaram a prevalência em amostras representativas da população (encontrando um valor de $20 \%$ ) e em estudos de famílias $(23,2 \%$ de prevalência de transtorno psiquiátrico) e também o indicador de morbidade proporcional, mostrando que as primeiras internações têm aumentado ao longo dos anos assim como o diagnóstico de esquizofrenia e dependência de drogas, incluindo o álcool.

A São Paulo Megacity Mental Health Survey - um segmento brasileiro da World Mental Health Survey Initiative, liderada pela OMS (VIANA et al., 2009) procurou investigar a prevalência de transtornos psiquiátricos na região paulista. 39 municípios de São Paulo foram incluídos no estudo e a amostra representativa da população foi de 5037 pessoas acima de 18 anos, sendo utilizados os critérios diagnósticos do DSM-IV para os transtornos psiquiátricos. A prevalência encontrada foi de $29,6 \%$ - os transtornos ansiosos foram os mais frequentes $(19,9 \%)$, seguidos pelos transtornos de humor (11\%) (ANDRADE et al., 2012).

Também foram realizados estudos que investigaram a prevalência dos chamados Transtornos Mentais Comuns (TMC), conceito introduzido por David Goldberg (1996, apud MEDEIROS, 2010). São considerados TMC os transtornos não-psicóticos depressivos, ansiosos e somatoformes que acometem a capacidade funcional do indivíduo, porém não preenchem os critérios formais para diagnóstico de depressão e/ou ansiedade segundo o DSM-IV e a CID-10. Este conceito foi amplamente utilizado nos estudos de prevalência devido à consideração de quadros subclínicos que apresentam sintomas como insônia, fadiga, irritabilidade, esquecimento, dificuldade de concentração e queixas somáticas e que, portanto, pode retratar de uma forma mais fidedigna a saúde mental da comunidade 
(COELHO, 2006). As prevalências encontradas desses TMC foram de 12,4 a 36,0\% (REICHENHEIM; HARPHAM, 1991; LIMA; SOARES; MARI, 1999; KORTEN; HENDERSON, 2000; ARAYA et al., 2001; WEICH; LEWIS; JENKINS, 2001; LUDERMIR; MELO FILHO, 2002; GISPERT et al., 2003; LIMA, 2004; MARAGNO et al., 2006; KING et al., 2008; COELHO et al., 2009; MEDEIROS, 2010).

Segundo Mayou e Hawton (1986), transtornos psiquiátricos são ainda mais recorrentes em enfermarias de emergência e em unidades que lidam com pacientes em estado crítico, sendo que a prevalência de transtornos psiquiátricos em hospitais gerais de modo geral, e universitários em particular, pode variar de 20 a $40 \%$ dos pacientes internados (MAYOU; HAWTON, 1986; SELTZER, 1989; LEUNG; CHAN; CHENG, 1992; SILVERSTONE, 1996; HANSEN et al., 2001). Neste mesmo sentido, achados de Gelfand e Kiely (1980) encontraram que um a cada cinco pacientes admitidos no serviço médico necessitaria de avaliação e cuidado psiquiátrico após o uso de um questionário de rastreamento.

Ao longo dos anos, houve, portanto, um aumento significativo na produção de conhecimento na área com o objetivo de analisar os transtornos psiquiátricos dentro do contexto hospitalar para assim poder explicar possíveis interações entre os quadros clínicos e transtornos psiquiátricos entre outros fatores e proporcionar um tratamento adequado e com melhores resultados. 


\subsection{ESTUDOS A RESPEITO DA INTERCONSULTA PSIQUIÁTRICA}

A partir da década de 80 , foram publicados muitos estudos que se propuseram a investigar características a respeito dos pacientes assistidos pelos serviços de Interconsulta (FAVA; PAVAN, 1980; RIES et al., 1980; CRAIG, 1982; LOEWENSTEIN; SHARFSTEIN, 1983; McKEGNEY; McMAHON; KING, 1983; PEREZ; SILVERMAN, 1983; TSOI; KOK, 1983; HENGEVELD; ROOYMANS; BERGH, 1984; MALHOTRA; MALHOTRA, 1984; HATTORI, 1985; ZUO; YANG; CHU, 1985; HALES et al., 1986; SCHOFIELD; DOONAN; DALY, 1986; SRINIVASAN et al., 1987; CHANDARANA; CONLON; STEINBERG, 1988; FIDO; MUGHAISSED, 1988; SOBEL; MUNITZ; KARP, 1988) assim como comparações entre períodos estabelecidos, grupos de pacientes e até entre serviços de Interconsulta (LIPOWSKI; WOLSTON, 1981; KUHN et al., 1986; BROWN; COOPER, 1987), com amostras variando de 75 a 2000 pacientes e períodos de três meses a quatro anos (Tabela 1.2). 
Tabela 1.2 - Estudos desenvolvidos na década de 80 a respeito do funcionamento dos serviços de Interconsulta, características das amostras atendidas, comparações entre períodos, grupos de pacientes e entre serviços.

\begin{tabular}{|c|c|c|c|}
\hline AUTORES (ANO) & PAÍS & PERÍODO & AMOSTRA \\
\hline Fava e Pavan (1980) & Itália & $5 m$ & 500 \\
\hline Ries et al. (1980) & EUA & Não informado & 388 \\
\hline \multirow{2}{*}{ Lipow ski e Wolston (1981) } & \multirow{2}{*}{ EUA } & Amostra $\mathrm{A}: 4 \mathrm{a} 3 \mathrm{~m}$ & Amostra A: 1000 \\
\hline & & Amostra B: $2 a 10 m$ & Amostra B: 1000 \\
\hline Craig (1982) & EUA & $1 \mathrm{a}$ & 308 \\
\hline Loew enstein e Sharfstein (1983) & EUA & 3a & 103 \\
\hline McKegney, McMahon e King (1983) & EUA & $8 m$ & 756 \\
\hline Pérez e Silverman (1983) & Canadá & $1 a$ & 255 \\
\hline Tsoi e Kok (1983) & Singapura & $2 a$ & 550 \\
\hline Hengeveld, Rooymans e Bergh (1984) & Holanda & $4 a$ & 1814 \\
\hline Malhotra e Malhotra (1984) & Índia & $1 \mathrm{a}$ & 336 \\
\hline Hattori (1985) & Japão & $1 a$ & 164 \\
\hline Zuo, Yang e Chu (1985) & China & $1 \mathrm{a}$ & 75 \\
\hline Hales et al. (1986) & EUA & $1 a$ & 1065 \\
\hline \multirow{2}{*}{ Kuhn et al. (1986) } & \multirow{2}{*}{ EUA } & \multirow{2}{*}{$3 m$} & Particular: 100 \\
\hline & & & Pública: 100 \\
\hline Schofield, Doonan e Daly (1986) & Irlanda & $1 \mathrm{a}$ & 231 \\
\hline \multirow{3}{*}{ Brow n e Cooper (1987) } & \multirow{3}{*}{ Inglaterra } & \multirow{3}{*}{$\begin{array}{l}\text { Três períodos de um } \\
\text { ano separados por } \\
\text { dois anos cada }\end{array}$} & Ano 1973: 252 \\
\hline & & & Ano 1976: 468 \\
\hline & & & Ano 1979: 420 \\
\hline Srinivasan et al. (1987) & Índia & $7 m$ & 150 \\
\hline Chandarana, Conlon e Steinberg (1988) & Inglaterra & $1 a$ & 320 \\
\hline Fido e Mughaissed (1988) & Kuw ait & $1 \mathrm{a}$ & 208 \\
\hline Sobel, Munitz e Karp (1988) & Israel & $1 a$ & 479 \\
\hline
\end{tabular}

Contudo, percebeu-se que algumas questões não eram possíveis de serem respondidas devido ao caráter retrospectivo das investigações até então conduzidas, assim como a necessidade de estudo em amostras mais representativas de localidades e países. Foi então que surgiram estudos prospectivos (HALL, 1994; CLARKE; SMITH, 1995; SOUZA, 1995; ANDREOLI et al., 1996; REBOLLEDO et al., 1996; SILVERSTONE, 1996; SPINELLI; TOLEDO; CANTINELLI, 1996; CARR et al., 1997; 
ALAJA et al., 1999; DIEFENBACHER, 2001; ROTHENHÄUSLER; ENRENTRAUT; KAPFHAMMER, 2001; SMAIRA; KERR-CORRÊA; CONTEL, 2003; ALHAMAD et al., 2006; HOLMES et al., 2011) com amostras variando de 60 a 1738 pacientes e períodos analisados de cinco meses a cinco anos, e também os estudos de caráter multicêntrico (GALA et al., 1999; VALDÉS et al., 2000; HUYSE et al., 2001), com amostras de 3608 a 12.279 pacientes e período analisado de um ano (Tabela 1.3).

Tabela 1.3 - Estudos prospectivos e multicêntricos a respeito dos serviços de Interconsulta Psiquiátrica.

\begin{tabular}{|c|c|c|c|}
\hline AUTORES (ANO) & PAÍS & PERÍODO & AMOSTRA \\
\hline Hall (1994) & Escócia & $6 m$ & 214 \\
\hline Clarke e Smith (1995) & Austrália & $1 \mathrm{a}$ & 165 \\
\hline Souza (1995) & Brasil & $11 \mathrm{~m}$ & 155 \\
\hline Andreoli et al. (1996) & Brasil & $5 \mathrm{~m}$ & 67 \\
\hline Rebolledo et al. (1996) & Chile & $3 a 6 m$ & 208 \\
\hline Silverstone (1996) & Inglaterra & $\begin{array}{l}\text { Dois períodos de } \\
\text { quatro semanas }\end{array}$ & 313 \\
\hline Spinelli, Toledo e Cantinelli (1996) & Brasil & $6 m$ & 60 \\
\hline Carr et al. (1997) & Austrália & $1 \mathrm{a}$ & 303 \\
\hline Alaja et al. (1999) & Finlândia & $1 \mathrm{a}$ & 1249 \\
\hline Gala et al. (1999)* & Itália & $1 \mathrm{a}$ & 4182 \\
\hline Valdés et al. $(2000)^{*}$ & Espanha & Não informado & 3608 \\
\hline \multirow{3}{*}{ Diefenbacher (2001) } & \multirow{3}{*}{ Alemanha } & \multirow{3}{*}{$1 \mathrm{a}$} & Período A: 88 \\
\hline & & & Período B: 85 \\
\hline & & & Período C: 107 \\
\hline Huyse et al. (2001)* & Holanda & $1 \mathrm{a}$ & 12.279 \\
\hline Rothenhäusler, Enrentraut e Kapfhammer (2001) & Alemanha & $\begin{array}{l}\text { Dois períodos de um } \\
\text { ano separados por } \\
\text { intervalo de oito anos }\end{array}$ & $\begin{array}{l}\text { Amostra A: } 713 \\
\text { Amostra B: } 1025\end{array}$ \\
\hline Smaira, Kerr-Corrêa e Contel (2003) & Brasil & $6 m$ & $\begin{array}{c}\text { Caso: } 47 \\
\text { Controle: } 94\end{array}$ \\
\hline Alhamad et al. (2006) & $\begin{array}{l}\text { Arábia } \\
\text { Saudita }\end{array}$ & $6 m$ & 206 \\
\hline Holmes et al. (2011) & Austrália & $5 a$ & Não informado \\
\hline
\end{tabular}


No geral, pesquisas prospectivas, pelo fato da coleta de dados ser concomitantemente ao surgimento dos casos, houve possibilidade de contato com diversos participantes do processo: o paciente, seus familiares e os profissionais da equipe. Desta forma, foi possível obter diversas informações e esclarecimentos através de entrevistas, aplicações de escalas, questionários e inventários, tornando a caracterização do paciente, do atendimento e do serviço mais rico e completo.

Já com relação às pesquisas retrospectivas apresentaram desvantagens que podem ser atribuídas a características do próprio objeto de estudo: documentos. Estudos com documentos, no caso solicitações, e consulta de prontuários apresentaram limitações quanto às informações disponíveis e acessíveis. Contudo, apesar dos fatores metodológicos limitantes, os estudos retrospectivos foram imprescindíveis para registrar a evolução e desenvolvimento dos serviços de interconsulta - no presente estudo, pôde-se investigar o desenvolvimento do serviço de Interconsulta Psiquiátrica no contexto brasileiro e as mudanças no padrão de solicitações psiquiátricas ao longo de um período de 30 anos.

Não se tem conhecimento de estudo semelhante, abrangendo período tão extenso na literatura nacional ou internacional. Desta forma, as informações obtidas no presente estudo auxiliaram na elucidação de diretrizes para o aprimoramento do serviço, além de um panorama acerca da conduta psiquiátrica relacionada à Interconsulta Psiquiátrica em um hospital geral universitário e das mudanças das características sócio-demográficas da população atendida. 


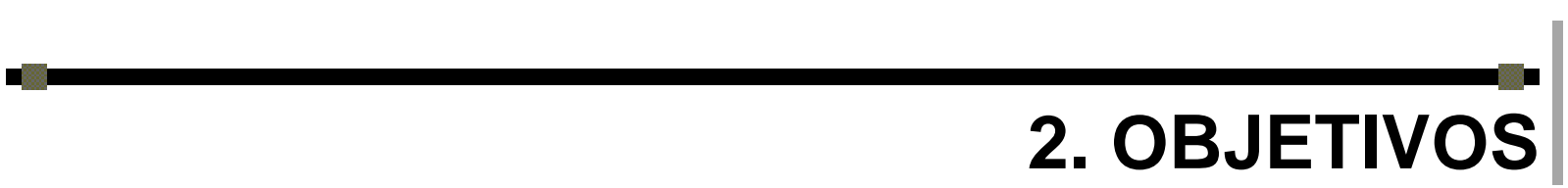


Realizar uma análise de caráter retrospectivo e longitudinal dos dados coletados nas solicitações psiquiátricas (também denominadas por Pedidos de Interconsulta - Pls) feitas para a Psiquiatria do Serviço de Interconsulta em Saúde Mental (SISMen) do Hospital das Clínicas da Faculdade de Medicina do campus universitário de Ribeirão Preto, da Universidade de São Paulo (HCFMRP-USP). Esta pesquisa se caracteriza como estudo descritivo, analítico e exploratório, de natureza quantitativa e qualitativa.

\subsection{ESPECÍFICOS}

Os objetivos específicos envolveram as seguintes vertentes:

1) Obter informações dos dados sociodemográficos dos pacientes e seus históricos em saúde mental (tratamentos anteriores e tentativa de suicídio);

2) Analisar o uso do serviço de Interconsulta Psiquiátrica, tais como as clínicas solicitantes, função dos profissionais solicitantes, motivos de solicitação, tempo de internação dos pacientes assistidos, tempo de solicitação do PI e de sua resposta, e o número de atendimentos realizados;

3) Descrever os diagnósticos clínicos e psiquiátricos dos pacientes avaliados através dos critérios estabelecidos pela CID-10 (Classificação Estatística 
Internacional de Doenças e Problemas relacionados à Saúde, 10ª revisão);

4) Analisar intervenções farmacoterapêuticas e não medicamentosas, tais como as condutas sugeridas pelo interconsultor, profissionais solicitados durante a internação, as medicações psicotrópicas em uso e prescritas;

5) Caracterizar aspectos relacionados aos médicos clínicos, aos profissionais de saúde e aos interconsultores;

6) Avaliar a qualidade estrutural da solicitação psiquiátrica realizada pelo profissional clínico e a resposta dada pelo interconsultor mediante leitura dos documentos. 


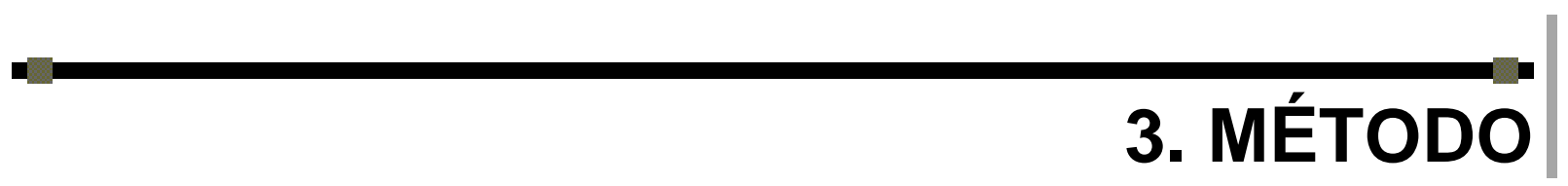




\subsection{CARACTERIZAÇÃO DO LOCAL DE ESTUDO}

Esta pesquisa foi desenvolvida no Hospital das Clínicas da Faculdade de Medicina do campus universitário de Ribeirão Preto, da Universidade de São Paulo (HCFMRP-USP). Por ser um hospital universitário de nível assistencial terciário de acordo com o Sistema Único de Saúde (SUS), este oferece serviços de alta tecnologia e procedimentos médicos especializados de alta complexidade, sendo considerado referência para uma grande área de abrangência do interior do estado de São Paulo, que engloba cerca de 1.200.000 habitantes (Secretaria Estadual de Saúde: Direção Regional de Saúde de Ribeirão Preto, 1997).

Devido ao aumento da demanda regional por serviços médicos, no início da década de 60, foi-se identificada a necessidade de ampliação das instalações hospitalares, o que acarretou na criação de duas unidades: a Unidade de Emergência (UE), localizada no centro do município de Ribeirão Preto e responsável pelo pronto socorro regional e pela unidade de queimados, e o Hospital das Clínicas do campus universitário, responsável pelas internações, procedimentos mais complexos e atendimentos ambulatoriais.

As enfermarias do HCFMRP-USP possuem 696 leitos distribuídos em 584 leitos gerais, 23 leitos particulares, 36 leitos de Hospital-Dia e 53 leitos de Unidade de Terapia Intensiva. Estas instalações estão distribuídas entre as seguintes clínicas: Berçário, Centro de Cirurgia e Epilepsia, Cirurgia, Cirurgia de Cabeça e Pescoço, Clínica Médica (Cardiologia, Dermatologia, Endocrinologia, Gastroenterologia, Geriatria, Hematologia, Imunologia, Pneumologia, Reumatologia e Urologia), Gine- 
cologia e Obstetrícia, Moléstias Infecciosas, Neurologia, Oftalmologia, Ortopedia, Otorrinolaringologia, Pediatria (Oncopediatria, Gastropediatria, Centro de Terapia Intensiva Pediátrica, Endocrinopediatria, Hematopediatria, Imunopediatria e Pneumopediatria), Psiquiatria, Serviço de Assistência Médica Social Pessoal, Unidade de Transplante Renal (Nefrologia), Unidade de Transplante de Medula Óssea, Unidade Especial de Terapia de Doenças Infecciosas (UETDI), Unidade Metabólica, Unidade de Terapia Intensiva Coronariana, Unidade de Terapia Intensiva Neonatal-berçário e Unidade de Terapia Intensiva Pós-operatória Tórax Cardiovascular.

O serviço de Interconsulta Psiquiátrica foi fundado em março de 1978 pelo Prof. Dr. José Onildo Betiolli Contel e a equipe inicial era constituída por profissionais da área médica, sendo um docente supervisor, um médico assistente, um residente do segundo ano de Psiquiatria e cinco residentes do primeiro ano de Psiquiatria. Em 1998, houve a contratação de psicólogos para atuarem no serviço de Interconsulta para assistência psicológica aos pacientes internados e, em 1999, terapeutas ocupacionais e aprimorandos ingressaram na equipe - foi então que, a partir de 2005, o serviço de Interconsulta passou a ser chamado de SISMen devido ao caráter multidisciplinar de sua equipe.

São realizadas reuniões periódicas entre a equipe para a discussão dos casos assistidos pelo SISMen e também entre as equipes das clínicas que requisitaram a assistência do serviço. Esta requisição, denominada solicitação psiquiátrica ou pedido de Interconsulta $(\mathrm{PI})$, pode ser realizada por qualquer clínica do HCFMRP-USP para os pacientes internados, e é feito através do preenchimento de um documento em papel padronizado para todo o hospital.

Posteriormente, esta solicitação é encaminhada ao SISMen e os residentes em Psiquiatria se responsabilizam pelo atendimento do paciente para o qual foi feita 
a solicitação. Após a visita do interconsultor, este então preenche a segunda parte do documento em papel padronizado pelo HCFMRP-USP referente à resposta do atendimento, registrando informações a respeito das características sociodemográficas do paciente, de seus antecedentes psiquiátricos e familiares, do histórico clínico, das impressões enquanto interconsultor e também do plano de tratamento, entre outros aspectos que o profissional julgue relevante.

Finalizado o acompanhamento do paciente, seja pela alta hospitalar, seja pela própria alta do SISMen, o documento referente à solicitação psiquiátrica é fotocopiado e arquivado no serviço, e o original é anexado ao prontuário do paciente.

Apesar da inauguração do serviço de Interconsulta ter sido em 1978, foi apenas a partir de janeiro de 1981 que se iniciou o registro das atividades da Interconsulta e o armazenamento dos documentos referentes às solicitações.

\subsection{PROCEDIMENTO DE COLETA E REGISTRO DOS DADOS}

\subsubsection{AMOSTRA}

Os objetos de estudo foram todas as solicitações psiquiátricas (também denominadas como pedidos de interconsulta, Pls) consecutivas e realizadas ao SISMen no período de janeiro de 1981 a dezembro de 2010 aos pacientes que estiveram internados nas enfermarias do HCFMRP-USP e os prontuários médicos armazenados no Serviço de Arquivo Médico (SAMe) do mesmo hospital. 


\subsubsection{REGISTRO DOS DADOS E ANÁLISE DAS SOLICITAÇÕES PSIQUIÁTRICAS}

O levantamento longitudinal dos dados foi realizado mediante a consulta retrospectiva dos prontuários de todos os pacientes, a leitura da solicitação e do respectivo protocolo de registro de atendimento anexado a este último. E em casos de divergência entre os dados escritos no PI e nos prontuários, foram consideradas as informações encontradas nestes últimos.

Foram utilizados dois protocolos ao longo do período de trinta anos de interconsulta. Em 1998, foi introduzido o primeiro protocolo de registro que abordava alguns dados sócio-demográficos do paciente, informações resumidas do próprio PI, histórico clínico, histórico medicamentoso e a avaliação realizada pelo interconsultor. Este protocolo foi substituído em agosto de 2005 pelo PRISMe (Protocolo de Registro de Interconsulta em Saúde Mental, Anexo 1), elaborado com base no Patient Registration Form do European Consultation-Liaison Workgroup for General Hospital Psychiatry and Psychosomatics (ECLW) (LOBO et al., 1996). Este protocolo é subdividido em quatro tópicos: i) dados demográficos; ii) dados relacionados ao $\mathrm{PI}$; iii) avaliação e diagnóstico do interconsultor; e iv) conduta e desfecho.

Foram computadas todas as solicitações realizadas por todas as especialidades clínicas durante o período de janeiro de 1981 a dezembro de 2010 à Psiquiatria. Para a análise, os trinta anos foram separados em seis períodos de cinco anos: 1981 a 1985, 1986 a 1990, 1991 a 1995, 1996 a 2000, 2001 a 2005 e 2006 a 2010.

Para avaliação da taxa de encaminhamento, foi considerado o número de internações realizadas no hospital em relação ao total de solicitações feitas nos períodos estabelecidos pelo presente estudo.

A respeito da caracterização sociodemográfica da população atendida: 
além do sexo, foram coletadas as idades dos pacientes e estas foram posteriormente categorizadas nas seguintes faixas etárias: até 14 anos, de 15 a 20 anos, de 21 a 30 anos, de 31 a 40 anos, de 41 a 50 anos, de 51 a 60 anos, de 61 a 70 anos, e acima de 71 anos.

Também foram coletadas informações a respeito do estado civil do paciente, de onde e com quem o ele vivia (somente cônjuge, cônjuge e filhos, em instituição, com pais, com parentes, só com filhos, sozinho e outros) e sua procedência (Ribeirão Preto, estado de São Paulo, outro estado e outro país).

As etnias consideradas foram: branca, negra, parda, amarela e índio.

Foram consideradas as seguintes situações laborais: afastado ou aposentado por invalidez, aposentado por tempo de serviço, autônomo, cuidando do lar, desempregado, empregado formalmente, estudante e outros.

A escolaridade do paciente seguiu a classificação: analfabeto, ensino fundamental incompleto, ensino fundamental completo, ensino médio incompleto, ensino médio completo, ensino superior incompleto, ensino superior completo, e mais de uma faculdade ou pós-graduação. Os dados que estavam de acordo com a antiga organização de escolaridade (primeiro, segundo e terceiro grau) foram adaptados às categorias equivalentes.

Sobre o histórico em saúde mental do paciente, foram coletadas informações referentes aos antecedentes em Saúde Mental, tais como internações psiquiátricas prévias, acompanhamento ambulatorial em Psiquiatria, psicoterapia e acompanhamento com outros profissionais de Saúde Mental. Também foi considerado o histórico de tentativas de suicídio de cada paciente assistido.

Acerca do uso do serviço de interconsulta psiquiátrica, as clínicas que solicitaram Pls foram: Berçário e Alojamento Conjunto, Centro de Terapia Intensiva, 
Cirurgia de Cabeça e Pescoço, Cirurgia Geral, Clínica de Dor, Clínica Médica Geral, Ginecologia e Obstetrícia, Moléstias Infecciosas e UETDI, Neurologia, Oftalmologia, Ortopedia, Otorrinolaringologia, Pediatria, Psicologia, Serviço Social, Terapia Ocupacional, Unidade Metabólica, Unidade de Transplante Renal e Unidade de Transplante de Medula Óssea.

Foi obtida a informação quanto a função do profissional solicitante, podendo este ser médico residente ou aprimorando, médico assistente, docente, aluno ou doutorando, psicólogo, terapeuta ocupacional e outros.

Os motivos de solicitação foram classificados em: i) abuso de psicotrópicos ou substâncias psicoativas; ii) antecedentes psiquiátricos; iii) atendimento ao familiar; iv) aval para procedimentos mutilantes ou de risco ou sem consentimento formal; v) avaliação quanto ao uso de psicotrópicos; vi) doença de etiologia associada a fatores psicossociais; vii) ociosidade e/ou internação longa; viii) problemas quanto à cooperação no tratamento ou manejo ou adesão, ix) psicodiagnóstico; x) risco suicida; xi) sintomas físicos mal definidos ou origem psicológica; e xii) sintomas psiquiátricos presentes.

Foram computadas as datas do $\mathrm{PI}$, da resposta ao $\mathrm{PI}$, da internação do paciente no HCFMRP-USP e a data da alta hospitalar para os cálculos dos tempos de internação (diferença entre a data da internação e da alta hospitalar), de solicitação (diferença entre a data de internação e a do $\mathrm{PI}$ ) e tempo de resposta (diferença entre a data do PI e de sua resposta pelo interconsultor).

Foram obtidos nos prontuários e nos protocolos de atendimento dos pacientes os números de atendimentos realizados pelo interconsultor durante a internação.

A respeito dos diagnósticos clínicos e psiquiátricos dos pacientes avaliados, estes foram classificados de acordo com a CID-10. Os diagnósticos 
clínicos variaram de A00 a U99 e as categorias foram: Doenças infecciosas e parasitárias (A00 a B99); Neoplasias (C00 a D48); Doenças endócrinas, nutricionais e metabólicas (E00 a E90); Doenças do sistema nervoso (G00 a G99); Doenças do aparelho circulatório (I00 a 199); Doenças do aparelho respiratório (J00 a J99); Doenças do aparelho digestivo (K00 a K93); Doenças da pele e do tecido subcutâneo (L00 a L99); Doenças do sistema osteomuscular e do tecido conjuntivo (M00 a M99); Doenças do aparelho geniturinário (N00 a N99); Gravidez, parto e puerpério e algumas afecções originadas no período perinatal (O00 a P96); Lesões, envenenamento e causas externas de mortalidade (S00 a Y98) e a categoria Outros (Doenças do sangue e dos órgãos hematopoiéticos e alguns transtornos imunitários, com os códigos da CID-10 de D50 a D89; Doenças do olho, anexos, do ouvido e da apófise mastoide, de $\mathrm{H} 00$ a H95; e Malformações congênitas, deformidades e anomalias cromossômicas, de Q00 a Q99).

Foram considerados os diagnósticos psiquiátricos fornecidos pelo interconsultor como também as hipóteses diagnósticas psiquiátricas informadas pelo profissional solicitante de acordo com as classificações da CID-10. Os diagnósticos psiquiátricos e suas hipóteses variaram de F00 a F98, sendo distribuídos nas seguintes categorias: Transtornos mentais orgânicos (F00 a F09); Transtornos mentais devido ao uso de substâncias (F10 a F19); Esquizofrenia, transtornos esquizotípicos e delirantes (F20 a F29); Transtornos do humor (F30 a F39); Transtornos neuróticos, somatoformes e relacionados ao estresse (F40 a F48); Transtornos de personalidade e do comportamento adulto (F60 a F69) e Outros (de F50 a F59 e de F70 a F98). Também foi investigada se foi constatada, pelo interconsultor, a presença de ideação suicida durante a sua visita.

As condutas sugeridas pelo interconsultor foram: i) atendimento aos 
familiares; ii) atendimento grupal; iii) atendimento individual; iv) entrevista com familiares; v) exames e outras avaliações; vi) orientação à equipe; vii) orientação aos familiares; viii) prescrição de psicotrópicos; ix) sugestão de outros profissionais; e x) suspensão de psicotrópicos.

Foram investigados também os profissionais que foram solicitados pelo interconsultor ao longo da internação do paciente: psicólogo, terapia ocupacional e serviço social; e também o encaminhamento após alta hospitalar.

As medicações psicotrópicas em uso antes da avaliação do interconsultor e as prescritas pelo mesmo foram coletadas, sendo as medicações posteriormente categorizadas de acordo com suas classes (benzodiazepínicos, antidepressivos, antipsicóticos, estabilizadores do humor e outros).

Sobre os aspectos relacionados aos médicos clínicos, aos profissionais de saúde e aos interconsultores, foi investigado se o interconsultor foi informado da alta hospitalar do paciente pela clínica solicitante e se o paciente estava ciente do atendimento da Psiquiatria antes da visita do interconsultor.

Em relação à qualidade estrutural do PI e de sua resposta, a legibilidade de ambos foi analisada por duas avaliadoras, tendo sido classificada como total, parcial e ilegível. Foi verificado o uso siglas para identificação dos diagnósticos clínicos dos pacientes (por exemplo, DPOC para doença pulmonar obstrutiva crônica, HSA para hemorragia subaracnóide, entre tantos outros). E também foi observado se o profissional registrou seu nome no PI e se manifestou expectativa para a avaliação do interconsultor. Ressalta-se que a presença de identificação do interconsultor também foi verificada na resposta ao $\mathrm{PI}$.

Para a análise do aspecto geral do $\mathrm{Pl}$, foram seguidas as recomendações preconizadas por Arribas et al. (2000), sendo classificados como bons os pedidos 
que informaram os antecedentes pessoais, dados referentes à enfermidade atual, impressão diagnóstica ou diagnóstico diferencial e motivo da interconsulta; aceitáveis os que apresentaram o motivo da interconsulta e que forneceram dados suficientes da enfermidade atual do paciente; e ruins os ilegíveis, sem dados sobre a enfermidade atual e sem outras informações clarificantes do estado do paciente. $E$ para a análise do aspecto geral da resposta ao $\mathrm{PI}$, foram classificados como bons aqueles que apresentaram histórico completo do paciente quanto aos antecedentes em Saúde Mental e tentativa de suicídio, ideação suicida no momento da avaliação, a data de resposta, os diagnósticos clínicos e psiquiátricos e plano de tratamento, considerados como aceitáveis aqueles que forneceram dados suficientes do paciente, em especial, os diagnóstico clínicos e psiquiátricos, e os ruins os ilegíveis, sem diagnósticos e outras informações relevantes do paciente.

\subsection{PROCEDIMENTO DE ANÁLISE DOS DADOS}

O procedimento incluiu análise descritiva por meio de porcentagem e frequência simples. Foram utilizados os programas IBM SPSS Statistics para Windows ${ }^{\circledR}$, versão 20 (IBM Company), e o STATA, versão 11.

Todos os dados foram organizados num banco de dados criado no programa Microsoft ${ }^{\circledR}$ Office Excel 2003, Service Pack 3, do produto Microsoft Office Professional Edição 2003. 


\subsection{ASPECTOS ÉTICOS}

Foram seguidas as normas definidas pelo Conselho Nacional de Saúde, na Resolução no 196/96 sobre pesquisa envolvendo seres humanos. Desta forma, o projeto foi encaminhado ao Comitê de Ética em Pesquisa do Hospital das Clínicas da Faculdade de Medicina de Ribeirão Preto da Universidade de São Paulo e, em sua 240ª reunião, foi aprovado de acordo com o Processo HCRP n¹4139/2006 (Anexo 2).

Como o presente estudo se propôs avaliar as solicitações psiquiátricas e prontuários dos pacientes internados, não foi levantada a necessidade de elaboração de um Termo de Consentimento Livre e Esclarecido. Desta forma, foi elaborado um Termo de Dispensa (Anexo 3) que também foi submetido à apreciação por tal comitê.

Em respeito aos preceitos éticos, a identificação dos participantes e dos profissionais de saúde envolvidos no presente estudo foram resguardados, sendo substituídos por números com a finalidade de contagem e armazenamento. Assim sendo, procurou-se manter em caráter sigiloso as informações obtidas através da consulta dos documentos. 


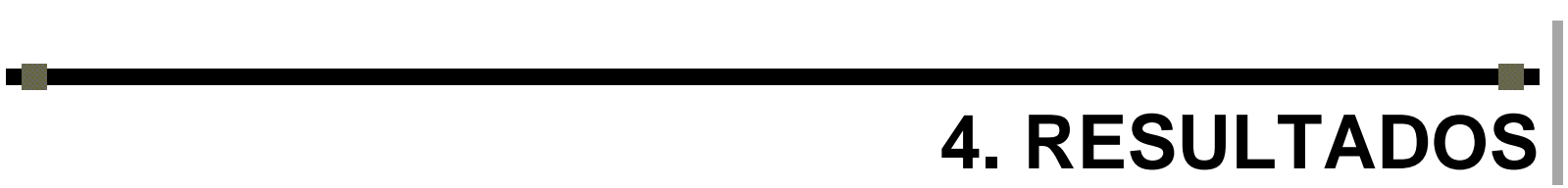


No período em que o primeiro protocolo de registro foi empregado, este foi preenchido e anexado à solicitação em $75,2 \%$ dos casos e o PRISMe, em 70,7\%. E ao longo dos trinta anos de interconsulta, passaram pelo serviço 299 interconsultores, dentre eles residentes e psiquiatras contratados.

Apesar de terem sido consultadas todas as fontes possíveis de informação registrada (PIs, prontuários médicos e o sistema interno do HCFMRP-USP), muitos dados não foram obtidos por se tratar de um estudo longitudinal retrospectivo que envolveu trinta anos. Os registros dos pacientes não foram obtidos em 5,9\% (N=289) dos casos.

Observou-se que, com o uso dos protocolos de registro (o primeiro foi implementado em 1998 e o segundo, o PRISMe, em agosto de 2005), houve um maior registro de informações acerca da caracterização sociodemográfica dos pacientes, do atendimento do interconsultor e do funcionamento do serviço (Tabela 4.1).

Tabela 4.1 - Frequência das variáveis com mais ausência de informação antes do uso dos protocolos de registro e depois da implementação dos mesmos.

\begin{tabular}{lcc} 
& \multicolumn{1}{c}{ Sem protocolo } & Com protocolo \\
\cline { 2 - 3 } & $\mathbf{N}(\%)$ & $\mathbf{N}(\%)$ \\
\hline TOTAL & 2118 & 2764 \\
CARACTERíSTICAS SOCIODEMOGRÁFICAS E & HISTÓRICO EM SAÚDE MENTAL \\
\hline \multicolumn{1}{c}{ Mora com/onde } & $1637(77,3)$ & $743(26,9)$ \\
Antecedentes em Saúde Mental & $921(43,5)$ & $542(19,6)$ \\
Tentativas de suicídio & $1861(87,9)$ & $1582(57,2)$ \\
USO DO SERVIÇO DE INTERCONSULTA & & \\
\hline Funções dos profissionais solicitantes & $1601(75,6)$ & $67(2,4)$ \\
Tempo de internação & $2104(99,3)$ & $616(22,3)$ \\
Tempo de solicitação & $1881(88,8)$ & $505(18,3)$ \\
Tempo de resposta & $752(35,5)$ & $467(16,9)$ \\
Número de atendimentos & $2116(99,9)$ & $1658(60,0)$ \\
OUTRAS VARIÁVES & & \\
\hline Ideação suicida & $1416(66,9)$ & $828(30,0)$ \\
Medicações em uso & $1465(69,2)$ & $642(23,2)$ \\
Aviso acerca da visita do interconsultor & $2062(97,4)$ & $913(33,0)$ \\
Aviso da alta hospitalar ao interconsultor & $1372(64,8)$ & $1408(50,9)$ \\
\hline
\end{tabular}


Foram realizados no período de janeiro de 1981 a dezembro de 2010, 4882 solicitações de atendimento à Psiquiatria do SISMen. Observou-se que o número de solicitações duplicou ao final de três décadas e o número de internações realizadas no HCFMRP-USP aumentou 50\% no mesmo período (o número de leitos se manteve relativamente constante, em torno de 690 , considerando os leitos gerais, do Centro de Terapia Intensiva, de Recuperação, de Hospital-Dia e particulares). A taxa de encaminhamento à Psiquiatria do SISMen variou de 0,7 a $1,1 \%$, apresentando sua menor frequência no período entre 1981 a 1985 e sua maior frequência entre 2001 a 2005 (Tabela 4.2).

Tabela 4.2 - Número de solicitações realizadas ao serviço de Interconsulta Psiquiátrica, número de internações totais realizadas no HCFMRP-USP e taxas de encaminhamento entre janeiro de 1981 a dezembro de 2010.

\begin{tabular}{lccccccc} 
& \multicolumn{1}{c}{$\mathbf{1 9 8 1 - 1 9 8 5}$} & $\mathbf{1 9 8 6 - 1 9 9 0}$ & $\mathbf{1 9 9 1 - 1 9 9 5}$ & $\mathbf{1 9 9 6 - 2 0 0 0}$ & $\mathbf{2 0 0 1 - 2 0 0 5}$ & $\mathbf{2 0 0 6 - 2 0 1 0}$ & TOTAL \\
\hline Número de solicitações & 531 & 633 & 690 & 738 & 1135 & 1155 & 4882 \\
Número total de internações & 78906 & 79298 & 69817 & 94839 & 105482 & 118745 & 547087 \\
Taxa de encaminhamento* & 0,7 & 0,8 & 1,0 & 0,8 & 1,1 & 1,0 & 0,9 \\
\hline * dado em porcentagem & & & & & & &
\end{tabular}




\subsection{CARACTERIZAÇÃO SOCIODEMOGRÁFICA E HISTÓRICO EM SAÚDE MENTAL DOS PACIENTES}

\subsubsection{CARACTERIZAÇÃO SOCIODEMOGRÁFICA}

Como se pode observar na Tabela 4.3, pacientes do sexo feminino tiveram maior frequência de Pls ao longo de todos os anos, variando em torno de $60 \%$. Dos trinta anos de serviço de Interconsulta, ocorreram 28,4\% ( $\mathrm{N}=1386)$ óbitos, sendo $52,1 \%(N=722)$ pacientes do sexo feminino e $47,9 \%(N=664)$ do sexo masculino.

\begin{tabular}{|c|c|c|c|c|c|c|c|}
\hline & 1981-1985 & $1986-1990$ & 1991-1995 & $1996-2000$ & $2001-2005$ & 2006-2010 & TOTAL \\
\hline & $\mathbf{N}(\%)$ & $\mathbf{N}(\%)$ & $\mathbf{N}(\%)$ & $\mathbf{N}(\%)$ & N (\%) & $\mathbf{N}(\%)$ & $\mathbf{N}(\%)$ \\
\hline Feminino & $307(57,8)$ & $357(56,4)$ & $413(59,9)$ & $416(56,4)$ & $703(61,9)$ & $749(64,8)$ & $2945(60,3)$ \\
\hline Masculino & $224(42,2)$ & $276(43,6)$ & $277(40,1)$ & $322(43,6)$ & $432(38,1)$ & $406(35,2)$ & $1937(39,7)$ \\
\hline TOTAL & 531 & 633 & 690 & 738 & 1135 & 1155 & 4882 \\
\hline
\end{tabular}

Foram calculadas as idades médias e medianas dos pacientes em cada período do estudo, sendo também categorizadas em faixas etárias. A idade média do pacientes do sexo feminino foi de $39,4(\mathrm{DP}=17,1)$ anos com mediana de 37,0 (Tabela 4.4). Já a idade média dos pacientes do sexo masculino foi de 41,9 $(\mathrm{DP}=17,7)$ anos com mediana de 41,0 (Tabela 4.5). Em ambos os sexos, os pacientes foram relativamente mais jovens na primeira metade da década de 80 , sendo que, ao longo dos trinta anos, os homens apresentaram idades médias 
maiores que as mulheres, com exceção do período de 1986 a 1990.

Por volta de $60 \%$ das mulheres e $55 \%$ dos homens apresentaram faixas etárias entre 21 a 50 anos. Ao longo dos anos, pode-se notar que a idade média da população atendida aumentou gradualmente e houve também mais atendimentos a pacientes homens acima de 51 anos quando comparado às mulheres.

Em relação à cor/etnia, a grande maioria de ambos os sexos foi caucasiana, compreendendo cerca de $80 \%$ dos pacientes atendidos.

Tabela 4.4 - Números e frequências das faixas etárias e da cor/etnia dos pacientes do sexo feminino atendidos entre janeiro de 1981 a dezembro de 2010.

\begin{tabular}{cccccccc} 
& $\mathbf{1 9 8 1 - 1 9 8 5}$ & $\mathbf{1 9 8 6 - 1 9 9 0}$ & $\mathbf{1 9 9 1 - 1 9 9 5}$ & $\mathbf{1 9 9 6 - 2 0 0 0}$ & $\mathbf{2 0 0 1 - 2 0 0 5}$ & $\mathbf{2 0 0 6 - 2 0 1 0}$ & TOTAL \\
\hline FAIXA ETÁRIA & $\mathbf{N}(\%)$ & $\mathbf{N}(\%)$ & $\mathbf{N}(\%)$ & $\mathbf{N}(\%)$ & $\mathbf{N}(\%)$ & $\mathbf{N}(\%)$ & $\mathbf{N}(\%)$ \\
\hline Até 14 anos & $11(3,8)$ & $17(4,9)$ & $22(5,4)$ & $12(2,9)$ & $25(3,6)$ & $33(4,5)$ & $120(4,2)$ \\
De 15 a 20 anos & $36(12,5)$ & $32(9,2)$ & $32(7,9)$ & $30(7,2)$ & $53(7,6)$ & $62(8,4)$ & $245(8,5)$ \\
De 21 a 30 anos & $83(28,8)$ & $79(22,7)$ & $76(18,8)$ & $104(25,1)$ & $154(22,1)$ & $155(21,0)$ & $651(22,5)$ \\
De 31 a 40 anos & $72(25,0)$ & $70(20,1)$ & $89(22,0)$ & $88(21,3)$ & $159(22,8)$ & $135(18,3)$ & $613(21,2)$ \\
De 41 a 50 anos & $38(13,2)$ & $71(20,4)$ & $78(19,3)$ & $55(13,3)$ & $120(17,2)$ & $158(21,4)$ & $520(18,0)$ \\
De 51 a 60 anos & $20(6,9)$ & $39(11,2)$ & $59(14,6)$ & $61(14,7)$ & $81(11,6)$ & $98(13,3)$ & $358(12,4)$ \\
De 61 a 70 anos & $20(6,9)$ & $21(6,0)$ & $28(6,9)$ & $36(8,7)$ & $66(9,5)$ & $65(8,8)$ & $236(8,2)$ \\
Acima de 71 anos & $8(2,8)$ & $19(5,5)$ & $20(5,0)$ & $28(6,8)$ & $38(5,5)$ & $33(4,5)$ & $146(5,1)$ \\
\hline TOTAL (N) & 288 & 348 & 404 & 414 & 696 & 739 & 2889 \\
IDADE MÉDIA (DP) & $35,6(16,2)$ & $38,6(17,2)$ & $39,6(17,1)$ & $40,4(17,9)$ & $40,2(17,4)$ & $39,4(17,2)$ & $39,4(17,1)$ \\
MEDIANA & 32,5 & 36,0 & 38,0 & 38,0 & 38,0 & 39,0 & 37,0 \\
COR/ETNIA & & & & & & & \\
\hline Branca & $243(82,1)$ & $257(73,9)$ & $319(78,4)$ & $332(81,2)$ & $546(79,0)$ & $569(77,0)$ & $2266(78,4)$ \\
Parda & $32(10,8)$ & $47(13,5)$ & $58(14,3)$ & $44(10,8)$ & $91(13,2)$ & $104(14,1)$ & $376(13,0)$ \\
Negra & $19(6,4)$ & $41(11,8)$ & $26(6,4)$ & $32(7,8)$ & $50(7,2)$ & $63(8,5)$ & $231(8,0)$ \\
Amarela & $2(0,7)$ & $3(0,9)$ & $4(1,0)$ & $1(0,2)$ & $4(0,6)$ & $3(0,4)$ & $17(0,6)$ \\
\hline TOTAL (N) & 296 & 348 & 407 & 409 & 691 & 739 & 2890 \\
\hline
\end{tabular}


Tabela 4.5 - Números e frequências das faixas etárias e da cor/etnia dos pacientes do sexo masculino atendidos entre janeiro de 1981 a dezembro de 2010.

\begin{tabular}{cccccccc} 
& $\mathbf{1 9 8 1 - 1 9 8 5}$ & $\mathbf{1 9 8 6 - 1 9 9 0}$ & $\mathbf{1 9 9 1 - 1 9 9 5}$ & $\mathbf{1 9 9 6 - 2 0 0 0}$ & $\mathbf{2 0 0 1 - 2 0 0 5}$ & $\mathbf{2 0 0 6 - 2 0 1 0}$ & TOTAL \\
\hline FAIXA ETÁRIA & $\mathbf{N}(\%)$ & $\mathbf{N}(\%)$ & $\mathbf{N}(\%)$ & $\mathbf{N}(\%)$ & $\mathbf{N}(\%)$ & $\mathbf{N}(\%)$ & $\mathbf{N}(\%)$ \\
\hline Até 14 anos & $4(1,9)$ & $18(6,7)$ & $\mathbf{9}(3,3)$ & $9(2,8)$ & $25(5,8)$ & $31(7,7)$ & $96(5,0)$ \\
De 15 a 20 anos & $30(14,2)$ & $33(12,3)$ & $20(7,3)$ & $24(7,5)$ & $9(2,1)$ & $19(4,7)$ & $135(7,1)$ \\
De 21 a 30 anos & $58(27,5)$ & $68(25,3)$ & $54(19,8)$ & $51(16,0)$ & $47(11,0)$ & $43(10,6)$ & $321(16,9)$ \\
De 31 a 40 anos & $47(22,3)$ & $39(14,5)$ & $55(20,1)$ & $83(26,0)$ & $99(23,1)$ & $66(16,3)$ & $389(20,4)$ \\
De 41 a 50 anos & $26(12,3)$ & $44(16,4)$ & $56(20,5)$ & $51(16,0)$ & $82(19,2)$ & $98(24,2)$ & $357(18,7)$ \\
De 51 a 60 anos & $26(12,3)$ & $35(13,0)$ & $35(12,8)$ & $41(12,9)$ & $79(18,5)$ & $67(16,5)$ & $283(14,9)$ \\
De 61 a 70 anos & $15(7,1)$ & $20(7,4)$ & $26(9,5)$ & $40(12,5)$ & $45(10,5)$ & $59(14,6)$ & $205(10,8)$ \\
Acima de 71 anos & $5(2,4)$ & $12(4,5)$ & $18(6,6)$ & $20(6,3)$ & $42(9,8)$ & $22(5,4)$ & $119(6,2)$ \\
\hline TOTAL (N) & 211 & 269 & 273 & 319 & 428 & 405 & 1905 \\
IDADE MÉDIA (DP) & $36,5(16,0)$ & $37,3(18,0)$ & $41,6(17,5)$ & $42,3(17,2)$ & $45,4(18,0)$ & $43,8(17,7)$ & $41,9(17,7)$ \\
MEDIANA & 33,0 & 35,0 & 40,0 & 39,0 & 45,0 & 44,0 & 41,0 \\
COR/ETNIA & & & & & & & 1840 \\
\hline Branca & $172(80,0)$ & $212(79,1)$ & $231(86,2)$ & $248(79,0)$ & $351(83,4)$ & $330(81,3)$ & $1544(81,6)$ \\
Parda & $22(10,2)$ & $25(9,3)$ & $20(7,5)$ & $30(9,6)$ & $43(10,2)$ & $40(9,9)$ & $180(9,5)$ \\
Negra & $19(8,8)$ & $31(11,6)$ & $13(4,9)$ & $33(10,5)$ & $24(5,7)$ & $36(8,9)$ & $156(8,2)$ \\
Amarela & $2(0,9)$ & 0,0 & $4(1,5)$ & $3(1,0)$ & $3(0,7)$ & 0,0 & $12(0,6)$ \\
\hline TOTAL (N) & 215 & 268 & 268 & 314 & 421 & 406 & 1892 \\
\hline
\end{tabular}

Quase a maioria dos pacientes do sexo feminino era casada (48\%) e esta tendência se mostrou constante ao longo dos anos. Até meados dos anos 90, com mais frequência foram atendidas mulheres que residiam com seus pais, e depois de 1996, passaram a ser mais frequentes mulheres que residiam com seus respectivos cônjuges e filhos (Tabela 4.6). 
Tabela 4.6 - Estado civil e com quem ou onde moravam as mulheres atendidas pelo serviço de Interconsulta Psiquiátrica entre janeiro de 1981 a dezembro de 2010.

\begin{tabular}{cccccccc} 
& $\mathbf{1 9 8 1 - 1 9 8 5}$ & $\mathbf{1 9 8 6 - 1 9 9 0}$ & $\mathbf{1 9 9 1 - 1 9 9 5}$ & $\mathbf{1 9 9 6 - 2 0 0 0}$ & $\mathbf{2 0 0 1 - 2 0 0 5}$ & $\mathbf{2 0 0 6 - 2 0 1 0}$ & TOTAL \\
\hline ESTADO CIVIL & $\mathbf{N}(\%)$ & $\mathbf{N}(\%)$ & $\mathbf{N}(\%)$ & $\mathbf{N}(\%)$ & $\mathbf{N}(\%)$ & $\mathbf{N}(\%)$ & $\mathbf{N}(\%)$ \\
\hline Casada & $105(43,0)$ & $154(46,1)$ & $199(50,6)$ & $194(47,5)$ & $354(50,7)$ & $347(46,6)$ & $1353(47,9)$ \\
Solteira & $79(32,4)$ & $122(36,5)$ & $118(30,0)$ & $114(27,9)$ & $186(26,6)$ & $191(25,6)$ & $810(28,7)$ \\
Separada & $31(12,7)$ & $24(7,2)$ & $31(7,9)$ & $45(11,0)$ & $94(13,5)$ & $123(16,5)$ & $348(12,3)$ \\
Viúva & $29(11,9)$ & $34(10,2)$ & $45(11,5)$ & $55(13,5)$ & $64(9,2)$ & $84(11,3)$ & $311(11,0)$ \\
\hline TOTAL $(\mathrm{N})$ & 244 & 334 & 393 & 408 & 698 & 745 & 2822
\end{tabular}

\begin{tabular}{lccccccc} 
MORA COM/ONDE & \multicolumn{7}{l}{} \\
\hline \multicolumn{1}{c}{ Cônjuge e filhos } & $6(9,8)$ & $11(10,8)$ & $22(24,4)$ & $78(32,2)$ & $131(27,3)$ & $182(32,0)$ & $430(27,8)$ \\
Pais & $19(31,1)$ & $44(43,1)$ & $32(35,6)$ & $69(28,5)$ & $129(26,9)$ & $130(22,8)$ & $423(27,4)$ \\
Só, com filhos & $10(16,4)$ & $11(10,8)$ & $17(18,9)$ & $37(15,3)$ & $88(18,3)$ & $105(18,5)$ & $268(17,4)$ \\
Cônjuge & $1(1,6)$ & $7(6,9)$ & $6(6,7)$ & $27(11,2)$ & $82(17,1)$ & $68(12,0)$ & $191(12,4)$ \\
Parentes & $9(14,8)$ & $15(14,7)$ & $7(7,8)$ & $15(6,2)$ & $22(4,6)$ & $38(6,7)$ & $106(6,9)$ \\
Sozinha & $5(8,2)$ & $5(4,9)$ & $3(3,3)$ & $10(4,1)$ & $20(4,2)$ & $33(5,8)$ & $76(4,9)$ \\
Em instituição & $5(8,2)$ & $4(3,9)$ & $1(1,1)$ & $3(1,2)$ & $4(0,8)$ & $5(0,9)$ & $22(1,4)$ \\
Outros & $6(9,8)$ & $5(4,9)$ & $2(2,2)$ & $3(1,2)$ & $4(0,8)$ & $8(1,4)$ & $28(1,8)$ \\
\hline TOTAL (N) & 61 & 102 & 90 & 242 & 480 & 569 & 1544 \\
\hline
\end{tabular}

Já a respeito do estado civil dos pacientes do sexo masculino, em torno de $45 \%$ eram casados e por volta de $40 \%$ eram solteiros, sendo que estes últimos foram mais frequentes até o fim dos anos 80 e, a partir dessa época, o estado civil mais frequente foi o casado. Em relação a quem ou onde os pacientes residiam na época do atendimento, ao longo dos anos, foram mais frequentes homens que residiam com seus pais (Tabela 4.7 ). 
Tabela 4.7 - Estado civil e com quem ou onde moravam os homens atendidos pelo serviço de Interconsulta Psiquiátrica entre janeiro de 1981 a dezembro de 2010.

\begin{tabular}{lccccccc} 
& $\mathbf{1 9 8 1 - 1 9 8 5}$ & $\mathbf{1 9 8 6 - 1 9 9 0}$ & $\mathbf{1 9 9 1 - 1 9 9 5}$ & $\mathbf{1 9 9 6 - 2 0 0 0}$ & $\mathbf{2 0 0 1 - 2 0 0 5}$ & $\mathbf{2 0 0 6 - 2 0 1 0}$ & TOTAL \\
\hline & $\mathbf{N}(\%)$ & $\mathbf{N}(\%)$ & $\mathbf{N}(\%)$ & $\mathbf{N}(\%)$ & $\mathbf{N}(\%)$ & $\mathbf{N}(\%)$ & $\mathbf{N}(\%)$ \\
\hline ESTADO CIVIL & $81(43,5)$ & $100(38,6)$ & $126(47,4)$ & $145(46,9)$ & $214(50,1)$ & $173(42,6)$ & $839(45,3)$ \\
Casado & $85(45,7)$ & $125(48,3)$ & $110(41,4)$ & $123(39,8)$ & $149(34,9)$ & $145(35,7)$ & $737(39,8)$ \\
Solteiro & $12(6,5)$ & $23(8,9)$ & $18(6,8)$ & $28(9,1)$ & $43(10,1)$ & $70(17,2)$ & $194(10,5)$ \\
Separado & $8(4,3)$ & $11(4,2)$ & $12(4,5)$ & $13(4,2)$ & $21(4,9)$ & $18(4,4)$ & $83(4,5)$ \\
Viúvo & 186 & 259 & 266 & 309 & 427 & 406 & 1853 \\
\hline TOTAL (N) & & & & & & \\
MORA COM/ONDE & & & & & & \\
\hline Pais & $8(25,0)$ & $35(41,7)$ & $14(28,6)$ & $53(28,6)$ & $84(28,6)$ & $91(29,2)$ & $285(29,8)$ \\
Cônjuge e filhos & $2(6,3)$ & $8(9,5)$ & $8(16,3)$ & $53(28,6)$ & $79(26,9)$ & $67(21,5)$ & $217(22,7)$ \\
Cônjuge & $2(6,3)$ & $6(7,1)$ & $5(10,2)$ & $33(17,8)$ & $62(21,1)$ & $49(15,7)$ & $157(16,4)$ \\
Sozinho & $9(28,1)$ & $3(3,6)$ & $6(12,2)$ & $15(8,1)$ & $22(7,5)$ & $39(12,5)$ & $94(9,8)$ \\
Parentes & $5(15,6)$ & $14(16,7)$ & $9(18,4)$ & $13(7,0)$ & $19(6,5)$ & $28(9,0)$ & $88(9,2)$ \\
Só, com filhos & $2(6,3)$ & 0,0 & $1(2,0)$ & $8(4,3)$ & $9(3,1)$ & $17(5,4)$ & $37(3,9)$ \\
Em instituição & $2(6,3)$ & $9(10,7)$ & $3(6,1)$ & $5(2,7)$ & $12(4,1)$ & $16(5,1)$ & $47(4,9)$ \\
Outros & $2(6,3)$ & $9(10,7)$ & $3(6,1)$ & $5(2,7)$ & $7(2,4)$ & $5(1,6)$ & $31(3,2)$ \\
\hline TOTAL (N) & 32 & 84 & 49 & 185 & 294 & 312 & 956 \\
\hline
\end{tabular}

Por volta de $45 \%$ das mulheres eram responsáveis pelo cuidado da casa, contudo, na última década, esta frequência decaiu, representando $32,8 \%$ delas. Houve um aumento na frequência de mulheres que se encontravam afastadas de seus empregos entre os anos de 1991 a 2000, passando esta frequência de 10,7 a 25,3\% respectivamente (Tabela 4.8 ). 
Tabela 4.8 - Situação laboral das mulheres atendidas pelo serviço de Interconsulta Psiquiátrica entre janeiro de 1981 a dezembro de 2010.

\begin{tabular}{lccccccc}
\cline { 2 - 7 } & $\mathbf{1 9 8 1 - 1 9 8 5}$ & $\mathbf{1 9 8 6 - 1 9 9 0}$ & $\mathbf{1 9 9 1 - 1 9 9 5}$ & $\mathbf{1 9 9 6 - 2 0 0 0}$ & $\mathbf{2 0 0 1 - 2 0 0 5}$ & $\mathbf{2 0 0 6 - 2 0 1 0}$ & TOTAL \\
\hline SITUAÇÃO LABORAL & $\mathbf{N}(\%)$ & $\mathbf{N}(\%)$ & $\mathbf{N}(\%)$ & $\mathbf{N}(\%)$ & $\mathbf{N}(\%)$ & $\mathbf{N}(\%)$ & $\mathbf{N}(\%)$ \\
\hline \multicolumn{1}{c}{ Cuidando do lar } & $116(52,0)$ & $166(51,6)$ & $216(56,4)$ & $183(45,8)$ & $314(45,4)$ & $244(32,8)$ & $1239(44,8)$ \\
Afastada & $38(17,0)$ & $36(11,2)$ & $41(10,7)$ & $101(25,3)$ & $134(19,4)$ & $144(19,3)$ & $494(17,9)$ \\
Autônoma & $19(8,5)$ & $55(17,1)$ & $31(8,1)$ & $39(9,8)$ & $70(10,1)$ & $84(11,3)$ & $298(10,8)$ \\
Empregada & $24(10,8)$ & $31(9,6)$ & $41(10,7)$ & $27(6,8)$ & $43(6,2)$ & $63(8,5)$ & $229(8,3)$ \\
Estudante & $6(2,7)$ & $14(4,3)$ & $33(8,6)$ & $20(5,0)$ & $51(7,4)$ & $73(9,8)$ & $197(7,1)$ \\
Desempregada & $11(4,9)$ & $9(2,8)$ & $8(2,1)$ & $10(2,5)$ & $37(5,3)$ & $77(10,3)$ & $152(5,5)$ \\
Aposentada & $6(2,7)$ & $9(2,8)$ & $11(2,9)$ & $17(4,3)$ & $35(5,1)$ & $49(6,6)$ & $127(4,6)$ \\
Outros & $3(1,3)$ & $2(0,6)$ & $2(0,5)$ & $3(0,8)$ & $8(1,2)$ & $11(1,5)$ & $29(1,0)$ \\
\hline TOTAL $(\mathrm{N})$ & 223 & 322 & 383 & 400 & 692 & 745 & 2765 \\
\hline
\end{tabular}

Já os pacientes do sexo masculino estavam afastados de seus empregos em quase $35 \%$ dos casos, sendo que até o ano de 1995, uma grande parcela dos homens era autônoma (Tabela 4.9).

Tabela 4.9 - Situação laboral dos homens atendidos pelo serviço de Interconsulta Psiquiátrica entre janeiro de 1981 a dezembro de 2010.

\begin{tabular}{lccccccc} 
& $\mathbf{1 9 8 1 - 1 9 8 5}$ & $\mathbf{1 9 8 6 - 1 9 9 0}$ & $\mathbf{1 9 9 1 - 1 9 9 5}$ & $\mathbf{1 9 9 6 - 2 0 0 0}$ & $\mathbf{2 0 0 1 - 2 0 0 5}$ & $\mathbf{2 0 0 6 - 2 0 1 0}$ & TOTAL \\
\hline SITUAÇÃO LABORAL & $\mathbf{N}(\%)$ & $\mathbf{N}(\%)$ & $\mathbf{N}(\%)$ & $\mathbf{N}(\%)$ & $\mathbf{N}(\%)$ & $\mathbf{N}(\%)$ & $\mathbf{N}(\%)$ \\
\hline Afastado & $60(32,1)$ & $71(27,2)$ & $60(23,2)$ & $131(42,0)$ & $173(40,8)$ & $147(36,3)$ & $642(34,7)$ \\
Autônomo & $72(38,5)$ & $98(37,5)$ & $104(40,2)$ & $72(23,1)$ & $74(17,5)$ & $71(17,5)$ & $491(26,6)$ \\
Empregado & $18(9,6)$ & $36(13,8)$ & $54(20,8)$ & $42(13,5)$ & $36(8,5)$ & $37(9,1)$ & $223(12,1)$ \\
Aposentado & $10(5,3)$ & $24(9,2)$ & $23(8,9)$ & $31(9,9)$ & $79(18,6)$ & $46(11,4)$ & $213(11,5)$ \\
Desempregado & $14(7,5)$ & $16(6,1)$ & $7(2,7)$ & $17(5,4)$ & $28(6,6)$ & $49(12,1)$ & $131(7,1)$ \\
Estudante & $13(7,0)$ & $15(5,7)$ & $9(3,5)$ & $12(3,8)$ & $33(7,8)$ & $48(11,9)$ & $130(7,0)$ \\
Cuidando do lar & 0,0 & $1(0,4)$ & $2(0,8)$ & $2(0,6)$ & 0,0 & 0,0 & $5(0,3)$ \\
Outros & 0,0 & 0,0 & 0,0 & $5(1,6)$ & $1(0,2)$ & $7(1,7)$ & $13(0,7)$ \\
\hline TOTAL (N) & 187 & 261 & 259 & 312 & 424 & 405 & 1848 \\
\hline
\end{tabular}

Em relação ao nível de escolaridade, mais de $65 \%$ dos pacientes do sexo feminino (Tabela 4.10) e 70\% do sexo masculino (Tabela 4.11) tinham até o ensino fundamental completo (chegando a 71,9\% das mulheres entre os anos de 1986 a 1990 
e $77,1 \%$ dos homens no mesmo período). Vale ressaltar que o analfabetismo, que na primeira metade da década de 80 abrangia $25 \%$ dos pacientes de ambos os sexos, decaiu para 8,1\% nas mulheres e 6,2\% nos homens em meados de 2006 a 2010.

Tabela 4.10 - Nível de escolaridade das mulheres atendidas pelo serviço de Interconsulta Psiquiátrica entre janeiro de 1981 a dezembro de 2010.

\begin{tabular}{lccccccc} 
& $\mathbf{1 9 8 1 - 1 9 8 5}$ & $\mathbf{1 9 8 6 - 1 9 9 0}$ & $\mathbf{1 9 9 1 - 1 9 9 5}$ & $\mathbf{1 9 9 6 - 2 0 0 0}$ & $\mathbf{2 0 0 1 - 2 0 0 5}$ & $\mathbf{2 0 0 6 - 2 0 1 0}$ & TOTAL \\
\hline ESCOLARIDADE & $\mathbf{N}(\%)$ & $\mathbf{N}(\%)$ & $\mathbf{N}(\%)$ & $\mathbf{N}(\%)$ & $\mathbf{N}(\%)$ & $\mathbf{N}(\%)$ & $\mathbf{N}(\%)$ \\
\hline Analfabeta & $53(25,0)$ & $59(19,3)$ & $62(16,4)$ & $42(10,8)$ & $75(10,9)$ & $60(8,1)$ & $351(12,9)$ \\
Ensino fundamental & $143(67,5)$ & $220(71,9)$ & $268(71,1)$ & $277(71,2)$ & $442(64,4)$ & $454(61,3)$ & $1804(66,5)$ \\
Ensino médio & $8(3,8)$ & $11(3,6)$ & $28(7,4)$ & $56(14,4)$ & $128(18,7)$ & $170(22,9)$ & $401(14,8)$ \\
Ensino superior & $8(3,8)$ & $16(5,2)$ & $19(5,0)$ & $14(3,6)$ & $40(5,8)$ & $51(6,9)$ & $148(5,5)$ \\
Pós-graduação & 0,0 & 0,0 & 0,0 & 0,0 & $1(0,1)$ & $6(0,8)$ & $7(0,3)$ \\
\hline TOTAL $(\mathrm{N})$ & 212 & 322 & 377 & 389 & 686 & 741 & 2727 \\
\hline
\end{tabular}

Tabela 4.11 - Nível de escolaridade dos homens atendidos pelo serviço de Interconsulta Psiquiátrica entre janeiro de 1981 a dezembro de 2010.

\begin{tabular}{lccccccc} 
& $\mathbf{1 9 8 1 - 1 9 8 5}$ & $\mathbf{1 9 8 6 - 1 9 9 0}$ & $\mathbf{1 9 9 1 - 1 9 9 5}$ & $\mathbf{1 9 9 6 - 2 0 0 0}$ & $\mathbf{2 0 0 1 - 2 0 0 5}$ & $\mathbf{2 0 0 6 - 2 0 1 0}$ & TOTAL \\
\hline ESCOLARIDADE & $\mathbf{N}(\%)$ & $\mathbf{N}(\%)$ & $\mathbf{N}(\%)$ & $\mathbf{N}(\%)$ & $\mathbf{N}(\%)$ & $\mathbf{N}(\%)$ & $\mathbf{N}(\%)$ \\
\hline Analfabeto & $43(25,0)$ & $31(12,4)$ & $34(13,7)$ & $20(6,8)$ & $45(10,8)$ & $25(6,2)$ & $198(11,1)$ \\
Ensino fundamental & $116(67,4)$ & $192(77,1)$ & $179(71,9)$ & $218(74,1)$ & $293(70,1)$ & $279(68,9)$ & $1277(71,5)$ \\
Ensino médio & $3(1,7)$ & $9(3,6)$ & $23(9,2)$ & $39(13,3)$ & $56(13,4)$ & $86(21,2)$ & $216(12,1)$ \\
Ensino superior & $10(5,8)$ & $17(6,8)$ & $12(4,8)$ & $17(5,8)$ & $23(5,5)$ & $15(3,7)$ & $94(5,3)$ \\
Pós-graduação & 0,0 & 0,0 & $1(0,4)$ & 0,0 & $1(0,2)$ & 0,0 & $2(0,1)$ \\
\hline TOTAL $(\mathrm{N})$ & 172 & 249 & 249 & 294 & 418 & 405 & 1787 \\
\hline
\end{tabular}

Por volta da metade das pacientes mulheres e dos pacientes homens procedeu de cidades do Estado de São Paulo seguido por Ribeirão Preto, sendo uma frequência relativamente constante ao longo dos anos (Tabela 4.12 e Tabela 4.13 respectivamente). 
Tabela 4.12 - Cidade de procedência das mulheres atendidas pelo serviço de Interconsulta Psiquiátrica entre janeiro de 1981 a dezembro de 2010.

\begin{tabular}{cccccccc} 
& $\mathbf{1 9 8 1 - 1 9 8 5}$ & $\mathbf{1 9 8 6 - 1 9 9 0}$ & $\mathbf{1 9 9 1 - 1 9 9 5}$ & $\mathbf{1 9 9 6 - 2 0 0 0}$ & $\mathbf{2 0 0 1 - 2 0 0 5}$ & $\mathbf{2 0 0 6 - 2 0 1 0}$ & TOTAL \\
\hline PROCEDÊNCIA & $\mathbf{N}(\%)$ & $\mathbf{N}(\%)$ & $\mathbf{N}(\%)$ & $\mathbf{N}(\%)$ & $\mathbf{N}(\%)$ & $\mathbf{N}(\%)$ & $\mathbf{N}(\%)$ \\
\hline Estado de SP & $123(55,9)$ & $171(54,1)$ & $225(58,4)$ & $193(47,8)$ & $379(54,4)$ & $390(52,4)$ & $1481(53,5)$ \\
Ribeirão Preto & $80(36,4)$ & $116(36,7)$ & $123(31,9)$ & $164(40,6)$ & $250(35,9)$ & $303(40,7)$ & $1036(37,5)$ \\
Outro estado & $17(7,7)$ & $29(9,2)$ & $37(9,6)$ & $47(11,6)$ & $68(9,8)$ & $51(6,9)$ & $249(9,0)$ \\
\hline TOTAL (N) & 220 & 316 & 385 & 404 & 697 & 744 & 2766 \\
\hline
\end{tabular}

Tabela 4.13 - Cidade de procedência dos homens atendidos pelo serviço de Interconsulta Psiquiátrica entre janeiro de 1981 a dezembro de 2010.

\begin{tabular}{cccccccc} 
& $\mathbf{1 9 8 1 - 1 9 8 5}$ & $\mathbf{1 9 8 6 - 1 9 9 0}$ & $\mathbf{1 9 9 1 - 1 9 9 5}$ & $\mathbf{1 9 9 6 - 2 0 0 0}$ & $\mathbf{2 0 0 1 - 2 0 0 5}$ & $\mathbf{2 0 0 6 - 2 0 1 0}$ & TOTAL \\
\hline PROCEDẾNCIA & $\mathbf{N}(\%)$ & $\mathbf{N}(\%)$ & $\mathbf{N}(\%)$ & $\mathbf{N}(\%)$ & $\mathbf{N}(\%)$ & $\mathbf{N}(\%)$ & $\mathbf{N}(\%)$ \\
\hline Estado de SP & $89(51,4)$ & $129(52,0)$ & $133(52,0)$ & $142(45,5)$ & $233(54,8)$ & $226(55,7)$ & $952(52,3)$ \\
Ribeirão Preto & $63(36,4)$ & $83(33,5)$ & $80(31,3)$ & $143(45,8)$ & $155(36,5)$ & $148(36,5)$ & $672(36,9)$ \\
Outro estado & $21(12,1)$ & $36(14,5)$ & $43(16,8)$ & $27(8,7)$ & $37(8,7)$ & $32(7,9)$ & $196(10,8)$ \\
\hline TOTAL (N) & 173 & 248 & 256 & 312 & 425 & 406 & 1820 \\
\hline
\end{tabular}

\subsubsection{HISTÓRICO EM SAÚDE MENTAL}

Até meados de 1995, informações a respeito dos antecedentes em tratamento psiquiátrico dos pacientes atendidos foram perdidas em mais de $36 \%$ dos pacientes femininos e $41 \%$ dos pacientes masculinos, sendo essa frequência por volta de $55 \%$ nos anos de 1981 a 1985. Dos dados válidos, ao longo dos anos, na grande maioria dos casos, foram atendidos pacientes de ambos os sexos que já tiveram algum tratamento psiquiátrico no passado (Tabela 4.14 para pacientes do sexo feminino e Tabela 4.15 para pacientes do sexo masculino).

Já o histórico de tentativas de suicídio não foi obtido em mais de $70 \%$ das mulheres e $80 \%$ dos homens até o ano de 2005. A porcentagem de ausência só decaiu a partir de 2006 , sendo de $28,4 \%$ para os pacientes do sexo feminino e 
$30,1 \%$, do masculino. Dos dados disponíveis, considerando os trinta anos de serviço

de Interconsulta, 40,8\% das mulheres e $33,7 \%$ dos homens assistidos tiveram

histórico de tentativa de suicídio.

Tabela 4.14 - Antecedentes em tratamento psiquiátrico e histórico de tentativas de suicídio das mulheres atendidas pelo serviço de Interconsulta Psiquiátrica entre janeiro de 1981 a dezembro de 2010.

\begin{tabular}{lccccccc} 
& $\mathbf{1 9 8 1 - 1 9 8 5}$ & $\mathbf{1 9 8 6 - 1 9 9 0}$ & $\mathbf{1 9 9 1 - 1 9 9 5}$ & $\mathbf{1 9 9 6 - 2 0 0 0}$ & $\mathbf{2 0 0 1 - 2 0 0 5}$ & $\mathbf{2 0 0 6 - 2 0 1 0}$ & TOTAL \\
\hline ANTECEDENTES & $\mathbf{N}(\%)$ & $\mathbf{N}(\%)$ & $\mathbf{N}(\%)$ & $\mathbf{N}(\%)$ & $\mathbf{N}(\%)$ & $\mathbf{N}(\%)$ & $\mathbf{N}(\%)$ \\
\hline Sim & $138(97,9)$ & $160(80,8)$ & $187(71,4)$ & $236(75,6)$ & $416(82,9)$ & $471(68,4)$ & $1608(76,4)$ \\
Não & $3(2,1)$ & $38(19,2)$ & $75(28,6)$ & $76(24,4)$ & $86(17,1)$ & $218(31,6)$ & $496(23,6)$ \\
\hline TOTAL (N) & 141 & 198 & 262 & 312 & 502 & 689 & 2104 \\
Dados perdidos & $166(54,1)$ & $159(44,5)$ & $151(36,6)$ & $104(25,0)$ & $201(28,6)$ & $60(8,0)$ & $841(28,5)$ \\
& & & & & & & \\
TENTATIVAS DE SUICídIO & & & & & & & \\
\hline Sim & $54(100)$ & $31(100)$ & $39(68,4)$ & $46(64,8)$ & $96(46,6)$ & $124(23,1)$ & $390(40,8)$ \\
Não & 0,0 & 0,0 & $18(31,6)$ & $25(35,2)$ & $110(53,4)$ & $412(76,9)$ & $565(59,2)$ \\
\hline TOTAL (N) & 54 & 31 & 57 & 71 & 206 & 536 & 955 \\
Dados perdidos & $253(82,4)$ & $326(91,3)$ & $356(86,2)$ & $345(82,9)$ & $497(70,7)$ & $213(28,4)$ & $1990(67,6)$ \\
\hline
\end{tabular}

* Porcentagem dos dados perdidos em relação ao número total de pacientes mulheres atendidas em cada período.

Tabela 4.15 - Antecedentes em tratamento psiquiátrico e histórico de tentativas de suicídio dos homens atendidos pelo serviço de Interconsulta Psiquiátrica entre janeiro de 1981 a dezembro de 2010.

\begin{tabular}{lccccccc} 
& $\mathbf{1 9 8 1 - 1 9 8 5}$ & $\mathbf{1 9 8 6 - 1 9 9 0}$ & $\mathbf{1 9 9 1 - 1 9 9 5}$ & $\mathbf{1 9 9 6 - 2 0 0 0}$ & $\mathbf{2 0 0 1 - 2 0 0 5}$ & $\mathbf{2 0 0 6 - 2 0 1 0}$ & TOTAL \\
\hline ANTECEDENTES & $\mathbf{N}(\%)$ & $\mathbf{N}(\%)$ & $\mathbf{N}(\%)$ & $\mathbf{N}(\%)$ & $\mathbf{N}(\%)$ & $\mathbf{N}(\%)$ & $\mathbf{N}(\%)$ \\
\hline Sim & $92(92,0)$ & $111(78,2)$ & $111(68,5)$ & $179(74,0)$ & $237(77,5)$ & $210(57,9)$ & $940(71,5)$ \\
Não & $8(8,0)$ & $31(21,8)$ & $51(31,5)$ & $63(26,0)$ & $69(22,5)$ & $153(42,1)$ & $375(28,5)$ \\
\hline TOTAL (N) & 100 & 142 & 162 & 242 & 306 & 363 & 1315 \\
Dados perdidos & $124(55,4)$ & $134(48,6)$ & $115(41,5)$ & $80(24,8)$ & $126(29,2)$ & $43(10,6)$ & $622(32,1)$ \\
& & & & & & & \\
TENTATIVAS DE SUICíDIO & & & & & & & \\
\hline Sim & $13(5,8)$ & $23(100)$ & $22(62,9)$ & $26(57,8)$ & $34(41,0)$ & $45(15,8)$ & $163(33,7)$ \\
Não & 0,0 & 0,0 & $13(37,1)$ & $19(42,2)$ & $49(59,0)$ & $239(84,2)$ & $320(66,3)$ \\
\hline TOTAL (N) & 13 & 23 & 35 & 45 & 83 & 284 & 483 \\
Dados perdidos & $211(94,2)$ & $253(91,7)$ & $242(87,4)$ & $277(86)$ & $349(80,8)$ & $122(30,1)$ & $1454(75,1)$ \\
\hline
\end{tabular}

* Porcentagem dos dados perdidos em relação ao número total de pacientes homens atendidos em cada período. 


\subsection{USO DO SERVIÇO DE INTERCONSULTA PSIQUIÁTRICA}

\subsubsection{CLÍNICAS SOLICITANTES}

A Clínica Médica foi a clínica que mais solicitou Pls tanto para os pacientes do sexo feminino quanto masculino ao longo dos trinta anos. No caso das mulheres, a segunda clínica mais solicitante foi a Ginecologia / Obstetrícia, seguida pela Neurologia e Cirurgia (Tabela 4.16), enquanto que, nos homens, a segunda clínica mais solicitante foi a Moléstias Infecciosas, seguida pela Cirurgia (Tabela 4.17).

Tabela 4.16 - Clínicas que solicitaram atendimento às mulheres internadas no HCFMRP-USP entre janeiro de 1981 a dezembro de 2010.

\begin{tabular}{lccccccc} 
& $\mathbf{1 9 8 1 - 1 9 8 5}$ & $\mathbf{1 9 8 6 - 1 9 9 0}$ & $\mathbf{1 9 9 1 - 1 9 9 5}$ & $\mathbf{1 9 9 6 - 2 0 0 0}$ & $\mathbf{2 0 0 1 - 2 0 0 5}$ & $\mathbf{2 0 0 6 - 2 0 1 0}$ & TOTAL \\
\hline \cline { 2 - 8 } CLíNICA SOLICITANTE & $\mathbf{N}(\%)$ & $\mathbf{N}(\%)$ & $\mathbf{N}(\%)$ & $\mathbf{N}(\%)$ & $\mathbf{N}(\%)$ & $\mathbf{N}(\%)$ & $\mathbf{N}(\%)$ \\
\hline Clínica Médica Geral & $132(43,3)$ & $150(42,7)$ & $184(44,8)$ & $158(38,2)$ & $226(32,2)$ & $243(32,4)$ & $1093(37,3)$ \\
Ginecologia / Obstetrícia & $31(10,2)$ & $40(11,4)$ & $28(6,8)$ & $36(8,7)$ & $72(10,3)$ & $107(14,3)$ & $314(10,7)$ \\
Neurologia & $51(16,7)$ & $25(7,1)$ & $54(13,1)$ & $41(9,9)$ & $63(9,0)$ & $54(7,2)$ & $288(9,8)$ \\
Cirurgia & $27(8,9)$ & $23(6,6)$ & $18(4,4)$ & $41(9,9)$ & $63(9,0)$ & $65(8,7)$ & $237(8,1)$ \\
Unidade Metabólica & $10(3,3)$ & $28(8,0)$ & $36(8,8)$ & $26(6,3)$ & $72(10,3)$ & $61(8,1)$ & $233(7,9)$ \\
Moléstias Infecciosas / UETDI & $14(4,6)$ & $13(3,7)$ & $13(3,2)$ & $36(8,7)$ & $73(10,4)$ & $71(9,5)$ & $220(7,5)$ \\
Unidade Transplante Renal & $8(2,6)$ & $12(3,4)$ & $24(5,8)$ & $27(6,5)$ & $44(6,3)$ & $28(3,7)$ & $143(4,9)$ \\
Ortopedia & $23(7,5)$ & $33(9,4)$ & $29(7,1)$ & $15(3,6)$ & $19(2,7)$ & $20(2,7)$ & $139(4,7)$ \\
Pediatria & $2(0,7)$ & $4(1,1)$ & $12(2,9)$ & $14(3,4)$ & $31(4,4)$ & $51(6,8)$ & $114(3,9)$ \\
Outros & $7(2,3)$ & $23(6,6)$ & $13(3,2)$ & $20(4,8)$ & $39(5,6)$ & $49(6,5)$ & $151(5,2)$ \\
\hline TOTAL (N) & 305 & 351 & 411 & 414 & 702 & 749 & 2932 \\
\hline
\end{tabular}


Tabela 4.17 - Clínicas que solicitaram atendimento aos homens internados no HCFMRP-USP entre janeiro de 1981 a dezembro de 2010.

\begin{tabular}{lccccccc} 
& $\mathbf{1 9 8 1 - 1 9 8 5}$ & $\mathbf{1 9 8 6 - 1 9 9 0}$ & $\mathbf{1 9 9 1 - 1 9 9 5}$ & $\mathbf{1 9 9 6 - 2 0 0 0}$ & $\mathbf{2 0 0 1 - 2 0 0 5}$ & $\mathbf{2 0 0 6 - 2 0 1 0}$ & TOTAL \\
\hline CLíNICA SOLICITANTE & $\mathbf{N}(\%)$ & $\mathbf{N}(\%)$ & $\mathbf{N}(\%)$ & $\mathbf{N}(\%)$ & $\mathbf{N}(\%)$ & $\mathbf{N}(\%)$ & $\mathbf{N}(\%)$ \\
\hline Clínica Médica Geral & $91(40,6)$ & $109(40,1)$ & $126(45,8)$ & $113(35,2)$ & $130(30,2)$ & $132(32,5)$ & $701(36,4)$ \\
Moléstias Infecciosas / UETDI & $10(4,5)$ & $23(8,5)$ & $14(5,1)$ & $71(22,1)$ & $80(18,6)$ & $83(15,0)$ & $281(14,6)$ \\
Cirurgia & $24(10,7)$ & $19(7,0)$ & $23(8,4)$ & $20(6,2)$ & $47(10,9)$ & $61(15,0)$ & $194(10,1)$ \\
Ortopedia & $42(18,8)$ & $38(14,0)$ & $26(9,5)$ & $16(5,0)$ & $16(3,7)$ & $27(6,7)$ & $165(8,6)$ \\
Neurologia & $26(11,6)$ & $22(8,1)$ & $28(10,2)$ & $17(5,3)$ & $31(7,2)$ & $26(6,4)$ & $150(7,8)$ \\
Unidade Transplante Renal & $11(4,9)$ & $18(6,6)$ & $25(9,1)$ & $26(8,1)$ & $27(6,3)$ & $21(5,2)$ & $128(6,6)$ \\
Unidade Metabólica & $12(5,4)$ & $18(6,6)$ & $11(4,0)$ & $19(5,9)$ & $41(9,5)$ & $19(4,7)$ & $120(6,2)$ \\
Pediatria & 0,0 & $4(1,5)$ & 0,0 & $10(3,1)$ & $13(3,0)$ & $16(3,9)$ & $43(2,2)$ \\
Outros & $8(3,5)$ & $21(7,7)$ & $22(8,0)$ & $29(9,1)$ & $45(10,5)$ & $21(5,1)$ & $146(7,6)$ \\
\hline TOTAL (N) & 224 & 272 & 275 & 321 & 430 & 406 & 1928 \\
\hline
\end{tabular}

Em relação às mulheres, a Ginecologia / Obstetrícia aumentou o número de solicitações ao longo dos anos (em especial a partir de 1996) assim como a Cirurgia, enquanto que a Neurologia decaiu gradualmente a frequência de solicitações ao longo dos anos (Figura 4.1).

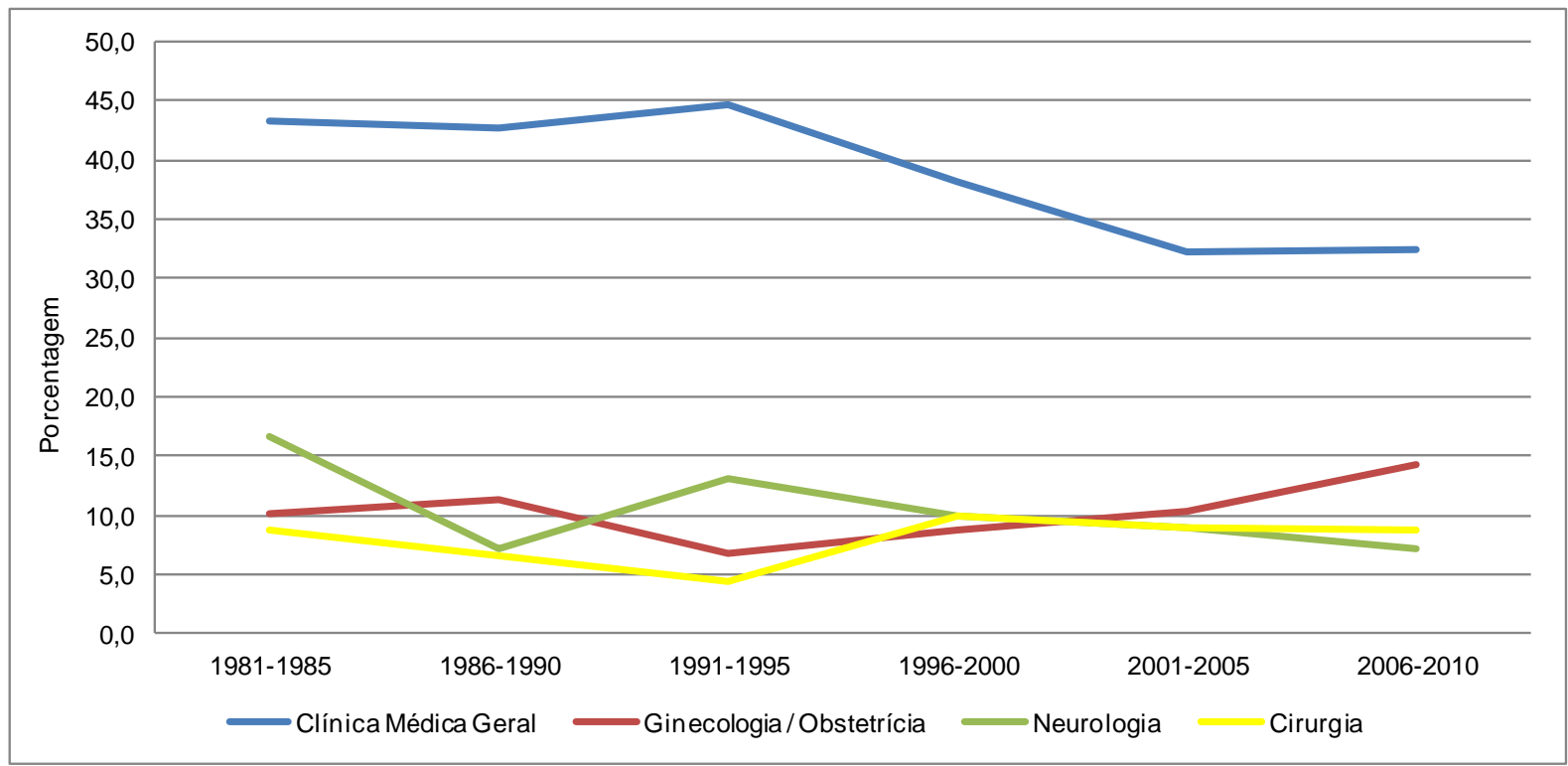

Figura 4.1 - Principais clínicas que solicitaram atendimento a pacientes do sexo feminino internados no HCFMRP-USP entre janeiro de 1981 a dezembro de 2010. 
Apesar da clínica referente às Moléstias Infecciosas / UETDI ter aumentado o número de solicitações ao longo dos anos para ambos os sexos, este número quadruplicou no caso dos homens a partir de 1996 e cresceu progressivamente até 2010 (apesar de ter reduzido a sua porcentagem de participação quando consideradas todas as outras clínicas). A Cirurgia duplicou seu número de solicitações para os pacientes do sexo masculino entre 1996 e 2005, chegando a 15\% na participação das solicitações no fim da última década (Figura 4.2).

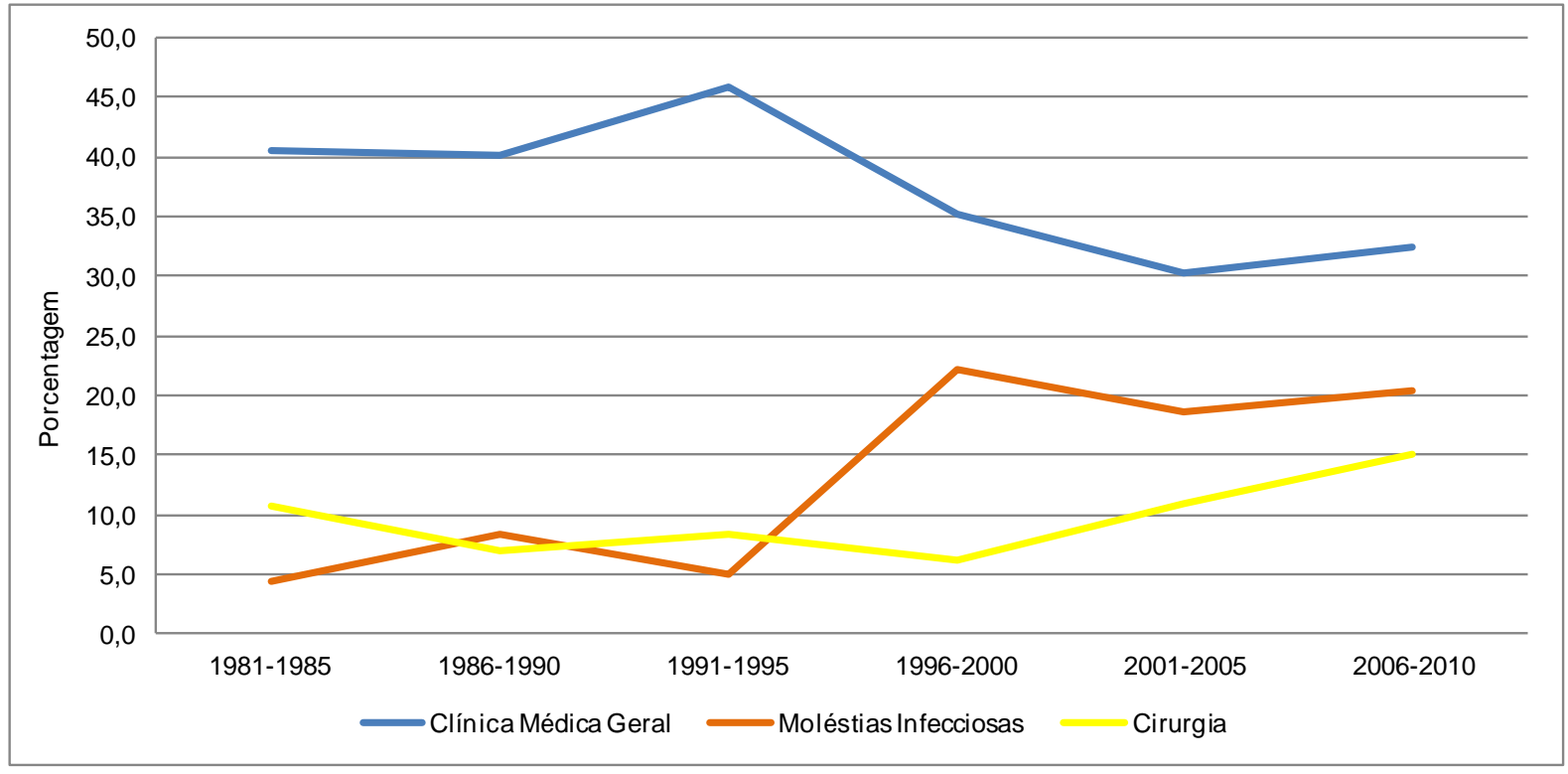

Figura 4.2 - Principais clínicas que solicitaram atendimento a pacientes do sexo masculino internados no HCFMRP-USP entre janeiro de 1981 a dezembro de 2010.

Notou-se também, para ambos os sexos, a redução da participação da Clínica Médica dentre todas as clínicas solicitantes a partir de 1996, apesar do número de solicitações provindas desta clínica ter crescido a partir de 2001.

Em relação às especialidades da Clínica Médica, considerando apenas 
aquelas que foram identificadas, a Imunologia foi responsável por $18,1 \%$ das solicitações para o sexo feminino, seguida pela Dermatologia, com 15,6\% e a Endocrinologia, com 15,4\% (Figura 4.3). Em contrapartida, para os pacientes do sexo masculino, as especialidades com mais solicitações foram a Dermatologia em $19,1 \%$ dos casos, a Hematologia em $17,4 \%$ e a Cardiologia em 16,2\% (Figura 4.4).

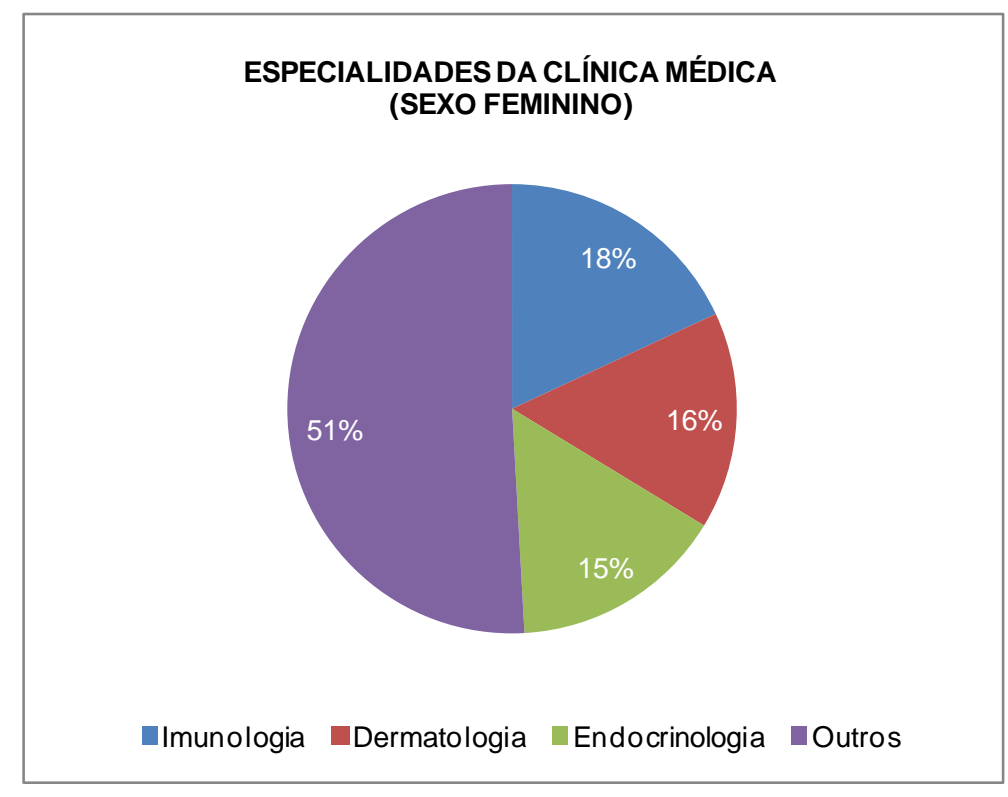

Figura 4.3 - Principais especialidades da Clínica Médica que solicitaram avaliação psiquiátrica a pacientes do sexo feminino em trinta anos de serviço de Interconsulta Psiquiátrica no HCFMRP-USP. 


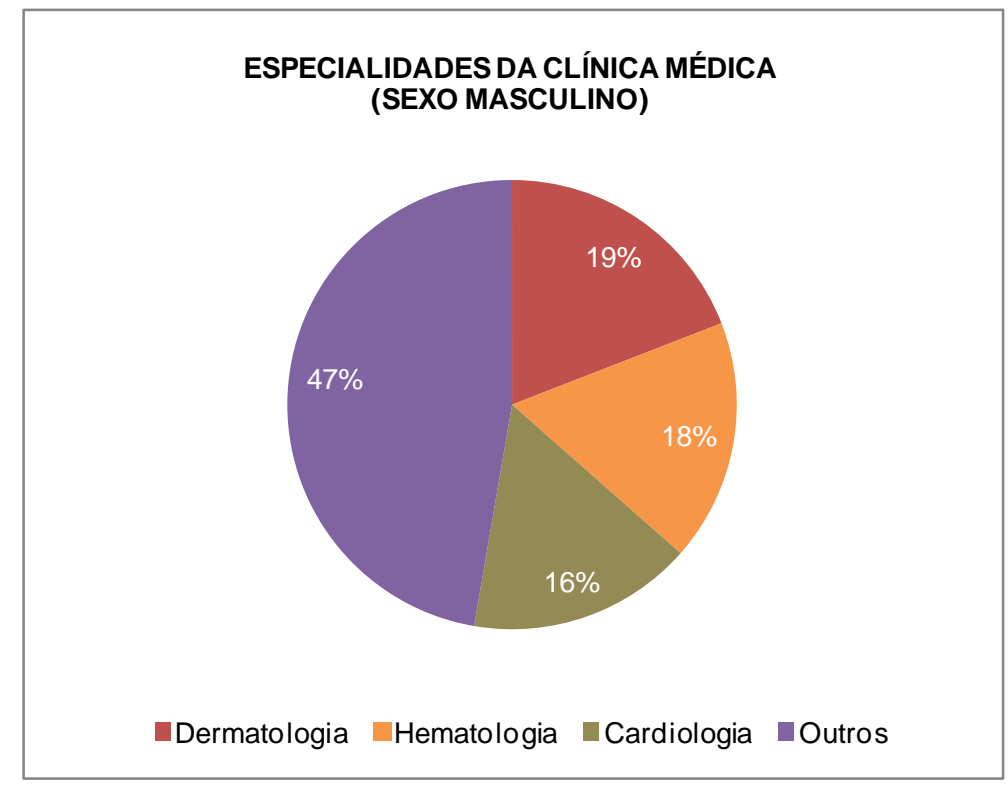

Figura 4.4 - Principais especialidades da Clínica Médica que solicitaram avaliação psiquiátrica a pacientes do sexo masculino em trinta anos de serviço de Interconsulta Psiquiátrica no HCFMRP-USP.

As solicitações para as pacientes do sexo feminino provindas da Imunologia se mantiveram relativamente estáveis até 1995, apresentando aumento considerável no número de Pls entre os anos de 1996 a 2005 e decaindo no final da última década. Já a Dermatologia e a Endocrinologia relativamente mantiveram seus números de solicitações ao longo dos anos (Tabela 4.18). 
Tabela 4.18 - Especialidades da Clínica Médica que solicitaram atendimento às mulheres internadas no HCFMRP-USP entre janeiro de 1981 a dezembro de 2010.

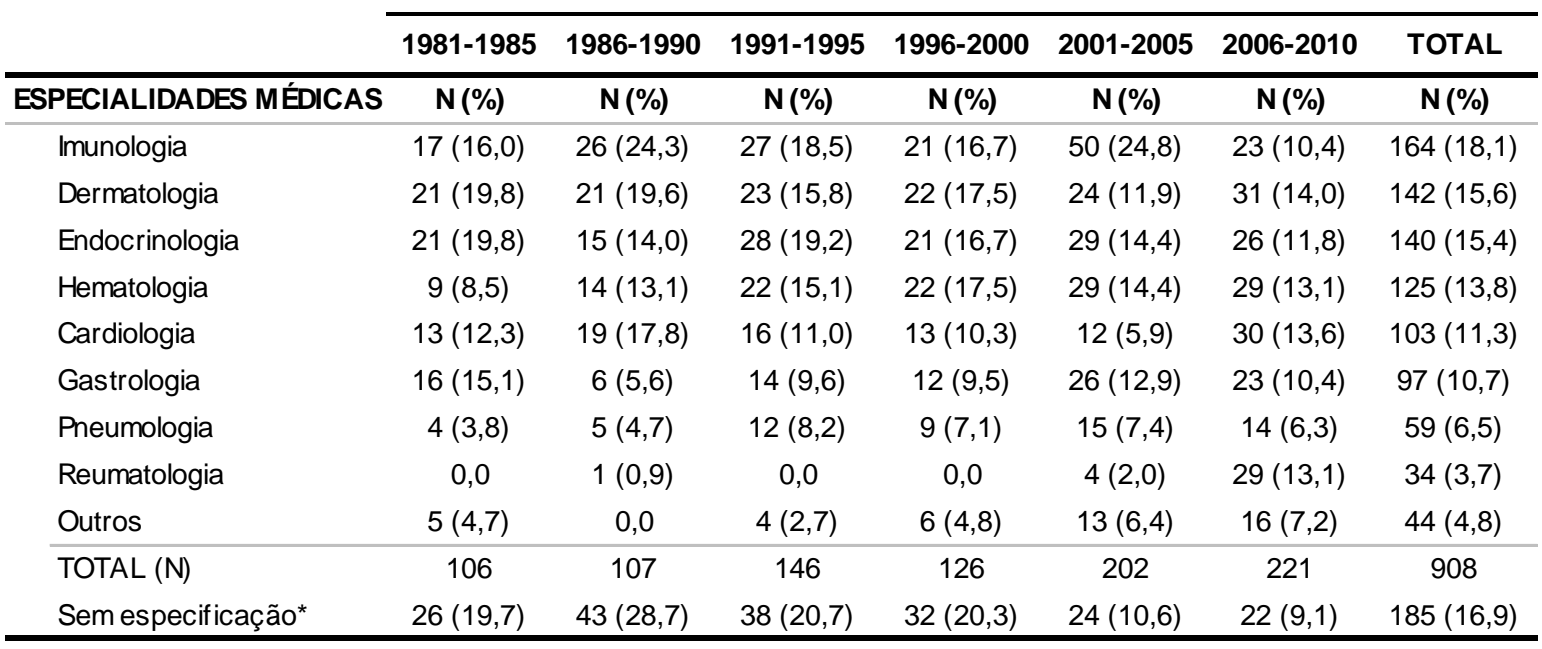

* Especialidades que não foram especificadas na solicitação psiquiátrica considerando toda a população de mulheres que tiveram solicitação provinda da Clínica Médica; a porcentagem informada é referente ao número total de solicitações realizadas por esta clínica no período.

No caso das solicitações para os pacientes do sexo masculino, a Dermatologia manteve a mesma tendência no número de solicitações, com um aumento apenas entre os anos de 1981 a 1990 e de 1996 a 2005. A Hematologia teve aumento progressivo no número de solicitações até 1995, decaindo entre 1996 e 2000, e aumentando novamente a partir de 2001. Já a Cardiologia teve um aumento discreto e progressivo a partir de 1991 (Tabela 4.19). 
Tabela 4.19 - Especialidades da Clínica Médica que solicitaram atendimento aos homens internados no HCFMRP-USP entre janeiro de 1981 a dezembro de 2010.

\begin{tabular}{lccccccc} 
& $\mathbf{1 9 8 1 - 1 9 8 5}$ & $\mathbf{1 9 8 6 - 1 9 9 0}$ & $\mathbf{1 9 9 1 - 1 9 9 5}$ & $\mathbf{1 9 9 6 - 2 0 0 0}$ & $\mathbf{2 0 0 1 - 2 0 0 5}$ & $\mathbf{2 0 0 6 - 2 0 1 0}$ & TOTAL \\
\hline ESPECIALIDADES MÉDICAS & $\mathbf{N}(\%)$ & $\mathbf{N}(\%)$ & $\mathbf{N}(\%)$ & $\mathbf{N}(\%)$ & $\mathbf{N}(\%)$ & $\mathbf{N}(\%)$ & $\mathbf{N}(\%)$ \\
\hline Dermatologia & $16(25,4)$ & $25(27,5)$ & $20(20,4)$ & $15(16,1)$ & $19(16,8)$ & $16(13,1)$ & $111(19,1)$ \\
Hematologia & $8(12,7)$ & $13(14,3)$ & $26(26,5)$ & $12(12,9)$ & $22(19,5)$ & $20(16,4)$ & $101(17,4)$ \\
Cardiologia & $8(12,74)$ & $17(18,7)$ & $14(14,3)$ & $15(16,1)$ & $18(15,9)$ & $22(18,0)$ & $94(16,2)$ \\
Gastrologia & $12(19,0)$ & $9(9,9)$ & $14(14,3)$ & $19(20,4)$ & $15(13,3)$ & $23(18,9)$ & $92(15,9)$ \\
Endocrinologia & $9(14,3)$ & $13(14,3)$ & $6(6,1)$ & $9(9,7)$ & $19(16,8)$ & $17(13,9)$ & $73(12,6)$ \\
Pneumologia & $1(1,6)$ & $8(8,8)$ & $7(7,1)$ & $14(15,1)$ & $11(9,7)$ & $9(7,4)$ & $50(8,6)$ \\
Imunologia & $3(4,8)$ & $3(3,3)$ & $6(6,1)$ & $4(4,3)$ & $3(2,7)$ & 0,0 & $19(3,3)$ \\
Reumatologia & 0,0 & 0,0 & 0,0 & 0,0 & 0,0 & $4(3,3)$ & $4(0,7)$ \\
Outros & $6(9,5)$ & $3(3,3)$ & $5(5,1)$ & $5(5,4)$ & $6(5,3)$ & $11(9,0)$ & $36(6,2)$ \\
\hline TOTAL (N) & 63 & 91 & 98 & 93 & 113 & 122 & 580 \\
Sem especificação* & $28(30,8)$ & $18(16,5)$ & $28(22,2)$ & $20(17,7)$ & $17(13,1)$ & $10(7,6)$ & $121(17,3)$ \\
\hline
\end{tabular}

* Especialidades que não foram especificadas na solicitação psiquiátrica considerando toda a população de homens que tiveram solicitação provinda da Clínica Médica; a porcentagem informada é referente ao número total de solicitações realizadas por esta clínica no período.

\subsubsection{FUNÇÕES DOS PROFISSIONAIS SOLICITANTES}

A função do profissional solicitante não foi registrado na grande maioria dos Pls até o ano de 1995. A partir de então, mais de $70 \%$ das solicitações foram realizadas pelos residentes e aprimorandos do hospital (Tabela 4.20).

Tabela 4.20 - Função do profissional solicitante do PI aos pacientes internados no HCFMRP-USP entre janeiro de 1981 a dezembro de 2010.

\begin{tabular}{lccccccc} 
& 1981-1985 & $\mathbf{1 9 8 6 - 1 9 9 0}$ & $\mathbf{1 9 9 1 - 1 9 9 5}$ & $\mathbf{1 9 9 6 - 2 0 0 0}$ & $\mathbf{2 0 0 1 - 2 0 0 5}$ & $\mathbf{2 0 0 6 - 2 0 1 0}$ & TOTAL \\
\hline FUNÇÃO DO SOLICITANTE & $\mathbf{N}(\%)$ & $\mathbf{N}(\%)$ & $\mathbf{N}(\%)$ & $\mathbf{N}(\%)$ & $\mathbf{N}(\%)$ & $\mathbf{N}(\%)$ & $\mathbf{N}(\%)$ \\
\hline Médico residente / aprimorando & $4(0,7)$ & $18(2,8)$ & $209(30,3)$ & $545(73,8)$ & $897(79,0)$ & $962(83,3)$ & $2635(54,0)$ \\
Aluno / doutorando & $4(0,7)$ & $13(2,1)$ & $30(4,3)$ & $108(14,6)$ & $89(7,8)$ & $48(4,2)$ & $292(6,0)$ \\
Psicólogo & $1(0,2)$ & 0,0 & 0,0 & $10(1,4)$ & $90(7,9)$ & $72(6,2)$ & $173(3,5)$ \\
Médico assistente & $1(0,2)$ & $2(0,3)$ & $3(0,4)$ & $22(3,0)$ & $35(3,1)$ & $34(2,9)$ & $97(2,0)$ \\
Terapia Ocupacional & 0,0 & 0,0 & 0,0 & $1(0,1)$ & $3(0,3)$ & $7(0,6)$ & $11(0,2)$ \\
Outros & $2(0,4)$ & $1(0,1)$ & 0,0 & $1(0,1)$ & $1(0,1)$ & $1(0,1)$ & $6(0,1)$ \\
Não registrado & $519(97,8)$ & $599(94,6)$ & $448(64,9)$ & $51(7,0)$ & $20(1,8)$ & $31(2,7)$ & $1668(34,2)$ \\
\hline TOTAL (N) & 531 & 633 & 690 & 738 & 1135 & 1155 & 4882 \\
\hline
\end{tabular}




\subsubsection{MOTIVOS PARA SOLICITAÇÃO PSIQUIÁTRICA}

Os motivos mais frequentemente alegados pelos profissionais solicitantes foram a presença de sintomas psiquiátricos seguido por antecedentes psiquiátricos para ambos os sexos, sintomas físicos mal definidos ou com possível origem psicológica para as mulheres (Tabela 4.21) e abuso de substâncias psicoativas para os homens (Tabela 4.22). Ao longo dos anos, observou-se um aumento progressivo na frequência de solicitações motivadas por antecedentes psiquiátricos de pacientes do sexo feminino enquanto que, para os pacientes do sexo masculino, houve um aumento considerável entre 1991 a 2000 dessas solicitações e depois uma relativa estabilidade na frequência.

Tabela 4.21 - Motivos alegados pelos profissionais clínicos para a avaliação psiquiátrica dos pacientes do sexo feminino internados entre janeiro de 1981 a dezembro de 2010.

\begin{tabular}{lccccccc} 
& $\mathbf{1 9 8 1 - 1 9 8 5}$ & $\mathbf{1 9 8 6 - 1 9 9 0}$ & $\mathbf{1 9 9 1 - 1 9 9 5}$ & $\mathbf{1 9 9 6 - 2 0 0 0}$ & $\mathbf{2 0 0 1 - 2 0 0 5}$ & $\mathbf{2 0 0 6 - 2 0 1 0}$ & TOTAL \\
\cline { 2 - 7 } MOTIVOS DE SOLICITAÇÃO & $\mathbf{N}(\%)$ & $\mathbf{N}(\%)$ & $\mathbf{N}(\%)$ & $\mathbf{N}(\%)$ & $\mathbf{N}(\%)$ & $\mathbf{N}(\%)$ & $\mathbf{N}(\%)$ \\
\hline Sintomas psiquiátricos presentes & $124(40,8)$ & $165(47,4)$ & $202(49,3)$ & $199(48,5)$ & $275(39,3)$ & $268(36,0)$ & $1233(42,3)$ \\
Antecedentes psiquiátricos & $60(19,7)$ & $45(12,9)$ & $59(14,4)$ & $62(15,1)$ & $144(20,6)$ & $186(25,0)$ & $556(19,1)$ \\
Sintomas físicos mal definidos & $27(8,9)$ & $47(13,5)$ & $50(12,2)$ & $44(10,7)$ & $80(11,4)$ & $63(8,5)$ & $311(10,7)$ \\
Problemas quanto cooperação no tratamento & $16(5,3)$ & $22(6,3)$ & $25(6,1)$ & $28(6,8)$ & $28(4,0)$ & $47(6,3)$ & $166(5,7)$ \\
Risco suicida & $35(11,5)$ & $19(5,5)$ & $17(4,1)$ & $23(5,6)$ & $32(4,6)$ & $37(5,0)$ & $163(5,6)$ \\
Avaliação quanto ao uso de psicotrópicos & $8(2,6)$ & $9(2,6)$ & $16(3,9)$ & $20(4,9)$ & $51(7,3)$ & $46(6,2)$ & $150(5,1)$ \\
Abuso de substâncias psicoativas & $13(4,3)$ & $13(3,7)$ & $9(2,2)$ & $6(1,5)$ & $27(3,9)$ & $26(3,5)$ & $94(3,2)$ \\
Atendimento ao familiar & $1(0,3)$ & $1(0,3)$ & $6(1,5)$ & $12(2,9)$ & $26(3,7)$ & $48(6,5)$ & $94(3,2)$ \\
Psicodiagnóstico & $7(2,3)$ & $7(2,0)$ & $6(1,5)$ & $4(1,0)$ & $5(0,7)$ & $5(0,7)$ & $34(1,2)$ \\
Aval para procedimentos de risco & $2(0,7)$ & $5(1,4)$ & $4(1,0)$ & $3(0,7)$ & $6(0,9)$ & $5(0,7)$ & $25(0,9)$ \\
Ociosidade e/ou internação longa & $1(0,3)$ & $2(0,6)$ & 0,0 & $1(0,2)$ & $5(0,7)$ & $3(0,4)$ & $12(0,4)$ \\
Outros & $10(3,3)$ & $13(3,7)$ & $16(3,9)$ & $8(2,0)$ & $21(3,0)$ & $10(1,3)$ & $78(2,6)$ \\
\hline TOTAL (N) & 304 & 348 & 410 & 410 & 700 & 744 & 2916 \\
Sem motivo especificado* & $3(1,0)$ & $4(1,1)$ & 0,0 & $4(1,0)$ & $3(0,4)$ & $4(0,5)$ & $18(0,6)$ \\
Dado perdido* & 0,0 & $5(1,4)$ & $3(0,7)$ & $2(0,5)$ & 0,0 & $1(0,1)$ & $11(0,4)$ \\
\hline
\end{tabular}

* Porcentagem informada é referente ao número total de solicitações realizadas no período. 
Tabela 4.22 - Motivos alegados pelos profissionais clínicos para a avaliação psiquiátrica dos pacientes do sexo masculino internados entre janeiro de 1981 a dezembro de 2010.

\begin{tabular}{|c|c|c|c|c|c|c|c|}
\hline & & & & & & & \\
\hline & 1981-1985 & 1986-1990 & 1991-1995 & $1996-2000$ & 2001-2005 & 2006-2010 & TOTAL \\
\hline MOTIVOS DE SOLICITAÇÃO & $\mathbf{N}(\%)$ & $\mathrm{N}(\%)$ & $N(\%)$ & $\mathbf{N}(\%)$ & $N(\%)$ & $N(\%)$ & $\mathrm{N}(\%)$ \\
\hline Sintomas psiquiátricos presentes & $89(40,5)$ & $122(45,7)$ & $118(43,4)$ & $140(43,8)$ & $176(41,0)$ & $178(44,2)$ & $823(43,1)$ \\
\hline Antecedentes psiquiátricos & $28(12,7)$ & $28(10,5)$ & $29(10,7)$ & $56(17,5)$ & $69(16,1)$ & $67(16,6)$ & $277(14,5)$ \\
\hline Abuso de substâncias psicoativas & $29(13,2)$ & $27(10,1)$ & $27(9,9)$ & $30(9,4)$ & $55(12,8)$ & $44(10,9)$ & $212(11,1)$ \\
\hline Sintomas físicos mal definidos & $29(13,2)$ & $14(5,2)$ & $31(11,4)$ & $26(8,1)$ & $19(4,4)$ & $25(6,2)$ & $144(7,5)$ \\
\hline Risco suicida & $15(6,8)$ & $14(5,2)$ & $22(8,1)$ & $22(6,9)$ & $33(7,7)$ & $27(6,7)$ & $133(7,0)$ \\
\hline Problemas quanto cooperação no tratamento & $14(6,4)$ & $31(11,6)$ & $19(7,0)$ & $13(4,1)$ & $26(6,1)$ & $24(6,0)$ & $127(6,6)$ \\
\hline Avaliação quanto ao uso de psicotrópicos & $4(1,8)$ & $12(4,5)$ & $11(4,0)$ & $19(5,9)$ & $27(6,3)$ & $23(5,7)$ & $96(5,0)$ \\
\hline Psicodiagnóstico & $3(1,44)$ & $8(3,0)$ & $2(0,7)$ & $1(0,3)$ & $1(0,2)$ & $1(0,2)$ & $16(0,8)$ \\
\hline Aval para procedimentos de risco & $3(1,44)$ & $3(1,1)$ & $3(1,1)$ & $1(0,3)$ & $2(0,5)$ & $3(0,7)$ & $15(0,8)$ \\
\hline Atendimento ao familiar & 0,0 & 0,0 & 0,0 & $1(0,3)$ & $4(0,9)$ & $3(0,7)$ & $8(0,4)$ \\
\hline Ociosidade e/ou internação longa & 0,0 & 0,0 & 0,0 & $1(0,3)$ & 0,0 & $5(1,2)$ & $6(0,3)$ \\
\hline Outros & $6(2,7)$ & $8(3,0)$ & $10(3,7)$ & $10(3,1)$ & $17(4,0)$ & $3(0,7)$ & $39(2,0)$ \\
\hline TOTAL (N) & 220 & 267 & 272 & 320 & 429 & 403 & 1911 \\
\hline Sem motivo especificado* & $2(0,9)$ & $3(1,1)$ & $3(1,1)$ & $1(0,3)$ & $2(0,5)$ & $3(0,7)$ & $14(0,7)$ \\
\hline Dado perdido* & $2(0,9)$ & $6(2,2)$ & $2(0,7)$ & $1(0,3)$ & $1(0,2)$ & 0,0 & $12(0,6)$ \\
\hline
\end{tabular}

* Porcentagem informada é referente ao número total de solicitações realizadas no período.

Nos casos em que foram registradas nos Pls as hipóteses diagnósticas psiquiátricas formuladas pelos profissionais solicitantes, nos pacientes do sexo feminino, as mais comuns foram possíveis transtornos de humor em $40 \%$ de todos os casos, seguidos por suspeitas de transtornos neuróticos, somatoformes e relacionados ao estresse em $14 \%$ e transtornos devido ao uso de substâncias em 13\%. Notou-se, ao longo dos anos, um aumento progressivo nas frequências de possíveis transtornos de humor e no número de possíveis transtornos de personalidade, enquanto que houve uma redução de possíveis transtornos mentais orgânicos e esquizofrenia, transtornos esquizotípicos e delirantes a partir de 2000 (Tabela 4.23). 
Tabela 4.23 - Hipóteses diagnósticas psiquiátricas dadas pelos profissionais para os pacientes do sexo feminino atendidos pelo serviço de Interconsulta Psiquiátrica entre janeiro de 1981 a dezembro de 2010.

\begin{tabular}{|c|c|c|c|c|c|c|c|}
\hline & \\
\hline & 1981-1985 & $1986-1990$ & 1991-1995 & $1996-2000$ & 2001-2005 & 2006-2010 & TOTAL \\
\hline HIPÓTESE DIAGNÓSTICA & $\mathbf{N}(\%)$ & $\mathbf{N}(\%)$ & $\mathbf{N}(\%)$ & $\mathbf{N}(\%)$ & $\mathbf{N}(\%)$ & $\mathbf{N}(\%)$ & $\mathbf{N}(\%)$ \\
\hline Transtornos do humor & $39(35,1)$ & $28(27,5)$ & $72(41,6)$ & $73(43,7)$ & $153(40,7)$ & $199(42,6)$ & $564(40,4)$ \\
\hline Transtornos neuróticos ${ }^{\star \star}$ & $15(13,5)$ & $12(11,8)$ & $23(13,3)$ & $20(12,0)$ & $51(13,6)$ & $71(15,2)$ & $192(13,8)$ \\
\hline Devido ao uso de substâncias & $21(18,9)$ & $16(15,7)$ & $15(8,7)$ & $18(10,8)$ & $44(11,7)$ & $65(13,9)$ & $179(12,8)$ \\
\hline Transtornos mentais orgânicos & $12(10,8)$ & $20(19,6)$ & $20(11,6)$ & $20(12,0)$ & $31(8,2)$ & $31(6,6)$ & $134(9,6)$ \\
\hline Transtornos da personalidade ${ }^{* \star *}$ & $4(3,6)$ & $6(5,9)$ & $10(5,8)$ & $12(7,2)$ & $40(10,6)$ & $43(9,2)$ & $115(8,2)$ \\
\hline Esquizofrenia ${ }^{\star \star \star \star}$ & $14(12,6)$ & $13(12,7)$ & $13(7,5)$ & $12(7,2)$ & $18(4,8)$ & $19(4,1)$ & $89(6,4)$ \\
\hline Outros & $6(5,4)$ & $7(6,9)$ & $20(11,6)$ & $12(7,2)$ & $39(10,4)$ & $39(8,4)$ & $123(8,8)$ \\
\hline TOTAL (N) & 111 & 102 & 173 & 167 & 376 & 467 & 1396 \\
\hline Sintomas* & $154(50,2)$ & $206(57,7)$ & $223(54,0)$ & $244(58,7)$ & $355(50,5)$ & $316(42,2)$ & $1498(50,9)$ \\
\hline Não informado* & $58(18,9)$ & $65(18,2)$ & $45(10,9)$ & $35(8,4)$ & $54(7,7)$ & $75(10,0)$ & $318(10,8)$ \\
\hline
\end{tabular}

Foram consideradas todas as hipóteses diagnósticas psiquiátricas fornecidas pelo interconsultor para cada paciente atendido, sendo, muitas vezes, casos de múltiplos diagnósticos; * porcentagem informada é referente ao número total de solicitações realizadas no período; ${ }^{* *}$ inclui também transtornos somatoformes e relacionados ao estresse; ${ }^{* \star *}$ inclui também transtornos do comportamento adulto; ${ }^{* * * *}$ inclui também transtornos esquizotípicos e delirantes.

Já nos pacientes do sexo masculino, as hipóteses mais frequentes foram transtornos mentais devido ao uso de substâncias em 35\% dos casos, seguidas por transtornos do humor em quase $30 \%$ e esquizofrenia, transtornos esquizotípicos e delirantes em 10\%. As hipóteses de transtornos mentais orgânicos duplicaram entre os anos de 1991 a 2000 e os possíveis transtornos de personalidade se mantiveram em baixa frequência (Tabela 4.24). 
Tabela 4.24 - Hipóteses diagnósticas psiquiátricas dadas pelos profissionais para os pacientes do sexo masculino atendidos pelo serviço de Interconsulta Psiquiátrica entre janeiro de 1981 a dezembro de 2010.

\begin{tabular}{|c|c|c|c|c|c|c|c|}
\hline & \\
\hline & 1981-1985 & $1986-1990$ & 1991-1995 & $1996-2000$ & 2001-2005 & 2006-2010 & TOTAL \\
\hline HIPÓTESE DIAGNÓSTICA & $\mathrm{N}(\%)$ & $\mathbf{N}(\%)$ & $\mathbf{N}(\%)$ & $\mathbf{N}(\%)$ & $\mathbf{N}(\%)$ & N (\%) & $\mathbf{N}(\%)$ \\
\hline Devido ao uso de substâncias & $38(40,0)$ & $38(49,4)$ & $38(33,0)$ & $44(28,2)$ & $83(37,2)$ & $73(32,4)$ & $314(35,2)$ \\
\hline Transtornos do humor & $16(16,8)$ & $25(32,5)$ & $33(28,7)$ & $47(30,1)$ & $79(35,4)$ & $65(28,9)$ & $265(29,7)$ \\
\hline Esquizof renia ${ }^{\star \star \star \star}$ & $12(12,6)$ & $3(3,9)$ & $14(12,2)$ & $21(13,5)$ & $13(5,8)$ & $25(11,1)$ & $88(9,9)$ \\
\hline Transtornos mentais orgânicos & $8(8,4)$ & $4(5,2)$ & $8(7,0)$ & $24(15,4)$ & $19(8,5)$ & $23(10,2)$ & $86(9,7)$ \\
\hline Transtornos neuróticos ${ }^{\star \star}$ & $13(13,7)$ & $2(2,6)$ & $13(11,3)$ & $11(7,1)$ & $21(9,4)$ & $22(9,8)$ & $82(9,2)$ \\
\hline Transtornos da personalidade ${ }^{\star \star *}$ & $3(3,2)$ & $1(1,3)$ & $2(1,7)$ & $6(3,8)$ & $4(1,8)$ & $9(4,0)$ & $25(2,8)$ \\
\hline Outros & $5(5,3)$ & $4(5,2)$ & $7(6,1)$ & $3(1,9)$ & $4(1,8)$ & $8(3,6)$ & $31(3,5)$ \\
\hline TOTAL (N) & 95 & 77 & 115 & 156 & 223 & 225 & 891 \\
\hline Sintomas* & $120(53,6)$ & $156(56,5)$ & $152(54,9)$ & $169(52,5)$ & $228(52,8)$ & $191(47,0)$ & $1016(52,5)$ \\
\hline Não informado* & $32(14,3)$ & $54(19,6)$ & $37(13,4)$ & $29(9,0)$ & $43(10,0)$ & $42(10,3)$ & $226(11,7)$ \\
\hline
\end{tabular}

Foram consideradas todas as hipóteses diagnósticas psiquiátricas fornecidas pelo interconsultor para cada paciente atendido, sendo, muitas vezes, casos de múltiplos diagnósticos; * porcentagem informada é referente ao número total de solicitações realizadas no período; ${ }^{* \star * *}$ inclui também transtornos esquizotípicos e delirantes; ${ }^{* *}$ inclui também transtornos somatoformes e relacionados ao estresse; ${ }^{* *}$ inclui também transtornos do comportamento adulto.

\subsubsection{TEMPO DE INTERNAÇÃO}

Considerou-se como tempo de internação o período entre a data de admissão no hospital e a alta hospitalar. Importante ressaltar que, apesar dessas variáveis não apresentarem uma distribuição normal, optou-se pelo uso das médias para a descrição dos resultados para possibilitar a comparabilidade dos dados posteriormente, uma vez que todos os estudos da literatura utilizaram médias ao invés de medianas.

O tempo de internação dos pacientes do sexo feminino foi menor que o dos pacientes do sexo masculino e quando comparado com as médias do tempo de internação dos pacientes em geral internados no HCFMRP-USP, observou-se que as médias do tempo de internação dos pacientes que tiveram solicitação psiquiátrica foram bem maiores para ambos os sexos (Tabela 4.25).

Notou-se que, apesar do tempo de internação dos pacientes em geral do HCFMRP-USP ter reduzido quando considerado o período de 1981 a 2010, houve 
um relativo aumento nas médias do tempo de internação dos pacientes de ambos os sexos que tiveram solicitação psiquiátrica entre os anos de 2001 a 2010. Contudo, quando comparadas as medianas, as mulheres em geral tiveram uma redução do tempo de internação, enquanto que os homens mantiveram o mesmo tempo mediano entre 2001 a 2010, apesar de ter reduzido quando comparado com meados dos anos 90 .

Tabela 4.25 - Médias e medianas do tempo de internação (período decorrido entre a data de admissão no hospital e a data da alta hospitalar) de todos os pacientes internados no HCFMRP-USP e dos pacientes do sexo feminino e do sexo masculino que tiveram solicitação psiquiátrica entre janeiro de 1981 a dezembro de 2010.

\begin{tabular}{|c|c|c|c|c|c|c|c|}
\hline & 1981-1985 & $1986-1990$ & 1991-1995 & $1996-2000$ & 2001-2005 & 2006-2010 & TOTAL \\
\hline \multicolumn{8}{|l|}{ HCFMRP-USP } \\
\hline MÉDIAS* & $8,9-7,6$ & $7,7-8,0$ & $8,3-6,9$ & $6,9-6,3$ & $6,0-6,4$ & $6,7-6,5$ & $8,9-6,5$ \\
\hline \multicolumn{8}{|l|}{ FEMININO } \\
\hline MÉDIA (DP) & Indisponível & Indisponível & Indisponível & $35,4(33,5)$ & $26,7(33,8)$ & $27,4(35,4)$ & $27,4(34,6)$ \\
\hline MEDIANA & Indisponível & Indisponível & Indisponível & 25,0 & 18,0 & 15,0 & 17,0 \\
\hline \multicolumn{8}{|l|}{ MASCULINO } \\
\hline MÉDIA (DP) & Indisponível & Indisponível & Indisponível & $35,8(41,1)$ & $29,7(29,4)$ & $32,7(36,1)$ & $31,5(33,4)$ \\
\hline MEDIANA & Indisponível & Indisponível & Indisponível & 26,0 & 21,0 & 21,0 & 21,0 \\
\hline
\end{tabular}

* Foram obtidas apenas as médias anuais do tempo de internação de todos os pacientes do HCFMRP-USP.

\subsubsection{TEMPO DE SOLICITAÇÃO}

Denominou-se tempo de solicitação o período entre a data de admissão no hospital e a data da solicitação psiquiátrica.

As solicitações psiquiátricas ocorreram em menor tempo para as mulheres após a internação, sendo a média do tempo de solicitação de 10,7 (DP=17,5) dias e mediana de 5 dias, enquanto que a dos homens foi de 14,0 (DP=19,0) dias e mediana de 7 dias (Tabela 4.26). 
O tempo de solicitação de Pls para as mulheres reduziu entre o período de 1981 a 2005, passando a média de 23,3 para 10,2 dias, e aumentou apenas a partir de 2006, passando para 10,9 dias. Já o tempo de solicitação de Pls para os homens teve redução na média entre os anos 1986 e 2000, passando de 25,8 para 12,3 dias, e aumentou progressivamente a partir de 2001, sendo o tempo médio de solicitação de 15 dias.

Tabela 4.26 - Médias e medianas do tempo de solicitação (período decorrido entre a data de admissão no hospital e a data da solicitação psiquiátrica) dos pacientes do sexo feminino e do sexo masculino que tiveram solicitação psiquiátrica entre janeiro de 1981 a dezembro de 2010.

\begin{tabular}{lccccccc}
\cline { 2 - 7 } TEMPO DE SOLICITAÇÃO & $\mathbf{1 9 8 1 - 1 9 8 5}$ & $\mathbf{1 9 8 6 - 1 9 9 0}$ & $\mathbf{1 9 9 1 - 1 9 9 5}$ & $\mathbf{1 9 9 6 - 2 0 0 0}$ & $\mathbf{2 0 0 1 - 2 0 0 5}$ & $\mathbf{2 0 0 6 - 2 0 1 0}$ & TOTAL \\
\hline FEMININO & & & & & & & \\
\hline MÉDIA (DP) & $23,3(36,6)$ & $12,7(14,3)$ & $11,8(12,2)$ & $10,5(16,4)$ & $10,2(16,9)$ & $10,9(18,4)$ & $10,7(17,5)$ \\
MEDIANA & 9,5 & 5,5 & 7,0 & 5,0 & 5,0 & 5,0 & 5,0 \\
MASCULINO & & & & & & & \\
\hline MÉDIA (DP) & $18,3(27,3)$ & $25,8(29,6)$ & $15,3(22,1)$ & $12,3(15,6)$ & $13,2(16,6)$ & $15,0(21,6)$ & $14,0(19,0)$ \\
MEDIANA & 6,0 & 14,5 & 7,5 & 7,0 & 8,0 & 7,0 & 7,0 \\
\hline
\end{tabular}

\subsubsection{TEMPO DE RESPOSTA}

Considerou-se como tempo de resposta o período entre a data da solicitação psiquiátrica feita pelo profissional solicitante e a data da resposta pelo interconsultor.

As solicitações psiquiátricas foram respondidas em até 48 horas em $81,4 \%$ do total de casos de pacientes do sexo feminino e em $83,4 \%$ dos casos de pacientes do sexo masculino, sendo que esta frequência aumentou ao longo dos anos (Tabela 4.27). A média do tempo de resposta para ambos os sexos foi de um dia (Tabela 4.28) e esta reduziu quando comparadas as décadas de 80 e de 2000. 
Tabela 4.27 - Frequências das solicitações psiquiátricas atendidas em até 48 horas após seu recebimento e posterior a esse prazo.

\begin{tabular}{cccccccc}
\cline { 2 - 7 } TEMPO DE RESPOSTA & $\mathbf{1 9 8 1 - 1 9 8 5}$ & $\mathbf{1 9 8 6 - 1 9 9 0}$ & $\mathbf{1 9 9 1 - 1 9 9 5}$ & $\mathbf{1 9 9 6 - 2 0 0 0}$ & $\mathbf{2 0 0 1 - 2 0 0 5}$ & $\mathbf{2 0 0 6 - 2 0 1 0}$ & TOTAL \\
\hline FEMININO & $\mathbf{N}(\%)$ & $\mathbf{N}(\%)$ & $\mathbf{N}(\%)$ & $\mathbf{N}(\%)$ & $\mathbf{N}(\%)$ & $\mathbf{N}(\%)$ & $\mathbf{N}(\%)$ \\
\hline Em até 48 horas & $146(69,5)$ & $143(73,7)$ & $229(80,4)$ & $276(80,9)$ & $515(85,7)$ & $498(84,7)$ & $1807(81,4)$ \\
Após 48 horas & $64(30,5)$ & $51(26,3)$ & $56(19,6)$ & $65(19,1)$ & $86(14,3)$ & $90(15,3)$ & $412(18,6)$ \\
\hline MASCULINO & $\mathbf{N}(\%)$ & $\mathbf{N}(\%)$ & $\mathbf{N}(\%)$ & $\mathbf{N}(\%)$ & $\mathbf{N}(\%)$ & $\mathbf{N}(\%)$ & $\mathbf{N}(\%)$ \\
\hline Em até 48 horas & $111(71,2)$ & $120(81,1)$ & $148(81,3)$ & $232(83,2)$ & $321(89,4)$ & $272(85,0)$ & $1204(83,4)$ \\
Após 48 horas & $45(28,8)$ & $28(18,9)$ & $34(18,7)$ & $47(16,8)$ & $38(10,6)$ & $48(15,0)$ & $240(16,6)$ \\
\hline
\end{tabular}

Tabela 4.28 - Médias e medianas do tempo de reposta (período decorrido entre a data da solicitação psiquiátrica e a data da resposta) dos pacientes do sexo feminino e do sexo masculino que tiveram solicitação psiquiátrica entre janeiro de 1981 a dezembro de 2010.

\begin{tabular}{|c|c|c|c|c|c|c|c|}
\hline TEMPO DE RESPOSTA & 1981-1985 & 1986-1990 & 1991-1995 & 1996-2000 & 2001-2005 & 2006-2010 & TOTAL \\
\hline \multicolumn{8}{|l|}{ FEMININO } \\
\hline MÉDIA (DP) & $2,3(3,4)$ & $2,0(3,0)$ & $1,5(2,0)$ & $1,5(2,1)$ & $1,1(1,5)$ & $1,3(2,0)$ & $1,4(2,2)$ \\
\hline MEDIANA & 1,0 & 1,0 & 1,0 & 1,0 & 1,0 & 1,0 & 1,0 \\
\hline \multicolumn{8}{|l|}{ MASCULINO } \\
\hline MÉDIA (DP) & $2,6(5,5)$ & $1,6(2,5)$ & $1,5(2,6)$ & $1,3(1,8)$ & $1,0(2,2)$ & $1,4(3,4)$ & $1,5(3,1)$ \\
\hline MEDIANA & 1,0 & 1,0 & 1,0 & 1,0 & 0,5 & 1,0 & 1,0 \\
\hline
\end{tabular}

\subsubsection{NÚMERO DE ATENDIMENTOS REALIZADOS}

A respeito do número de atendimentos realizados pelo interconsultor, foram realizados, em média, quatro atendimentos aos pacientes de ambos os sexos antes da alta hospitalar ou da alta do próprio serviço de Interconsulta Psiquiátrica (Tabela 4.29). Ao longo dos anos, observou-se uma redução no número de atendimentos realizados. 
Tabela 4.29 - Médias e medianas do número de atendimentos realizados pelo interconsultor para os pacientes do sexo feminino e do sexo masculino que tiveram solicitação psiquiátrica entre janeiro de 1981 a dezembro de 2010.

\begin{tabular}{llllllll}
\cline { 3 - 7 } NÚMERO DE ATENDIMENTOS & $\mathbf{1 9 8 1 - 1 9 8 5}$ & $\mathbf{1 9 8 6 - 1 9 9 0}$ & $\mathbf{1 9 9 1 - 1 9 9 5}$ & $\mathbf{1 9 9 6 - 2 0 0 0}$ & $\mathbf{2 0 0 1 - 2 0 0 5}$ & $\mathbf{2 0 0 6 - 2 0 1 0}$ & TOTAL \\
\hline FEMININO & & & & & & \\
\hline MÉDIA (DP) & Indisponível & Indisponível & Indisponível & $5,5(3,7)$ & $4,7(3,7)$ & $3,4(2,5)$ & $4,4(3,3)$ \\
MEDIANA & Indisponível & Indisponível & Indisponível & 5,0 & 4,0 & 3,0 & 3,0 \\
\hline MASCULINO & & & & & \\
\hline MÉDIA (DP) & Indisponível Indisponível Indisponível & $5,7(4,2)$ & $4,3(3,4)$ & $3,5(2,3)$ & $4,3(3,3)$ \\
MEDIANA & Indisponível & Indisponível & Indisponível & 4,0 & 4,0 & 3,0 & 3,0 \\
\hline
\end{tabular}

\subsubsection{TEMPO DE INTERNAÇÃO, TEMPO DE SOLICITAÇÃO E OUTROS ACHADOS}

\subsubsection{TEMPO DE INTERNAÇÃO, DE SOLICITAÇÃO E FAIXA ETÁRIA}

Pacientes de ambos os sexos com idades entre 51 a 70 anos ficaram mais tempo internados assim como tiveram os maiores tempos de quando comparados com pacientes de outras faixas etárias (Tabela 4.30).

Tabela 4.30 - Médias e medianas gerais do tempo de internação (período decorrido entre a data de admissão no hospital e a data da alta hospitalar) e do tempo de solicitação (período decorrido entre a data de admissão no hospital e a data da solicitação psiquiátrica) de acordo com as faixas etárias dos pacientes do sexo feminino e do sexo masculino que tiveram solicitação psiquiátrica entre janeiro de 1981 a dezembro de 2010.

\begin{tabular}{|c|c|c|c|c|c|c|c|c|}
\hline \multirow[b]{3}{*}{ FAIXA ETÁRIA } & \multicolumn{4}{|c|}{ FEMININO } & \multicolumn{4}{|c|}{ MASCULINO } \\
\hline & \multicolumn{2}{|c|}{$\begin{array}{c}\text { TEMPO DE } \\
\text { INTERNAÇÃO }\end{array}$} & \multicolumn{2}{|c|}{$\begin{array}{c}\text { TEMPO DE } \\
\text { SOLICITAÇÃO }\end{array}$} & \multicolumn{2}{|c|}{$\begin{array}{c}\text { TEMPO DE } \\
\text { INTERNAÇÃO }\end{array}$} & \multicolumn{2}{|c|}{$\begin{array}{c}\text { TEMPO DE } \\
\text { SOLICITAÇÃO }\end{array}$} \\
\hline & MÉDIA (DP) & MEDIANA & MÉDIA (DP) & MEDIANA & MÉDIA (DP) & MEDIANA & MÉDIA (DP) & MEDIANA \\
\hline Até 14 anos & $22,6(21,0)$ & 15,0 & $10,8(23,3)$ & 6,0 & $31,5(33,4)$ & 21,0 & $14,0(19,0)$ & 7,0 \\
\hline De 15 a 20 anos & $24,8(38,0)$ & 14,0 & $7,9(13,2)$ & 3,5 & $22,9(21,8)$ & 13,0 & $10,1(10,7)$ & 4,0 \\
\hline De 21 a 30 anos & $26,6(37,2)$ & 14,0 & $10,6(17,3)$ & 5,0 & $25,3(24,1)$ & 17,5 & $13,0(17,6)$ & 7,0 \\
\hline De 31 a 40 anos & $25,2(36,6)$ & 15,0 & $8,9(12,6)$ & 4,0 & $32,6(27,7)$ & 24,0 & $14,2(19,6)$ & 7,0 \\
\hline De 41 a 50 anos & $25,9(26,8)$ & 18,0 & $10,0(15,4)$ & 5,0 & $29,4(26,4)$ & 20,5 & $14,2(17,5)$ & 8,0 \\
\hline De 51 a 60 anos & $29,2(36,0)$ & 19,0 & $11,9(24,2)$ & 6,0 & $35,7(41,2)$ & 23,0 & $14,9(20,8)$ & 7,0 \\
\hline De 61 a 70 anos & $36,4(38,3)$ & 24,0 & $15,6(20,0)$ & 7,0 & $34,8(37,0)$ & 22,0 & $14,4(17,0)$ & 9,0 \\
\hline Acima de 71 anos & $30,8(33,8)$ & 15,0 & $11,6(14,9)$ & 6,0 & $24,2(29,7)$ & 15,0 & $12,2(18,1)$ & 7,0 \\
\hline
\end{tabular}




\subsubsection{TEMPOS DE INTERNAÇÃO, DE SOLICITAÇÃO E CLÍNICAS SOLICITANTES}

Internações de mulheres na Ginecologia / Obstetrícia e de homens na Cirurgia e Clínica Médica Geral foram menores quando comparadas com outras clínicas solicitantes. Já mulheres internadas na Ortopedia e homens internados na Unidade Metabólica tiveram maiores tempos de internação quando comparados com outros pacientes (Tabela 4.31).

Quanto ao tempo de solicitação e as clínicas solicitantes, a Ginecologia / Obstetrícia solicitou Pls para as mulheres mais rapidamente considerando outras clínicas solicitantes, assim como a Neurologia para os homens. E a Ortopedia apresentou maiores tempos de solicitação de PI para pacientes de ambos os sexos (Tabela 4.31).

Tabela 4.31 - Médias e medianas gerais do tempo de internação (período decorrido entre a data de admissão no hospital e a data da alta hospitalar) e do tempo de solicitação (período decorrido entre a data de admissão no hospital e a data da solicitação psiquiátrica) de acordo com as clínicas solicitantes dos pacientes do sexo feminino e do sexo masculino que tiveram solicitação psiquiátrica entre janeiro de 1981 a dezembro de 2010.

\begin{tabular}{|c|c|c|c|c|c|c|c|c|}
\hline \multirow[b]{3}{*}{ CLÍNICA SOLICITANTE } & \multicolumn{4}{|c|}{ FEMININO } & \multicolumn{4}{|c|}{ MASCULINO } \\
\hline & \multicolumn{2}{|c|}{$\begin{array}{c}\text { TEMPO DE } \\
\text { INTERNAÇÃO }\end{array}$} & \multicolumn{2}{|c|}{$\begin{array}{c}\text { TEMPO DE } \\
\text { SOLICITAÇÃO }\end{array}$} & \multicolumn{2}{|c|}{$\begin{array}{c}\text { TEMPO DE } \\
\text { INTERNAÇÃO }\end{array}$} & \multicolumn{2}{|c|}{$\begin{array}{c}\text { TEMPO DE } \\
\text { SOLICITAÇÃO }\end{array}$} \\
\hline & MÉDIA (DP) & MEDIANA & MÉDIA (DP) & MEDIANA & MÉDIA (DP) & MEDIANA & MÉDIA (DP) & MEDIANA \\
\hline Ortopedia & $39,5(32,3)$ & 39,5 & $16,3(15,6)$ & 9,0 & $40,2(33,5)$ & 29,5 & $19,7(24,6)$ & 12,0 \\
\hline Unidade Metabólica & $35,7(38,4)$ & 28,0 & $7,2(12,4)$ & 2,0 & $47,5(50,5)$ & 38,0 & $15,4(20,4)$ & 7,0 \\
\hline Unidade Transplante Renal & $34,2(28,7)$ & 22,0 & $13,8(16,0)$ & 8,0 & $46,6(49,6)$ & 25,0 & $19,6(30,9)$ & 10,5 \\
\hline Moléstias Infecciosas / UETDI & $33,9(38,6)$ & 22,0 & $13,0(16,0)$ & 7,0 & $34,7(31,5)$ & 27,0 & $14,8(17,1)$ & 9,0 \\
\hline Pediatria & $31,7(42,9)$ & 14,0 & $13,9(23,4)$ & 5,0 & $34,2(33,0)$ & 20,0 & $16,8(19,6)$ & 8,0 \\
\hline Cirurgia & $27,4(33,1)$ & 16,0 & $12,4(16,7)$ & 6,0 & $25,9(33,6)$ & 16,0 & $11,2(15,5)$ & 7,0 \\
\hline Neurologia & $24,2(42,1)$ & 15,0 & $10,2(17,3)$ & 5,5 & $26,2(29,4)$ & 17,0 & $9,1(14,0)$ & 5,0 \\
\hline Clínica Médica Geral & $23,6(26,7)$ & 16,0 & $9,8(18,9)$ & 5,0 & $26,0(26,7)$ & 18,0 & $12,8(17,8)$ & 7,0 \\
\hline Ginecologia / Obstetrícia & $10,3(12,7)$ & 6,0 & $4,7(8,9)$ & 2,0 & 0,0 & 0,0 & 0,0 & 0,0 \\
\hline Outros & $45,9(53,4)$ & 31,0 & $18,3(22,9)$ & 8,0 & $26,3(21,5)$ & 19,0 & $15,3(18,6)$ & 7,0 \\
\hline
\end{tabular}


Considerando apenas os dados do ano de 2010, observou-se que as médias do tempo de internação de todas as clínicas do HCFMRP-USP foram menores quando comparadas com as médias do tempo de internação dos pacientes que solicitaram atendimento à Psiquiatria do SISMen, com destaque para a Ortopedia e para a Unidade de Transplante Renal (Tabela 4.32).

Tabela 4.32 - Médias e medianas do tempo de internação (período decorrido entre a data de admissão no hospital e a data da alta hospitalar) das clínicas do HCFMRP-USP e dos pacientes que tiveram solicitação para atendimento psiquiátrico do SISMen no ano de 2010.

\begin{tabular}{lccc}
\cline { 2 - 4 } & \multicolumn{2}{c}{ TEMPO DE INTERNAÇÃO EM 2010 } \\
\cline { 2 - 4 } & \multicolumn{2}{c}{ SISMen } & HCFMRP-USP \\
\hline CLÍNICA SOLICITANTE & $52,6(44,0)$ & 37,5 & 6,2 \\
Ortopedia & $47,1(77,2)$ & 13,0 & 4,8 \\
Unidade Transplante Renal & MEDIANA & MÉDIA* $^{*}$ \\
Unidade Metabólica & $31,8(27,7)$ & 24,0 & 7,3 \\
Moléstias Infecciosas / UETDI & $28,2(21,3)$ & 16,0 & 13,1 \\
Cirurgia & $24,8(24,4)$ & 17,0 & 5,1 \\
Clínica Médica Geral & $24,3(32,2)$ & 13,0 & 6,1 \\
Neurologia & $21,8(21,9)$ & 12,5 & 3,9 \\
Pediatria & $18,0(37,8)$ & 6,0 & 5,7 \\
Ginecologia / Obstetrícia & $7,4(7,3)$ & 5,0 & 4,9 \\
Outros & $35,3(28,3)$ & 35,5 & 13,5 \\
\hline
\end{tabular}

* Foi obtida apenas a média do tempo de internação de todos os pacientes internados em 2010 do HCFMRP-USP.

\subsubsection{TEMPO DE SOLICITAÇÃO E MOTIVOS DOS PIS}

Solicitações motivadas por antecedentes psiquiátricos para as mulheres e solicitações motivadas pelo abuso de substâncias psicoativas para os homens foram realizadas mais rapidamente quando comparadas com solicitações motivadas por outras razões. Para pacientes de ambos os sexos, solicitações para atendimento familiar e devido à ociosidade e/ou internação longa foram realizadas mais 
tardiamente (Tabela 4.33).

Tabela 4.33 - Motivos de solicitação psiquiátrica e as médias e medianas do tempo de solicitação (período decorrido entre a data de admissão no hospital e a data da solicitação psiquiátrica).

\begin{tabular}{lccccc}
\cline { 2 - 5 } TEMPO DE SOLICITAÇÃO & \multicolumn{2}{c}{ FEMININO } & \multicolumn{2}{c}{ MASCULINO } \\
\hline MOTIVOS DE SOLICITAÇÃO & MÉDIA (DP) & MEDIANA & MÉDIA (DP) & MEDIANA \\
Antecedentes psiquiátricos & $6,4(9,0)$ & 3,0 & $12,2(21,8)$ & 5,0 \\
Aval para procedimentos de risco & $6,6(8,3)$ & 5,0 & $12,4(12,1)$ & 7,0 \\
Abuso de substâncias psicoativas & $6,7(10,6)$ & 3,0 & $8,2(12,7)$ & 5,0 \\
Sintomas físicos mal definidos & $7,0(10,8)$ & 4,0 & $9,8(9,6)$ & 7,0 \\
Risco suicida & $8,0(11,0)$ & 4,0 & $10,8(15,4)$ & 6,0 \\
Problemas quanto cooperação no tratamento & $11,0(22,0)$ & 6,5 & $13,5(12,5)$ & 10,0 \\
Sintomas psiquiátricos presentes & $12,4(17,9)$ & 6,0 & $17,2(20,9)$ & 10,0 \\
Avaliação quanto ao uso de psicotrópicos & $13,5(26,9)$ & 6,0 & $13,7(18,6)$ & 8,0 \\
Psicodiagnóstico & $22,0(33,0)$ & 6,0 & $22,0(11,3)$ & 22,0 \\
Atendimento ao familiar & $22,6(27,7)$ & 10,0 & $28,6(11,5)$ & 22,0 \\
Ociosidade e/ou internação longa & $33,0(30,4)$ & 25,0 & $56,0(26,6)$ & 50,5 \\
Outros & $7,9(14,4)$ & 5,0 & $8,4(8,4)$ & 4,0 \\
\hline
\end{tabular}

\subsubsection{TEMPOS DE INTERNAÇÃO, DE SOLICITAÇÃO E DIAGNÓSTICOS CLÍNICOS}

Pacientes do sexo feminino com quadros relacionados à gravidez, parto e puerpério ficaram menos tempo internadas e tiveram solicitações psiquiátricas realizadas mais rapidamente quando comparadas com outras pacientes do mesmo sexo. Já aquelas com doenças do aparelho respiratório ficaram mais tempo internadas e também tiveram solicitações psiquiátricas realizadas em um maior intervalo de tempo (Tabela 4.34).

Já pacientes do sexo masculino com doenças do aparelho circulatório e neoplasias tiveram uma internação mais curta enquanto que aqueles com doenças rela- 
cionadas ao aparelho geniturinário tiveram uma internação mais prolongada. Em relação ao tempo de solicitação, homens com doenças endócrinas, metabólicas e nutricionais tiveram solicitações psiquiátricas realizadas em um menor intervalo de tempo, ao contrário dos pacientes com doenças do aparelho geniturinário (Tabela 4.34).

Tabela 4.34 - Médias e medianas gerais do tempo de internação (período decorrido entre a data de admissão no hospital e a data da alta hospitalar) e do tempo de solicitação (período decorrido entre a data de admissão no hospital e a data da solicitação psiquiátrica) de acordo com os diagnósticos clínicos dos pacientes do sexo feminino e do sexo masculino que tiveram solicitação psiquiátrica entre janeiro de 1981 a dezembro de 2010.

\begin{tabular}{|c|c|c|c|c|c|c|c|c|}
\hline & \multirow{2}{*}{\multicolumn{4}{|c|}{ FEMININO }} & & & & \\
\hline & & & & & \multicolumn{4}{|c|}{ MASCULINO } \\
\hline & \multicolumn{2}{|c|}{$\begin{array}{c}\text { TEMPO DE } \\
\text { INTERNAÇÃO }\end{array}$} & \multicolumn{2}{|c|}{$\begin{array}{c}\text { TEMPO DE } \\
\text { SOLICITAÇÃO }\end{array}$} & \multicolumn{2}{|c|}{$\begin{array}{l}\text { TEMPO DE } \\
\text { INTERNAÇÃO }\end{array}$} & \multicolumn{2}{|c|}{$\begin{array}{c}\text { TEMPO DE } \\
\text { SOLICITAÇÃO }\end{array}$} \\
\hline DIAGNÓSTICO CLÍNICO & MÉDIA (DP) & MEDIANA & MÉDIA (DP) & MEDIANA & MÉDIA (DP) & MEDIANA & MÉDIA (DP) & MEDIANA \\
\hline Doenças do aparelho respiratório & $43,0(51,0)$ & 27,0 & $19,2(26,1)$ & 8,0 & $32,7(33,8)$ & 21,5 & $17,7(20,6)$ & 10,0 \\
\hline Lesões e envenenamento+++ & $41,6(47,8)$ & 25,0 & $18,8(25,6)$ & 9,0 & $37,2(35,0)$ & 26,0 & $17,9(22,2)$ & 9,0 \\
\hline Doenças do aparelho geniturinário & $34,2(46,4)$ & 19,0 & $14,5(22,9)$ & 7,0 & $39,2(50,5)$ & 21,0 & $19,2(26,2)$ & 11,0 \\
\hline Doenças do sistema nervoso & $33,7(47,8)$ & 19,0 & $12,1(21,9)$ & 6,0 & $31,1(37,1)$ & 19,0 & $13,6(18,5)$ & 6,0 \\
\hline Doenças infecciosas e parasitárias & $32,4(34,0)$ & 22,0 & $14,0(16,7)$ & 8,0 & $34,9(31,0)$ & 28,0 & $16,0(19,6)$ & 10,0 \\
\hline Doenças do aparelho digestivo & $32,0(47,7)$ & 16,0 & $13,4(22,5)$ & 7,0 & $34,0(39,8)$ & 21,0 & $13,9(17,3)$ & 9,5 \\
\hline Doenças do aparelho circulatório & $29,2(30,3)$ & 18,0 & $11,2(14,5)$ & 6,0 & $27,1(25,4)$ & 19,0 & $11,8(14,0)$ & 7,0 \\
\hline Doenças da pele++++ & $26,5(33,5)$ & 19,0 & $11,5(29,9)$ & 5,0 & $33,5(34,6)$ & 22,0 & $13,5(14,2)$ & 10,0 \\
\hline Doenças endócrinas+ & $26,4(25,5)$ & 18,0 & $8,8(15,7)$ & 5,0 & $31,7(42,0)$ & 20,0 & $11,1(15,9)$ & 5,0 \\
\hline Neoplasias & $24,6(25,0)$ & 17,0 & $10,5(13,3)$ & 6,0 & $27,0(28,5)$ & 21,0 & $13,6(15,3)$ & 8,5 \\
\hline Doenças do sistema osteomuscular++ & $21,4(23,4)$ & 13,0 & $8,3(13,0)$ & 4,0 & $35,8(34,7)$ & 23,0 & $17,5(24,9)$ & 9,0 \\
\hline Gravidez, parto e puerpério & $9,9(9,2)$ & 7,0 & $4,6(6,4)$ & 2,0 & 0,0 & 0,0 & 0,0 & 0,0 \\
\hline Outros+++++ & $26,6(36,3)$ & 18,0 & $9,5(12,7)$ & 5,0 & $32,8(29,3)$ & 27,0 & $12,4(14,4)$ & 6,0 \\
\hline
\end{tabular}

+++ Inclui também causas externas de mortalidade; ++++ inclui também doenças do tecido subcutâneo; + inclui também doenças nutricionais e metabólicas; ++ inclui também doenças do tecido conjuntivo; +++++ Doenças do sangue e dos órgãos hematopoiéticos e alguns tecidos imunitários, Doenças do olho e anexos, Doenças do ouvido e da apófise mastoide e Malformações congênitas, deformidades e anomalias cromossômicas.

\subsubsection{TEMPO DE INTERNAÇÃO E DIAGNÓSTICOS PSIQUIÁTRICOS}

As mulheres diagnosticadas com transtorno de personalidade e os homens diagnosticados com transtornos relacionados ao uso de substâncias psicoativas ficaram menos tempo internados, ao contrário das mulheres com transtornos neuróticos, somatoformes e relacionados ao estresse e dos homens com transtornos 
de humor (Tabela 4.35).

Tabela 4.35 - Médias e medianas gerais do tempo de internação (período decorrido entre a data de admissão no hospital e a data da alta hospitalar) de acordo com os diagnósticos psiquiátricos dos pacientes do sexo feminino e do sexo masculino que tiveram solicitação psiquiátrica entre janeiro de 1981 a dezembro de 2010.

\begin{tabular}{cccccc}
\cline { 2 - 6 } TEMPO DE INTERNAÇÃO & \multicolumn{2}{c}{ FEMININO } & \multicolumn{2}{c}{ MASCULINO } \\
\hline DIAGNÓSTICO PSIQUIÁTRICO & MÉDIA (DP) & MEDIANA & MÉDIA (DP) & MEDIANA \\
Transtornos neuróticos* & $30,9(38,6)$ & 20,0 & $31,5(29,0)$ & 23,0 \\
Transtornos do humor & $27,9(35,0)$ & 17,0 & $35,5(40,7)$ & 21,0 \\
Transtornos mentais orgânicos & $26,3(25,3)$ & 18,0 & $32,7(26,4)$ & 27,0 \\
Esquizofrenia*** & $25,8(22,4)$ & 18,0 & $27,3(30,1)$ & 16,0 \\
Devido ao uso de substâncias & $24,8(44,4)$ & 15,0 & $24,6(24,5)$ & 17,0 \\
Transtornos da personalidade** & $23,1(33,3)$ & 14,0 & $29,2(27,0)$ & 18,0 \\
Outros & $27,1(24,5)$ & 19,0 & $35,3(36,9)$ & 17,0 \\
\hline
\end{tabular}

* Inclui também transtornos somatoformes e relacionados ao estresse; ${ }^{* * *}$ inclui também transtornos esquizotípicos e delirantes; ${ }^{* *}$ inclui também transtornos do comportamento adulto.

\subsection{DIAGNÓSTICOS CLÍNICOS, DIAGNÓSTICOS PSIQUIÁTRICOS E IDEAÇÃO SUICIDA}

\subsubsection{DIAGNÓSTICOS CLÍNICOS}

Das mulheres assistidas pelo serviço de Interconsulta Psiquiátrica ao longo de todos os anos, por volta de 15\% tinham doenças endócrinas, metabólicas e nutricionais (com destaque para a diabetes mellitus), 12\% sofriam de doenças do aparelho circulatório (maior frequência de mulheres com hipertensão arterial sistêmica), e 8,5\% tinham doenças infecciosas e parasitárias (em especial decorrente do vírus da imunodeficiência humana), entre outros diagnósticos clínicos (Tabela 4.36). 
Mulheres com doenças endócrinas, metabólicas e nutricionais tiveram um aumento na frequência dos casos ao longo das décadas, assim como as doenças infecciosas e parasitárias, sendo que estas últimas triplicaram de frequência em 2010. Já a frequência de mulheres com doenças do aparelho circulatório foi relativamente constante quando considerada década de 80 e a de 2000.

Tabela 4.36 - Diagnósticos clínicos segundo a CID-10 dos pacientes do sexo feminino atendidos pelo serviço de Interconsulta Psiquiátrica entre janeiro de 1981 a dezembro de 2010.

\begin{tabular}{lccccccc} 
& $\mathbf{1 9 8 1 - 1 9 8 5}$ & $\mathbf{1 9 8 6 - 1 9 9 0}$ & $\mathbf{1 9 9 1 - 1 9 9 5}$ & $\mathbf{1 9 9 6 - 2 0 0 0}$ & $\mathbf{2 0 0 1 - 2 0 0 5}$ & $\mathbf{2 0 0 6 - 2 0 1 0}$ & TOTAL \\
\hline \cline { 2 - 8 } DIAGNóSTICO CLÍNICO & $\mathbf{N}(\%)$ & $\mathbf{N}(\%)$ & $\mathbf{N}(\%)$ & $\mathbf{N}(\%)$ & $\mathbf{N}(\%)$ & $\mathbf{N}(\%)$ & $\mathbf{N}(\%)$ \\
\hline Doenças endócrinas+ & $37(10,7)$ & $69(13,2)$ & $98(16,0)$ & $96(12,9)$ & $224(16,4)$ & $229(17,2)$ & $753(15,3)$ \\
Doenças do aparelho circulatório & $43(12,5)$ & $73(13,9)$ & $58(9,5)$ & $79(10,6)$ & $160(11,7)$ & $168(12,7)$ & $581(11,8)$ \\
Doenças infecciosas e parasitárias & $12(3,5)$ & $31(5,9)$ & $27(4,4)$ & $78(10,5)$ & $139(10,1)$ & $132(9,9)$ & $419(8,5)$ \\
Doenças do sistema nervoso & $34(9,9)$ & $42(8,0)$ & $65(10,6)$ & $46(6,2)$ & $115(8,4)$ & $111(8,4)$ & $413(8,4)$ \\
Doenças do sistema osteomuscular++ & $25(7,2)$ & $54(10,3)$ & $70(11,4)$ & $51(6,9)$ & $107(7,8)$ & $98(7,4)$ & $405(8,2)$ \\
Doenças do aparelho digestivo & $21(6,1)$ & $24(4,6)$ & $37(6,0)$ & $64(8,6)$ & $133(9,7)$ & $109(8,2)$ & $388(7,9)$ \\
Neoplasias & $26(7,5)$ & $36(6,9)$ & $67(10,9)$ & $56(7,5)$ & $81(5,9)$ & $101(7,6)$ & $367(7,5)$ \\
Gravidez, parto e puerpério & $31(9,0)$ & $50(9,5)$ & $26(4,2)$ & $40(5,4)$ & $93(6,8)$ & $137(10,3)$ & $364(7,4)$ \\
Lesões e envenenamento+++ & $48(13,9)$ & $44(8,4)$ & $36(5,9)$ & $55(7,4)$ & $60(4,4)$ & $61(4,6)$ & $304(6,2)$ \\
Doenças do aparelho geniturinário & $18(5,2)$ & $20(3,8)$ & $46(7,5)$ & $52(7,0)$ & $95(6,9)$ & $53(4,0)$ & $284(5,8)$ \\
Doenças do aparelho respiratório & $12(3,5)$ & $26(5,0)$ & $35(5,7)$ & $52(7,0)$ & $62(4,5)$ & $48(3,6)$ & $235(4,8)$ \\
Doenças da pele++++ & $15(4,3)$ & $17(3,2)$ & $14(2,3)$ & $33(4,4)$ & $40(2,9)$ & $45(3,4)$ & $164(3,3)$ \\
Outros+++++ & $23(6,7)$ & $38(7,3)$ & $34(5,5)$ & $42(5,6)$ & $61(4,5)$ & $36(2,7)$ & $247(3,8)$ \\
\hline
\end{tabular}

Foram considerados todos os diagnósticos clínicos de cada paciente atendido, sendo, muitas vezes, casos de múltiplos diagnósticos; + inclui também doenças nutricionais e metabólicas; ++ inclui também doenças do tecido conjuntivo; +++ inclui também causas externas de mortalidade; ++++ inclui também doenças do tecido subcutâneo; +++++ Doenças do sangue e dos órgãos hematopoiéticos e alguns tecidos imunitários, Doenças do olho e anexos, Doenças do ouvido e da apófise mastoide e Malformações congênitas, deformidades e anomalias cromossômicas.

Já os homens apresentaram maior frequência em doenças infecciosas e parasitárias (maior frequência de quadros desencadeados pelo vírus da imunodeficiência humana), seguidas por doenças do aparelho circulatório (com destaque para a hipertensão arterial sistêmica) e doenças endócrinas, metabólicas e nutricionais (em especial diabetes mellitus), entre outros diagnósticos clínicos (Tabelas 4.37). 
A frequência de homens com doenças infecciosas e parasitárias aumentou, chegando a quadriplicar em três décadas. Já a frequência de homens com doenças do aparelho circulatório se mostrou relativamente constante ao longo dos anos e os homens com doenças endócrinas, metabólicas e nutricionais apresentaram aumento na frequência de casos.

Tabela 4.37 - Diagnósticos clínicos segundo a CID-10 dos pacientes do sexo masculino atendidos pelo serviço de Interconsulta Psiquiátrica entre janeiro de 1981 a dezembro de 2010.

\begin{tabular}{lccccccc} 
& $\mathbf{1 9 8 1 - 1 9 8 5}$ & $\mathbf{1 9 8 6 - 1 9 9 0}$ & $\mathbf{1 9 9 1 - 1 9 9 5}$ & $\mathbf{1 9 9 6 - 2 0 0 0}$ & $\mathbf{2 0 0 1 - 2 0 0 5}$ & $\mathbf{2 0 0 6 - 2 0 1 0}$ & TOTAL \\
\hline DIAGNÓSTICO CLíNICO & $\mathbf{N}(\%)$ & $\mathbf{N}(\%)$ & $\mathbf{N}(\%)$ & $\mathbf{N}(\%)$ & $\mathbf{N}(\%)$ & $\mathbf{N}(\%)$ & $\mathbf{N}(\%)$ \\
\hline Doenças infecciosas e parasitárias & $11(4,6)$ & $33(8,1)$ & $29(7,1)$ & $154(23,5)$ & $158(17,0)$ & $152(19,8)$ & $537(15,8)$ \\
Doenças do aparelho circulatório & $30(12,5)$ & $60(14,7)$ & $57(13,9)$ & $73(11,2)$ & $123(13,2)$ & $98(12,8)$ & $441(12,9)$ \\
Doenças endócrinas+ & $15(6,3)$ & $42(10,3)$ & $36(8,8)$ & $56(8,6)$ & $144(15,5)$ & $85(11,1)$ & $378(11,1)$ \\
Neoplasias & $28(11,7)$ & $28(6,9)$ & $49(12,0)$ & $61(9,3)$ & $108(11,6)$ & $86(12,2)$ & $360(10,6)$ \\
Doenças do aparelho digestivo & $23(9,6)$ & $33(8,1)$ & $37(9,0)$ & $55(8,4)$ & $106(11,4)$ & $94(12,3)$ & $348(10,2)$ \\
Lesões e envenenamento+++ & $54(22,5)$ & $76(18,7)$ & $50(12,2)$ & $50(7,6)$ & $62(6,7)$ & $51(6,6)$ & $343(10,1)$ \\
Doenças do sistema nervoso & $29(12,1)$ & $52(12,8)$ & $38(9,3)$ & $36(5,5)$ & $54(5,8)$ & $50(6,5)$ & $259(7,6)$ \\
Doenças do aparelho respiratório & $10(4,2)$ & $18(4,4)$ & $27(6,6)$ & $63(9,6)$ & $57(6,1)$ & $41(5,3)$ & $216(6,3)$ \\
Doenças do aparelho geniturinário & $8(3,3)$ & $17(4,2)$ & $26(6,3)$ & $42(6,4)$ & $46(4,9)$ & $40(5,2)$ & $179(5,3)$ \\
Doenças da pele++++ & $12(5,0)$ & $21(5,2)$ & $22(5,4)$ & $23(3,5)$ & $22(2,4)$ & $24(3,1)$ & $124(3,6)$ \\
Doenças do sistema osteomuscular++ & $12(5,0)$ & $10(2,5)$ & $14(3,4)$ & $16(2,4)$ & $27(2,9)$ & $26(3,4)$ & $105(3,1)$ \\
Outros+++++ & $8(3,3)$ & $17(4,2)$ & $25(6,1)$ & $25(3,8)$ & $24(2,6)$ & $20(2,6)$ & $119(3,5)$ \\
\hline
\end{tabular}

Foram considerados todos os diagnósticos clínicos de cada paciente atendido, sendo, muitas vezes, casos de múltiplos diagnósticos; + inclui também doenças nutricionais e metabólicas; +++ inclui também causas externas de mortalidade; ++++ inclui também doenças do tecido subcutâneo; ++ inclui também doenças do tecido conjuntivo; +++++ Doenças do sangue e dos órgãos hematopoiéticos e alguns tecidos imunitários, Doenças do olho e anexos, Doenças do ouvido e da apófise mastoide e Malformações congênitas, deformidades e anomalias cromossômicas.

$\mathrm{Na}$ Tabela 4.38, pode-se observar os diagnósticos clínicos específicos mais frequentes em ambos os sexos. 
Tabela 4.38 - Diagnósticos clínicos específicos dos pacientes de ambos os sexos atendidos pelo serviço de Interconsulta Psiquiátrica entre janeiro de 1981 a dezembro de 2010.

\begin{tabular}{|c|c|c|}
\hline & \\
\hline & Mulheres & Homens \\
\hline DIAGNÓSTICOS CLÍNICOS ESPECÍFICOS & $\mathbf{N}(\%)$ & $\mathbf{N}(\%)$ \\
\hline \multicolumn{3}{|l|}{ Doenças endócrinas, nutricionais e metabólicas } \\
\hline Diabetes mellitus & $246(32,7)$ & $131(34,6)$ \\
\hline Outros & $507(67,3)$ & $217(65,4)$ \\
\hline \multicolumn{3}{|l|}{ Doenças do aparelho circulatório } \\
\hline Hipertensão arterial sistêmica & $222(38,6)$ & $132(29,9)$ \\
\hline Outros & $359(61,4)$ & $310(70,1)$ \\
\hline \multicolumn{3}{|l|}{ Doenças infecciosas e parasitárias } \\
\hline Doença pelo vírus da imunodeficiência humana & $148(35,3)$ & $199(37,1)$ \\
\hline Outros & $272(64,7)$ & $418(62,9)$ \\
\hline \multicolumn{3}{|l|}{ Doenças do sistema nervoso } \\
\hline Epilepsia & $79(19,1)$ & $45(17,4)$ \\
\hline Outros & $334(78,6)$ & $214(82,6)$ \\
\hline \multicolumn{3}{|l|}{ Doenças do sistema osteomuscular e do tecido conjuntivo } \\
\hline Lúpus eritematoso & $178(43,8)$ & $9(8,6)$ \\
\hline Osteomielite & $8(2,0)$ & $13(12,4)$ \\
\hline Outros & $220(54,2)$ & $83(79,0)$ \\
\hline \multicolumn{3}{|l|}{ Doenças do aparelho digestivo } \\
\hline Transtornos funcionais do intestino & $87(22,4)$ & $62(17,8)$ \\
\hline Outros & $301(77,6)$ & $286(82,2)$ \\
\hline \multicolumn{3}{|l|}{ Gravidez, parto e puerpério } \\
\hline Gestação & $117(31,0)$ & 0,0 \\
\hline Outros & $260(69,0)$ & 0,0 \\
\hline \multicolumn{3}{|l|}{ Neoplasias } \\
\hline Leucemia mielóide & $44(12,0)$ & $41(11,4)$ \\
\hline Outros & $324(88,0)$ & $319(88,6)$ \\
\hline \multicolumn{3}{|l|}{ Doenças do aparelho geniturinário } \\
\hline Insuficiência renal crônica & $90(31,7)$ & $63(35,2)$ \\
\hline Outros & $194(68,3)$ & $116(64,8)$ \\
\hline \multicolumn{3}{|l|}{ Doenças do aparelho respiratório } \\
\hline Pneumonia & $98(41,7)$ & $96(44,4)$ \\
\hline Outros & $137(58,3)$ & $120(55,6)$ \\
\hline \multicolumn{3}{|l|}{ Lesões, envenenamento e causas externas de mortalidade } \\
\hline Auto-intoxicação por substâncias & $80(26,3)$ & $46(13,4)$ \\
\hline Complicações de procedimentos não classificadas em outra parte & $35(11,5)$ & $17(5,0)$ \\
\hline Falha e rejeição de órgãos e tecidos transplantados & $20(6,6)$ & $33(9,6)$ \\
\hline Outros & $169(55,6)$ & $181(78,3)$ \\
\hline \multicolumn{3}{|l|}{ Doenças da pele e do tecido subcutâneo } \\
\hline Afecções da pele e do tecido cutâneo não especificados & $28(17,1)$ & $9(7,3)$ \\
\hline Psoríase & $21(12,8)$ & $32(25,8)$ \\
\hline Outros & $115(70,1)$ & $83(66,9)$ \\
\hline
\end{tabular}

De toda a população atendida com diagnósticos clínicos válidos, 33,6\% $(\mathrm{N}=1552)$ tiveram apenas um diagnóstico, 32,3\% ( $\mathrm{N}=1494)$ dois diagnósticos e 
$34,1 \%(\mathrm{~N}=1579)$ tiveram três ou mais diagnósticos. Observou-se também que as múltiplas comorbidades clínicas se tornaram mais frequentes com o passar dos anos. Na década de 80 , apenas $14,4 \%$ pacientes tinham mais que três comorbidades enquanto que, a partir de 2000, esta frequência subiu para 39,8\%.

\subsubsection{DIAGNÓSTICOS PSIQUIÁTRICOS}

Os diagnósticos psiquiátricos mais frequentes nos pacientes do sexo feminino foram os transtornos neuróticos, somatoformes e relacionados ao estresse (com destaque para os transtornos de adaptação), seguidos pelos transtornos de humor (em especial para os episódios depressivos) e pelos transtornos mentais orgânicos (com mais frequência para as psicoses orgânicas seguidas pelo delirium) (Tabela 4.39 e Tabela 4.40).

Tabela 4.39 - Diagnósticos psiquiátricos segundo a CID-10 dos pacientes do sexo feminino atendidos pelo serviço de Interconsulta Psiquiátrica entre janeiro de 1981 a dezembro de 2010.

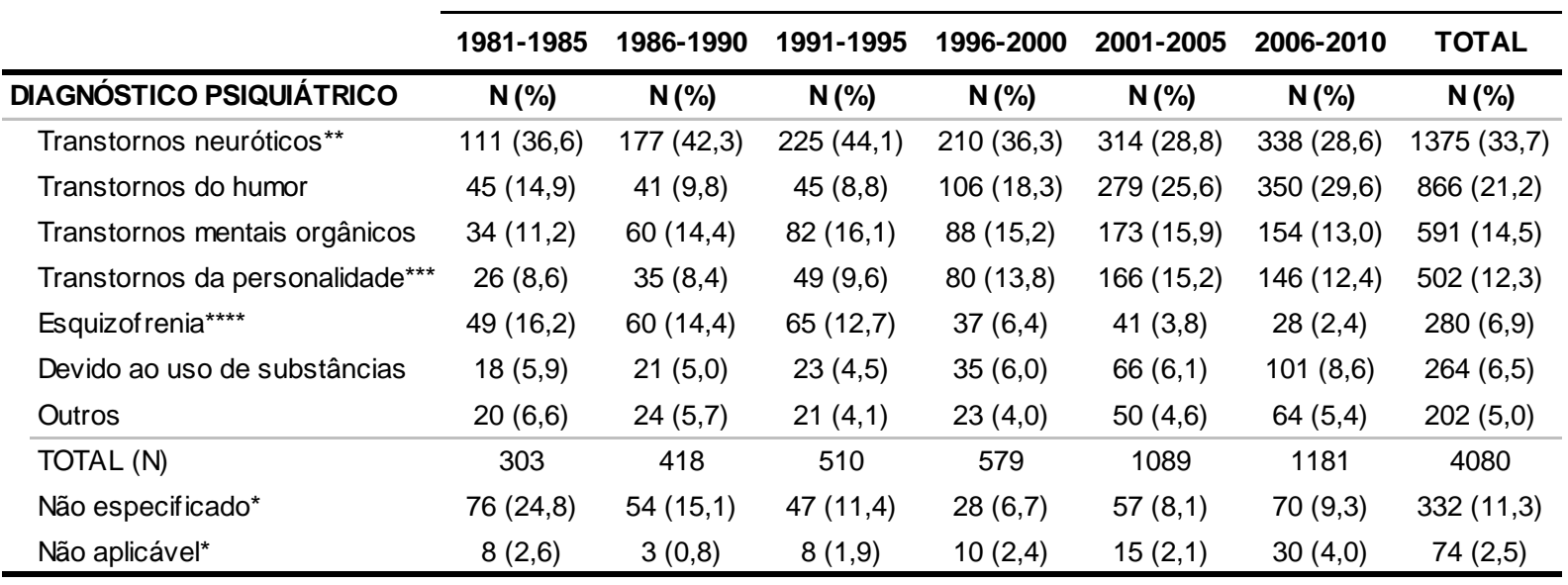

Foram considerados todos os diagnósticos psiquiátricos fornecidos pelo interconsultor para cada paciente atendido, sendo, muitas vezes, casos de múltiplos diagnósticos; * porcentagem informada é referente ao número total de solicitações realizadas no período; ${ }^{* \star}$ inclui também transtornos somatoformes e relacionados ao estresse; ${ }^{* \star *}$ inclui também transtornos do comportamento adulto; ${ }^{* * *}$ inclui também transtornos esquizotípicos e delirantes. 
Tabela 4.40 - Diagnósticos psiquiátricos específicos segundo a CID-10 dos pacientes do sexo feminino atendidos pelo serviço de Interconsulta Psiquiátrica entre janeiro de 1981 a dezembro de 2010.

\begin{tabular}{|c|c|c|c|c|c|c|c|}
\hline & & & & & & & \\
\hline & $1981-1985$ & $1986-1990$ & 1991-1995 & $1996-2000$ & 2001-2005 & 2006-2010 & TOTAL \\
\hline DIAGNÓSTICOS ESPECÍFICOS & $\mathbf{N}(\%)$ & $\mathrm{N}(\%)$ & $\mathbf{N}(\%)$ & $\mathbf{N}(\%)$ & $\mathbf{N}(\%)$ & $\mathbf{N}(\%)$ & $\mathrm{N}(\%)$ \\
\hline \multicolumn{8}{|l|}{ Transtornos neuróticos ${ }^{* *}$} \\
\hline Transtorno de adaptação & $55(49,5)$ & $108(61,0)$ & $157(69,8)$ & $170(81,0)$ & $197(62,7)$ & $164(48,5)$ & $851(61,9)$ \\
\hline Outros & $56(50,5)$ & $69(39,0)$ & $68(30,2)$ & $40(19,0)$ & $117(37,3)$ & $174(51,5)$ & $524(38,1)$ \\
\hline \multicolumn{8}{|l|}{ Transtornos do humor } \\
\hline Episódio depressivo & $29(64,4)$ & $27(65,9)$ & $26(57,8)$ & $75(70,8)$ & $194(69,5)$ & $197(56,3)$ & $548(63,3)$ \\
\hline Outros & $16(35,6)$ & $14(34,1)$ & $19(42,2)$ & $31(29,2)$ & $85(30,5)$ & $153(43,7)$ & $318(36,7)$ \\
\hline \multicolumn{8}{|l|}{ Transtornos mentais orgânicos } \\
\hline Psicose orgânica & $16(47,1)$ & $23(38,3)$ & $17(20,7)$ & $26(29,5)$ & $42(24,3)$ & $36(23,4)$ & $170(28,8)$ \\
\hline Delirium & $8(23,5)$ & $9(15,0)$ & $15(18,3)$ & $18(20,5)$ & $49(28,3)$ & $46(29,9)$ & $145(24,5)$ \\
\hline Outros & $10(29,4)$ & $28(46,7)$ & $50(61,0)$ & $44(50,0)$ & $82(47,4)$ & $72(46,7)$ & $276(46,7)$ \\
\hline \multicolumn{8}{|l|}{ Transtornos da personalidade ${ }^{\star \star \star}$} \\
\hline Transtorno de personalidade & $26(100,0)$ & $33(94,3)$ & $45(91,8)$ & $75(93,8)$ & $148(89,2)$ & $126(86,3)$ & $453(90,2)$ \\
\hline Outros & 0,0 & $2(5,7)$ & $4(8,2)$ & $5(6,2)$ & $18(10,8)$ & $20(13,7)$ & $49(9,8)$ \\
\hline \multicolumn{8}{|l|}{ Esquizofrenia ${ }^{* \star *}$} \\
\hline Esquizofrenia & $19(38,8)$ & $15(25,0)$ & $10(15,4)$ & $13(35,1)$ & $21(51,2)$ & $14(50,0)$ & $92(32,8)$ \\
\hline Transtorno psicótico agudo e transitório & $12(24,5)$ & $10(16,7)$ & $14(21,5)$ & $15(40,5)$ & $6(14,6)$ & $7(25,0)$ & $64(22,9)$ \\
\hline Transtorno esquizotípico & $12(24,5)$ & $22(36,7)$ & $26(40,0)$ & $3(8,1)$ & 0,0 & 0,0 & $63(22,5)$ \\
\hline Outros & $6(12,2)$ & $13(21,7)$ & $15(23,1)$ & $6(16,2)$ & $14(34,1)$ & $7(25,0)$ & $6121,8)$ \\
\hline \multicolumn{8}{|l|}{ Devido ao uso de substâncias } \\
\hline Devido ao álcool & $17(94,4)$ & $13(61,9)$ & $18(78,3)$ & $18(51,4)$ & $21(31,8)$ & $22(21,8)$ & $109(41,3)$ \\
\hline Devido a múltiplas substâncias & $1(5,6)$ & $1(4,8)$ & $2(8,7)$ & $4(11,4)$ & $10(15,2)$ & $31(30,7)$ & $49(18,6)$ \\
\hline Outros & 0,0 & $7(33,3)$ & $3(13,0)$ & $13(37,1)$ & $35(53,0)$ & $48(47,5)$ & $106(40,1)$ \\
\hline
\end{tabular}

Foram considerados todos os diagnósticos psiquiátricos fornecidos pelo interconsultor para cada paciente atendido, sendo, muitas vezes, casos de múltiplos diagnósticos; ${ }^{* *}$ inclui também transtornos somatoformes e relacionados ao estresse; ${ }^{* * *}$ inclui também transtornos do comportamento adulto; **** inclui também transtornos esquizotípicos e delirantes.

Pode-se observar que os transtornos neuróticos, somatoformes e relacionados ao estresse reduziram ao final de três décadas, enquanto que os transtornos mentais orgânicos aumentaram e os transtornos do humor duplicaram (Figura 4.5). 


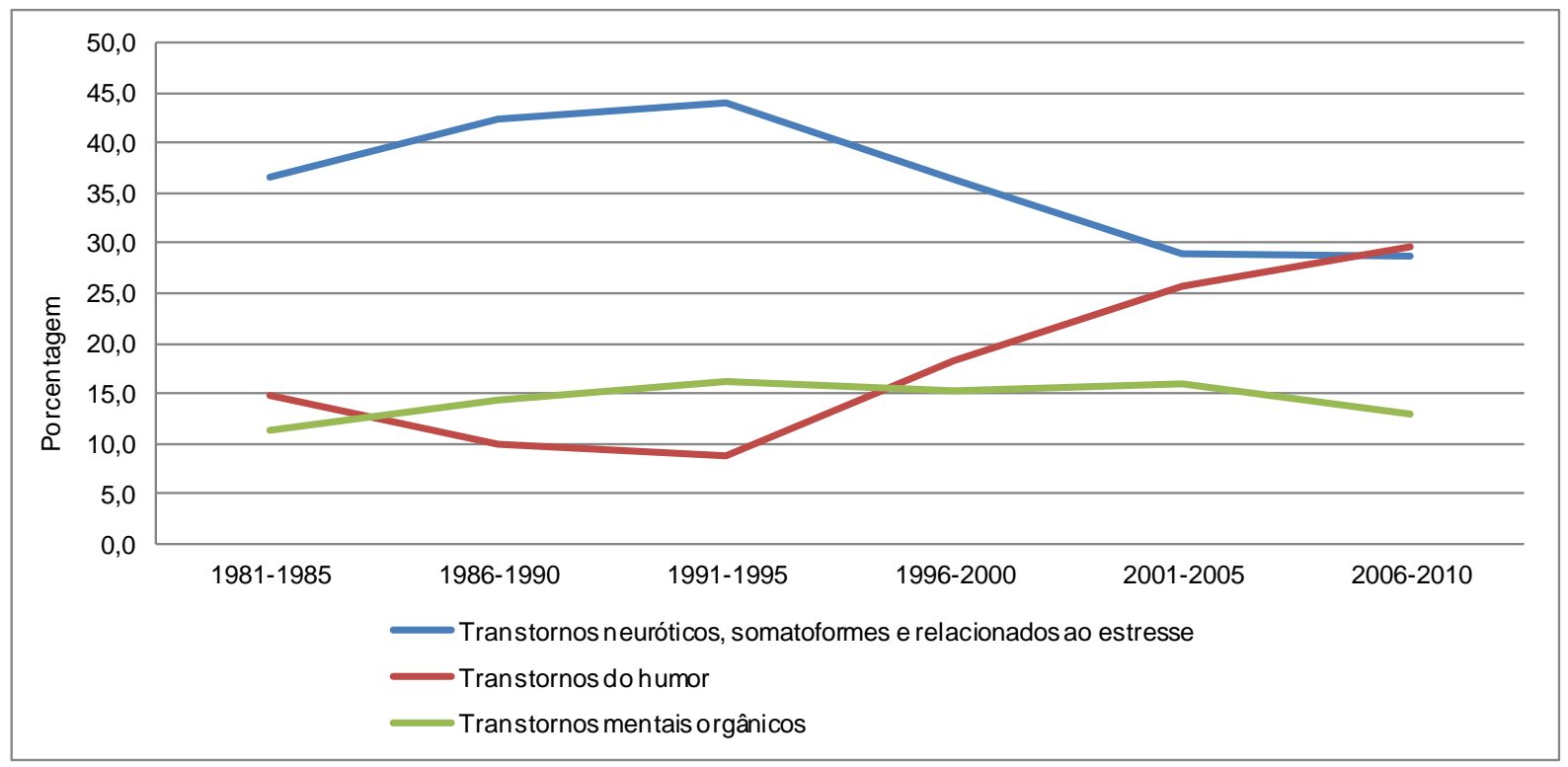

Figura 4.5 - Principais diagnósticos psiquiátricos dos pacientes do sexo feminino internados no HCFMRP-USP entre janeiro de 1981 a dezembro de 2010.

Nos pacientes do sexo masculino, os diagnósticos psiquiátricos mais frequentes foram os transtornos neuróticos, somatoformes e relacionados ao estresse (destacando os transtornos de adaptação), seguidos pelos transtornos mentais orgânicos (com destaque para o delirium) e devido ao uso de substâncias (causados, em especial, pelo uso do álcool) (Tabela 4.41 e Tabela 4.42). 
Tabela 4.41 - Diagnósticos psiquiátricos segundo a CID-10 dos pacientes do sexo masculino atendidos pelo serviço de Interconsulta Psiquiátrica entre janeiro de 1981 a dezembro de 2010.

\begin{tabular}{|c|c|c|c|c|c|c|c|}
\hline & \\
\hline & $1981-1985$ & 1986-1990 & 1991-1995 & $1996-2000$ & 2001-2005 & 2006-2010 & TOTAL \\
\hline DIAGNÓSTICO PSIQUIÁTRICO & $\mathbf{N}(\%)$ & $\mathbf{N}(\%)$ & $\mathbf{N}(\%)$ & $\mathbf{N}(\%)$ & $\mathbf{N}(\%)$ & $\mathbf{N}(\%)$ & N (\%) \\
\hline Transtornos neuróticos ${ }^{* *}$ & $79(32,1)$ & $122(34,9)$ & $126(39,0)$ & $139(31,2)$ & $153(22,9)$ & $157(24,7)$ & $776(29,1)$ \\
\hline Transtornos mentais orgânicos & $31(12,6)$ & $38(10,9)$ & $45(13,9)$ & $100(22,4)$ & $159(23,8)$ & $141(22,2)$ & $514(19,3)$ \\
\hline Devido ao uso de substâncias & $35(14,2)$ & $61(17,4)$ & $46(14,2)$ & $77(17,3)$ & $107(16,0)$ & $138(21,7)$ & $464(17,4)$ \\
\hline Transtornos do humor & $23(9,3)$ & $28(8,0)$ & $13(4,0)$ & $52(11,7)$ & $139(20,8)$ & $126(19,8)$ & $381(14,3)$ \\
\hline Esquizofrenia*** & $40(16,3)$ & $64(18,3)$ & $52(16,1)$ & $35(7,8)$ & $39(5,8)$ & $22(3,5)$ & $252(9,4)$ \\
\hline Transtornos da personalidade ${ }^{* * *}$ & $23(9,3)$ & $20(5,7)$ & $30(9,3)$ & $34(7,6)$ & $56(8,4)$ & $34(5,4)$ & $197(7,4)$ \\
\hline Outros & $15(6,1)$ & $17(4,9)$ & $11(3,4)$ & $9(2,0)$ & $15(2,2)$ & $17(2,7)$ & $84(3,1)$ \\
\hline TOTAL (N) & 246 & 350 & 323 & 446 & 668 & 635 & 2668 \\
\hline Não especificado* & $54(24,1)$ & $32(11,6)$ & $38(13,7)$ & $23(7,1)$ & $37(8,6)$ & $37(9,1)$ & $221(11,4)$ \\
\hline Não aplicável ${ }^{\star}$ & $5(2,2)$ & $4(1,4)$ & $3(1,1)$ & $5(1,6)$ & $15(3,5)$ & $13(3,2)$ & $45(2,3)$ \\
\hline
\end{tabular}

Foram considerados todos os diagnósticos psiquiátricos fornecidos pelo interconsultor para cada paciente atendido, sendo, muitas vezes, casos de múltiplos diagnósticos; * porcentagem informada é referente ao número total de solicitações realizadas no período; ** inclui também transtornos somatoformes e relacionados ao estresse; *** inclui também transtornos esquizotípicos e delirantes; ${ }^{* \star \star}$ inclui também transtornos do comportamento adulto.

Tabela 4.42 - Diagnósticos psiquiátricos específicos segundo a CID-10 dos pacientes do sexo masculino atendidos pelo serviço de Interconsulta Psiquiátrica entre janeiro de 1981 a dezembro de 2010 .

\begin{tabular}{|c|c|c|c|c|c|c|c|}
\hline & \\
\hline & 1981-1985 & $1986-1990$ & 1991-1995 & $1996-2000$ & 2001-2005 & 2006-2010 & TOTAL \\
\hline DIAGNÓSTICOS ESPECÍFICOS & $\mathbf{N}(\%)$ & $\mathbf{N}(\%)$ & $\mathrm{N}(\%)$ & $\mathbf{N}(\%)$ & $\mathbf{N}(\%)$ & $\mathbf{N}(\%)$ & $\mathrm{N}(\%)$ \\
\hline \multicolumn{8}{|l|}{ Transtornos neuróticos ${ }^{\star *}$} \\
\hline Transtorno de adaptação & $50(63,3)$ & $89(73,0)$ & $106(84,1)$ & $115(82,7)$ & $102(66,7)$ & $107(68,2)$ & $569(73,3)$ \\
\hline Outros & $29(36,7)$ & $33(27,0)$ & $20(15,9)$ & $24(17,3)$ & $51(33,3)$ & $50(31,8)$ & $207(26,7)$ \\
\hline \multicolumn{8}{|l|}{ Transtornos mentais orgânicos } \\
\hline Delirium & $13(41,9)$ & $6(15,8)$ & $17(37,8)$ & $33(33,0)$ & $55(34,6)$ & $58(41,1)$ & $182(35,4)$ \\
\hline Psicose orgânica & $3(9,7)$ & $16(42,1)$ & $6(13,3)$ & $22(22,0)$ & $32(20,1)$ & $26(18,4)$ & $105(20,4)$ \\
\hline Outros & $15(48,4)$ & $16(42,1)$ & $22(48,9)$ & $45(45,0)$ & $72(45,3)$ & $57(40,5)$ & $227(44,2)$ \\
\hline \multicolumn{8}{|l|}{ Devido ao uso de substâncias } \\
\hline Devido ao álcool & $31(88,6)$ & $52(85,2)$ & $39(84,8)$ & $53(68,8)$ & $73(68,2)$ & $86(62,3)$ & $334(72,0)$ \\
\hline Devido a múltiplas substâncias & $2(5,7)$ & $7(11,5)$ & $4(8,7)$ & $11(14,3)$ & $11(10,3)$ & $22(15,9)$ & $57(12,3)$ \\
\hline Outros & $2(5,7)$ & $2(3,3)$ & $3(6,5)$ & $13(16,9)$ & $23(21,5)$ & $30(21,8)$ & $73(15,7)$ \\
\hline \multicolumn{8}{|l|}{ Transtornos do humor } \\
\hline Episódio depressivo & $21(91,3)$ & $19(67,9)$ & $6(46,2)$ & $38(73,1)$ & $107(77,0)$ & $98(77,8)$ & $289(75,9)$ \\
\hline Outros & $2(8,7)$ & $9(32,1)$ & $7(53,8)$ & $14(26,9)$ & $32(33,0)$ & $28(22,2)$ & $92(24,1)$ \\
\hline \multicolumn{8}{|l|}{ Esquizofrenia ${ }^{* \star * *}$} \\
\hline Esquizofrenia & $21(52,5)$ & $29(45,3)$ & $22(42,3)$ & $26(74,3)$ & $19(48,7)$ & $14(63,6)$ & $131(52,0)$ \\
\hline Transtorno psicótico agudo e transitório & $7(17,5)$ & $15(23,4)$ & $8(15,4)$ & $6(17,1)$ & $11(28,2)$ & $5(22,7)$ & $52(20,6)$ \\
\hline Outros & $12(30,0)$ & $20(31,3)$ & $22(42,3)$ & $3(8,6)$ & $9(23,1)$ & $3(13,7)$ & $69(27,4)$ \\
\hline \multicolumn{8}{|l|}{ Transtornos da personalidade ${ }^{\star \star \star}$} \\
\hline Transtorno de personalidade & $20(87,0)$ & $19(95,0)$ & $27(90,0)$ & $32(94,1)$ & $55(98,2)$ & $32(94,1)$ & $185(93,9)$ \\
\hline Outros & $3(13,0)$ & $1(5,0)$ & $3(10,0)$ & $2(5,9)$ & $1(1,8)$ & $2(5,9)$ & $12(6,1)$ \\
\hline
\end{tabular}

Foram considerados todos os diagnósticos psiquiátricos fornecidos pelo interconsultor para cada paciente atendido, sendo, muitas vezes, casos de múltiplos diagnósticos; ${ }^{* *}$ inclui também transtornos somatoformes e relacionados ao estresse; ${ }^{* * * \star}$ inclui também transtornos esquizotípicos e delirantes; ${ }^{* * *}$ inclui também transtornos do comportamento adulto. 
Assim como nas mulheres, os casos de homens com transtornos neuróticos, somatoformes e relacionados ao estresse reduziram ao final de três décadas, enquanto que os transtornos mentais orgânicos e devido ao uso de substâncias tiveram aumento na frequência de casos (Figura 4.6).

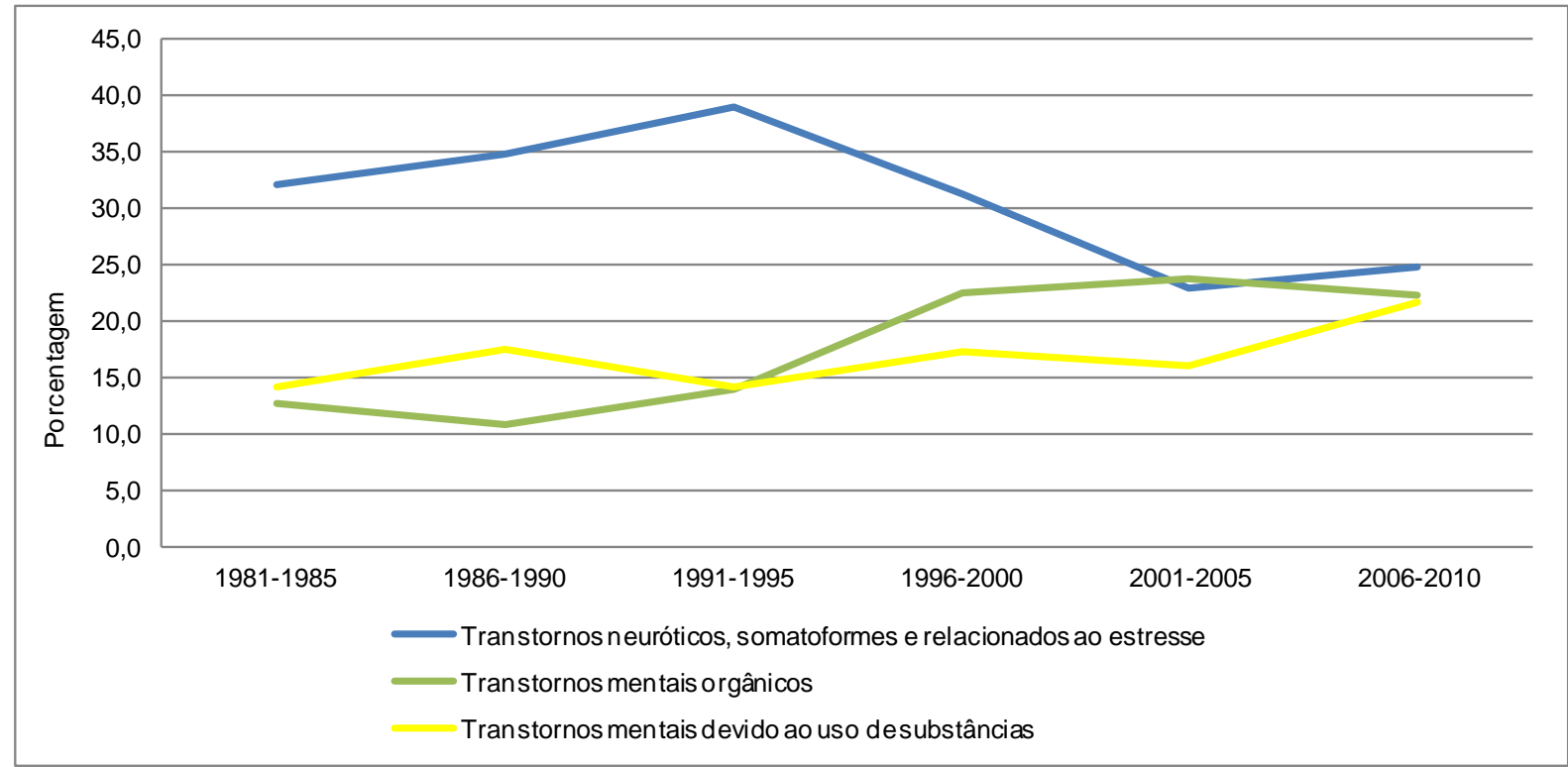

Figura 4.6 - Principais diagnósticos psiquiátricos dos pacientes do sexo masculino internados no HCFMRP-USP entre janeiro de 1981 a dezembro de 2010.

Os transtornos psiquiátricos relacionados ao uso de substâncias foram mais recorrentes nos homens, variando de 14,2 a $21,7 \%$ dos casos nos períodos avaliados. Nas mulheres, este diagnóstico foi de 4,5 a $8,6 \%$. Foi observado um crescimento progressivo dos casos ao longo dos anos, sendo que as maiores frequências foram obtidas entre os anos de 2006 a 2010 para ambos os sexos.

O diagnóstico de esquizofrenia, transtornos esquizotípicos e delirantes obteve uma frequência em torno de $16 \%$ para ambos os sexos na primeira metade da 
década de 80 , decaindo para $2,4 \%$ no sexo feminino e $3,5 \%$ no sexo masculino a partir do ano de 2006.

Em relação aos diagnósticos psiquiátricos mais específicos (Tabela 4.40 para o sexo feminino e Tabela 4.42 para o masculino), nos transtornos mentais orgânicos, a partir de 2006, mais de $40 \%$ dos pacientes do sexo masculino tiveram como diagnóstico específico delirium contra aproximadamente $30 \%$ do sexo feminino. Já a psicose orgânica foi mais frequente nas mulheres ao longo dos trinta anos, com exceção dos anos 1986 a 1990.

Transtornos psiquiátricos relacionados ao uso de substâncias aumentaram em ambos os sexos ao longo dos anos. Contudo, transtornos causados pelo uso especialmente do álcool, que no início da década de 80 atingia a grande maioria das mulheres, decaiu após trinta anos, e transtornos causados pelo uso de múltiplas substâncias psicoativas aumentaram, chegando a quase $31 \%$ no fim de 2010 . Em contrapartida, transtornos psiquiátricos atribuídos ao uso de álcool permaneceram elevados ao longo dos trinta anos nos pacientes do sexo masculino.

Durante duas décadas, dentre os diagnósticos referentes à esquizofrenia, transtornos esquizotípicos e delirantes, quase o dobro de homens apresentou esquizofrenia comparado às mulheres. Porém, a partir de 2000, este panorama mudou, pois o número de casos de esquizofrenia nos homens se manteve relativamente constante e nas mulheres aumentou, atingindo cerca de metade delas em 2010 contra $63,6 \%$ nos homens dentre as esquizofrenias, transtornos esquizotípicos e delirantes.

De toda a população atendida com diagnósticos psiquiátricos válidos, 58,3\% $(\mathrm{N}=2452)$ tiveram apenas um diagnóstico, 29,8\% $(\mathrm{N}=1255)$ dois diagnósticos psiquiátricos e 11,9\% ( $\mathrm{N}=502)$ tiveram três ou mais diagnósticos. 


\subsubsection{DIAGNÓSTICOS CLÍNICOS, DIAGNÓSTICOS PSIQUIÁTRICOS E OUTROS ACHADOS}

$47,0 \%$ dos pacientes que tiveram solicitações cujo motivo principal foi a avaliação de sintomas físicos mal definidos foram diagnosticados com transtornos neuróticos, somatoformes e relacionados ao estresse. E dos pacientes que foram avaliados devido aos antecedentes psiquiátricos, 24,5\% tinham transtornos do humor, 19,4\% transtornos neuróticos, 15,3\% esquizofrenia (ou transtornos esquizotípicos ou delirantes) e 15,3\% tinham transtornos mentais orgânicos.

Dos pacientes masculinos que alegaram estarem afastados de seus trabalhos, em relação ao diagnóstico clínico, $20 \%$ deles estavam acometidos por doenças infecciosas e parasitárias. Quanto ao diagnóstico psiquiátrico, em quase $26 \%$ dos casos eram transtornos neuróticos, somatoformes e relacionados ao estresse.

Para o sexo feminino, das pacientes diagnosticadas com: transtornos neuróticos, somatoformes e relacionados ao estresse; transtornos do humor; transtornos de personalidade e do comportamento do adulto; esquizofrenia, transtornos esquizotípicos e delirantes; e transtornos mentais devido ao uso de substâncias, o diagnóstico clínico mais frequente foi doenças endócrinas, metabólicas e nutricionais. Já as pacientes com transtornos mentais orgânicos, o diagnóstico clínico mais frequente foi doenças infecciosas e parasitárias (Tabela 4.43).

Para os pacientes do sexo masculino que foram diagnosticados com transtornos mentais orgânicos; transtornos de personalidade e do comportamento adulto; e transtornos mentais devido ao uso de substâncias, o diagnóstico clínico mais frequente foi doenças infecciosas e parasitárias; e aqueles diagnosticados com transtornos do humor; e esquizofrenia, transtornos esquizotípicos e delirantes, o diagnós- 
tico clínico mais frequente foi doenças do aparelho circulatório. E, por fim, aqueles que foram diagnosticados com transtornos neuróticos, somatoformes e relacionados ao estresse tiveram as neoplasias como diagnóstico clínico mais frequente (Tabela 4.43).

Tabela 4.43 - Frequências dos principais diagnósticos clínicos encontrados nos pacientes com diagnósticos psiquiátricos entre janeiro de 1981 a dezembro de 2010.

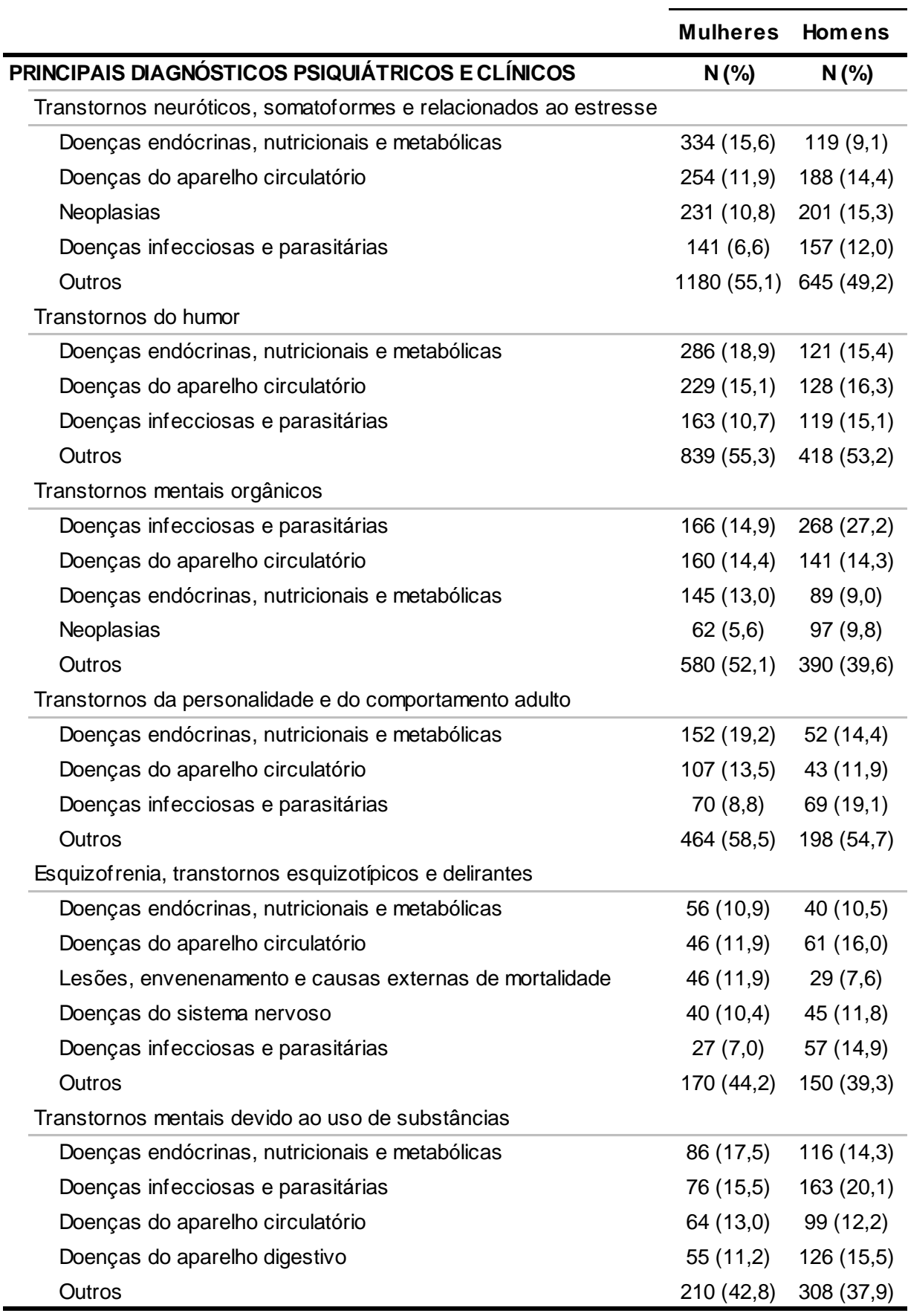

Foram consideradas todas as combinações entre os diagnósticos clínicos e os diagnósticos psiquiátricos. 


\subsubsection{CONCORDÂNCIA ENTRE HIPÓTESES E DIAGNÓSTICOS PSIQUIÁTRICOS}

Para avaliar a concordância entre as hipóteses diagnósticas psiquiátricas levantadas pelos clínicos e os diagnósticos psiquiátricos fornecidos pelos interconsultores, foram considerados apenas os casos em que foram apresentados uma hipótese diagnóstica e um diagnóstico psiquiátrico $(14,7 \%, \mathrm{~N}=717$, do total dos pacientes atendidos pela Interconsulta nos trinta anos de serviço). Considerando todas as hipóteses e todas as confirmações, as hipóteses diagnósticas foram confirmadas em $63,3 \%(\mathrm{~N}=454)$ dos casos, sendo que foi observada uma melhora deste aspecto ao longo dos anos (no início da década de 80, as confirmações diagnósticas das hipóteses ocorreram em $66,7 \%$ dos casos, decaindo no início da década de 90 para $48,0 \%$ dos casos, e aumentando para $75,2 \%$ no fim de 2010 ).

As suspeitas diagnósticas que tiveram a maior concordância entre as equipes solicitantes e os interconsultores foram as relacionadas ao uso de substâncias (92\% das suspeitas confirmadas pelos interconsultores) (Figura 4.7) e os transtornos que tiveram a menor concordância foram os de humor ( $45 \%$ das suspeitas confirmadas) (Figura 4.12).

De modo geral, ao longo dos anos, pode-se observar que a concordância entre as hipóteses diagnósticas de transtornos devido ao uso de substâncias e a confirmação do diagnóstico por parte dos psiquiatras foi alta, sendo que, dos 25 possíveis casos em 2006 a 2010, todos foram confirmados pelos interconsultores (Figura 4.7). 


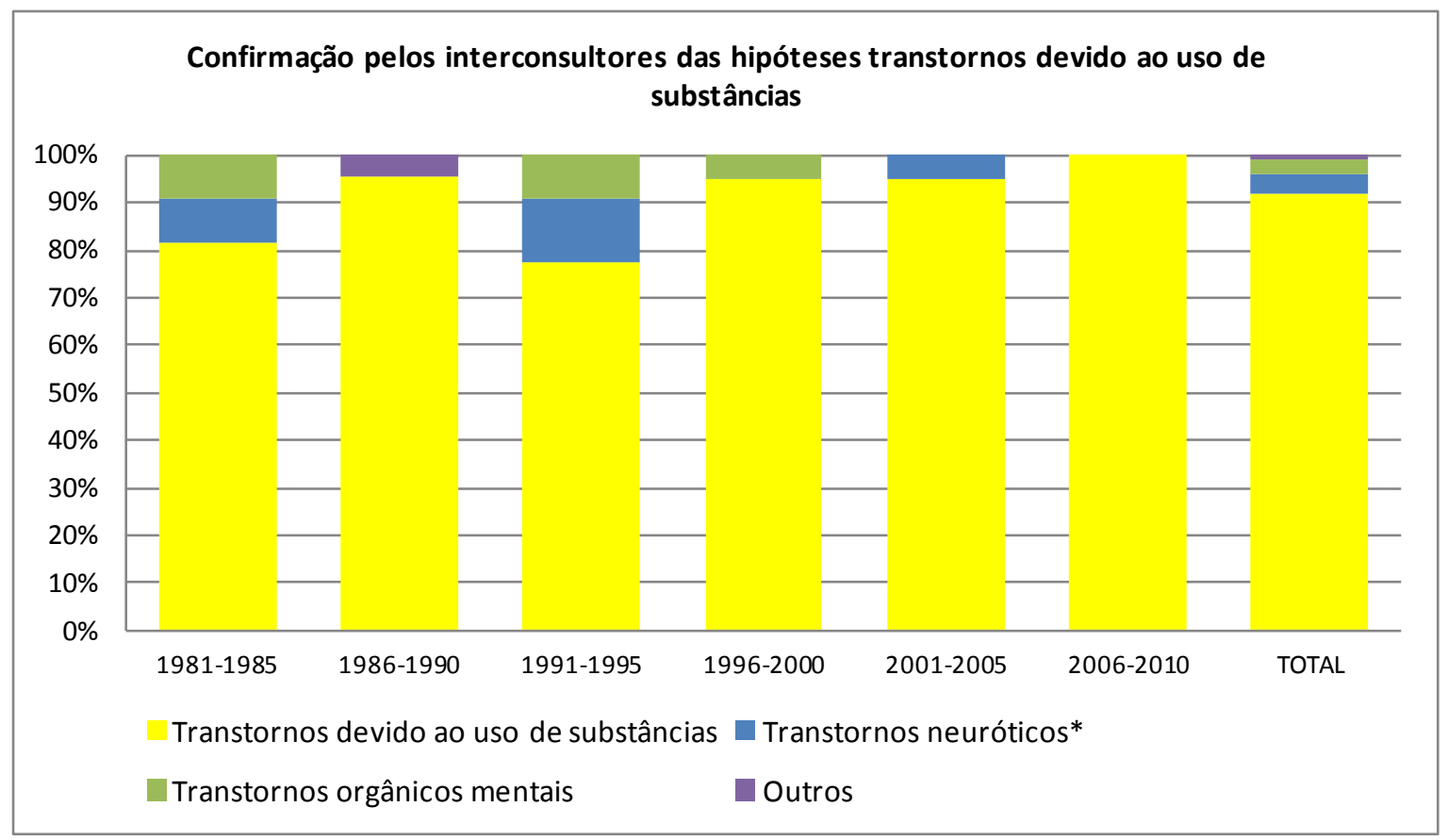

* Inclui também transtornos somatoformes e relacionados ao estresse.

Figura 4.7 - Confirmações diagnósticas pelos interconsultores das hipóteses de transtornos devido ao uso de substâncias levantadas pelos profissionais solicitantes.

Em relação às hipóteses diagnósticas de transtornos neuróticos, somatoformes e relacionados ao estresse, estes foram confirmados em $90 \%$ dos casos considerando todo o período analisado pelo estudo. Notou-se também que os profissionais solicitantes confundiram transtornos mentais orgânicos com transtornos neuróticos com certa frequência a partir da década de 90 (Figura 4.8). 


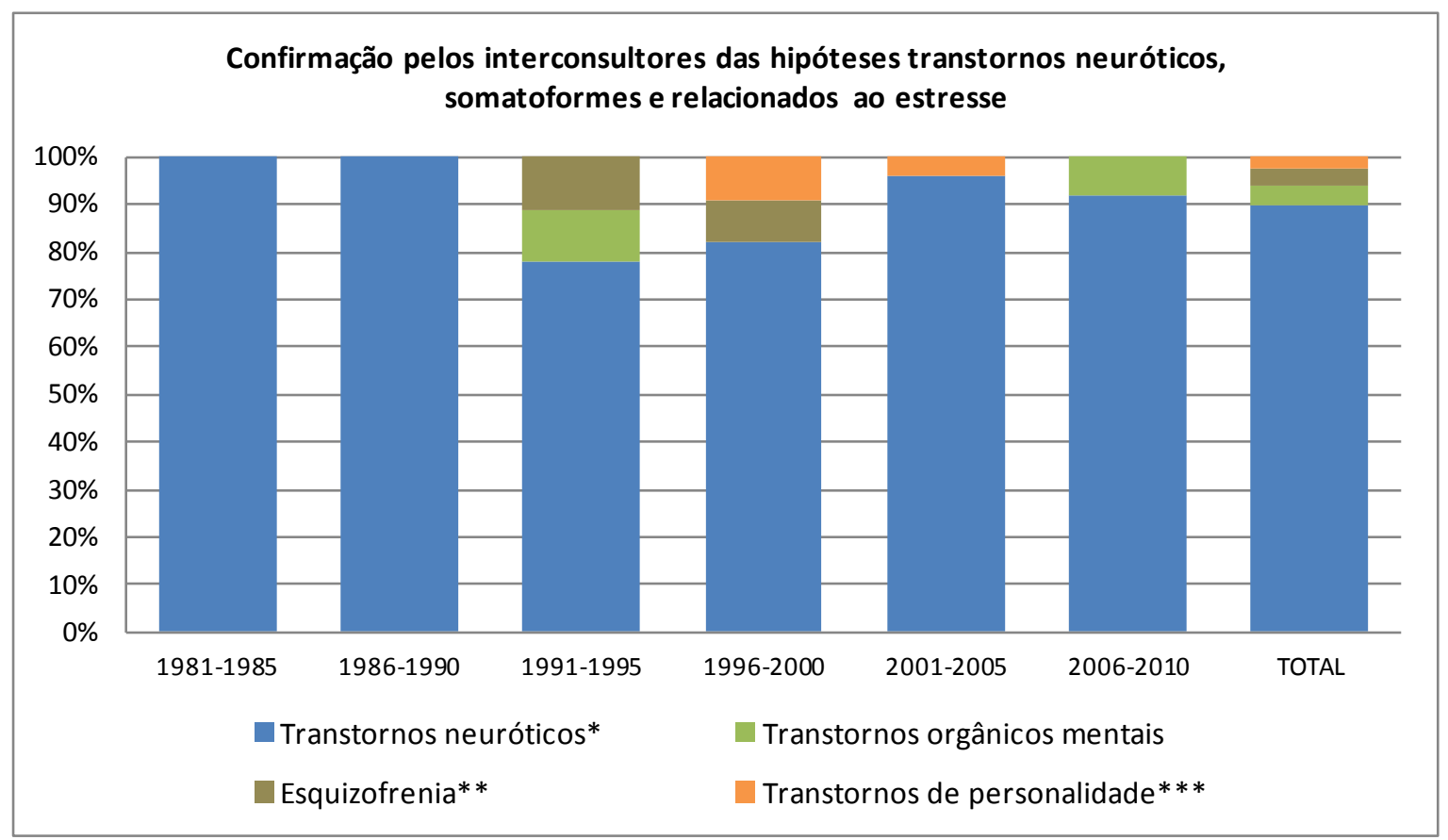

* Inclui também transtornos somatoformes e relacionados ao estresse; ** inclui também transtornos esquizotípicos e delirantes; ${ }^{* \star *}$ inclui também transtornos do comportamento adulto.

Figura 4.8 - Confirmações diagnósticas pelos interconsultores das hipóteses de transtornos neuróticos, somatoformes e relacionados ao estresse levantadas pelos profissionais solicitantes.

Já a confirmação de hipóteses de esquizofrenia, transtornos esquizotípicos e delirantes ocorreu em $72 \%$ dos pacientes, porém esta frequência oscilou ao longo dos anos, sendo que, no período de 2006 a 2010, 30\% dos pacientes considerados com esquizofrenia pela equipe solicitante tiveram diagnóstico de transtorno mental orgânico dado pelo psiquiatra (Figura 4.9). 


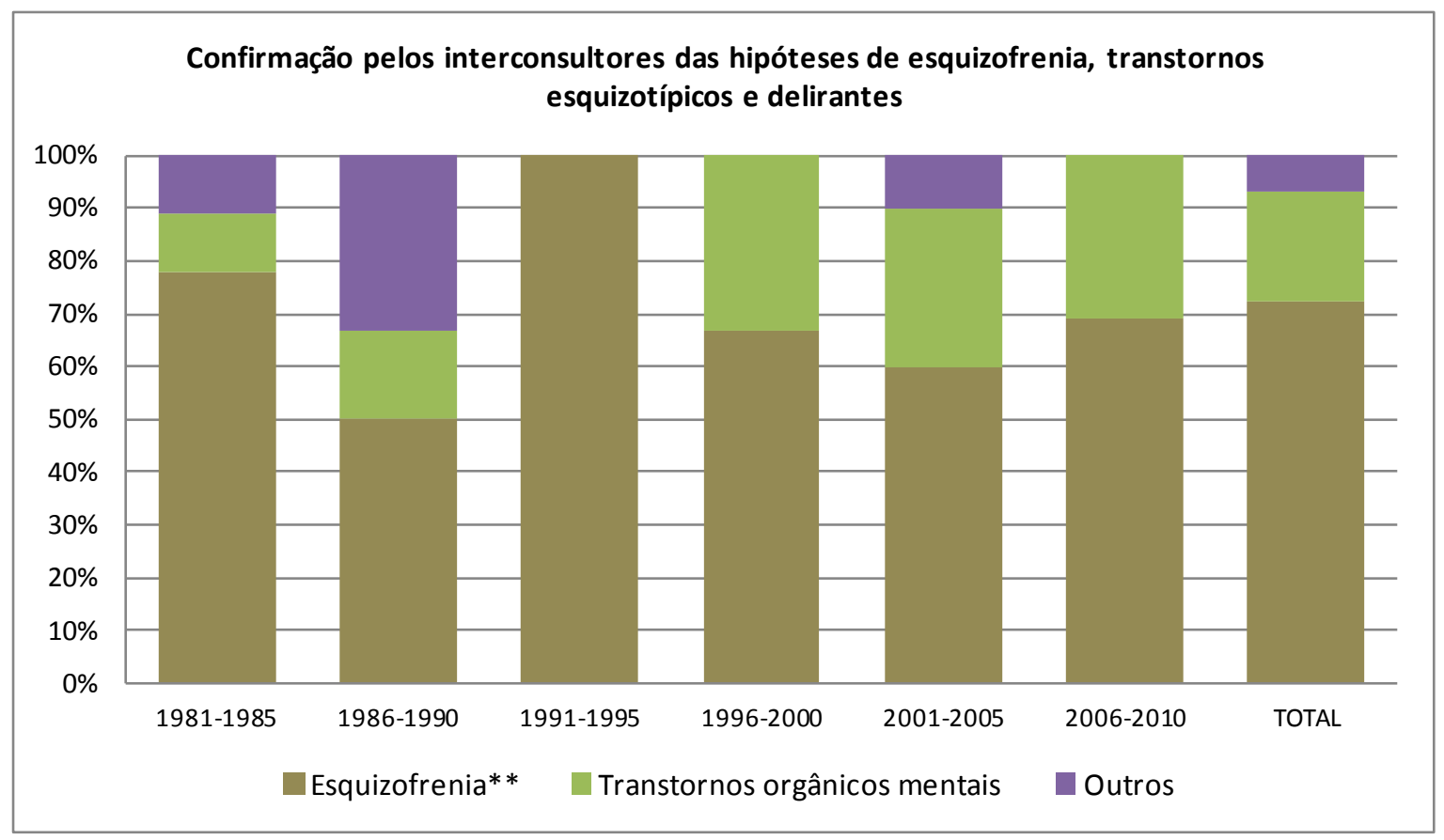

** Inclui também transtornos esquizotípicos e delirantes.

Figura 4.9 - Confirmações diagnósticas pelos interconsultores das hipóteses de esquizofrenia, transtornos esquizotípicos e delirantes levantadas pelos profissionais solicitantes.

O reconhecimento correto de transtornos mentais orgânicos por parte da equipe médica foi de $71 \%$, sendo que este valor variou ao longo dos anos, vindo a ter uma relativa melhora a partir de 2006. Observou-se também que os transtornos de humor, a partir de meados dos anos 90, foram confundidos com transtornos mentais orgânicos pelos profissionais clínicos com mais frequência (Figura 4.10). 


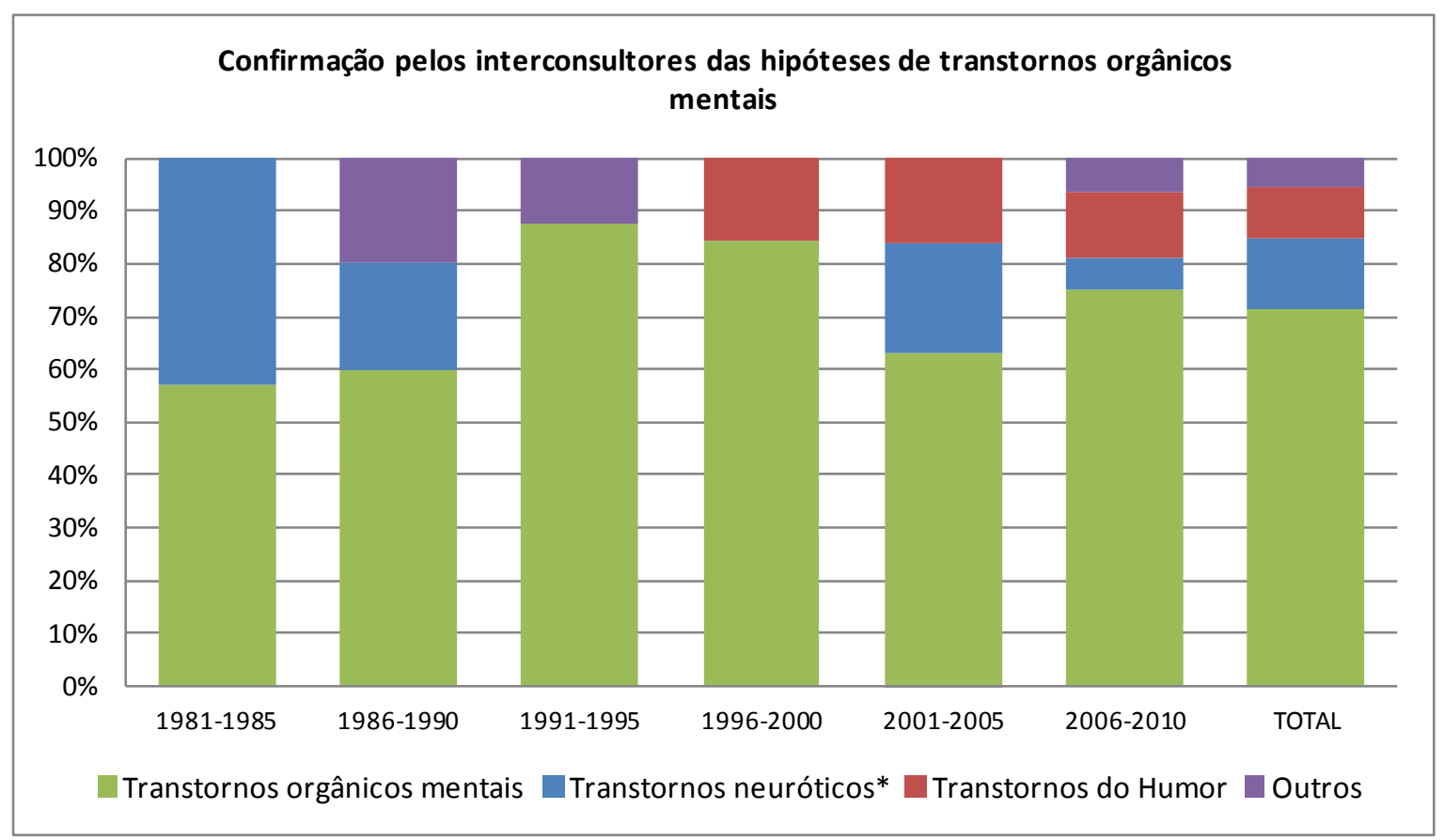

* Inclui também transtornos somatoformes e relacionados ao estresse.

Figura 4.10 - Confirmações diagnósticas pelos interconsultores das hipóteses de transtornos orgânicos mentais levantadas pelos profissionais solicitantes.

Hipóteses de transtorno de personalidade começaram a ser levantadas a partir da metade da década de 80 , sendo que o reconhecimento correto deste transtorno ocorreu em $62 \%$ dos pacientes de modo geral. Os transtornos neuróticos, somatoformes e relativos ao estresse foram os mais confundidos com transtornos de personalidade pelos clínicos em $24 \%$ dos casos no geral (Figura 4.11). 


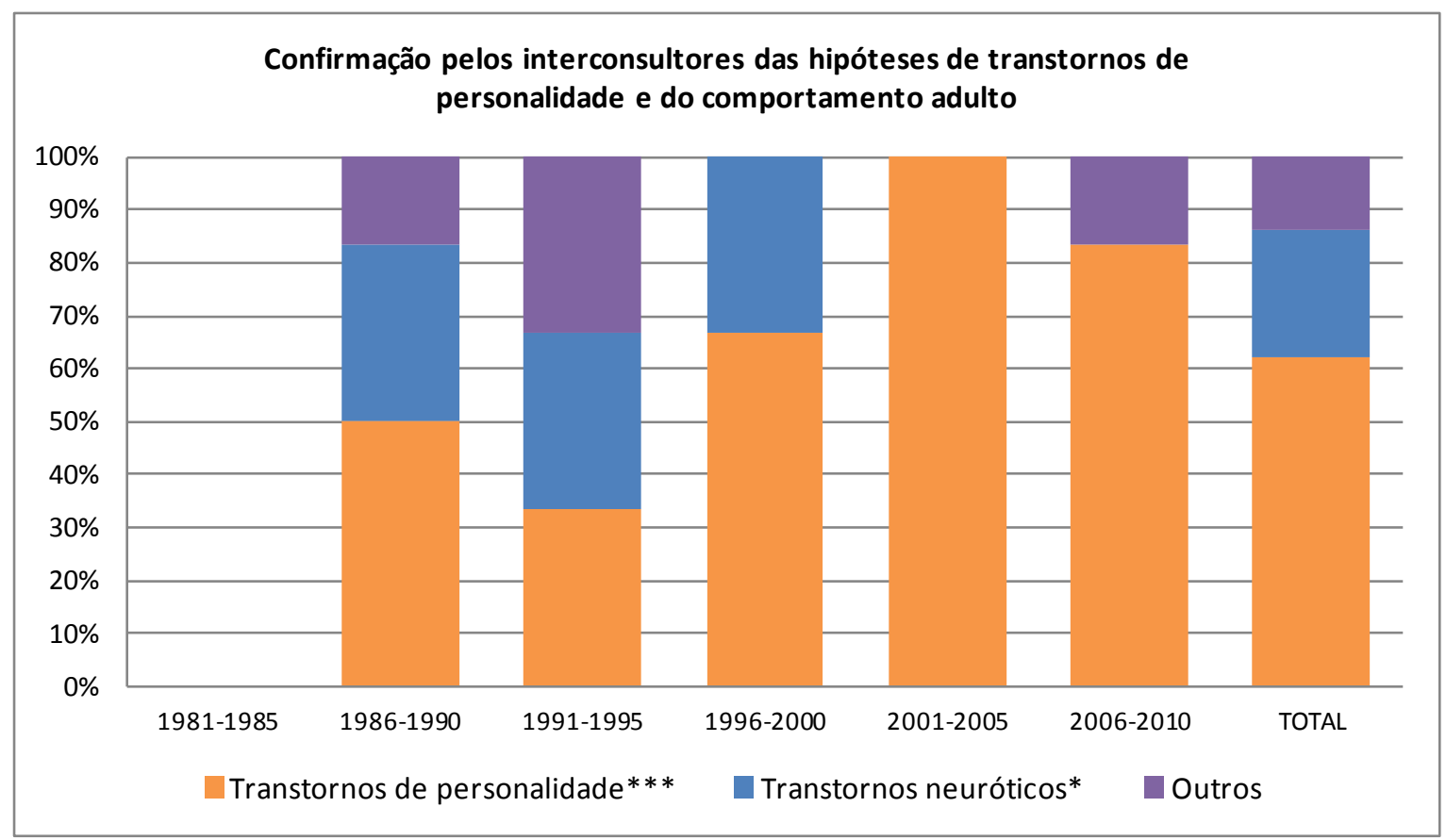

*** Inclui também transtornos do comportamento adulto; * inclui também transtornos somatoformes e relacionados ao estresse.

Figura 4.11 - Confirmações diagnósticas pelos interconsultores das hipóteses de transtornos de personalidade e do comportamento adulto levantadas pelos profissionais solicitantes.

Em relação ao total de possíveis transtornos do humor levantados pelas equipes solicitantes, apenas $45 \%$ dos casos foram confirmados pelos interconsultores após avaliação do paciente. No restante das confirmações diagnósticas, em 47\% dos possíveis casos de transtornos do humor sugeridos pelos clínicos, os diagnósticos dados pelos interconsultores foram transtornos neuróticos, somatoformes e relacionados ao estresse (no período de 1991 a 1995, 75\% das suspeitas de transtorno do humor foram diagnosticadas como transtornos neuróticos). Apesar do diagnóstico correto por parte dos clínicos ter aumentado ao longo dos anos, a dificuldade na diferenciação desses dois transtornos persistiu (Figura 4.12). 


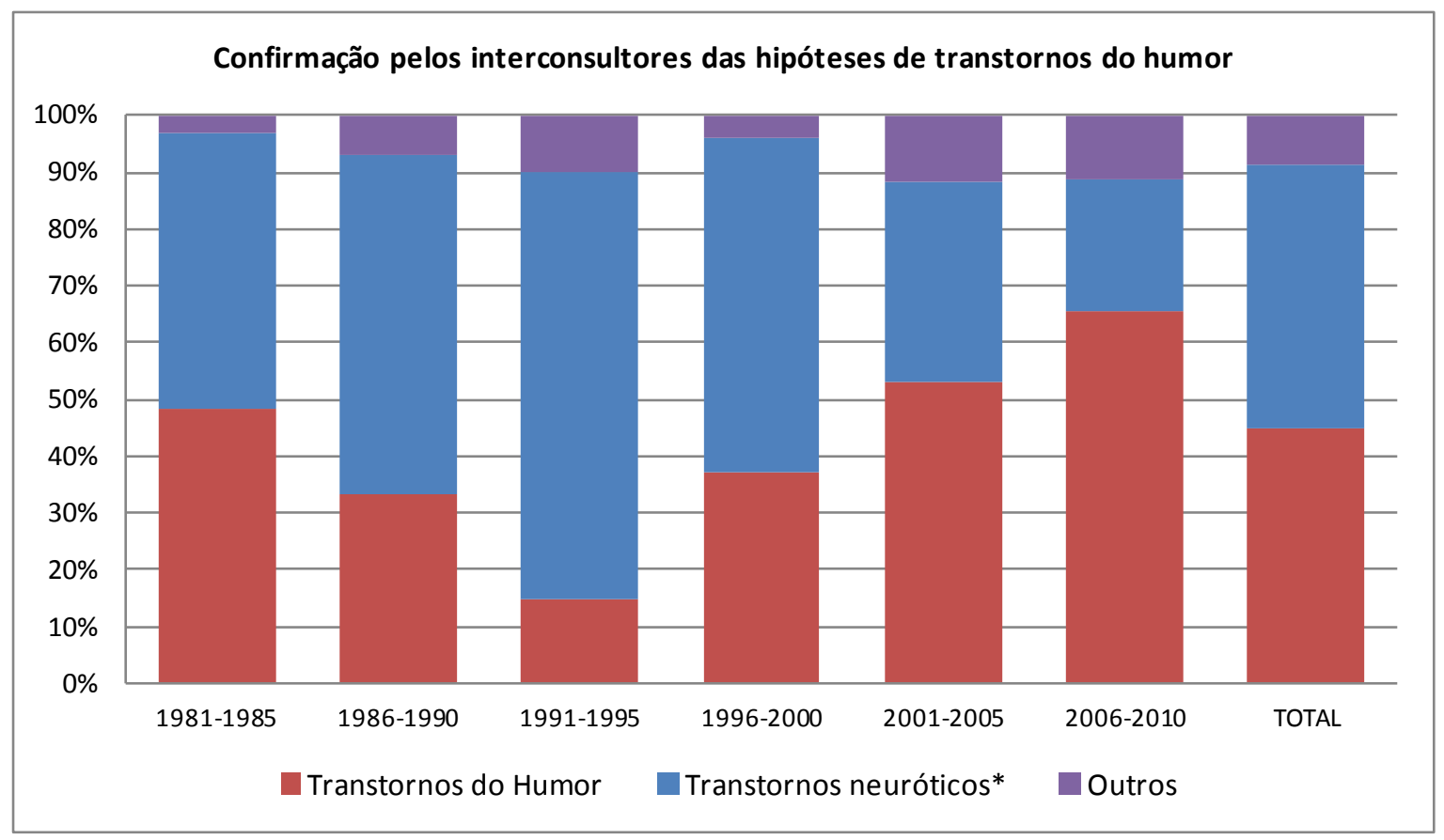

* Inclui também transtornos somatoformes e relacionados ao estresse.

Figura 4.12 - Confirmações diagnósticas pelos interconsultores das hipóteses de transtornos do humor levantadas pelos profissionais solicitantes.

\subsubsection{IDEAÇÃO SUICIDA}

A avaliação da ideação suicida no momento da consulta do interconsultor não foi informada em quase $60 \%$ dos casos das mulheres e em $87 \%$ dos homens atendidos até fim de 1995, sendo que a ausência dessa informação foi menor nos anos seguintes. Considerando apenas as informações válidas, 8,4\% das mulheres e 10,2\% dos homens apresentaram ideação suicida no momento da avaliação (Tabela 4.44).

Dos pacientes que tiveram solicitações psiquiátricas motivadas pelo risco suicida segundo o profissional solicitante, 32,9\% tiveram ideação suicida confirmada pelo interconsultor. 
Tabela 4.44 - Ideação suicida detectada pelo interconsultor nos pacientes de ambos os sexos atendidos pelo serviço de Interconsulta Psiquiátrica entre janeiro de 1981 a dezembro de 2010.

\begin{tabular}{|c|c|c|c|c|c|c|c|}
\hline & \\
\hline & $1981-1985$ & $1986-1990$ & 1991-1995 & $1996-2000$ & 2001-2005 & 2006-2010 & TOTAL \\
\hline IDEAÇÃO SUICIDA NAS MULHERES & $\mathbf{N}(\%)$ & N (\%) & $\mathbf{N}(\%)$ & N (\%) & $\mathbf{N}(\%)$ & $\mathbf{N}(\%)$ & $\mathbf{N}(\%)$ \\
\hline Não & $42(66,7)$ & $48(87,3)$ & $152(87,9)$ & $297(94,6)$ & $429(93,5)$ & $540(92,6)$ & $1508(91,6)$ \\
\hline Sim & $21(33,3)$ & $7(12,7)$ & $21(12,1)$ & $17(5,4)$ & $30(6,5)$ & $43(7,4)$ & $139(8,4)$ \\
\hline TOTAL (N) & 63 & 55 & 173 & 314 & 459 & 583 & 1647 \\
\hline Dados perdidos* & $244(79,5)$ & $302(84,6)$ & $240(58,1)$ & $102(24,5)$ & $244(34,7)$ & $166(22,2)$ & $1298(44,1)$ \\
\hline \multicolumn{8}{|l|}{ IDEAÇÃO SUICIDA NOS HOMENS } \\
\hline Não & $29(90,6)$ & $32(74,4)$ & $22(62,9)$ & $217(96,9)$ & $230(87,8)$ & $280(91,5)$ & $810(89,8)$ \\
\hline $\operatorname{Sim}$ & $3(9,4)$ & $11(25,6)$ & $13(37,1)$ & $7(3,1)$ & $32(12,2)$ & $26(8,5)$ & $92(10,2)$ \\
\hline TOTAL $(\mathrm{N})$ & 32 & 43 & 35 & 224 & 262 & 306 & 902 \\
\hline Dados perdidos* & $192(85,7)$ & $233(84,4)$ & $242(87,4)$ & $98(30,4)$ & $170(39,4)$ & $100(24,6)$ & $1035(53,4)$ \\
\hline
\end{tabular}

\subsubsection{PLANOS DE TRATAMENTO}

As principais condutas sugeridas pelo interconsultor para as mulheres foram: atendimento individual em $61,6 \%$ dos casos, orientações à equipe médica em $45,1 \%$ e prescrição de medicações psicotrópicas em 40,8\% das pacientes (Tabela 4.45). 
Tabela 4.45 - Condutas sugeridas pelo interconsultor para os pacientes do sexo feminino avaliadas entre janeiro de 1981 a dezembro de 2010.

\begin{tabular}{lccccccc} 
& $\mathbf{1 9 8 1 - 1 9 8 5}$ & $\mathbf{1 9 8 6 - 1 9 9 0}$ & $\mathbf{1 9 9 1 - 1 9 9 5}$ & $\mathbf{1 9 9 6 - 2 0 0 0}$ & $\mathbf{2 0 0 1 - 2 0 0 5}$ & $\mathbf{2 0 0 6 - 2 0 1 0}$ & TOTAL \\
\cline { 2 - 8 } & $\mathbf{N}(\%)$ & $\mathbf{N}(\%)$ & $\mathbf{N}(\%)$ & $\mathbf{N}(\%)$ & $\mathbf{N}(\%)$ & $\mathbf{N}(\%)$ & $\mathbf{N}(\%)$ \\
\hline CONDUTAS SUGERIDAS & $129(42,0)$ & $186(52,1)$ & $252(61,0)$ & $271(65,1)$ & $499(71,0)$ & $478(63,8)$ & $1815(61,6)$ \\
\hline Atendimento individual & $150(48,9)$ & $119(33,3)$ & $173(41,9)$ & $186(44,7)$ & $342(48,6)$ & $358(47,8)$ & $1328(45,1)$ \\
Orientação à equipe & $105(34,2)$ & $98(27,5)$ & $103(24,9)$ & $154(37,0)$ & $365(51,9)$ & $377(50,3)$ & $1202(40,8)$ \\
Prescrição de psicofármacos & $43(14,0)$ & $80(22,4)$ & $71(17,2)$ & $91(21,9)$ & $188(26,7)$ & $174(23,2)$ & $647(22,0)$ \\
Exames e outras avaliações & $16(5,2)$ & $26(7,3)$ & $33(8,0)$ & $71(17,1)$ & $179(25,5)$ & $225(30,0)$ & $550(18,7)$ \\
Sugestão de outros profissionais & $33(10,7)$ & $52(14,6)$ & $57(13,8)$ & $45(10,8)$ & $73(10,4)$ & $96(12,8)$ & $356(12,1)$ \\
Entrevista com familiares & $25(8,1)$ & $14(3,9)$ & $31(7,5)$ & $24(5,8)$ & $64(9,1)$ & $104(13,9)$ & $262(8,9)$ \\
Orientação aos familiares & $8(2,6)$ & $9(2,5)$ & $21(5,1)$ & $31(7,5)$ & $71(10,1)$ & $94(12,6)$ & $234(7,9)$ \\
Suspensão de psicofármacos & $2(0,7)$ & $1(0,3)$ & $2(0,5)$ & $5(1,2)$ & $12(1,7)$ & $47(6,3)$ & $69(2,3)$ \\
Atendimento aos familiares & $1(0,3)$ & $1(0,3)$ & 0,0 & $3(0,7)$ & $1(0,1)$ & $5(0,7)$ & $11(0,4)$ \\
Atendimento grupal & 307 & 357 & 413 & 416 & 703 & 749 & 2945 \\
\hline TOTAL DE MULHERES & $7(2,3)$ & $5(1,4)$ & $3(0,7)$ & $4(1,0)$ & $2(0,3)$ & $3(0,4)$ & $24(0,8)$ \\
Sem necessidade de acompanhamento & $7(2,3)$ & $11(3,1)$ & $14(3,4)$ & $22(5,3)$ & $11(1,6)$ & $36(4,8)$ & $101(3,4)$ \\
Não informado & & &
\end{tabular}

Todas as porcentagens foram calculadas em relação ao número total de mulheres em cada período.

Notou-se que as frequências de mulheres que foram atendidas individualmente e de mulheres que tiveram medicações psicotrópicas prescritas após a visita do interconsultor cresceram até meados de 2001 vindo a declinar no fim da última década (Figura 4.13). Contudo, de maneira geral, observou-se um aumento na sugestão de todas as condutas (em especial a sugestão de outros profissionais) quando comparadas as décadas de 80 e de 2000, com exceção da orientação à equipe, que teve uma redução discreta. 


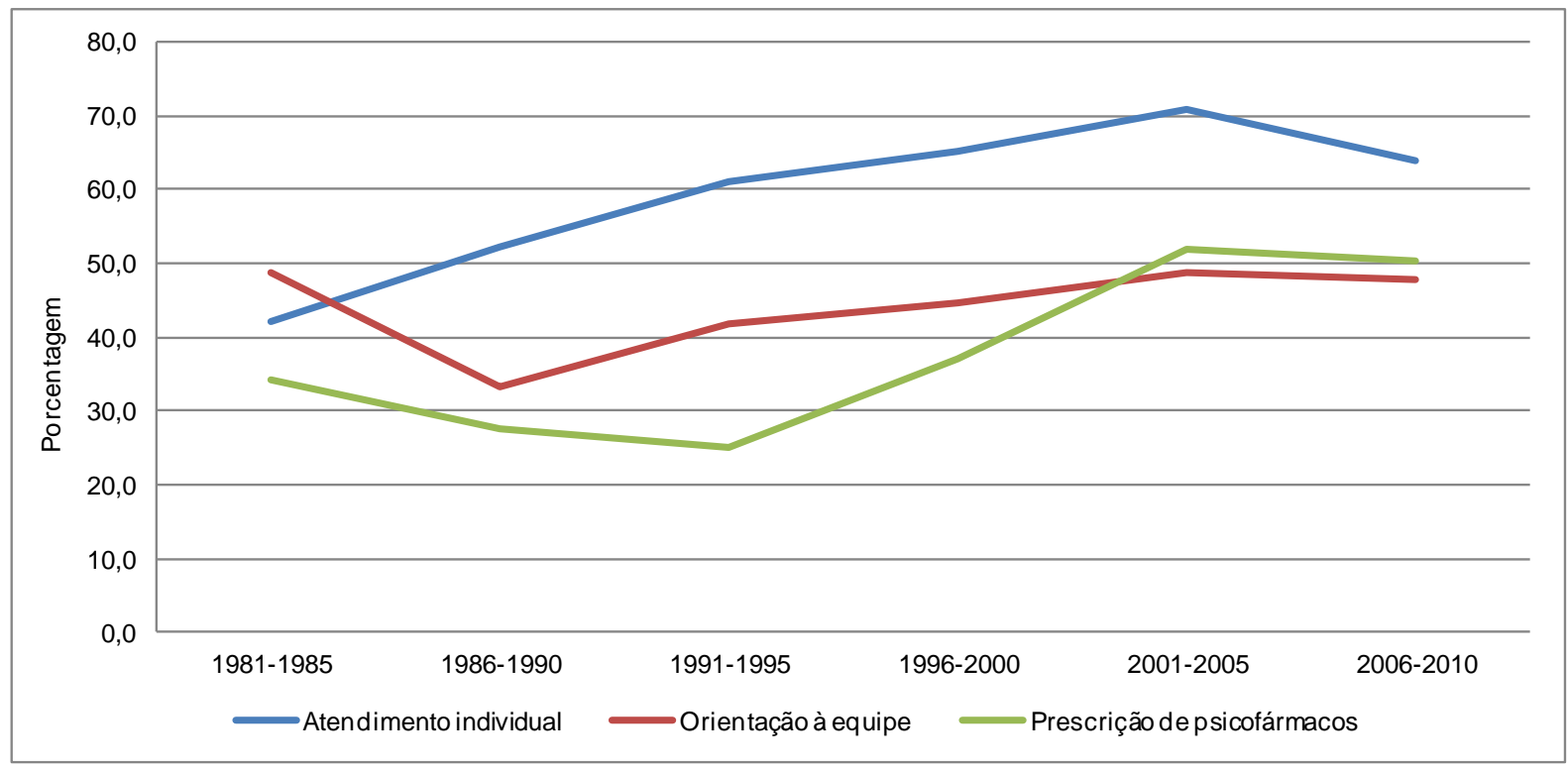

Figura 4.13 - Principais condutas sugeridas pelo interconsultor aos pacientes do sexo feminino entre janeiro de 1981 a dezembro de 2010.

Já para os homens, as principais condutas sugeridas pelo interconsultor foram: atendimento individual em aproximadamente $60 \%$ do casos - assim como as mulheres, orientações à equipe médica em 49,5\% e prescrição de medicações psicotrópicas em 45,3\% dos pacientes (Tabela 4.46).

Tabela 4.46 - Condutas sugeridas pelo interconsultor para os pacientes do sexo masculino avaliados entre janeiro de 1981 a dezembro de 2010.

\begin{tabular}{lccccccc} 
& $\mathbf{1 9 8 1 - 1 9 8 5}$ & $\mathbf{1 9 8 6 - 1 9 9 0}$ & $\mathbf{1 9 9 1 - 1 9 9 5}$ & $\mathbf{1 9 9 6 - 2 0 0 0}$ & $\mathbf{2 0 0 1 - 2 0 0 5}$ & $\mathbf{2 0 0 6 - 2 0 1 0}$ & TOTAL \\
\hline \cline { 2 - 8 } & $\mathbf{N}(\%)$ & $\mathbf{N}(\%)$ & $\mathbf{N}(\%)$ & $\mathbf{N}(\%)$ & $\mathbf{N}(\%)$ & $\mathbf{N}(\%)$ & $\mathbf{N}(\%)$ \\
\hline CONDUTAS SUGERIDAS & $99(44,2)$ & $156(56,5)$ & $167(60,3)$ & $212(65,8)$ & $277(64,1)$ & $249(61,3)$ & $1160(59,9)$ \\
Atendimento individual & $109(48,7)$ & $119(43,1)$ & $125(45,1)$ & $165(51,2)$ & $229(53,0)$ & $211(52,0)$ & $958(49,5)$ \\
Orientação à equipe & $96(42,9)$ & $90(32,6)$ & $71(25,6)$ & $144(44,7)$ & $234(54,2)$ & $243(59,9)$ & $878(45,3)$ \\
Prescrição de psicofármacos & $37(16,5)$ & $54(19,6)$ & $56(20,2)$ & $79(24,5)$ & $113(26,2)$ & $98(24,1)$ & $437(22,6)$ \\
Exames e outras avaliações & $7(3,1)$ & $18(6,5)$ & $14(5,1)$ & $50(15,5)$ & $86(19,9)$ & $123(30,3)$ & $298(15,4)$ \\
Sugestão de outros profissionais & $20(8,9)$ & $38(13,8)$ & $39(14,1)$ & $33(10,2)$ & $45(10,4)$ & $41(10,1)$ & $216(11,2)$ \\
Entrevista com familiares & $9(4,0)$ & $17(6,2)$ & $19(6,9)$ & $23(7,1)$ & $42(9,7)$ & $43(10,6)$ & $153(7,9)$ \\
Orientação aos familiares & $9(4,0)$ & $11(4,0)$ & $10(3,6)$ & $31(9,6)$ & $42(9,7)$ & $46(11,3)$ & $149(7,7)$ \\
Suspensão de psicofármacos & $2(0,9)$ & $1(0,4)$ & 0,0 & $4(1,2)$ & $6(1,4)$ & $21(5,2)$ & $34(1,8)$ \\
Atendimento aos familiares & 0,0 & 0,0 & $3(1,1)$ & 0,0 & 0,0 & $7(1,7)$ & $10(0,5)$ \\
Atendimento grupal & 224 & 276 & 277 & 322 & 432 & 406 & 1937 \\
\hline TOTAL DE HOMENS & $7(3,1)$ & $3(1,1)$ & $7(2,5)$ & $3(0,9)$ & $3(0,7)$ & $2(0,5)$ & $25(1,3)$ \\
Sem necessidade de acompanhamento & $4(1,8)$ & $9(3,3)$ & $11(4,0)$ & $18(5,6)$ & $14(3,2)$ & $11(2,7)$ & $67(3,5)$ \\
Não informado & &
\end{tabular}

Todas as porcentagens foram calculadas em relação ao número total de homens em cada período. 
Entre os anos de 1991 a 2010, pôde-se observar um aumento considerável dos homens que foram medicados após a visita do interconsultor, já a frequência de homens que foram atendidos individualmente após a visita cresceu progressivamente até meados de 2000, vindo a reduzir na última década (Figura 4.14). Contudo, de maneira geral, quando comparadas as décadas de 80 e 2000, todas sugestões de conduta aumentaram, especialmente a sugestão de outros profissionais - assim como para as mulheres.

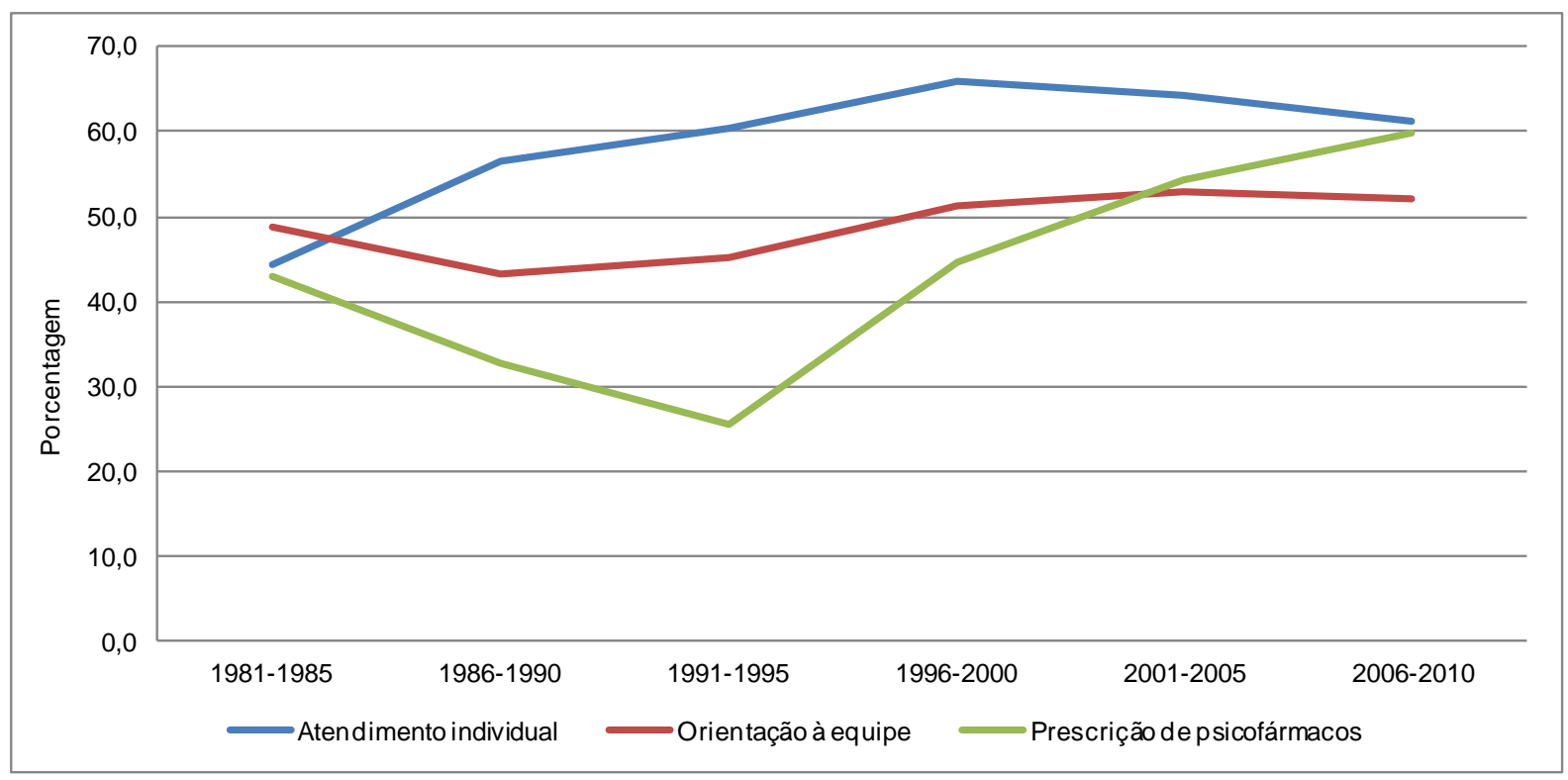

Figura 4.14 - Principais condutas sugeridas pelo interconsultor aos pacientes do sexo masculino entre janeiro de 1981 a dezembro de 2010.

Ao longo dos anos, também foi observado um aumento progressivo da complexidade do plano de tratamento sugerido pelo interconsultor. Na década de 80, a grande maioria dos planos de tratamento propostos tinha até duas condutas e, ao final da última década, mais de $60 \%$ dos planos de tratamento eram compostos de, no mínimo, três condutas, sendo que por volta de $20 \%$, eram compostos por até sete 
sugestões de conduta (Tabela 4.47).

Tabela 4.47 - Planos de tratamentos e o número de condutas sugeridas para os pacientes de ambos os sexos avaliados entre janeiro de 1981 a dezembro de 2010.

\begin{tabular}{lccccccc}
\cline { 2 - 7 } PLANO DE TRATAMENTO & $\mathbf{1 9 8 1 - 1 9 8 5}$ & $\mathbf{1 9 8 6 - 1 9 9 0}$ & $\mathbf{1 9 9 1 - 1 9 9 5}$ & $\mathbf{1 9 9 6 - 2 0 0 0}$ & $\mathbf{2 0 0 1 - 2 0 0 5}$ & $\mathbf{2 0 0 6 - 2 0 1 0}$ & TOTAL \\
\hline FEMININO & $\mathbf{N}(\%)$ & $\mathbf{N}(\%)$ & $\mathbf{N}(\%)$ & $\mathbf{N}(\%)$ & $\mathbf{N}(\%)$ & $\mathbf{N}(\%)$ & $\mathbf{N}(\%)$ \\
\hline Um conduta & $73(26,7)$ & $96(28,7)$ & $112(29,0)$ & $73(19,2)$ & $80(11,9)$ & $58(8,4)$ & $492(18,0)$ \\
Duas condutas & $102(37,4)$ & $155(46,3)$ & $161(41,7)$ & $125(32,8)$ & $171(25,4)$ & $160(23,2)$ & $874(31,9)$ \\
De três a quatro condutas & $97(35,5)$ & $82(24,5)$ & $110(28,5)$ & $161(42,2)$ & $316(47,0)$ & $324(47,0)$ & $1090(39,8)$ \\
Acima de cinco condutas & $1(0,4)$ & $2(0,6)$ & $3(0,8)$ & $22(5,8)$ & $105(15,6)$ & $147(21,4)$ & $280(10,2)$ \\
\hline TOTAL (N) & 273 & 335 & 386 & 381 & 672 & 689 & 2736 \\
\hline MASCULINO & $\mathbf{N}(\%)$ & $\mathbf{N}(\%)$ & $\mathbf{N}(\%)$ & $\mathbf{N}(\%)$ & $\mathbf{N}(\%)$ & $\mathbf{N}(\%)$ & $\mathbf{N}(\%)$ \\
\hline Um conduta & $52(26,3)$ & $60(23,0)$ & $79(31,1)$ & $50(16,7)$ & $49(12,1)$ & $36(9,4)$ & $326(18,1)$ \\
Duas condutas & $83(41,9)$ & $131(50,2)$ & $95(37,4)$ & $90(30,1)$ & $106(26,2)$ & $92(23,9)$ & $597(33,1)$ \\
De três a quatro condutas & $62(31,3)$ & $68(26,1)$ & $77(30,3)$ & $135(45,2)$ & $199(49,1)$ & $186(48,3)$ & $727(40,3)$ \\
Acima de cinco condutas & $1(0,5)$ & $2(0,8)$ & $3(1,2)$ & $24(8,0)$ & $51(12,6)$ & $71(18,4)$ & $152(8,4)$ \\
\hline TOTAL $(\mathrm{N})$ & 198 & 261 & 254 & 299 & 405 & 385 & 1802 \\
\hline
\end{tabular}

Em relação os profissionais que foram solicitados pelo interconsultor para oferecer assistência às mulheres (Tabela 4.48) e aos homens (Tabela 4.49) avaliados, na década de 80, podem-se destacar o Serviço Social e a Psicologia, seguido pela Terapia Ocupacional na década de 90, e a Psicologia sendo solicitada em mais de $50 \%$ dos casos avaliados na última década.

Tabela 4.48 - Profissionais solicitados pelo interconsultor para os pacientes do sexo feminino avaliados entre janeiro de 1981 a dezembro de 2010.

\begin{tabular}{lccccccc} 
& $\mathbf{1 9 8 1 - 1 9 8 5}$ & $\mathbf{1 9 8 6 - 1 9 9 0}$ & $\mathbf{1 9 9 1 - 1 9 9 5}$ & $\mathbf{1 9 9 6 - 2 0 0 0}$ & $\mathbf{2 0 0 1 - 2 0 0 5}$ & $\mathbf{2 0 0 6 - 2 0 1 0}$ & TOTAL \\
\hline PROFISSIONAIS SOLICITADOS & $\mathbf{N}(\%)$ & $\mathbf{N}(\%)$ & $\mathbf{N}(\%)$ & $\mathbf{N}(\%)$ & $\mathbf{N}(\%)$ & $\mathbf{N}(\%)$ & $\mathbf{N}(\%)$ \\
\hline Psicologia & $7(43,8)$ & $20(74,1)$ & $12(36,4)$ & $34(42,5)$ & $115(54,2)$ & $153(54,6)$ & $341(52,6)$ \\
Terapia Ocupacional & 0,0 & $4(14,8)$ & $16(48,5)$ & $40(50)$ & $82(38,7)$ & $94(33,6)$ & $236(36,4)$ \\
Serviço Social & $9(56,2)$ & $3(11,1)$ & $5(15,2)$ & $6(7,5)$ & $15(7,1)$ & $33(11,8)$ & $71(11,0)$ \\
\hline TOTAL $(\mathrm{N})$ & 16 & 27 & 33 & 80 & 212 & 280 & 648 \\
\hline
\end{tabular}


Tabela 4.49 - Profissionais solicitados pelo interconsultor para os pacientes do sexo masculino avaliados entre janeiro de 1981 a dezembro de 2010.

\begin{tabular}{lccccccc} 
& $\mathbf{1 9 8 1 - 1 9 8 5}$ & $\mathbf{1 9 8 6 - 1 9 9 0}$ & $\mathbf{1 9 9 1 - 1 9 9 5}$ & $\mathbf{1 9 9 6 - 2 0 0 0}$ & $\mathbf{2 0 0 1 - 2 0 0 5}$ & $\mathbf{2 0 0 6 - 2 0 1 0}$ & TOTAL \\
\hline PROFISSIONAIS SOLICITADOS & $\mathbf{N}(\%)$ & $\mathbf{N}(\%)$ & $\mathbf{N}(\%)$ & $\mathbf{N}(\%)$ & $\mathbf{N}(\%)$ & $\mathbf{N}(\%)$ & $\mathbf{N}(\%)$ \\
\hline Psicologia & 0,0 & $11(57,9)$ & $1(7,7)$ & $19(35,8)$ & $56(58,9)$ & $81(53,6)$ & $168(49,7)$ \\
Terapia Ocupacional & 0,0 & $5(26,3)$ & $12(92,3)$ & $33(62,3)$ & $29(30,5)$ & $53(35,1)$ & $132(39,1)$ \\
Serviço Social & $7(100,0)$ & $3(15,8)$ & 0,0 & $1(1,9)$ & $10(10,5)$ & $17(11,3)$ & $38(11,2)$ \\
\hline TOTAL (N) & 7 & 19 & 13 & 53 & 95 & 151 & 338 \\
\hline
\end{tabular}

\subsubsection{MEDICAÇÕES PSICOTRÓPICAS}

Dos dados válidos, $67,3 \%(\mathrm{~N}=1138)$ de todos os pacientes do sexo feminino faziam uso de medicação psicotrópica antes da visita do interconsultor.

Das medicações em uso antes da visita, os benzodiazepínicos foram as drogas mais utilizadas pelas mulheres ao longo dos anos, seguidos pelos antidepressivos, antipsicóticos, estabilizadores do humor e outros (Tabela 4.50).

Já as medicações suspensas após a visita do interconsultor, as mais frequentes foram os antidepressivos, seguidos pelos benzodiazepínicos, antipsicóticos, estabilizadores do humor e outros (Tabela 4.50).

E as mais prescritas ou tiveram suas doses reajustadas com mais frequência foram os benzodiazepínicos, seguidos pelos antidepressivos, antipsicóticos, estabilizadores do humor e outros (Tabela 4.50). 
Tabela 4.50 - Medicações em uso antes da avaliação do interconsultor, medicações suspensas e prescritas após a avaliação dos pacientes do sexo feminino avaliados entre janeiro de 1981 a dezembro de 2010.

\begin{tabular}{|c|c|c|c|c|c|c|c|}
\hline & \\
\hline & $1981-1985$ & $1986-1990$ & 1991-1995 & $1996-2000$ & 2001-2005 & 2006-2010 & TOTAL \\
\hline MEDICAÇÕES EM USO & N (\%) & $\mathbf{N}(\%)$ & N (\%) & N (\%) & N (\%) & N (\%) & N (\%) \\
\hline Benzodiazepínicos & $45(42,5)$ & $59(49,2)$ & $65(40,6)$ & $113(40,8)$ & $180(32,3)$ & $202(30,0)$ & $664(35,1)$ \\
\hline Antidepressivos & $4(3,8)$ & $18(15,0)$ & $14(8,8)$ & $55(19,9)$ & $159(28,5)$ & $243(36,1)$ & $493(26,0)$ \\
\hline Antipsicóticos & $33(31,1)$ & $18(15,0)$ & $42(26,3)$ & $56(20,2)$ & $97(17,4)$ & $128(19,0)$ & $374(19,7)$ \\
\hline Estabilizadores do Humor & $5(4,7)$ & $5(4,2)$ & $10(6,3)$ & $9(3,2)$ & $35(6,3)$ & $52(7,7)$ & $116(6,1)$ \\
\hline Outros & $19(17,9)$ & $20(16,7)$ & $29(18,1)$ & $44(15,9)$ & $87(15,6)$ & $48(7,1)$ & $247(13,0)$ \\
\hline TOTAL (N) & 106 & 120 & 160 & 277 & 558 & 673 & 1894 \\
\hline \multicolumn{8}{|l|}{ MEDICAÇÕES SUSPENSAS ${ }^{*}$} \\
\hline Antidepressivos & $2(50,0)$ & $3(16,7)$ & $3(21,4)$ & $9(16,4)$ & $25(15,7)$ & $46(18,9)$ & $88(17,8)$ \\
\hline Benzodiazepínicos & $1(2,2)$ & $5(8,5)$ & $14(21,5)$ & $16(14,2)$ & $36(20,0)$ & $37(18,3)$ & $109(16,4)$ \\
\hline Antipsicóticos & $5(15,2)$ & $1(5,6)$ & $4(9,5)$ & $8(14,3)$ & $13(13,4)$ & $22(17,2)$ & $53(14,2)$ \\
\hline Estabilizadores do Humor & 0,0 & 0,0 & $1(10,0)$ & $1(11,1)$ & 0,0 & $8(15,4)$ & $10(8,6)$ \\
\hline Outros & 0,0 & 0,0 & $2(6,9)$ & $1(2,3)$ & $6(6,9)$ & $7(14,6)$ & $16(6,5)$ \\
\hline \multicolumn{8}{|l|}{ MEDICAÇÕES PRESCRITAS } \\
\hline Benzodiazepínicos & $63(49,6)$ & $55(46,2)$ & $69(48,6)$ & $89(36,2)$ & $165(31,5)$ & $161(27,2)$ & $602(34,4)$ \\
\hline Antidepressivos & $8(6,3)$ & $15(12,6)$ & $18(12,7)$ & $63(25,6)$ & $205(39,1)$ & $253(42,8)$ & $562(32,1)$ \\
\hline Antipsicóticos & $46(36,2)$ & $44(37,0)$ & $45(31,7)$ & $75(30,5)$ & $133(25,4)$ & $146(24,7)$ & $489(28,0)$ \\
\hline Estabilizadores do Humor & $9(7,1)$ & $5(4,2)$ & $5(3,5)$ & $16(6,5)$ & $19(3,6)$ & $17(2,9)$ & $71(4,1)$ \\
\hline Outros & $1(0,8)$ & 0,0 & $5(3,5)$ & $3(1,2)$ & $2(0,4)$ & $14(2,4)$ & $25(1,4)$ \\
\hline TOTAL (N) & 127 & 119 & 142 & 246 & 524 & 591 & 1749 \\
\hline
\end{tabular}

* Porcentagens das medicações suspensas foram calculadas considerando o total de cada medicação em uso no período.

A prescrição de benzodiazepínicos para as mulheres decaiu progressivamente a partir de meados dos anos 90 enquanto que a prescrição de antidepressivos aumentou. As recomendações de antipsicóticos decaíram discretamente a partir de meados dos anos 80 e os estabilizadores do humor se mantiveram relativamente estáveis ao longo dos anos, com redução de prescrição na última década (Figura 4.15). 


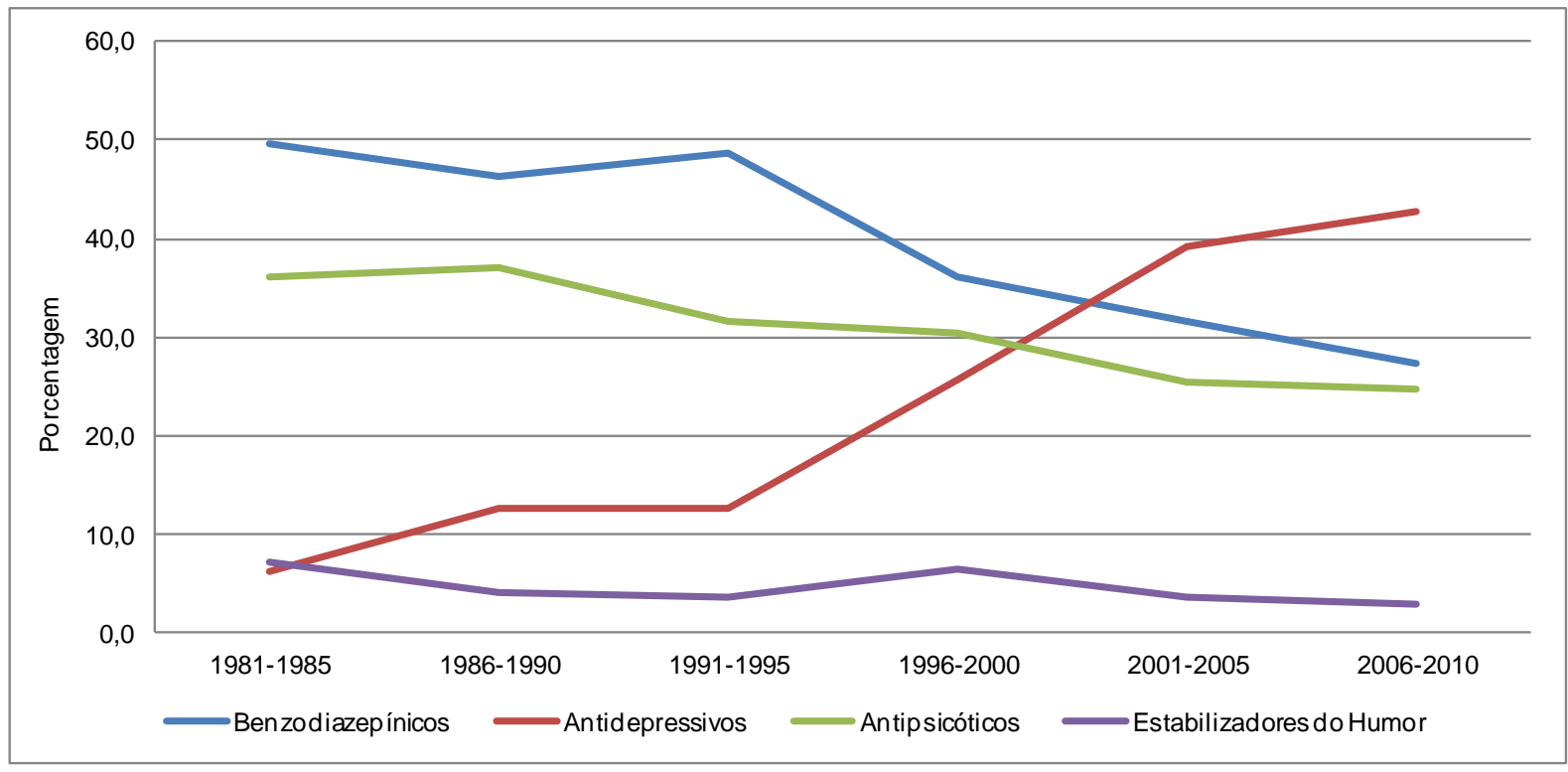

Figura 4.15 - Principais medicações prescritas ou com doses reajustadas pelo interconsultor após a visita aos pacientes do sexo feminino entre janeiro de 1981 a dezembro de 2010.

Em relação aos homens, dos dados válidos, 69,4\% (N=751) de todos os pacientes deste sexo faziam uso de medicações psicotrópicas antes da visita do interconsultor.

Das medicações em uso, as mais frequentes foram os benzodiazepínicos, seguidos pelos antipsicóticos, antidepressivos, estabilizadores do humor e outros (Tabela 4.51).

As medicações mais suspensas pelo interconsultor foram os benzodiazepínicos, seguidos pelos antidepressivos, estabilizadores do humor, antipsicóticos e outros (Tabela 4.51).

E as mais recomendadas foram os benzodiazepínicos, antipsicóticos, antidepressivos, estabilizadores do humor e outros (Tabela 4.51). 
Tabela 4.51 - Medicações em uso antes da avaliação do interconsultor, medicações suspensas e prescritas após a avaliação dos pacientes do sexo masculino avaliados entre janeiro de 1981 a dezembro de 2010.

\begin{tabular}{|c|c|c|c|c|c|c|c|}
\hline & & & & & & & \\
\hline & 1981-1985 & $1986-1990$ & 1991-1995 & $1996-2000$ & 2001-2005 & 2006-2010 & TOTAL \\
\hline MEDICAÇÕES EM USO & $\mathbf{N}(\%)$ & $\mathbf{N}(\%)$ & $\mathbf{N}(\%)$ & $\mathbf{N}(\%)$ & $\mathbf{N}(\%)$ & $\mathbf{N}(\%)$ & $\mathbf{N}(\%)$ \\
\hline Benzodiazepínicos & $35(41,7)$ & $42(37,2)$ & $38(36,5)$ & $87(36,4)$ & $107(34,6)$ & $123(34,4)$ & $432(35,8)$ \\
\hline Antipsicóticos & $22(26,2)$ & $28(24,8)$ & $34(32,7)$ & $56(23,4)$ & $58(18,8)$ & $96(26,8)$ & $294(24,4)$ \\
\hline Antidepressivos & 0,0 & $8(7,1)$ & $7(6,7)$ & $26(10,9)$ & $61(19,7)$ & $77(21,5)$ & $179(14,8)$ \\
\hline Estabilizadores do Humor & $4(4,8)$ & $3(2,7)$ & $8(7,7)$ & $12(5,0)$ & $24(7,8)$ & $20(5,6)$ & $71(5,9)$ \\
\hline Outros & $23(27,4)$ & $32(28,3)$ & $17(16,3)$ & $58(24,3)$ & $59(19,7)$ & $42(11,7)$ & $231(19,1)$ \\
\hline TOTAL $(\mathrm{N})$ & 84 & 113 & 104 & 239 & 309 & 358 & 1207 \\
\hline \multicolumn{8}{|l|}{ MEDICAÇÕES SUSPENSAS ${ }^{*}$} \\
\hline Benzodiazepínicos & $4(14,3)$ & $8(66,7)$ & $6(54,5)$ & $20(60,6)$ & $24(47,1)$ & $21(35,0)$ & $83(19,2)$ \\
\hline Antidepressivos & 0,0 & $3(25,0)$ & 0,0 & $3(9,1)$ & $10(19,6)$ & $17(28,3)$ & $33(18,4)$ \\
\hline Estabilizadores do Humor & $4(14,3)$ & 0,0 & 0,0 & $2(6,1)$ & $3(5,9)$ & $4(6,7)$ & $13(18,3)$ \\
\hline Antipsicóticos & $10(35,7)$ & $1(8,3)$ & $4(36,4)$ & $8(24,2)$ & $13(25,5)$ & $12(20,0)$ & $48(16,3)$ \\
\hline Outros & $10(35,7)$ & 0,0 & $1(9,1)$ & 0,0 & $1(2,0)$ & $6(10,0)$ & $18(7,8)$ \\
\hline \multicolumn{8}{|l|}{ MEDICAÇÕES PRESCRITAS } \\
\hline Benzodiazepínicos & $62(55,9)$ & $53(48,2)$ & $39(45,3)$ & $86(38,2)$ & $114(34,2)$ & $103(27,2)$ & $457(36,8)$ \\
\hline Antipsicóticos & $34(30,6)$ & $39(35,5)$ & $36(41,9)$ & $89(39,6)$ & $106(31,8)$ & $122(32,3)$ & $426(34,3)$ \\
\hline Antidepressivos & $5(4,5)$ & $10(9,1)$ & $6(7,0)$ & $33(14,7)$ & $94(28,2)$ & $123(32,5)$ & $271(21,8)$ \\
\hline Estabilizadores do Humor & $1(0,9)$ & 0,0 & $1(1,2)$ & $3(1,3)$ & $5(1,5)$ & $5(1,3)$ & $15(1,2)$ \\
\hline Outros & $9(8,1)$ & $8(7,3)$ & $4(4,7)$ & $14(6,2)$ & $14(4,2)$ & $25(6,6)$ & $74(6,0)$ \\
\hline TOTAL (N) & 111 & 110 & 86 & 225 & 333 & 378 & 1243 \\
\hline
\end{tabular}

* Porcentagens das medicações suspensas foram calculadas considerando o total de cada medicação em uso no período.

Tanto os benzodiazepínicos quanto os antipsicóticos tiveram uma queda na frequência de prescrição para os homens a partir de meados dos anos 90 , enquanto que as recomendações de uso de antidepressivos aumentaram ao longo dos anos. Os estabilizadores do humor, assim como nas mulheres, se mantiveram relativamente constantes e com baixa frequência (Figura 4.16). 


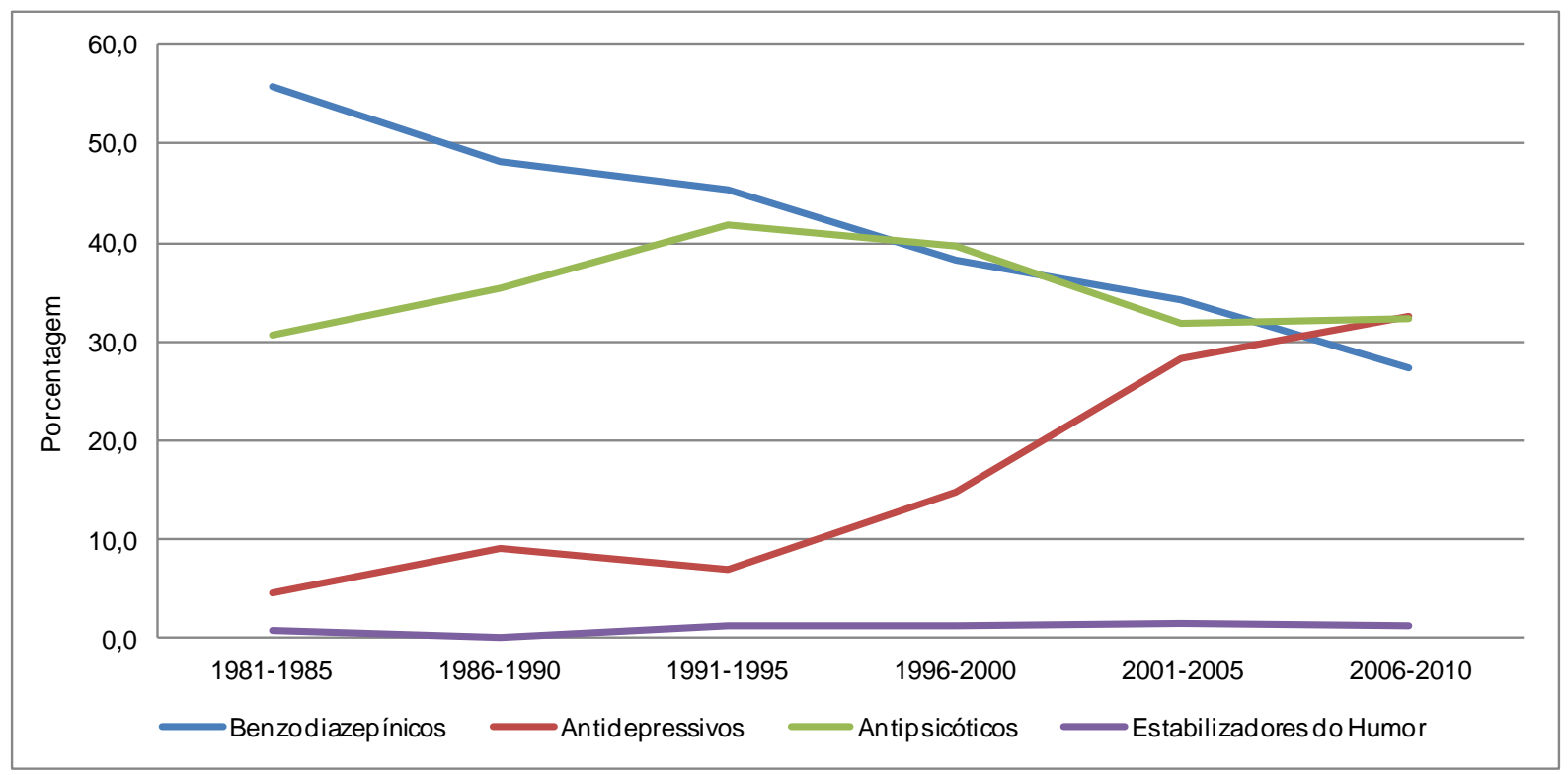

Figura 4.16 - Principais medicações prescritas ou com doses reajustadas pelo interconsultor após a visita aos pacientes do sexo masculino entre janeiro de 1981 a dezembro de 2010.

De maneira geral, foram observadas diferenças entre mulheres e homens quanto aos antidepressivos e antipsicóticos em uso e prescritos. As mulheres fizeram mais uso de antidepressivos assim como foram as medicações mais prescritas, enquanto que os homens fizeram mais uso de antipsicóticos assim como foram as medicações mais prescritas.

\subsubsection{ENCAMINHAMENTOS}

Houve um aumento do número de encaminhamentos para as mulheres após a alta hospitalar a partir do fim da década de 90 , sendo esta frequência de $45 \%$ na metade da última década. A grande maioria dos encaminhamentos foi para atendimento psiquiátrico ambulatorial seguido pelo atendimento psicológico (Tabela 4.52). 
Tabela 4.52 - Encaminhamentos dos pacientes do sexo feminino propostos pelo interconsultor após a alta hospitalar.

\begin{tabular}{|c|c|c|c|c|c|c|c|}
\hline & \\
\hline & 1981-1985 & $1986-1990$ & 1991-1995 & $1996-2000$ & 2001-2005 & 2006-2010 & TOTAL \\
\hline ENCAMINHAMENTO & $\mathbf{N}(\%)$ & $\mathbf{N}(\%)$ & $\mathbf{N}(\%)$ & $\mathbf{N}(\%)$ & $\mathbf{N}(\%)$ & $\mathbf{N}(\%)$ & $\mathbf{N}(\%)$ \\
\hline TOTAL (N) & $79(25,7)$ & $96(26,9)$ & $63(15,3)$ & $96(23,1)$ & $277(39,4)$ & $337(45,0)$ & $948(32,2)$ \\
\hline TOTAL DE MULHERES & 307 & 357 & 413 & 416 & 703 & 479 & 2945 \\
\hline \multicolumn{8}{|l|}{ SERVIÇO* } \\
\hline Psiquiatria & $57(70,4)$ & $53(55,2)$ & $56(88,9)$ & $79(79,8)$ & $210(69,8)$ & $283(63,0)$ & $738(67,8)$ \\
\hline Psicologia & $22(27,2)$ & $38(39,6)$ & $5(7,9)$ & $10(10,1)$ & $53(17,6)$ & $135(30,1)$ & $263(24,2)$ \\
\hline Terapia Ocupacional & 0,0 & 0,0 & 0,0 & $2(2,0)$ & $2(0,7)$ & $21(4,7)$ & $25(2,3)$ \\
\hline Não especificado & $2(2,5)$ & $5(5,2)$ & $2(3,2)$ & $8(8,1)$ & $36(12,0)$ & $10(2,2)$ & $63(5,8)$ \\
\hline
\end{tabular}

* Foram considerados todos os serviços para os quais os pacientes foram encaminhados, sendo, muitas vezes, casos com múltiplos serviços sugeridos.

No caso dos homens, também houve um aumento no número de encaminhamentos ao longo dos anos. Os serviços para os quais os homens foram encaminhados com mais frequência foram de Psiquiatria e de Psicologia, e raramente para a Terapia Ocupacional (Tabela 4.53).

Tabela 4.53 - Encaminhamentos dos pacientes do sexo masculino propostos pelo interconsultor após a alta hospitalar.

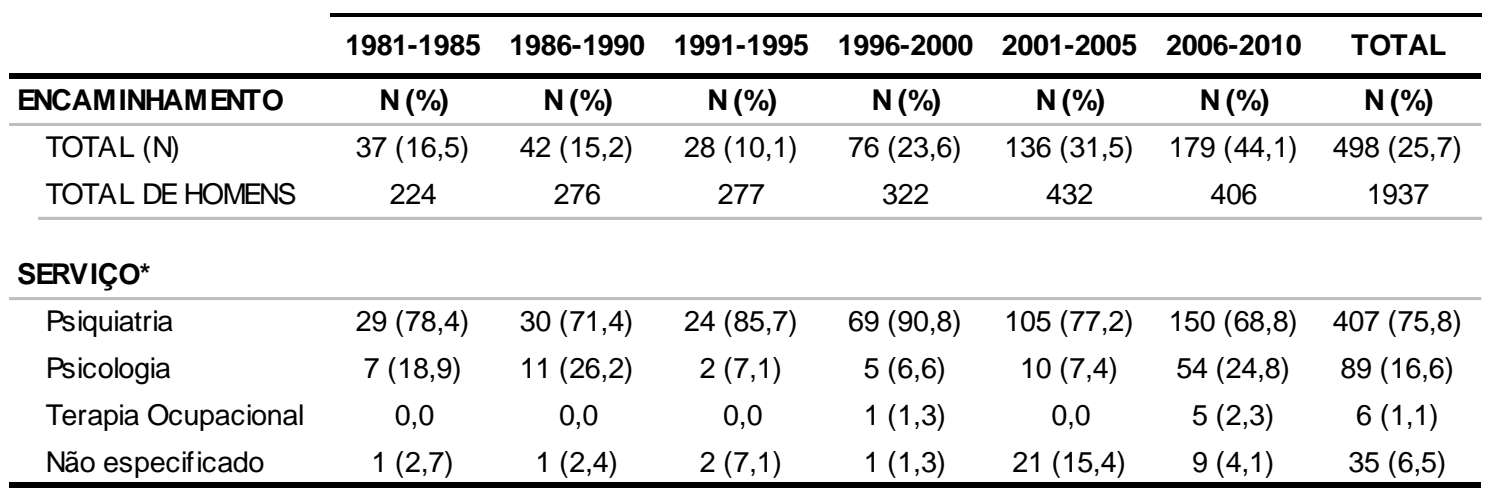

* Foram considerados todos os serviços para os quais os pacientes foram encaminhados, sendo, muitas vezes, casos com múltiplos serviços sugeridos. 
Quando comparados mulheres e homens, observou-se que uma maior frequência de mulheres foram encaminhadas para a Psicologia e Terapia Ocupacional e uma maior frequência de homens foram encaminhados para a Psiquiatria.

\subsection{ASPECTOS RELACIONADOS AOS PROFISSIONAIS DE SAÚDE E AOS INTERCONSULTORES}

Não foi possível ter conhecimento se o profissional solicitante avisou ou não o paciente acerca da visita do interconsultor em $61 \%(\mathrm{~N}=2975)$ de todos os atendimentos, sendo esta ausência em mais de 95\% dos casos entre os anos de 1981 a 1995, 55\% dos casos nos anos de 1996 a 2000 e 33\% em 2010 (Tabela 4.54).

De modo geral, $52 \%$ dos pacientes não foram avisados pelos profissionais clínicos sobre a visita do interconsultor e esta tendência se manteve relativamente constante na última década.

Em relação à alta hospitalar do paciente sem o conhecimento por parte do interconsultor, esta informação não pôde ser obtida em 57\% (N=2780) do total dos casos, sendo esta ausência em mais de $80 \%$ entre os anos de 1981 a 2005 e por volta de 50\% em 2006 a 2010.

Considerando apenas os dados válidos, de maneira geral, 42,9\% dos pacientes teve alta hospitalar sem o conhecimento do interconsultor, vindo este a descobrir apenas no momento de reavaliação do paciente. Já especificadamente no período de 2006 a 2010, em mais de $70 \%$ dos casos os interconsultores tiveram conhecimento da alta hospitalar e puderam finalizar a assistência ao paciente. 
Tabela 4.54 - Frequências dos casos em que o profissional solicitante informou o paciente a respeito da consulta do psiquiatra interconsultor e dos casos em que o paciente recebeu alta hospitalar sem o conhecimento do psiquiatra interconsultor.

\begin{tabular}{|c|c|c|c|c|c|c|c|}
\hline & \\
\hline & 1981-1985 & $1986-1990$ & 1991-1995 & $1996-2000$ & 2001-2005 & $2006-2010$ & TOTAL \\
\hline $\begin{array}{l}\text { INFORM AÇÃO DA CONSULTA AO } \\
\text { PACIENTE }\end{array}$ & $\mathbf{N}(\%)$ & $\mathbf{N}(\%)$ & $\mathbf{N}(\%)$ & $\mathbf{N}(\%)$ & N (\%) & $\mathbf{N}(\%)$ & $\mathbf{N}(\%)$ \\
\hline Não & $5(23,8)$ & 0,0 & $6(40,0)$ & $209(62,8)$ & $359(47,9)$ & $414(53,5)$ & $993(52,1)$ \\
\hline Sim & $16(76,2)$ & $15(100)$ & $9(60,0)$ & $124(37,2)$ & $391(52,1)$ & $359(46,5)$ & $914(47,9)$ \\
\hline TOTAL (N) & 21 & 15 & 15 & 333 & 750 & 773 & 1907 \\
\hline Dados perdidos* & $510(96,0)$ & $618(97,6)$ & $675(97,8)$ & $405(54,9)$ & $385(33,9)$ & $382(33,1)$ & $2975(60,9)$ \\
\hline $\begin{array}{l}\text { ALTA DO PACIENTE SEM } \\
\text { CONHECIMENTO DO INTERCONSULTOR }\end{array}$ & N (\%) & $\mathbf{N}(\%)$ & $\mathrm{N}(\%)$ & $\mathrm{N}(\%)$ & $N(\%)$ & $\mathrm{N}(\%)$ & $\mathbf{N}(\%)$ \\
\hline Não & $8(22,2)$ & $11(50)$ & $15(25,4)$ & $14(28,6)$ & $41(35,6)$ & $320(73,6)$ & $409(57,1)$ \\
\hline $\operatorname{Sim}$ & $28(77,8)$ & $11(50)$ & $44(74,6)$ & $35(71,4)$ & $74(64,4)$ & $115(26,4)$ & $307(42,9)$ \\
\hline TOTAL $(\mathrm{N})$ & 36 & 22 & 59 & 49 & 115 & 435 & 716 \\
\hline Dados perdidos* & $495(93,2)$ & $611(96,5)$ & $631(91,4)$ & $689(93,4)$ & $1020(89,9)$ & $720(62,3)$ & $4166(85,3)$ \\
\hline
\end{tabular}

* Porcentagem dos dados perdidos em relação ao número total de pacientes atendidos em cada período.

\subsection{QUALIDADE ESTRUTURAL DO PI E DE SUA RESPOSTA}

Foram considerados alguns aspectos estruturais dos Pls e de suas respostas para avaliar a qualidade de comunicação entre os diferentes profissionais realizada através de tais documentos.

A legibilidade foi considerada total em mais de $65 \%$ dos Pls e por volta de $60 \%$ das respostas (Tabela 4.55 ). 
Tabela 4.55 - Legibilidade da solicitação psiquiátrica escrita pelo profissional clínico e a legibilidade da resposta escrita pelo interconsultor para os pacientes de ambos os sexos atendidos pelo serviço de Interconsulta Psiquiátrica entre janeiro de 1981 a dezembro de 2010.

\begin{tabular}{|c|c|c|c|c|c|c|c|}
\hline & \\
\hline & 1981-1985 & $1986-1990$ & 1991-1995 & $1996-2000$ & 2001-2005 & 2006-2010 & TOTAL \\
\hline LEGIBILIDADE DA SOLICITAÇÃO & $\mathbf{N}(\%)$ & $\mathbf{N}(\%)$ & $\mathbf{N}(\%)$ & $\mathbf{N}(\%)$ & $\mathbf{N}(\%)$ & $\mathbf{N}(\%)$ & $\mathbf{N}(\%)$ \\
\hline Total & $368(69,4)$ & $336(53,8)$ & $423(61,3)$ & $465(64,8)$ & $790(70,1)$ & $825(71,9)$ & $3207(66,3)$ \\
\hline Parcial & $159(30,0)$ & $285(45,6)$ & $261(37,8)$ & $253(35,2)$ & $333(29,6)$ & $319(27,8)$ & $1610(33,3)$ \\
\hline llegível & $3(0,6)$ & $4(0,6)$ & $6(0,9)$ & 0,0 & $3(0,3)$ & $2(0,3)$ & $18(0,4)$ \\
\hline TOTAL (N) & 530 & 625 & 690 & 718 & 1126 & 1146 & 4835 \\
\hline LEGIBILIDADE DA RESPOSTA & $\mathbf{N}(\%)$ & N (\%) & N (\%) & $\mathbf{N}(\%)$ & $\mathbf{N}(\%)$ & $\mathbf{N}(\%)$ & N (\%) \\
\hline Total & $288(54,3)$ & $460(72,7)$ & $313(45,4)$ & $357(49,8)$ & $684(60,7)$ & $722(63,4)$ & $2824(58,4)$ \\
\hline Parcial & $242(45,7)$ & $146(23,1)$ & $369(53,5)$ & $360(50,2)$ & $443(39,3)$ & $417(36,6)$ & $1977(40,9)$ \\
\hline llegível & 0,0 & $27(4,3)$ & $7(1,1)$ & 0,0 & 0,0 & 0,0 & $34(0,7)$ \\
\hline TOTAL (N) & 530 & 633 & 689 & 717 & 1127 & 1139 & 4835 \\
\hline
\end{tabular}

Ao longo dos anos, notou-se um aumento no uso de siglas para identificação dos diagnósticos clínicos dos pacientes para os quais foi solicitada a avaliação psiquiátrica. No início da década de 80 , a presença de siglas era por volta de $17 \%$ nos Pls e chegou a 32\% entre os anos de 2006 a 2010 (Tabela 4.56).

Tabela 4.56 - Uso de siglas para a identificação dos diagnósticos clínicos nas solicitações psiquiátricas escritas pelos profissionais clínicos para os pacientes de ambos os sexos atendidos pelo serviço de Interconsulta Psiquiátrica entre janeiro de 1981 a dezembro de 2010.

\begin{tabular}{lccccccc} 
& $\mathbf{1 9 8 1 - 1 9 8 5}$ & $\mathbf{1 9 8 6 - 1 9 9 0}$ & $\mathbf{1 9 9 1 - 1 9 9 5}$ & $\mathbf{1 9 9 6 - 2 0 0 0}$ & $\mathbf{2 0 0 1 - 2 0 0 5}$ & $\mathbf{2 0 0 6 - 2 0 1 0}$ & TOTAL \\
\hline USO DE SIGLAS & $\mathbf{N}(\%)$ & $\mathbf{N}(\%)$ & $\mathbf{N}(\%)$ & $\mathbf{N}(\%)$ & $\mathbf{N}(\%)$ & $\mathbf{N}(\%)$ & $\mathbf{N}(\%)$ \\
\hline Não & $438(82,6)$ & $469(75,4)$ & $506(74,0)$ & $530(73,9)$ & $802(71,3)$ & $778(68,1)$ & $3523(73,1)$ \\
Sim & $92(17,4)$ & $153(24,6)$ & $178(26,0)$ & $187(26,1)$ & $323(28,7)$ & $365(31,9)$ & $1298(26,9)$ \\
\hline TOTAL (N) & 530 & 622 & 684 & 717 & 1125 & 1143 & 4821 \\
\hline
\end{tabular}

O registro do nome do profissional solicitante ocorreu na grande maioria das solicitações, assim como a manifestação por escrito de sua expectativa por 
atendimento. E a identificação do interconsultor responsável pelo acompanhamento do paciente ocorreu em quase $94 \%$ dos casos (Tabela 4.57 ).

Tabela 4.57 - Registro do nome do profissional clínico, manifestação por escrito de sua expectativa por atendimento na solicitação psiquiátrica e a identificação do interconsultor responsável pelo atendimento do caso.

\begin{tabular}{lccccccc} 
& \multicolumn{1}{c}{$\mathbf{1 9 8 1 - 1 9 8 5}$} & $\mathbf{1 9 8 6 - 1 9 9 0}$ & $\mathbf{1 9 9 1 - 1 9 9 5}$ & $\mathbf{1 9 9 6 - 2 0 0 0}$ & $\mathbf{2 0 0 1 - 2 0 0 5}$ & $\mathbf{2 0 0 6 - 2 0 1 0}$ & TOTAL \\
\hline REGISTRO DO NOME & $\mathbf{N}(\%)$ & $\mathbf{N}(\%)$ & $\mathbf{N}(\%)$ & $\mathbf{N}(\%)$ & $\mathbf{N}(\%)$ & $\mathbf{N}(\%)$ & $\mathbf{N}(\%)$ \\
\hline Sim & $513(96,8)$ & $614(98,2)$ & $668(96,8)$ & $697(97,1)$ & $1116(98,8)$ & $1136(98,6)$ & $4744(97,9)$ \\
Não & $17(3,2)$ & $11(1,8)$ & $22(3,2)$ & $21(2,9)$ & $13(1,2)$ & $16(1,4)$ & $100(2,1)$ \\
\hline TOTAL (N) & 530 & 625 & 690 & 718 & 1129 & 1152 & 4844 \\
& & & & & & & \\
MANIFESTAÇÃO DA EXPECTATIVA & $\mathbf{N}(\%)$ & $\mathbf{N}(\%)$ & $\mathbf{N}(\%)$ & $\mathbf{N}(\%)$ & $\mathbf{N}(\%)$ & $\mathbf{N}(\%)$ & $\mathbf{N}(\%)$ \\
\hline Sim & $439(83,0)$ & $536(86,2)$ & $574(83,8)$ & $583(81,2)$ & $914(81,1)$ & $922(79,9)$ & $3968(82,1)$ \\
Não & $90(7,0)$ & $86(13,8)$ & $111(16,2)$ & $135(18,8)$ & $213(18,9)$ & $232(20,1)$ & $867(17,9)$ \\
\hline TOTAL (N) & 529 & 622 & 685 & 718 & 1127 & 1154 & 4835 \\
& & & & & & $\mathbf{N}(\%)$ & $\mathbf{N}(\%)$ \\
IDENTIFICAÇÃO DO INTERCONSULTOR & $\mathbf{N}(\%)$ & $\mathbf{N}(\%)$ & $\mathbf{N}(\%)$ & $\mathbf{N}(\%)$ & $\mathbf{N}(\%)$ & $\mathbf{N}(\%)$ & $\mathbf{4}(\%)$ \\
\hline Sim & $481(90,7)$ & $628(99,2)$ & $670(97,2)$ & $650(88,3)$ & $1047(92,5)$ & $1078(94,1)$ & $4554(93,6)$ \\
Não & $49(9,3)$ & $5(0,8)$ & $19(2,8)$ & $86(11,7)$ & $85(7,5)$ & $67(5,9)$ & $311(6,4)$ \\
\hline TOTAL (N) & 530 & 633 & 689 & 736 & 1132 & 1145 & 4865 \\
\hline
\end{tabular}

O aspecto geral do PI foi considerado bom em $8,4 \%$ dos documentos analisados segundo as recomendações preconizadas por Arriba et al. (2000), 81\% dos documentos foram considerados aceitáveis e 10,6\%, ruins. Pode-se dizer, de maneira geral, que houve uma melhora na qualidade dos Pls ao longo dos trinta anos do serviço de Interconsulta, uma vez que, quando comparadas as décadas de 80 e de 2000 , os Pls considerados bons quintuplicaram de frequência.

Já o aspecto geral da resposta ao PI foi considerado bom em $24,4 \%$ dos documentos analisados, $54,1 \%$ foram considerados aceitáveis e $21,5 \%$, ruins. Quando comparadas as décadas de 80 e 2000, houve um aumento considerável dos 
Pls classificados como bons, passando de 2,5 para $68,8 \%$ dos documentos analisados, e redução dos classificados como ruins, passando de $47,6 \%$ nos anos 80 para 8,9\% em 2010 (Tabela 4.58).

Tabela 4.58 - Aspectos gerais da solicitação psiquiátrica feita pelo profissional clínico e de sua resposta escrita feita pelo interconsultor.

\begin{tabular}{lccccccc} 
& $\mathbf{1 9 8 1 - 1 9 8 5}$ & $\mathbf{1 9 8 6 - 1 9 9 0}$ & $\mathbf{1 9 9 1 - 1 9 9 5}$ & $\mathbf{1 9 9 6 - 2 0 0 0}$ & $\mathbf{2 0 0 1 - 2 0 0 5}$ & $\mathbf{2 0 0 6 - 2 0 1 0}$ & TOTAL \\
\hline \multicolumn{1}{c}{ ASPECTO DA SOLICITAÇÃO } & $\mathbf{N}(\%)$ & $\mathbf{N}(\%)$ & $\mathbf{N}(\%)$ & $\mathbf{N}(\%)$ & $\mathbf{N}(\%)$ & $\mathbf{N}(\%)$ & $\mathbf{N}(\%)$ \\
\hline Bom & $17(3,2)$ & $16(2,6)$ & $36(5,2)$ & $56(7,8)$ & $106(9,4)$ & $173(15,1)$ & $404(8,4)$ \\
Aceitável & $431(81,3)$ & $533(85,7)$ & $590(85,5)$ & $598(83,3)$ & $897(79,7)$ & $864(75,4)$ & $3913(81,0)$ \\
Ruim & $80(15,5)$ & $73(11,7)$ & $64(9,3)$ & $64(8,9)$ & $123(10,9)$ & $109(9,5)$ & $513(10,6)$ \\
\hline TOTAL (N) & 528 & 622 & 690 & 718 & 1126 & 1146 & 4830 \\
& & & & & & & \\
ASPECTO DA RESPOSTA & $\mathbf{N}(\%)$ & $\mathbf{N}(\%)$ & $\mathbf{N}(\%)$ & $\mathbf{N}(\%)$ & $\mathbf{N}(\%)$ & $\mathbf{N}(\%)$ & $\mathbf{N}(\%)$ \\
\hline $\begin{array}{l}\text { Bom } \\
\text { Aceitável }\end{array}$ & $12(2,5)$ & $15(2,4)$ & $63(9,4)$ & $84(11,6)$ & $211(19,2)$ & $766(68,8)$ & $1151(24,4)$ \\
Ruim & $244(49,9)$ & $356(57,9)$ & $421(62,6)$ & $555(76,6)$ & $725(65,9)$ & $248(22,3)$ & $2549(54,1)$ \\
\hline TOTAL (N) & $233(47,6)$ & $244(39,7)$ & $188(28,0)$ & $85(11,8)$ & $163(14,9)$ & $100(8,9)$ & $1013(21,5)$ \\
\hline
\end{tabular}


De acordo com o encontrado na literatura, pode-se dizer que este foi 0 primeiro estudo longitudinal a analisar consecutivamente trinta anos (de janeiro de 1981 a dezembro de 2010) e também toda a população assistida por um serviço de Interconsulta Psiquiátrica. Somente dois estudos analisaram dez anos consecutivos (ABUMADINI; RAHIM, 2002; DIEFENBACHER; STRAIN, 2002).

O uso de protocolo de registro, em especial o PRISMe, se mostrou eficiente e seu uso promissor em pesquisas, pois houve um aumento considerável no fornecimento de informações, inclusive, no registro de particularidades do próprio atendimento que muitas vezes não são mencionadas nos prontuários dos pacientes (como, por exemplo, se o paciente foi avisado pela equipe solicitante a respeito do atendimento do interconsultor e se este foi avisado da alta hospitalar do paciente, entre outros aspectos). Neste sentido, destaque-se o estudo desenvolvido por Nakabayashi et al. (2010) em que o PRISMe foi utilizado em dois hospitais universitários brasileiros - no próprio HCFMRP-USP e no Hospital Universitário Professor Polydoro Ernani de São Thiago da Universidade Federal de Santa Catarina (HUUFSC) - nos períodos entre agosto de 2005 a dezembro de 2007 no HCFMRP-USP e entre janeiro a dezembro de 2007 no HU-UFSC. Foi possível comparar os dados obtidos nos dois hospitais e evidenciar as diferenças e semelhanças entre os serviços de Interconsulta Psiquiátrica. E, em relação ao uso do PRISMe, a aplicabilidade do protocolo se mostrou viável e seu uso oportuno em futuras investigações em diferentes serviços de Interconsulta.

No presente estudo, apesar do impacto positivo do PRISMe no registro de informações, ainda foram omitidos muitos dados a respeito das características sociodemográficas e do histórico dos pacientes atendidos (em especial a respeito das 
tentativas de suicídio), assim como dados sobre o uso do serviço de Interconsulta (datas da admissão hospitalar, da alta hospitalar, do atendimento e do próprio PI para o cálculo dos tempos de internação, de solicitação e de resposta) e de outros aspectos. As ausências ou perdas de informações ocorridas no presente estudo, de maneira geral, também foram abordadas por diversos estudos desenvolvidos no contexto nacional (ANDREOLI et al., 1996; BOTEGA, 2006; SILVA; OLIVEIRA; IDE, 2011).

Em 1996, Andreoli et al. relataram a experiência de padronização e informatização do registro de atendimento no serviço de Interconsulta do Departamento de Psiquiatria e Psicologia Médica da Universidade Federal de São Paulo (UNIFESP) e também observaram muita omissão de dados e do próprio registro dos casos, e sugeriram que apresentar as informações obtidas para os profissionais do serviço de Interconsulta, isto é, aqueles que preencheram os protocolos de registro, poderia ser uma estratégia para criar um senso de responsabilidade e comprometimento com o registro dos atendimentos.

Em relação às limitações encontradas, por se tratar de um estudo de caráter retrospectivo e longitudinal de trinta anos, muitos dados não puderam ser obtidos, o que reduz, portanto, a capacidade de retratar de forma mais precisa o funcionamento do serviço de Interconsulta e as características da população atendida, considerando, inclusive, as mudanças sofridas ao longo de três décadas.

Da mesma forma, pelo aspecto retrospectivo do estudo, não foi possível a aplicação de instrumentos e entrevistas para a confirmação dos diagnósticos psiquiátricos, bem como o uso de escalas e inventários para mensurar a gravidade do quadro clínico e avaliar os prejuízos funcionais e/ou sintomas psiquiátricos dos pacientes no momento da admissão hospitalar e no decorrer de sua internação. Assim, não foi possível investigar, de forma mais apurada, a relação entre diagnósticos e 
complicações clínicas e transtornos psiquiátricos, dos diagnósticos e tempo de internação e de solicitação, entre outros aspectos.

\subsection{TAXAS DE ENCAMINHAMENTO}

Observou-se que número de solicitações psiquiátricas aumentou ao longo dos anos, assim como observado em outros estudos sobre o funcionamento do serviço de Interconsulta (MILLAN et al., 1986; TAPIA; EVA; Ortiz, 1997; ROTHENHÄUSLER; EHRENTRAUT; KAPFHAMMER, 2001; DEVASAGAYAM; CLARKE, 2008). Tal fato pode estar relacionado ao aumento da própria demanda hospitalar no HCFMRPUSP, cujo número de internações aumentou 50\% entre janeiro de 1981 a dezembro de 2010, como pelo aumento da frequência de atendimentos de pacientes mais idosos ao longo dos anos que, segundo a literatura, são mais comuns de desenvolverem algum transtorno psiquiátrico (SCHELLHORN et al., 2009) e também ser indício de uma maior aceitabilidade do serviço de Interconsulta dentro do hospital - muitos autores atribuíram ao aumento no número de solicitações o próprio impacto positivo do serviço de Interconsulta na dinâmica hospitalar (VAZ; SALCEDO, 1996; ALHAMAD et al., 2004).

As taxas de encaminhamento obtidas no HCFMRP-USP apresentaram um aumento discreto ao longo dos anos (de 0,7\% na década de 80 para 1,0\% em 2010) e estão de acordo com a obtida pelo estudo longitudinal de Diefenbacher e Strain (2002), que foi de 1,2\% ao longo dos dez anos analisados (o estudo de ADUMADINI 
e RAHIM, 2002, não informou este dado). Importante ressaltar, também, que as taxas de encaminhamento do HCFMRP-USP foram similares às reportadas na literatura nacional (MILLAN et al., 1986; ANDREOLI et al., 1996; SMAIRA; KERRCORRÊA; CONTEL, 2003) e internacional (HATTORI, 1985; ZUO; YANG; CHU, 1985; LUCAS; DOYLE, 1995; OZKAN et al., 1995; AGHANWA; MORAKINYO; AINA, 1996; GALA et al., 1999; SALVO; CASTRO, 2003), apesar de que ainda inferiores a de países como os Estados Unidos, que apresentaram taxas de encaminhamento entre 2 a 6\% (McKEGNEY; McMAHON; KING, 1983; HALES et al., 1986; KUHN et al., 1986; COLLINS; DIMSDALE; WILKINS, 1992; GRANT; MELLER; UREVIG, 2001; DHOSSCHE; LORANT, 2002; KISHI et al., 2004; BOURGEOIS et al.; 2005; SCHELLHORN et al.; 2009; TENNEN; RUNDELL; STEVENS, 2009).

Em relação ao contexto internacional, nos estudos desenvolvidos na década de 80 , foram atribuídos às baixas taxas de encaminhamento os seguintes fatores: a infraestrutura precária do serviço de Interconsulta por ainda estar em fase de instalação em boa parte dos hospitais gerais (HENGEVELD; ROOYMANS; BERGH, 1984; BROWN; COPPER, 1987), a não identificação dos psiquiatras como membros da comunidade médica e o fato de que clínicos e cirurgiões acreditarem ter habilidades para detectar e lidar com aspectos psiquiátricos dos seus pacientes não necessitando encaminhá-los a uma assistência mais especializada (MALHOTRA; MALHOTRA, 1984), além da resistência dos médicos clínicos ao tratamento psiquiátrico (BROWN; COPPER, 1987).

Na década de 90, mesmo com diversos estudos sobre o tema e um aumento na divulgação do papel do interconsultor no hospital geral, muitos estudos ainda reportaram baixas taxas de encaminhamento ao serviço de Interconsulta. Tal fato foi atribuído à falha dos médicos clínicos e cirurgiões em reconhecer os transtornos 
psiquiátricos pela falta de conhecimento e pessimismo quanto à intervenção psiquiátrica, além de alegarem preocupação quanto à reação não favorável por parte do paciente quanto a um tratamento deste tipo (NEEHALL; PSYCH; BEHARRY, 1993; LUCAS; DOYLE, 1995; OZKAN et al., 1995; AGHANWA; MORAKINYO; AINA, 1996). Segundo Magdaleno Jr e Botega (1991) e Toro, Lizama e Seguel (1994), os médicos clínicos tenderam a solicitar avaliação somente em casos bem definidos ou de difícil manejo. E Gala et al. (1999) atribuíram à baixa taxa de encaminhamento $(0,7 \%)$ as diferenças na organização, seja estrutural ou administrativa, dos hospitais que participaram de seu estudo multicêntrico, o que reforçaria, também, a dificuldade em desenvolver estudos comparativos entre diferentes países e culturas.

Já os estudos da última década constataram que, apesar de mais de três décadas de Interconsulta Psiquiátrica, muitos serviços ainda não tinham infraestrutura adequada (HUYSE et al., 2001; ARBABI et al., 2012), tal como o número limitado de profissionais interconsultores (DHOSSCHE; LORANT, 2002), o que poderia estar relacionado à baixa taxa de encaminhamento aos serviços. Este fato também foi relacionado, por muitos autores, às primeiras hipóteses levantadas na década de 80, em que o serviço de Interconsulta ainda não era reconhecido como uma unidade profissional inserida no hospital geral (HUYSE et al., 2001; AGHANWA, 2002). Também foram levantadas hipóteses relacionadas à curta duração da internação e consequente impossibilidade de detectar sintomas psiquiátricos (HUYSE et al, 2001).

Em contexto nacional, Millan et al. (1986) atribuíram à baixa taxa de encaminhamento questões relacionadas à localização geográfica do serviço na época, à falta de divulgação da existência do grupo de Interconsulta, à descrença dos médicos em relação à atuação do psiquiatra e ao não conhecimento, por parte do médico clínico, de alterações psiquiátricas que necessitam de atendimento especializado, 
fatores que também foram considerados pela literatura internacional.

Aqueles estudos que apresentaram taxas de encaminhamento maiores que 3\% atribuíram ao fato aspectos muito específicos do serviço de Interconsulta, tais como o contexto hospitalar (no caso do estudo de HALES et al., 1986, por exemplo, por ser um hospital militar, o custo da internação dos pacientes não era debitado dos mesmos, o que proporcionava, assim, uma certa liberdade na escolha do tratamento) e os tipos de paciente atendidos, como, por exemplo, os com tentativa de suicídio e envenenamento que possivelmente inflacionaram a procura pela avaliação do interconsultor (SRINIVASAN et al., 1987; FIDO; MUGHAISSED, 1988; CLARKE; SMITH, 1995). No caso da investigação liderada por Bourgeois et al. (2005) em um hospital universitário, os autores atribuíram à taxa de encaminhamento relativamente alta $(4,2 \%)$ os investimentos administrativos do próprio hospital no serviço de Interconsulta, especialmente o suporte financeiro.

De maneira geral, as taxas de encaminhamento mais elevadas obtidas em diversos estudos desenvolvidos em diferentes países não necessariamente retrataram uma tendência a um melhor desempenho dos clínicos, cirurgiões e outros profissionais em reconhecer as comorbidades psiquiátricas ou até mesmo um melhor funcionamento e maior aceitação dos serviços de Interconsulta, pois tais taxas foram atribuídas a fatores específicos de atendimento e aspectos administrativos e financeiros segundo os estudos.

Considerando os trinta anos de serviço de Interconsulta no HCFMRP-USP, apesar do discreto aumento das taxas de encaminhamento ao longo dos anos, estas foram baixas mesmo após todo o desenvolvimento do serviço de Interconsulta através da ampliação da equipe de interconsultores e da contratação de psicólogos e terapeutas ocupacionais, além de melhorias na infraestrutura do serviço e da adap- 
tação do próprio hospital (como, por exemplo, a formalização da solicitação de atendimento via documento padronizado para todo o HCFMRP-USP).

Outro fato que pode estar relacionado às baixas taxas de encaminhamento no HCFMRP-USP é a divisão física e do tipo de assistência oferecida pelo hospital, localizado no campus da Universidade de São Paulo na zona oeste da cidade de Ribeirão Preto, e pela Unidade de Emergência, localizada no centro da cidade. Por exemplo, pacientes com tentativa de suicídio e envenenamento, que segundo achados na literatura (SRINIVASAN et al., 1987; FIDO; MUGHAISSED, 1988; CLARKE; SMITH, 1995) foram atendidos em maior frequência pelos serviços de Interconsulta e possivelmente colaboraram para o aumento da taxa de encaminhamento, no contexto do presente estudo, em um primeiro momento, são atendidos pela Unidade de Emergência e depois, caso sendo necessária uma assistência mais complexa, são encaminhados ao HCFMRP-USP. Portanto, pacientes com este tipo de acometimento são assistidos em menor frequência dentro do hospital, o que talvez tenha refletido nas taxas de encaminhamento.

De maneira geral, considerando que prevalência de transtornos psiquiátricos em hospitais gerais pode variar de 20 a $40 \%$ das internações no contexto nacional e internacional (GELFAND; KIELY, 1980; MAYOU; HAWTON, 1986; SELTZER, 1989; LEUNG; CHAN; CHENG, 1992; BOTEGA et al., 1995; SILVERSTONE, 1996; HANSEN et al., 2001) e de 20 a 30\% de prevalência em amostras representativas da população brasileira (MORGADO; COUTINHO, 1985; ANDRADE et al., 2012), pode-se especular que ainda exista uma enorme demanda reprimida para atendimento psiquiátrico dentro do HCFMRP-USP.

Para compreender melhor os motivos pelos quais muitos pacientes internados (e possivelmente com transtornos psiquiátricos) não foram atendidos, Torem, 
Saravay e Steinberg (1979) desenvolveram um estudo no hospital geral com duração de seis meses em duas unidades médicas. O departamento médico deste hospital era conhecido por ter uma visão mais holística do paciente e com uma prática com ênfase em aspectos psicológicos das doenças. Foram estabelecidos, então, duas condutas da equipe a serem avaliadas: a primeira que os autores denominaram de "reativa", que era comumente empregada pelo hospital (os pacientes eram tratados pelas equipes de médicos e enfermeiros e estes se reuniam semanal ou quinzenalmente para discutir com o psiquiatra residente aspectos psiquiátricos de seus interesses); e a segunda, denominada como "ativa" e proposta por um dos autores do estudo, que estabelecia semanalmente visitas às enfermarias e discussão ficha a ficha dos pacientes para avaliar sua evolução entre o psiquiatra e as equipes de médicos e enfermeiros.

Os autores encontraram que apenas $2 \%$ dos pacientes foram encaminhados pela conduta reativa, enquanto que, pela conduta ativa, $20 \%$ dos pacientes internados tiveram que receber assistência psiquiátrica. Outro aspecto interessante foi que, com a conduta ativa, o número de transtornos mentais orgânicos que foi diagnosticado corretamente pelos médicos clínicos aumentou significativamente. Vale ressaltar que as duas unidades envolvidas na investigação de Torem, Saravay e Steinberg (1979) tinham cerca de 30 leitos, o que sugere que esta técnica pode ser mais efetiva em um número reduzido de pacientes que são ativamente acompanhados.

Neste mesmo sentido, Desan et al. (2011) encontraram evidências de que uma postura mais ativa do próprio serviço de Interconsulta facilitaria o cuidado médico do paciente e reduziria o tempo de internação.

Já em relação à enfermagem, Lipowski e Wolston (1981) encontraram evidências de que a atuação da enfermagem melhora a identificação de sintomas 
psiquiátricos e também o tratamento das comorbidades psiquiátricas pelo fato do contato direto e constate com os pacientes. Achados de Silverstone (1996) reforçam as evidências de Lipowski e Wolston (1981) ao observarem em seu estudo que a equipe de enfermagem apresentou um melhor desempenho em detectar possíveis comorbidades psiquiátricas enquanto que a taxa de reconhecimento por parte dos médicos clínicos foi extremamente baixa, assim como relatado em outros estudos (MAGUIRE et al., 1974, apud SILVERSTONE, 1996; DePAULO; FOLSTEIN, 1978, apud SILVERSTONE, 1996; BRODY, 1980, apud SILVERSTONE, 1996; NIELSEN; WILLIAMS, 1980, apud SILVERSTONE, 1996; BRIDGES; GOLDBERG, 1984, apud SILVERSTONE, 1996; NABARRO, 1984, apud SILVERSTONE, 1996; FELDMAN et al., 1987, apud SILVERSTONE, 1996; SHIELL; SHIELL, 1991, apud SILVERSTONE, 1996).

Magdaleno Jr e Botega (1991) verificaram uma taxa de encaminhamento mais elevada e levantaram algumas hipóteses para o fato: estimulação, através de grupos Balint (BALINT, 1973), da valorização do vínculo emocional por parte dos clínicos que atendem na enfermaria geral proporcionando, assim, familiaridade com os aspectos psíquicos dos pacientes (o que aumentaria o encaminhamento ao psiquiatra). Tal aspecto está de acordo com o defendido por Malhotra e Malhotra (1984) e Huyse et al. (2001). Segundo estes autores, melhorias na organização dos serviços de Interconsulta, maior interação entre psiquiatras e clínicos, maior treinamento dos residentes de todas as clínicas para aprimorar o reconhecimento de sintomas psiquiátricos, além de uma ampla divulgação da importância da atuação do interconsultor, poderiam aumentar as taxas de encaminhamento para os serviços.

No caso do HCFMRP-USP, uma saída para elevar a detecção e encaminhamento ao psiquiatra seria propor uma ação mais ativa por parte do corpo clínico, seja com o uso de instrumentos para avaliação psiquiátrica de aplicação breve pelos 
médicos (como, por exemplo, a Escala Hospitalar de Ansiedade e Depressão HAD, desenvolvida por ZIGMOND e SNAITH, 1983) e também uma postura mais investigativa quanto ao histórico do paciente, seja com uma atenção mais voltada às possíveis alterações psiquiátricas dos pacientes por parte da enfermagem, uma vez que esta tem um contato mais frequente e diário.

Também se mostra pertinente um maior treinamento dos residentes e da enfermagem de todas as clínicas quanto ao reconhecimento das comorbidades psiquiátricas, assim como promover uma maior interação entre tais profissionais com psiquiatras.

\subsection{CARACTERIZAÇÃO SOCIODEMOGRÁFICA E HISTÓRICO EM SAÚDE MENTAL DOS PACIENTES}

Evidências encontradas por Lipowski e Wolston (1981) e Rothenhäusler, Ehrentraut e Kapfhammer (2001) demonstraram que os dados sociodemográficos tenderam a permanecer estáveis ao longo dos anos, o que também foi observado em algumas características sociodemográficas da população investigada no presente estudo.

Em relação aos óbitos na população assistida pela Interconsulta Psiquiátrica no HCFMRP-USP, algumas ressalvas precisam ser feitas. Por se tratar de um estudo longitudinal de trinta anos, para obtenção deste dado, o registro de cada paciente foi consultado no sistema interno do hospital e não foi possível ter conhecimento, nos casos mais antigos, se o paciente faleceu durante a internação ou em um momento posterior. Portanto, não foi possível investigar mais detalhadamente a 
mortalidade dos pacientes assistidos pela Interconsulta.

A maioria das solicitações foi feita para pacientes do sexo feminino, o que também está de acordo com os resultados encontrados no Brasil (MAGDALENO JR; BOTEGA, 1991; CARVALHO et al., 1993; ANDREOLI et al., 1996) e em diversos países como Alemanha (DIEFENBACHER, 2001; ROTHENHÄUSLER; EHRENTRAUT; KAPFHAMMER, 2001;), Austrália (CARR et al., 1997; DEVASAGAYAM; CLARKE, 2008), Canadá (PÉREZ; SILVERMAN, 1983), China (ZUO; YANG; CHU, 1985), Espanha (NEEHALL; PSYCH; BEHARRY, 1993; VALDÉS et al., 2000), Estados Unidos (LIPOWSKI; WOLSTON, 1981; McKEGNEY; McMAHON; KING, 1983; ORMONT et al., 1997; GRANT; MELLER; UREVIG, 2001; KISHI et al., 2004; SCHELLHORN et al., 2009), Grécia (CHRISTODOULOU et al., 2008), Holanda (HENGEVELD; ROOYMANS; BERGH, 1984; DE JONGE et al., 2000), Inglaterra (CHANDARANA; CONLON; STEINBERG, 1988; CREED et al., 1993; MAYOU; SIMKIN; COBB, 1994), Irã (YASSINI et al., 2011; ARBABI et al., 2012), Irlanda (SCHOFIELD; DOONAN; DALY, 1986), Israel (SOBEL; MUNITZ; KARP, 1988), Itália (FAVA; PAVAN, 1980; GALA et al., 1999), Kuwait (FIDO; MUGHAISSED, 1988), Japão (HATTORI, 1985), Singapura (TSOI; KOK, 1983; PEH; TAY, 1990) e Turquia (OZKAN et al., 1995).

Segundo a maioria dos autores, este fato pode estar relacionado à população assistida pelo hospital, à política de atendimento da instituição, à distribuição de mais mulheres na população do país e à sua cultura. No estudo de Nehall, Psych e Beharry (1993), por exemplo, foi evidenciada uma alta frequência de pacientes com tentativa de suicídio, sendo que muitos deles eram do sexo feminino e foram avaliados pelos interconsultores, pois a política do hospital recomendava avaliação psiquiátrica para todo paciente com tentativa de suicídio. Desta forma, poder-se-ia esperar 
uma frequência maior de solicitações feitas para pacientes do sexo feminino. Este mesmo fato também foi relatado por Hengeveld, Rooymans e Bergh (1984) e por Doongaji, Nadkarni e Bhatawdekar (1989) em seus estudos.

Já no HCFMRP-USP, tal predominância do sexo feminino pode refletir o maior número de internação deste sexo no hospital (aproximadamente 60\%), a própria população brasileira (que tem prevalência de mulheres, em especial na região sudeste do Brasil) e também estar relacionada a um aspecto manifestado pelo próprio sexo feminino: maior capacidade e facilidade de comunicar suas inquietudes psicológicas e ansiedade (CRAIG, 1982; AGHANWA, 2002; BOTEGA, 2006). Importante ressaltar também que a Ginecologia e Obstetrícia foi responsável por 6,4\% ( $\mathrm{N}=314)$ de todas as solicitações, uma clínica exclusivamente de pacientes do sexo feminino, o que contribuiu para uma maior frequência total deste sexo.

Por ser um estudo longitudinal que analisou uma população, no caso a população atendida pelo serviço de Interconsulta Psiquiátrica do HCFMRP-USP, optou-se por investigar separadamente os pacientes do sexo feminino e do sexo masculino. Infelizmente, na literatura, não foi encontrado nenhum estudo com este tipo de consideração, comprometendo, desta forma, a comparabilidade dos dados obtidos no presente estudo com a literatura.

Com maior frequência, foi solicitado atendimento para pacientes entre 21 a 50 anos de ambos os sexos, fato este possivelmente relacionado à própria população atendida pelo HCFMRP-USP, cuja grande maioria tem idade entre 16 a 60 anos. Contudo, esta frequência também foi observada em estudos internacionais (FAVA; PAVAN, 1980; RIES et al., 1980; LIPOWSKI; WOLSTON, 1981; PÉREZ; SILVERMAN, 1983; HENGEVELD; ROOYMANS; BERGH, 1984; BROWN; COOPER, 1987; SOBEL; MUNITZ; KARP, 1988; DHAVALE; BARVE, 1990; PEH; 
TAY, 1990; NEEHALL; PSYCH; BEHARRY, 1993; AGHANWA; MORAKINYO; AINA, 1996; ROTHENHÄUSLER; EHRENTRAUT; KAPFHAMMER, 2001; AGHANWA, 2002; DHOSSCHE; LORANT, 2002) e nacionais (KERR-CORRÊA; SILVA, 1985; MAGDALENO JR; BOTEGA, 1991; SOUZA, 1995).

Autores como Dhavale e Barve (1990), Aghanwa, Morakinyo e Aina (1996), Aghanwa (2002) levantaram algumas hipóteses para a explicação dessa frequência: características da própria distribuição populacional dos países (no caso do presente estudo, o aumento gradual da idade média da população assistida pelo SISMen pode estar relacionado ao aumento da própria expectativa de vida que, na década de 80 , era 62,6 anos e passou a ser 73,5 anos em 2010 , segundo dados publicados nas Tábuas de Mortalidade pelo Instituto Brasileiro de Geografia e Estatística, IBGE) e maior tendência de adultos a reagir com emoções alteradas perante a ocorrência de doenças clínicas e o tratamento. Estudos que apresentaram maior frequência de tentativas de suicídio apresentaram também maior frequência de pacientes entre 15 a 40 anos, uma vez que tal comportamento seria mais incidente nesta faixa etária (SOBEL; MUNITZ; KARP, 1988).

Assim como reportado na literatura (RIES et al., 1980; KERR-CORRÊA; SILVA, 1985; KUHN et al., 1986; ANDREOLI et al., 1996; GRANT; MELLER; UREVIG, 2001; DHOSSCHE; LORANT, 2002), a grande maioria dos pacientes assistidos pelo serviço de Interconsulta Psiquiátrica do HCFMRP-USP foi caucasiana, o que é compatível com a etnia mais frequente na região sudoeste do Brasil (Censo Demográfico, IBGE, 2010), onde o HCFMRP-USP é localizado.

Em relação ao estado civil, foram atendidos predominantemente pacientes casados e solteiros ao longo das décadas, o que também está de acordo com a literatura internacional (FAVA; PAVAN, 1980; PÉREZ; SILVERMAN, 1983; CREED 
et al., 1993; CARR et al., 1997; GALA et al., 1999; CHRISTODOULOU et al., 2008; ARBABI et al., 2012) e nacional (KERR-CORRÊA; SILVA, 1985; MAGDALENO JR; BOTEGA, 1991; ANDREOLI et al., 1996). Apenas dois estudos investigaram com quem os pacientes moravam na época do atendimento (HUYSE; STRAIN; HAMMER, 1990; DIEFENBACHER; STRAIN, 2002), no caso cônjuges e filhos; e vivendo sozinho foram os mais encontrados (e no presente estudo, pacientes residindo com cônjuges e filhos, e com pais).

A respeito da situação laboral, as mulheres foram mais frequentemente responsáveis pelo cuidado da casa, fato este também encontrado em muitos estudos (FAVA; PAVAN, 1980; (KERR-CORRÊA; SILVA, 1985; CARR et al., 1997; AGHANWA, 2002; YASSINI et al., 2011) e relacionado ao predomínio do sexo feminino na população atendida no presente estudo. A respeito dos homens, o afastamento do trabalho foi a situação laboral mais frequentemente alegada nos pacientes atendidos no HCFMRP-USP e também em alguns estudos (HUYSE; STRAIN; HAMMER, 1990; CLARKE; SMITH, 1995; ANDREOLI et al., 1996; CARR et al., 1997; KISHI et al., 2004), o que poderia estar relacionado à condição de saúde marcada pela gravidade ou cronicidade do quadro clínico e/ou psiquiátrico dos pacientes.

Pode-se dizer que os dados referentes ao reduzido nível de escolaridade dos pacientes atendidos pelo serviço de Interconsulta do HCFMRP-USP representam um recorte da realidade da população do Brasil (Censo Demográfico, IBGE, 2010), em que metade da população total (em torno de 81 milhões de habitantes de um total de quase 162 milhões de brasileiros) ou é analfabeto ou tem o ensino fundamental incompleto. Mais especificadamente dos pacientes assistidos pelo hospital, a maioria não possui condições econômicas e sociais favoráveis, e muitos deles provêm de uma região caracterizada pela agroindústria canavieira cujos trabalhos rurais 
são muito frequentes. Vale ressaltar também que o HCFMRP-USP realiza poucos atendimentos particulares e de outros convênios, portanto, assiste indivíduos desprovidos de maiores recursos econômicos, fato que normalmente está relacionado com o nível de escolaridade. Contudo, apesar da reduzida escolaridade encontrada nos pacientes poder estar relacionada às características da população brasileira, esta mesma característica também foi reportada por muitos estudos (FAVA; PAVAN, 1980; CLARKE; SMITH, 1995; GALA et al., 1999; GRANT; MELLER; UREVIG, 2001; YASSINI et al., 2011).

Em grande maioria, os pacientes procederam de municípios do Estado de São Paulo. Uma possível explicação para este achado é o fato do HCFMRP-USP ser um hospital universitário predominantemente de nível assistencial terciário, cujo atendimento é livre a qualquer paciente da rede de saúde pública que necessite de serviços de alta complexidade e procedimentos médicos especializados. Sendo assim, são atendidos pacientes de todo o estado de São Paulo e também de outros estados brasileiros.

Houve uma perda de quase um terço do total dos dados a respeito dos antecedentes em atendimento e internação psiquiátrica dos pacientes avaliados, 0 que afetou nos resultados encontrados devido à possível valorização da informação quando esta foi positiva.

Estudos que avaliaram antecedentes psiquiátricos dos pacientes considerando os últimos cinco anos obtiveram frequências de 54 a $58 \%$ de casos positivos (GALA et al., 1999; HUYSE et al., 2001), sendo que aqueles que avaliaram os antecedentes sem critérios de tempo encontraram frequências que variaram de 17 a 75\% (CHANDARANA; CONLON; STEINBERG, 1988; HUYSE; STRAIN; HAMMER, 1990; NEEHALL; PSYCH; BEHARRY, 1993; DE JONGE et al., 2000; VALDÉS et al., 
2000; KISHI et al., 2004; KISHI et al., 2007; SCHELLHORN et al., 2009).

Andreoli et al. (1996) avaliaram os pacientes atendidos pelo serviço de Interconsulta de um hospital-escola e encontraram uma frequência de $32 \%$ de pacientes com antecedentes psiquiátricos, isto é, metade da frequência encontrada no presente estudo (que foi de $76,4 \%$ no sexo feminino e $71,5 \%$ no sexo masculino). Frequência semelhante à encontrada por Andreoli et al. (1996) foi obtida por Terroni, Silva e Estevão (2003) no trabalho realizado no Hospital do Servidor Público Estadual "Francisco Morato de Oliveira".

Este achado possivelmente pode estar relacionado a três fatores: a) pacientes com comorbidades psiquiátricas já no momento de admissão hospitalar tendem a ser reinternados (MAYOU, 1991; SARAVAY et al., 1996); b) os pacientes com determinados quadros clínicos podem estar mais susceptíveis a desencadear um transtorno psiquiátrico e também a serem mais reinternados; e c) os profissionais do HCFMRP-USP tenderam a registrar a informação apenas para os pacientes que já tiveram algum histórico psiquiátrico, ficando omissos os casos sem antecedentes, como ressaltado anteriormente. Este último fator é sustentado pelo resultado obtido após a implementação dos protocolos de registro, em especial o PRISMe, pois foi observado, a partir de 2006, que $68,4 \%$ das mulheres e $57,9 \%$ dos homens apresentaram antecedentes psiquiátricos (e a ausência da informação foi de $8 \%$ para as mulheres e $10,6 \%$ para os homens) contra $97,9 \%$ das mulheres e $92 \%$ dos homens com antecedentes psiquiátricos no início da década de 80 (e com ausência da informação em $54,1 \%$ das mulheres e $55,4 \%$ dos homens).

Em relação às tentativas de suicídio, este dado foi perdido em mais de $70 \%$ de todos os pacientes assistidos pela Interconsulta, podendo esta ausência estar relacionada à própria omissão dos casos em que os pacientes não tentaram suicídio 
- observou-se uma relação inversa entre a frequência de pacientes com tentativa de suicídio e a ausência desse dado. A partir de 2006, a ausência foi de aproximadamente $30 \%$ e a frequência de pacientes com histórico de tentativa foi de $23,1 \%$ para as mulheres e 15,8\% para os homens (o oposto do que foi encontrado no fim da década de 90, em que todos os pacientes cuja informação era disponível tentaram suicídio - sendo a informação ausente em mais de $90 \%$ de todos os casos). Considerando a literatura internacional, apenas dois estudos informaram este dado dentro do contexto do hospital geral e Interconsulta Psiquiátrica (VALDÉS et al., 2000, relataram que $14,7 \%$ dos pacientes atendidos tentaram suicídio e SCHELLHORN et al., 2009, em 3,4\% dos casos não geriátricos).

\subsection{USO DO SERVIÇO DE INTERCONSULTA PSIQUIÁTRICA}

A respeito das clínicas solicitantes, a mais frequente foi a Clínica Médica, fato este bem estabelecido em estudos desenvolvidos em diversos países na década de 80 (FAVA; PAVAN, 1980; RIES et al., 1980; CRAIG, 1980; LIPOWSKI; WOLSTON, 1981; McKEGNEY; McMAHON; KING, 1983; PÉREZ; SILVERMAN, 1983; HENGEVELD; ROOYMANS; BERGH, 1984; HATTORI, 1985; ZUO; YANG; CHU, 1985; HALES et al., 1986; SRINIVASAN et al., 1987; CHANDARANA; CONLON; STEINBERG, 1988), na década de 90 (DHAVALE; BARVE, 1990; CREED et al., 1993; NEEHALL; PSYCH; BEHARRY, 1993; MAYOU; SIMKIN; COBB, 1994; TORO; LIZAMA; SEGUEL, 1994; LUCAS; DOYLE, 1995; OZKAN et al., 1995; AGHANWA; 
MORAKINYO; AINA, 1996; REBOLLEDO et al., 1996; VAZ; SALCEDO, 1996; TAPIA; EVA; ORTIZ, 1997; GALA et al., 1999), na última década (VALDÉS et al., 2000; DIEFENBACHER, 2001; GRANT; MELLER; UREVIG, 2001; ROTHENHÄUSLER; EHRENTRAUT; KAPFHAMMER, 2001; DHOSSCHE; LORANT, 2002; AGHANWA, 2002; DIEFENBACHER; STRAIN, 2002; SALVO; CASTRO , 2003; KISHI et al., 2004; ALHAMAD et al., 2006; KISHI et al., 2007; DEVASAGAYAM; CLARKE, 2008; YASSINI et al., 2011) e no Brasil (MAGDALENO JR; BOTEGA, 1991; ANDREOLI et al., 1996).

Algumas hipóteses foram levantadas para a explicação desse achado. Muitos autores (HENGEVELD; ROOYMANS; BERGH, 1984; MILLAN et al., 1986; SPINELLI; TOLEDO; CANTINELLI, 1996; DHAVALE; BARVE, 1990; OZKAN et al., 1995; ROTHENHÄUSLER; EHRENTRAUT; KAPFHAMMER, 2001; KISHI et al., 2004; ALHAMAD et al., 2006) atribuíram tal fato à possível receptividade por parte dos médicos clínicos ao trabalho do interconsultor ser maior quando comparada com outras especialidades (em especial os cirurgiões), provavelmente por terem em seu cotidiano mais intimidade com pacientes com transtorno psiquiátrico.

Outros estudos consideraram características da população atendida pelo hospital para uma possível explicação da frequência da Clínica Médica, tais como as tentativas de suicídio serem atendidas por esta clínica (NEHALL; PSYCH; BEHARRY, 1993) e a alta frequência de pacientes com doenças infecciosas assistidos pelo hospital e a internação desses ser da responsabilidade da Clínica Médica (AGHANWA; MORAKINYO; AINA, 1996).

Vale ressaltar também que a Clínica Médica, no caso do HCFMRP-USP e de muitos outros hospitais gerais, abarca o maior número de especialidades como, por exemplo, a Cardiologia, a Dermatologia, a Endocrinologia, a Hematologia e a 
Imunologia, responsáveis por grande parcela de pacientes, o que poderia aumentar a frequência de solicitações psiquiátricas desta clínica em geral.

Das especialidades da Clínica Médica que mais solicitaram o serviço de Interconsulta, destacaram-se a Imunologia, a Dermatologia e a Endocrinologia para os pacientes femininos e a Dermatologia, a Hematologia e a Cardiologia para os pacientes masculinos. Pelo fato de ser uma característica particular de cada hospital no que tange as especialidades consideradas como Clínica Médica, a comparação deste dado ficou, de certo, comprometida. Alguns estudos reportaram as frequências de algumas especialidades, tais como a Dermatologia (FAVA; PAVAN, 1980; OZKAN et al., 1995; DIEFENBACHER, 2001) e a Cardiologia (DIEFENBACHER, 2001), porém estas não eram consideradas, pelos estudos, especialidades da Clínica Médica, e sim, como clínicas solicitantes de modo independente. Apesar das ressalvas, os números de solicitações obtidos no presente estudo foram maiores quando comparados com tais estudos.

Uma possível explicação para uma maior frequência dessas especialidades é o fato de elas tratarem pacientes com quadros clínicos que apresentam comorbidades psiquiátricas bem estabelecidas e divulgadas pela literatura, como é o caso, por exemplo, do lúpus eritematoso sistêmico (que foi a doença mais frequente nos pacientes internados na Imunologia do HCFMRP-USP do presente estudo), em que existe um predomínio do sexo feminino e a prevalência de manifestações psiquiátricas em 15 a 75\% dos casos (WEKKING, 1993; STOJANOVICH et al., 2007; HAWRO et al., 2011), das dermatites factícias, pênfigo e psoríase (doenças mais frequentes nos pacientes atendidos pela Dermatologia do HCFMRP-USP), que também foram objeto de estudos de diversos estudos a fim de investigar a relação entre essas doenças e manifestações psiquiátricas e/ou o impacto na qualidade de vida 
dos pacientes (COSSIDENTE; SARTI, 1984; RUSSO; ILCHEF; COOPER, 2004; SAMPOGNA; TABOLLI; ABENI, 2007; TABOLLI et al., 2008; PARADISI et al., 2009; ARBABI et al., 2011; RIEDER; TAUSK, 2012). Em relação aos pacientes assistidos pela Endocrinologia no HCFMRP-USP, a diabetes mellitus foi o diagnóstico clínico mais frequente e muitos estudos avaliaram a relação com transtornos psiquiátricos nesses pacientes em diversos contextos (ANDERSON et al., 2001; LLORENTE; URRUTIA, 2006; LIN; KORFF, 2008; BALHARA, 2011). O estudo de Maia et al. (2012) foi desenvolvido em um ambulatório de uma clínica de saúde pública e contou com a participação de 200 pacientes que foram submetidos ao Mini International Neuropsychiatric Interview, MINI (SHEEHAN et al., 1998). Neste estudo, a prevalência de pelo menos um transtorno psiquiátrico nos pacientes com diabetes tipo $1 \mathrm{e}$ 2 foi de $42,5 \%$.

Em relação às solicitações da Ginecologia / Obstetrícia, as frequências encontradas foram similares às de outros estudos (FAVA; PAVAN, 1980; CRAIG, 1980; SOBEL; MUNITZ; KARP, 1988; ROTHENHÄUSLER; EHRENTRAUT; KAPFHAMMER, 2001; AGHANWA, 2002; YASSINI et al., 2011), assim como as frequências de solicitações da Cirurgia (FAVA; PAVAN, 1980; HATTORI, 1985; SCHOFIELD; DOONAN; DALY, 1986; GRANT; MELLER; UREVIG, 2001; ROTHENHÄUSLER; EHRENTRAUT; KAPFHAMMER, 2001; AGHANWA, 2002).

Notou-se que, na última década, as frequências de solicitação da Cirurgia, de modo geral, foram altas em diversos estudos desenvolvidos no mundo (DE JONGE et al., 2000; DIEFENBACHER, 2001; DIEFENBACHER; STRAIN, 2002; SALVO; CASTRO , 2003; KISHI et al., 2004; ALHAMAD et al., 2006; KISHI et al., 2007) e, no HCFMRP-USP, também foi observado um aumento na frequência de solicitações para assistência psiquiátrica ao longo dos anos, o pode ser indicativo de uma tendência 
dos cirurgiões a estarem mais atentos às alterações psiquiátricas de seus pacientes.

Em relação à Neurologia, as frequências encontradas se aproximaram das obtidas por Chandara, Conlon e Steinberg (1988), porém foram menores que alguns estudos (CRAIG, 1980; LIPOWSKI; WOLSTON, 1981; HENGEVELD; ROOYMANS; BERGH, 1984; SCHOFIELD; DOONAN; DALY, 1986; HALES et al., 1986; DE JONGE et al., 2000; ROTHENHÄUSLER; EHRENTRAUT; KAPFHAMMER, 2001) e maiores do que outros (TORO; LIZAMA; SEGUEL, 1994). No estudo de Lipowski e Wolston (1981), o número de solicitações desta clínica aumentou ao longo dos anos, enquanto que Rothenhäusler, Ehrentraut e Kapfhammer (2001) evidenciaram o oposto. A tendência encontrada no presente estudo se aproxima da relatada por Lipowski e Wolston (1981) e a redução no número de solicitações desta clínica pode estar relacionada à própria contratação de psiquiatras para a equipe em meados da década de 90.

O aumento no número de solicitações da clínica de Moléstias Infecciosas / UETDI se deu, provavelmente, pelo aumento no número de casos de indivíduos que contraíram, em especial, o vírus da imunodeficiência humana - HIV. Segundo o boletim epidemiológico do Ministério da Saúde publicado em 2010, no Brasil, foram diagnosticados somente em 1990, quase oito mil casos por 100 mil habitantes no sexo masculino e quase mil e quinhentos casos por 100 habitantes no sexo feminino, sendo a taxa de incidência de 10,8 e 2,0 respectivamente. O ápice foi em 1998 com mais de vinte mil casos diagnosticados no ano para os homens (e taxa de incidência de 25,1) e em 2003 com mais de doze mil casos para as mulheres (taxa de incidência de 13,5). Na literatura, alguns estudos também obtiveram as frequências de solicitações desta clínica (ZUO; YANG; CHU, 1985; DIEFENBACHER, 2001; DIEFENBACHER; STRAIN, 2002). 
Acerca da função do profissional solicitante, pelo HCFMRP-USP ser um hospital universitário, houve uma maior frequência de solicitações realizadas por residentes e aprimorandos, pois são oferecidos programas de aprimoramento, especialização e estágios nas diversas clínicas do hospital. Este fato também foi encontrado em outros estudos realizados em hospitais universitários brasileiros (KERR-CORRÊA; SILVA, 1985; ANDREOLI et al., 1996). O HCFMRP-USP conta com uma equipe assistencial à Saúde Mental constituída por diversas categorias de profissionais, tais como alunos da Faculdade de Medicina de Ribeirão Preto da própria universidade, terapeutas ocupacionais, psicólogos e estagiários, além dos residentes e dos médicos assistentes.

Os motivos alegados pelos profissionais para a avaliação psiquiátrica se concentraram, principalmente, na presença de sintomas psiquiátricos e na existência de antecedentes psiquiátricos nos pacientes. Quando estes achados foram confrontados com a literatura, notou-se uma heterogeneidade na terminologia utilizada para designar os motivos de solicitação nos estudos desenvolvidos em outros países, fato este evidenciado por Lipowski (1967), Pérez e Silverman (1983) e Hengeveld, Rooymans e Bergh (1984) e que ainda se mostra atual.

Segundo Cassorla (1994), esta múltipla terminologia pode estar vinculada à dificuldade dos clínicos em lidar e descrever pacientes que apresentam transtornos mentais e de comportamento, utilizando, assim, diversos termos para descrevê-los e razões variadas para a solicitação de avaliação psiquiátrica. Em 1991, Mayou propôs uma terminologia para os motivos de solicitação a fim de homogeneizar os dados obtidos em pesquisa e facilitar a comparação dos mesmos. Porém, pouquíssimos estudos conseguiram empregar tal terminologia (TORO; LIZAMA; SEGUEL, 1994; ROTHENHÄUSLER; EHRENTRAUT; KAPFHAMMER, 2001). 
Considerando as proximidades de significado no que se denominou "presença de sintomas psiquiátricos" em relação aos motivos alegados em outros estudos, as frequências encontradas no presente estudo foram próximas às obtidas em muitos trabalhos (RIES et al., 1980; LIPOWSKI; WOLSTON, 1981; LOEWENSTEIN; SHARFSTEIN, 1983; HATTORI, 1985; KERR-CORRÊA; SILVA, 1985; MAGDALENO JR; BOTEGA, 1991; VALDÉS et al., 2000; DIEFENBACHER, 2001; CHRISTODOULOU et al., 2008). Esta dificuldade dos clínicos em lidar com possíveis pacientes psiquiátricos e a falta de conhecimento nesta área podem estar diretamente relacionadas à alta frequência de solicitações para avaliar sintomas psiquiátricos e a instalação de um possível quadro. Cerqueira e Smaira (1992, apud SMAIRA; KERR-CORRÊA; CONTEL, 2003) também consideraram a possibilidade da existência de motivos implícitos nas próprias solicitações psiquiátricas, uma vez que muitas solicitações poderiam ocorrer devido à dificuldade da equipe médica em lidar com algum sintoma em específico ou até mesmo com a própria reação do paciente e da família perante o adoecimento.

Além da presença de sintomas psiquiátricos, foram encontrados estudos que apresentaram as frequências relativamente próximas ao obtido no presente estudo acerca dos antedentes psiquiátricos como motivadores para a solicitação (DEVASAGAYAM; CLARKE, 2008; ARBABI et al., 2012; HOLMES et al., 2011; YASSINI et al., 2011) assim como os sintomas físicos mal definidos ou de origem psicológica (PÉREZ; SILVERMAN, 1983; HENGEVELD; ROOYMANS; BERGH, 1984; HATTORI, 1985; SCHOFIELD; DOONAN; DALY, 1986; HALES et al., 1986; GALA et al., 1999; VALDÉS et al., 2000; DIEFENBACHER, 2001; YASSINI et al., 2011).

Em relação às solicitações motivadas pelos antecedentes psiquiátricos no HCFMRP-USP, algumas observações precisam ser ressaltadas. Considerando os 
números de pacientes com antecedentes psiquiátricos atendidos pelo serviço de Interconsulta, 1608 mulheres e 940 homens tinham histórico de antecedentes, porém apenas $556(34,6 \%)$ mulheres e 277 (29,4\%) homens foram encaminhados por este motivo. Perante este achado, algumas hipóteses podem ser levantadas: a) boa parte dos pacientes com antecedentes psiquiátricos poderia estar com o quadro estabilizado, o que passaria despercebido pela equipe; b) outras razões mais alarmantes poderiam ter motivado as solicitações; e c) os clínicos não investigaram de forma mais detalhada o passado dos pacientes.

Já a respeito dos sintomas físicos mal definidos, $47 \%$ dos pacientes que tiveram solicitações com este motivo foram diagnosticados com transtornos neuróticos, somatoformes e relacionados ao estresse - o que poderia justificar a dificuldade em definir e/ou descrever os sintomas por parte dos clínicos, pois os transtornos somatoformes, em especial, apresentam também manifestações físicas.

O abuso de substâncias psicoativas como motivação para solicitação psiquiátrica, em especial para pacientes do sexo masculino no presente estudo, também foi relatado na literatura (HENGEVELD; ROOYMANS; BERGH, 1984; VAZ; SALCEDO, 1996; VALDÉS et al., 2000; DIEFENBACHER, 2001; GRANT; MELLER; UREVIG, 2001; KISHI et al., 2004; KISHI et al., 2007).

No caso do HCFMRP-USP, o fato do abuso de substâncias psicoativas ser o terceiro motivo mais frequente de solicitação, no caso dos pacientes do sexo masculino, pode estar relacionado à alta prevalência de uso e abuso de tais substâncias por este sexo no Brasil, em especial na região sudeste. Segundo o levantamento domiciliar sobre o uso de drogas psicotrópicas no Brasil realizado em 2005 pela Secretaria Nacional Antidrogas (SENAD) em parceria com o Centro Brasileiro de Informações sobre Drogas Psicotrópicas (CEBRID), 24,5\% dos indivíduos entrevistados 
já fizeram uso de alguma substância psicoativa ao longo da vida e quanto à dependência, 12,7\% eram dependentes de álcool e 10,4\% de tabaco, entre outras drogas.

Em relação às hipóteses diagnósticas psiquiátricas levantadas pelos profissionais solicitantes, mais da metade forneceu apenas os sintomas dos pacientes (próximo ao encontrado por SMAIRA; KERR-CORRÊA; CONTEL, 2003) e 11\% não forneceram nenhuma informação a respeito do possível diagnóstico psiquiátrico (menos da metade da frequência reportada por SMAIRA; KERR-CORRÊA; CONTEL, 2003). Este achado pode estar vinculado à própria dificuldade dos clínicos, cirurgiões e outros profissionais solicitantes em diferenciar possíveis transtornos psiquiátricos de reações emocionais normais dos pacientes perante o adoecimento.

Dos profissionais que forneceram hipóteses diagnósticas, podem-se destacar os transtornos de humor (com mais frequência nas mulheres) e os transtornos devido ao uso de substâncias (com mais frequência nos homens), assim como relatado por Smaira, Kerr-Corrêa e Contel (2003).

Importante ressaltar que, devido ao problema já relatado anteriormente acerca da multiplicidade na terminologia para designar os motivos de solicitação, uma maior comparabilidade das hipóteses diagnósticas com a literatura ficou comprometida, visto que muitos estudos incluíram os possíveis diagnósticos psiquiátricos como motivos de solicitação, vindo a dissolver a frequência desses como hipóteses diagnósticas propriamente ditas (RIES et al., 1980; OZKAN et al., 1995; VAZ; SALCEDO, 1996; CARR et al., 1997; GRANT; MELLER; UREVIG, 2001; DIEFENBACHER; STRAIN, 2002; KISHI et al., 2004; KISHI et al., 2007; HOLMES et al., 2011).

O tempo de internação dos pacientes diagnosticados com comorbidades psiquiátricas foi bem maior quando comparado aos pacientes internados no HCFMRP-USP de modo geral, sendo este fato também relatado por muitos outros 
estudos em diversos hospitais gerais (FULOP et al., 1987; HOSAKA et al., 1999; SMAIRA, 1999; DE JONGE et al., 2000; FURLANETTO; SILVA; BUENO, 2003; BOURGEOIS et al., 2006; BRESSI; MARCUS; SOLOMON, 2006; ALHUTHAIL, 2008; BOURGEOIS; WEGELIN, 2009). O tempo de internação médio foi de 27,4 dias para as mulheres e 31,5 dias para os homens, e apenas alguns estudos encontraram tempos de internação próximos (SMAIRA, 1999; DE JONGE et al., 2000; DIEFENBACHER, 2001; DIEFENBACHER; STRAIN, 2002; CHRISTODOULOU et al., 2008), enquanto que outros estudos relataram internações variando de 9 a 18 dias (CHANDARANA; CONLON; STEINBERG, 1988; CLARKE; SMITH, 1995; REBOLLEDO et al., 1996; GALA et al., 1999; KISHI et al., 2004) e acima de 40 dias (ABUMADINI; RAHIM, 2002; KISHI et al., 2007).

Segundo os autores, tal variação nos tempos de internação pode estar relacionada ao contexto hospitalar no qual o serviço estaria inserido (KOOPMANS; DONKER; RUTTEN, 2005) ou até mesmo a particularidades da população atendida, como foi o caso do estudo desenvolvido por Kishi et al. (2007) que avaliou dois serviços de Interconsulta Psiquiátrica em dois países distintos, Estados Unidos e Japão, e encontrou tempos de internação de 18 dias em média para os pacientes americanos e 43 dias para os pacientes japoneses.

No presente estudo, foi observado que os pacientes que apresentaram os seguintes aspectos apresentaram maiores médias no tempo de internação quando comparados com o todo: a) pacientes do sexo masculino; b) pacientes com idades entre 51 a 70 anos; c) mulheres internadas na Ortopedia e homens internados na Unidade Metabólica; d) mulheres com doenças do aparelho respiratório e homens com doenças do aparelho geniturinário; e e) mulheres com transtornos neuróticos, somatoformes e relacionados ao estresse e homens com transtornos do humor. 
Importante ressaltar que não foi possível investigar se as comorbidades psiquiátricas contribuíram para o aumento do tempo de internação e se estas foram manifestadas devido às consequências das doenças clínicas ou pelo próprio fato da internação prolongada, uma vez que o presente estudo teve caráter retrospectivo e não foi possível a aplicação de escalas, entrevistas e inventários para mensurar a gravidade do quadro clínico e também avaliar os prejuízos funcionais e/ou sintomas psiquiátricos dos pacientes no momento da admissão hospitalar e no decorrer de sua internação.

Já os estudos que se propuseram a investigar esta relação apresentaram diversos problemas metodológicos. Segundo a revisão feita por Saravay e Lavin em 1994 a respeito das metodologias empregadas pelos estudos desenvolvidos entre 1980 a 1992, apenas três estudos prospectivos consideraram a gravidade do quadro clínico e prejuízos cognitivos e funcionais na investigação da relação entre o tempo de internação e comorbidades psiquiátricas.

Os achados desses três estudos revisados foram: em pacientes geriátricos, foram encontradas evidências de associação entre o delirium e o aumento do tempo de internação (FRANCIS; MARTIN; KAPOOR, 1990, apud SARAVAY; LAVIN, 1994), evidências de associação entre depressão, ansiedade, prejuízos cognitivos e dor com aumento do tempo de internação (LEVENSON; HAMER; ROSSITER, 1990, apud SARAVAY; LAVIN, 1994) e relação entre depressão e prejuízos cognitivos com tempo de internação prolongado (SARAVAY et al., 1991, apud SARAVAY; LAVIN, 1994).

Já em 2005, Koopmans, Donker e Rutten realizaram uma revisão sistemática dos estudos prospectivos que investigaram a relação entre o tempo de internação e os transtornos mentais não cognitivos, desconsiderando estudos envolvendo transtornos mentais orgânicos, esquizofrenia, transtornos psicóticos, de personalidade e 
devido ao uso de substâncias psicoativas. Assim como relatado por Saravay e Lavin (1994), foram encontrados diversos entraves metodológicos, dentre eles, falhas quanto às correções de variáveis confundidoras, em especial, a gravidade do quadro clínico. Em apenas dois estudos foram apresentadas as análises de associação com e sem a correção para a gravidade da doença clínica: transtornos de humor foram relacionados ao tempo de internação antes da correção, mas não depois da correção (BÉROD et al., 2000; WANCATA et al., 2001).

O estudo desenvolvido por Bressi, Marcus e Solomon (2006) investigou a associação entre o tempo de internação e as comorbidades psiquiátricas em uma amostra nacional representativa americana obtida no banco de dados Nationwide Inpatient Sample do Healthcare Cost and Utilization Project. Este banco de dados contém informações de $20 \%$ de todos os hospitais americanos, sendo o maior banco de dados com informações de pacientes com planos de saúde oferecidos pelo governo. Os autores constataram, assim como no presente estudo, que os pacientes com comorbidades psiquiátricas ficaram mais tempo internados quando comparados com aqueles sem essas condições, sendo que tais comorbidades tiveram um impacto, porém leve, no aumento do tempo de internação em pacientes mais velhos, pacientes diagnosticados com esquizofrenia ou com transtorno de humor mesmo com o controle de variáveis confundidoras.

Em contrapartida, tais autores também encontraram alguns fatores associados à internação mais breve: pacientes extremamente debilitados pela doença física, mesmo com comorbidade psiquiátrica, receberam alta hospitalar em até três dias a menos que os outros pacientes (pela possibilidade de serem tratados em outros serviços mais adequados), assim como pacientes diagnosticados com transtornos devido ao uso de substâncias psicoativas (provavelmente devido aos problemas de 
comportamento e atritos com a equipe médica, tais pacientes teriam uma internação mais breve, segundo os autores).

Perante esse panorama tão diversificado de achados, algumas ressalvas podem ser feitas, além das já explicitadas a respeito das variáveis confundidoras: a) o tempo de internação pode ser um aspecto diretamente relacionado ao contexto hospitalar, especialmente porque, com o passar dos anos, muitos hospitais desenvolveram medidas para tentar reduzir o tempo de internação e consequentemente os custos hospitalares; b) o tempo de internação pode ter um aspecto também relacionado às particularidades de cada população, incluindo sistemas de saúde específicos, como, por exemplo, no próprio estudo de Bressi, Marcus e Solomon (2006), em que foi realizada uma investigação com amostra representativa americana, porém somente de pacientes com planos de saúde financiados pelo governo, o que pode, portanto, ter particularidades quando comparada com uma amostra representativa nacional sem restrição de pacientes; e c) o tempo de internação pode estar relacionado à própria intervenção psiquiátrica, pois o próprio acompanhamento psiquiátrico pode ter prolongado o tempo de internação do paciente.

No caso do HCFMRP-USP, algumas hipóteses em relação às particularidades dos quadros clínicos podem ser levantadas para tentar explicar porque as mulheres ficaram mais tempo internadas na Ortopedia e os homens, na Unidade Metabólica. No caso das mulheres, observou-se que metade das pacientes internadas na Ortopedia foram vítimas de acidente automobilístico com múltiplas fraturas, sendo que os tempos médio (45,8 dias, $\mathrm{DP}=40,7)$ e mediano (42 dias) dessas pacientes foram superiores à média e mediana da Ortopedia (39,5 dias, DP=32,3, e 39,5 dias respectivamente). E, no caso dos homens, houve uma maior frequência de pacientes internados com obesidade e desnutrição, isto é, quadros clínicos crônicos, com tempos 
médio e mediano de internação de 54 dias $(\mathrm{DP}=56,9)$ e 46 dias, respectivamente tempos bem superiores à média e mediana total dos homens internados na Unidade Metabólica (47,5 dias, $\mathrm{DP}=50,5$, e 38,0 dias respectivamente). Contudo, não foi possível investigar se realmente foram as complicações dos quadros clínicos que resultaram num maior tempo de internação ou se foi a presença de comorbidades psiquiátricas que agravaram os quadros e estenderam o tempo de internação.

É sabido, portanto, que pacientes com comorbidades psiquiátricas podem ter dificuldades particulares que resultam em um tempo de internação mais prolongado, especialmente porque boa parcela dos pacientes apresentam múltiplos diagnósticos clínicos e múltiplas comorbidades psiquiátricas, indicando, assim, a existência de um quadro complexo que pode influenciar de diversas maneiras no tempo de internação.

Em relação ao tempo de solicitação, a média foi de 10,7 dias para as mulheres e 14,0 dias para os homens, tempos médios próximos aos encontrados por outros estudos (REBOLLEDO et al., 1996; DE JONGE et al., 2000; VALDÉS et al., 2000; DIEFENBACHER, 2001; DIEFENBACHER; STRAIN, 2002) porém superiores a outros, que apresentaram tempos médios variando de 3 a 8,7 dias (CLARKE; SMITH, 1995; ANDREOLI et al., 1996; GALA et al., 1999; GRANT; MELLER; UREVIG, 2001; HUYSE et al., 2001; SMAIRA; KERR-CORRÊA; CONTEL, 2003; KISHI et al., 2004; KISHI et al., 2007; DEVASAGAYAM; CLARKE, 2008).

Observou-se também que o tempo de solicitação reduziu ao longo de três décadas, passando de 23,3 para 10,9 dias para as mulheres e 18,3 para 15,0 dias para os homens, o que poderia ser um indício positivo de uma maior atenção a outros aspectos além do físico por parte do corpo clínico.

Solicitações motivadas devido aos antecedentes psiquiátricos nas mulheres e devido ao abuso de substâncias psicoativas nos homens foram realizadas em menor 
tempo quando comparado com outros motivos, assim como achados de Handrinos, McKenzie e Smith (1998) e Kishi et al. (2004).

Pacientes com idades superiores a 51 anos tiveram Pls realizados em um maior intervalo de tempo após a admissão hospitalar talvez pelo fato da dificuldade dos médicos clínicos e outros profissionais em diferenciar sintomas psiquiátricos de aspectos relacionados ao próprio envelhecimento, assim como o relatado por Wilkinson, Bolton e Bass (2001).

Algumas hipóteses podem ser levantadas a respeito dos tempos de solicitação encontrados no HCFMRP-USP: 1) existem diferenças entre mulheres e homens quanto ao tempo de solicitação - no presente estudo, o tempo de solicitação foi menor para as mulheres e possíveis justificativas para o fato se relacionam com a maior capacidade das mesmas em expressar suas inquietudes; já Kishi et al. (2004) observaram que os homens tiveram menores tempos de solicitação e tais autores atribuíram ao fato diferenças quanto à manifestação dos sintomas: no caso, as mulheres apresentariam sintomas psiquiátricos de forma mais branda, o que levaria um maior tempo a serem percebidos pela equipe; 2) alta frequência de pacientes internados com antecedentes psiquiátricos (em torno de $70 \%$ de todos os pacientes) 0 que levaria a um menor tempo na solicitação de avaliação psiquiátrica em determinadas clínicas devido à própria existência do transtorno psiquiátrico e possíveis manifestações do quadro - no caso da Ginecologia e Obstetrícia, por exemplo, 80\% das mulheres tiveram alguma passagem pela Psiquiatria e a avaliação do psiquiatra quanto à capacidade das mesmas nos cuidados com o recém-nascido foi requisitada, sendo o tempo médio de solicitação de 4,7 dias; 3) pacientes com quadros clínicos crônicos ou de lenta recuperação, como é o caso dos pacientes internados na Unidade Metabólica e na Ortopedia, em que solicitações psiquiátricas foram feitas 
mais tardiamente; 4) necessidade de diferenciação entre alterações devido ao quadro clínico ou devido a uma possível comorbidade psiquiátrica, podendo ter um efeito antecipatório ou retardatário (pacientes com doenças infecciosas e parasitárias, por exemplo, tiveram solicitações mais tardias, assim como relatado por ORMONT et al., 1997, e mulheres com doenças endócrinas, metabólicas ou nutricionais tiveram solicitações mais rapidamente); 5) quadros clínicos que possivelmente podem desencadear com mais frequência comorbidades psiquiátricas tiveram solicitações em menor tempo (como, por exemplo, transtornos relacionados ao puerpério, pacientes internados devido à rejeição de órgãos transplantados ou devido a doenças endócrinas e metabólicas); e 6) características dos próprios profissionais da equipe médica assistencial (como, por exemplo, o nível de tolerância quanto às manifestações dos pacientes) possivelmente podem ser fatores que também influenciaram no tempo de solicitação - no caso de pacientes cujo motivo de solicitação foi problemas quanto à cooperação no tratamento, por exemplo, tiveram Pls realizados em média após 11 dias da admissão hospitalar para as mulheres e 13 dias para os homens, ou seja, duas vezes a média do tempo de internação dos pacientes em geral do HCFMRP-USP.

Alguns estudos encontraram evidências de associação entre os tempos de solicitação e de internação, sendo que autores como Lyons et al. (1986), Ormont et al. (1997) e Alhuthail (2009) relataram que quanto mais rápido foi solicitada a avaliação do psiquiatra, menor foi o tempo de internação do paciente, e Kishi et al. (2004) observaram que, quanto mais demorada foi a avaliação do psiquiatra, maior foi o tempo de internação do paciente - mesmo quando controlados a condição médica do paciente, o motivo de solicitação, diagnóstico psiquiátrico e o plano de tratamento, segundo esses últimos autores. 
Portanto, pode-se dizer que, no caso do HCMFPR-USP, o tempo de solicitação foi longo, excedendo, inclusive, o próprio tempo médio da internação dos pacientes do hospital, e também possivelmente influenciado por diversos fatores - sejam eles relacionados às características dos pacientes, ao que a própria equipe assistencial de cada clínica entende por sintomas psiquiátricos e sua tolerância perante eles, às próprias habilidades interpessoais dos profissionais, à comorbidade psiquiátrica e/ou a severidade do quadro clínico, entre outros. Somente a análise de fatores individuais não se mostra suficiente para entender a complexidade da interação desses aspectos e é importante ressaltar também que não foi possível investigar no presente estudo associações entre essas variáveis e o tempo de solicitação do PI, assim como outras relações entre o tempo de solicitação e o tempo de internação.

Em relação ao tempo de resposta à solicitação psiquiátrica, segundo normas internas do serviço de Interconsulta Psiquiátrica do HCFMRP-USP, o PI deve ser atendido em até 48 horas após seu recebimento e, em mais de $80 \%$ dos casos, a solicitação foi respondida dentro deste prazo para pacientes de ambos os sexos, sendo a média do tempo de resposta de um dia. Estes achados estão de acordo resultados divulgados por outros estudos, tais como Mayou, Simkin e Cobb (1994), em que $70 \%$ das solicitações foram respondidas em até um dia, como Gala et al. (1999), cujo tempo médio de resposta foi de um dia e meio, sendo $77 \%$ das solicitações atendidas em até dois dias, e o estudo brasileiro desenvolvido por Andreoli et al. (1996), em que o tempo de resposta médio foi de um dia.

Observou-se também que o tempo de resposta reduziu quando comparadas as décadas de 80 e 2000, podendo ser indício de uma melhora no funcionamento do serviço de Interconsulta.

Em relação ao número de atendimentos realizados pelo interconsultor, a 
média total para ambos os sexos foi de três visitas, sendo que, em meados da década de 90, foram realizadas, em média, cinco visitas para o sexo feminino e quatro para o sexo masculino. Este número foi maior do que o divulgado por Gala et al. (1999) em seu estudo multicêntrico italiano, cuja média de atendimentos foi de 1,5, porém menor do que o relatado por Hales et al. (1986), que foi de aproximadamente seis visitas. Apenas o achado de Holmes et al. (2011) se aproximou do encontrado no presente estudo, com média de quatro atendimentos por paciente, sendo que os autores encontraram evidências de que pacientes com múltiplos diagnósticos psiquiátricos necessitaram de mais atendimentos.

Um fato que possivelmente pode explicar o número reduzido de atendimentos no HCFMRP-USP é o tempo de solicitação relativamente longo (que em média foi de 10 dias para as mulheres e 14 dias para os homens) sendo que, só esse período entre a admissão do paciente no hospital e a data da solicitação psiquiátrica, já ultrapassa o tempo médio de internação de um paciente no hospital. Sendo assim, muitos casos, apesar da solicitação de atendimento psiquiátrico, podem ter recebido alta hospitalar sem terem propriamente recebido alta do serviço de Interconsulta.

\subsection{DIAGNÓSTICOS CLÍNICOS, DIAGNÓSTICOS PSIQUIÁTRICOS E IDEAÇÃO SUICIDA}

Os principais diagnósticos clínicos de ambos os pacientes que tiveram solicitação psiquiátrica foram: doenças endócrinas, metabólicas e nutricionais (15,3\% nas mulheres e 11,1\% nos homens), doenças do aparelho circulatório $(11,8$ 
e 12,9\%, respectivamente) e doenças infecciosas e parasitárias (8,5 e 15,8\%, respectivamente), sendo que esses diagnósticos foram os mais frequentes em $35,6 \%$ da população feminina atendida e $39,8 \%$ da população masculina.

Estudos que abordaram essa questão apresentaram resultados diferentes, o que sugere que quadros clínicos com comorbidades psiquiátricas é uma questão complexa, especialmente considerando o predomínio de diferentes diagnósticos clínicos nos hospitais (como, por exemplo, predomínio de doenças gastrointestinais no estudo de FAVA e PAVAN, 1980, e de GALA et al., 1999; de doença do sistema nervoso no estudo de RIES et al., 1980, e de SOBEL, MUNITZ e KARP, 1988; de doenças musculoesqueléticas no estudo de McKEGNEY, McMAHON e KING, 1983, e de CARR et al., 1997; de doenças do trato geniturinário no estudo de MALHOTRA e MALHOTRA, 1984; de neoplasias no estudo de ZUO, YANG e CHU, 1985, HALES et al., 1986, e HUYSE, STRAIN e HAMMER, 1990) e também a falta de uma metodologia adequada para investigar a relação de causa-efeito entre os quadros clínicos e os transtornos psiquiátricos.

No caso do HCFMRP-USP, uma possível explicação ao fato de que mais avaliações psiquiátricas foram feitas a pacientes com doenças endócrinas, metabólicas e nutricionais, com destaque para a diabetes mellitus, está relacionada à alta prevalência de transtornos psiquiátricos ao longo da vida desses pacientes, atingindo cerca de $70 \%$ deles segundo alguns achados (POPKIN; CALLIES; LENTZ, 1988, apud FORLENZA; VIEIRA FILHO, 1997).

De maneira geral, os diferentes resultados quanto aos quadros clínicos mais frequentes podem ser considerados um aspecto particular do contexto, seja este mais restrito ao contexto hospitalar, seja este mais amplo e referente à população, no qual os serviços de Interconsulta estão inseridos. Por exemplo, considerando o 
contexto hospitalar, hospitais que atenderam pacientes em estado crítico como overdose e envenenamento apresentaram maiores frequências de solicitações psiquiátricas para pacientes com esses quadros (PÉREZ; SILVERMAN, 1983; MALHOTRA; MALHOTRA, 1984; ZUO; YANG; CHU, 1985; SRINIVASAN et al., 1987; CHANDARANA; CONLON; STEINBERG, 1988; SALVO; CASTRO , 2003; CHRISTODOULOU et al., 2008), o que, no caso, não aconteceu com o HCFMRPUSP, pois a Unidade de Emergência deste hospital não se localiza no mesmo ambiente físico e os casos de emergência são, em um primeiro momento, atendidos na Unidade e, se caso necessário um atendimento mais complexo e prolongado, são encaminhados ao HCFMRP-USP.

Já considerando um contexto mais amplo, pode-se citar as doenças infecciosas, em especial por causa do HIV, que, apesar de terem sido um evento mundial, atingiram as populações em diferentes proporções - apenas em meados de 1984 que estudos internacionais começaram a reportar pacientes internados com doenças infecciosas e que apresentaram comorbidades psiquiátricas (MALHOTRA; MALHOTRA, 1984; ZUO; YANG; CHU, 1985; HALES et al., 1986; SRINIVASAN et al., 1987) sendo que, a partir da década de 90, a frequência desses pacientes internados em hospitais gerais aumentou significativamente, chegando, inclusive, a ser o diagnóstico clínico mais comum em alguns hospitais (HUYSE; LYONS; STRAIN, 1992; AGHANWA; MORAKINYO; AINA, 1996; BOURGEOIS et al., 2005).

No caso do HCFMRP-USP, o aumento abrupto de solicitações para pacientes com doenças infecciosas (assim como de solicitações provindas da clínica de Moléstias Infecciosas / UETDI), especialmente na década de 90, refletiu o retrato da saúde pública na época: o aumento da contaminação de pessoas com o vírus do HIV, sendo que, em 1982, foi registrado o primeiro caso de contaminação com o HIV 
e, em 1984, devido à rápida propagação do vírus, foi estruturado o primeiro programa de controle de AIDS no Brasil (Departamento de DST, AIDS e Hepatites Virais do Ministério da Saúde, 2012).

Estudos nacionais como o de Kerr-Corrêa e Silva (1985) e Smaira, KerrCorrêa e Contel (2003) encontraram maiores frequências de pacientes com doenças do aparelho digestivo e neoplasias, respectivamente. No HCFMRP-USP, considerando pacientes de ambos os sexos com apenas um diagnóstico clínico ( $\mathrm{N}=1427$, 29,2\% da população total atendida pelo SISMen), o diagnóstico clínico mais frequente foi o de neoplasia $(18,9 \%, \mathrm{~N}=269)$.

Dos estudos que encontraram frequências de pacientes com doenças endócrinas, metabólicas e nutricionais, estas variaram de 1,15 a 10\% de todos os pacientes assistidos pela Interconsulta (McKEGNEY; McMAHON; KING, 1983; PÉREZ; SILVERMAN, 1983; MALHOTRA; MALHOTRA, 1984; ZUO; YANG; CHU, 1985; HALES et al., 1986; SRINIVASAN et al., 1987; CHANDARANA; CONLON; STEINBERG, 1988; HUYSE; LYONS; STRAIN, 1992; AGHANWA; MORAKINYO; AINA, 1996; CARR et al., 1997; GALA et al., 1999; SALVO; CASTRO , 2003; ARBABI et al., 2012) e dos estudos que encontraram frequências de pacientes com doenças do aparelho circulatório, estas variaram de 1,6 a 45\% (McKEGNEY; McMAHON; KING, 1983; PÉREZ; SILVERMAN, 1983; ZUO; YANG; CHU, 1985; HALES et al., 1986; SRINIVASAN et al., 1987; CHANDARANA; CONLON; STEINBERG, 1988; HUYSE; LYONS; STRAIN, 1992; CLARKE; SMITH, 1995; AGHANWA; MORAKINYO; AINA, 1996; CARR et al., 1997; GALA et al., 1999; SALVO; CASTRO , 2003; BOURGEOIS et al., 2005).

Apesar das possíveis complicações físicas e psiquiátricas ocasionadas pelos principais diagnósticos clínicos encontrados no HCFMRP-USP já divulgadas na 
literatura (como, por exemplo, alterações no funcionamento da tireoide que podem gerar alterações psiquiátricas e disfunções cognitivas), é de certa audácia tentar estabelecer relações de causa e efeito, tanto entre a doença física e o transtorno psiquiátrico, quanto o contrário, devido a basicamente dois fatores: a) mais de $80 \%$ da população do presente estudo apresentaram mais de dois diagnósticos clínicos simultâneos, sendo que, especificadamente em pacientes com doenças endócrinas, metabólicas e nutricionais, doenças do aparelho circulatório e doenças infecciosas e parasitárias, mais de $45 \%$ dos pacientes apresentaram mais de quatro diagnósticos clínicos simultâneos. Observou-se também que as múltiplas comorbidades clínicas se tornaram mais frequentes com o passar dos anos. Na década de 80 , apenas $14,4 \%$ pacientes tinham mais que três comorbidades enquanto que, a partir de 2000 , esta frequência subiu para 39,8\%; e b) a falta de informações sobre a gravidade dos quadros clínicos, assim como a evolução desses ao longo da internação, foi um fator limitante, especialmente devido ao próprio caráter retrospectivo do presente estudo, pois não foi possível aplicar instrumentos para a avaliação deste aspecto. Inclusive, diagnósticos psiquiátricos propostos pela Classificação Internacional da Doença não seriam adequados para investigações psicossomáticas, pois não levariam em conta detalhes como a gravidade das doenças e comprometimentos funcionais (CLARKE; SMITH, 1995).

Em relação aos principais diagnósticos psiquiátricos dos pacientes atendidos pelo serviço de Interconsulta, quase um terço dos pacientes foi diagnosticado com transtornos neuróticos, somatoformes e relacionados ao estresse em ambos os sexos, o que está de acordo com a literatura nacional e internacional (McKEGNEY; McMAHON; KING, 1983; PÉREZ; SILVERMAN, 1983; TSOI; KOK, 1983; MALHOTRA; MALHOTRA, 1984; HATTORI, 1985; KERR-CORRÊA; SILVA, 1985; 
SCHOFIELD; DOONAN; DALY, 1986; HALES et al., 1986; SRINIVASAN et al., 1987; DHAVALE; BARVE, 1990; MAGDALENO JR; BOTEGA, 1991; CARVALHO et al., 1993; NEEHALL; PSYCH; BEHARRY, 1993; HALL, 1994; REBOLLEDO et al., 1996; GALA et al., 1999; VALDÉS et al., 2000; ROTHENHÄUSLER; EHRENTRAUT; KAPFHAMMER, 2001).

As frequências dos transtornos mentais orgânicos foram de 14,5\% nas mulheres e de $19,3 \%$ nos homens, valores próximos aos verificados em outros estudos (LIPOWSKI; WOLSTON, 1981; PÉREZ; SILVERMAN, 1983; TSOI; KOK, 1983; MALHOTRA; MALHOTRA, 1984; KUHN et al., 1986; HALES et al., 1986; CHANDARANA; CONLON; STEINBERG, 1988; MAGDALENO JR; BOTEGA, 1991; COLLINS; DIMSDALE; WILKINS, 1992; TORO; LIZAMA; SEGUEL, 1994; VAZ; SALCEDO, 1996; TAPIA; EVA; ORTIZ, 1997; VALDÉS et al., 2000; ROTHENHÄUSLER; EHRENTRAUT; KAPFHAMMER, 2001; KISHI et al., 2004; KISHI et al., 2007) e bem inferiores a outros achados (McKEGNEY; McMAHON; KING, 1983; ZUO; YANG; CHU, 1985; HUYSE; STRAIN; HAMMER, 1990; HUYSE; LYONS; STRAIN, 1992; CLARKE; SMITH, 1995; DE JONGE et al., 2000; DIEFENBACHER; STRAIN, 2002; SMAIRA; KERR-CORRÊA; CONTEL, 2003; SCHELLHORN et al., 2009).

Já os transtornos de humor, segunda comorbidade psiquiátrica mais frequente nas mulheres, foram diagnosticados em $21,2 \%$ das pacientes (considerando a população de mulheres e homens, esta frequência chegou a 18\%), valor próximo de estudos desenvolvidos por Sobel, Munitz e Karp (1988), Magdaleno Jr e Botega (1991), Collins, Dimsdale e Wilkins (1992), Creed et al. (1993), Neehall, Psych e Beharry (1993), Hall (1994), Toro, Lizama e Seguel (1994), Lucas e Doyle (1995), Vaz e Salcedo (1996), Tapia, Eva e Ortiz (1997), Leo, Sherry e Jones (1998), Gala et al. 
(1999), Holmes et al. (2011) e Smaira, Kerr-Corrêa e Contel (2003), embora achados divergentes existam (FAVA; PAVAN, 1980; LIPOWSKI; WOLSTON, 1981; LOEWENSTEIN; SHARFSTEIN, 1983; CHANDARANA; CONLON; STEINBERG, 1988; CLARKE; SMITH, 1995; OZKAN et al., 1995; GRANT; MELLER; UREVIG, 2001; AGHANWA, 2002; KISHI et al., 2004; BOURGEOIS et al., 2005; KISHI et al., 2007; SCHELLHORN et al., 2009; YASSINI et al., 2011; ARBABI et al., 2012).

Quanto aos transtornos devido ao uso do álcool, estes foram diagnosticados em $17,4 \%$ dos homens e em $6,5 \%$ das mulheres (e considerando toda a população atendida pelo SISMen, foi de 16\%), sendo essas frequências bem superiores a de muitos outros estudos, nas quais variaram de 1,8 a 13,2\% dos pacientes (LIPOWSKI; WOLSTON, 1981; LOEWENSTEIN; SHARFSTEIN, 1983; McKEGNEY; McMAHON; KING, 1983; PÉREZ; SILVERMAN, 1983; HENGEVELD; ROOYMANS; BERGH, 1984; MALHOTRA; MALHOTRA, 1984; SCHOFIELD; DOONAN; DALY, 1986; HALES et al., 1986; SRINIVASAN et al., 1987; CHANDARANA; CONLON; STEINBERG, 1988; SOBEL; MUNITZ; KARP, 1988; DHAVALE; BARVE, 1990; HUYSE; STRAIN; HAMMER, 1990; HUYSE; LYONS; STRAIN, 1992; CREED et al., 1993; NEEHALL; PSYCH; BEHARRY, 1993; CARR et al., 1997; TAPIA; EVA; ORTIZ, 1997; GALA et al., 1999; VALDÉS et al., 2000; ROTHENHÄUSLER; EHRENTRAUT; KAPFHAMMER, 2001; DIEFENBACHER; STRAIN, 2002; SALVO; CASTRO , 2003; ARBABI et al., 2012).

Diefenbacher e Strain (2002) ficaram surpresos por não terem encontrado em seu estudo longitudinal maiores frequências de transtornos mentais orgânicos ou devido ao uso de substâncias psicoativas com o aumento do número de pacientes com HIV no hospital geral. No presente estudo, ao contrário, foi observada esta tendência, sendo que, dos pacientes diagnosticados com transtornos mentais devido ao 
uso de substâncias, $15,5 \%$ das mulheres e $20,1 \%$ dos homens também sofriam de doenças infecciosas e parasitárias, e dos pacientes diagnosticados com transtornos mentais orgânicos, $15 \%$ das mulheres e $27 \%$ dos homens eram acometidos por doenças infecciosas e parasitárias.

Nos estudos brasileiros desenvolvidos por Kerr-Corrêa e Silva (1985) e Smaira, Kerr-Corrêa e Contel (2003), também foram reportadas frequências relativamente altas de pacientes com transtornos devido ao uso de álcool e substâncias psicoativas, o que talvez retrate a realidade nacional. Estima-se que a prevalência de dependência de álcool é de $18,9 \%$ nos homens e $7,8 \%$ nas mulheres no sudeste do país (LARANJEIRA et al., 2007).

Segundo Forlenza e Vieira Filho (1997), muitos estudos se propuseram a investigar a associação entre transtornos psiquiátricos e condição médico geral, porém raros foram aqueles com rigor diagnóstico e metodológico que possibilitasse considerações etiológicas consistentes. Investigações que envolveram populações psiquiátricas para avaliar a associação entre a psicopatologia e determinadas condições orgânicas tiveram falhas metodológicas, especialmente no estabelecimento da suposta relação de causa e efeito.

Apesar do transtorno mental e da doença orgânica poderem ser condições independentes, estudos encontraram que, para a maioria das doenças relacionadas ao sistema nervoso central, a associação entre transtorno mental e doença orgânica superou essa probabilidade (SLATER; BEARD; GLITHERO, 1963, apud FORLENZA; VIEIRA FILHO, 1997; DAVISON; BAGLEY, 1969, apud FORLENZA; VIEIRA FILHO, 1997; FEINSTEIN; RON, 1990, apud FORLENZA; VIEIRA FILHO, 1997), sendo que esta associação se daria, mais provavelmente na maioria dos casos, à doença orgânica do sistema nervoso central causando ou precipitando o 
transtorno psiquiátrico.

Já os transtornos de humor seriam mais frequentes em indivíduos com doenças clínicas e neurológicas quando comparado com a população geral, sendo que muitos autores investigaram a prevalência de transtornos de humor em amostras cada vez mais específicas a fim de encontrar respostas mais homogêneas para a relação entre doenças clínicas e as comorbidades psiquiátricas, como, por exemplo, a depressão e condições clínicas como acidente vascular cerebral (em que 50\% dos casos foi diagnosticada depressão), esclerose múltipla (frequente em até $60 \%$ dos pacientes), diabetes mellitus (em até $33 \%$ dos pacientes), sendo que, na grande maioria das vezes, a depressão seria o produto da interação de diversos fatores biológicos e psicossociais (FORLENZA; VIEIRA FILHO, 1997), porém sem mais propensão de ocorrer em uma ou outra doença clínica específica (SILVERSTONE, 1996).

A respeito do diagnóstico psiquiátrico em si, esses mesmos autores alegaram ser regra obrigatória a exclusão de organicidade na abordagem diagnóstica dos pacientes com possíveis transtornos psiquiátricos. Contudo, segundo Clarke e Smith (1995), o interconsultor psiquiátrico também apresentaria dificuldades em realizar esse diagnóstico diferencial, em especial, em pacientes com mais idade, devido à similaridade nas manifestações de estado confusional agudo, humor deprimido, comprometimento cognitivo crônico e lentificação psicomotora, que poderiam ter causas tanto orgânicas quanto psiquiátricas.

No caso do HCFMRP-USP, observou-se um aumento no número de exames clínicos e laboratoriais, além de avaliações de outros profissionais, sugeridos pelos interconsultores, muito possivelmente para um diagnóstico diferencial mais preciso.

Em relação aos possíveis diagnósticos levantados pelas equipes solicitantes, os clínicos reconheceram sintomas e relacionaram-nos com o que eles acreditariam 
ser um determinado transtorno psiquiátrico. No HCFMRP-USP, de uma maneira geral, os profissionais se mostraram familiarizados com os sintomas relacionados aos transtornos mentais devido ao uso de substâncias, transtornos neuróticos (incluindo transtornos somatoformes e relacionados ao estresse), esquizofrenia (e transtornos esquizotípicos e delirantes) e transtornos orgânicos mentais, levantando hipóteses corretas quanto ao diagnóstico psiquiátrico.

Apesar do presente estudo ter encontrado um aumento de hipóteses corretas de diagnóstico ao longo dos anos $(66,7 \%$ das hipóteses levantadas no início da década de 80 foram confirmadas, passando esta frequência para 75,2\% no fim de 2010), este fato não necessariamente foi um indicativo de que os profissionais clínicos estariam identificando mais rapidamente os sintomas como alterações psiquiátricas. Este achado sugere apenas que, uma vez identificados os sintomas, os profissionais clínicos conseguiram elaborar hipóteses diagnósticas mais precisas.

Já os pacientes com possíveis transtornos de humor foram confirmados em menos da metade dos casos e o restante dos pacientes foram diagnosticados pelos psiquiatras, em sua grande maioria, com transtornos neuróticos, somatoformes e relacionados ao estresse - o que está consoante com os achados do estudo desenvolvido por Boland et al. (1996) e Leo, Sherry e Jones (1998). O aumento do número de possíveis transtornos de humor, em especial a depressão, pode ser um "efeito colateral" do aumento da vigilância dos profissionais clínicos e a ampla divulgação da prevalência de transtornos de humor em pacientes internados (BOLAND et al., 1996). Em relação à confusão entre transtornos de humor e transtornos neuróticos, somatoformes e relacionados ao estresse, estes mesmos autores alegaram que a distinção destes transtornos em pacientes fisicamente debilitados seria particularmente complexo pela possibilidade da depressão poder 
ser "mascarada" por sintomas somáticos, consequência esta também mencionada por Leo, Sherry e Jones (1998).

A ideação suicida foi identificada em $8,4 \%$ das mulheres e $10,2 \%$ dos homens no momento da visita do interconsultor, quase três vezes mais frequente que o reportado pelo estudo multicêntrico espanhol de Valdés et al. (2000). Segundo estudo nacional desenvolvido por Botega et al. (2010), a ideação suicida se mostrou associada a indicadores de transtornos mentais, sendo a prevalência de ideação suicida em $4,9 \%$ de todos pacientes internados - porém menor que a relatada por Furlanetto e Stefanello (2011), que foi de $7,2 \%$.

No HCFMRP-USP, notou-se que os profissionais solicitantes superestimaram possíveis riscos suicidas em seus pacientes, pois apenas um terço dos casos em que foi solicitada avaliação psiquiátrica por este motivo teve ideação suicida confirmada pelo interconsultor.

\subsection{PLANOS DE TRATAMENTO E MEDICAÇÕES PSICOTRÓPICAS}

Assim como na literatura, as principais condutas sugeridas pelos interconsultores foram: atendimento individual, orientação à equipe e prescrição de psicofármacos para ambos os pacientes (FAVA; PAVAN, 1980; RIES et al., 1980; LIPOWSKI; WOLSTON, 1981; LOEWENSTEIN; SHARFSTEIN, 1983; PÉREZ; SILVERMAN, 1983; HENGEVELD; ROOYMANS; BERGH, 1984; MALHOTRA; MALHOTRA, 1984; HALES et al., 1986; HUYSE; STRAIN; HAMMER, 1990; HUYSE; 
LYONS; STRAIN, 1992; CLARKE; SMITH, 1995; GALA et al., 1999; GRANT; MELLER; UREVIG, 2001; ROTHENHÄUSLER; EHRENTRAUT; KAPFHAMMER, 2001; DIEFENBACHER; STRAIN, 2002), sendo que a frequência de pacientes que tiveram prescrição de psicofármacos após a visita do interconsultor (40,8\% das muIheres e 45,3\% dos homens) está de acordo com diversos estudos (RIES et al., 1980; HUYSE; STRAIN; HAMMER, 1990; HUYSE; LYONS; STRAIN, 1992; GALA et al., 1999; GRANT; MELLER; UREVIG, 2001; ROTHENHÄUSLER; EHRENTRAUT; KAPFHAMMER, 2001).

Notou-se também que os planos de tratamento se tornaram mais complexos com o passar dos anos - os interconsultores, que no início da década de 80 , se concentravam apenas no atendimento individual e na orientação da equipe, ao final da última década, começaram a sugerir outras condutas além dessas, tais como a assistência de outros profissionais da saúde e o próprio atendimento aos familiares do paciente.

Este fato pode ser indício de alguns aspectos: a) o interconsultor, ao longo dos anos, se mostrou cada vez mais preocupado com outros fatores além daqueles relacionados ao quadro psiquiátrico do paciente, voltando-se, então, a planos de tratamento cada vez mais abrangentes; b) os casos atendidos se mostraram cada vez mais complexos; e c) houve uma expansão da infraestrutura do próprio hospital que pôde oferecer mais recursos aos pacientes internados, tais como, por exemplo, a contratação de mais psicólogos e terapeutas ocupacionais a partir de meados da década de 90, e assim, o interconsultor pôde contar com a assistência de tais profissionais.

A respeito das medicações psicotrópicas em uso antes da visita do interconsultor, é de certo surpreendente a observação de que quase $70 \%$ dos 
pacientes para os quais foi solicitada avaliação psiquiátrica já estavam em uso de alguma medicação psicotrópica, em especial, os benzodiazepínicos. Gala et al. (1999) também se depararam com este fato, porém em frequência menor: em torno de $40 \%$ - e desses pacientes que faziam uso de alguma medicação, $60 \%$ deles utilizavam benzodiazepínicos.

No caso do HCFMRP-USP, o fato da maioria dos pacientes já estarem em uso de alguma medicação psicotrópica pode estar relacionado a três possíveis aspectos: a) foram atendidos pela Interconsulta mais de $70 \%$ dos pacientes com antecedentes psiquiátricos, o que justificaria a alta frequência de pacientes com medicações psicotrópicas em uso; b) por se tratar de um hospital terciário que é responsável pelo tratamento de casos mais complexos, situações emergenciais em que o paciente necessite ser medicado devido à agitação, por exemplo, ocorrem com certa frequência e depois, então, é solicitada a avaliação psiquiátrica; e c) os benzodiazepínicos, em específico, continuam sendo receitados indiscriminadamente por médicos clínicos (HOLDEN; HUGHES; TREE, 1994) - um estudo desenvolvido por Nakao et al. (2009) identificaram que $20 \%$ de todos os pacientes internados em um hospital universitário japonês em um período de quinze meses receberam esta medicação com benzodiazepínicos, porém não foi verificado o motivo pelo qual os pacientes foram medicados nem por qual tipo de profissional. Este achado é relevante, pois, apesar da ampla divulgação a respeito dos problemas de dependência e abuso que este tipo de medicamento pode ocasionar, os benzodiazepínicos ainda são medicações frequentemente utilizadas.

Das medicações que foram prescritas pelos interconsultores após a visita, houve diferença quanto aos sexos, com exceção dos benzodiazepínicos, que foi a medicação mais frequente para ambos. As mulheres tiveram mais prescrição de 
antidepressivos enquanto os homens, de antipsicóticos. Quando comparado com outros estudos (HUYSE; STRAIN; HAMMER, 1990; CARR et al., 1997; GALA et al., 1999), as frequências encontradas no presente estudo foram superiores e, em muitos casos, quase o dobro - no estudo de Gala et al. (1999), por exemplo, os antidepressivos e benzodiazepínicos foram prescritos em apenas 19\%, enquanto que, no presente estudo, os benzodiazepínicos foram prescritos em $34,4 \%$ das mulheres e $36,8 \%$ dos homens e os antidepressivos, em $32,1 \%$ e $21,8 \%$ respectivamente. Já as frequências de prescrição especificadamente de antidepressivos foram menores que a reportada por Schofield, Doonan e Daly (1986), que foi de 48,3\%, assim como as frequências de prescrição de antipsicóticos e estabilizadores de humor encontradas por Schellhorn et al. (2009), que no estudo foram de $42,9 \%$ e $12,2 \%$ respectivamente, e no HCFMRP-USP, em torno de $30 \%$ e $3 \%$ respectivamente.

Notou-se que o aumento das prescrições de antidepressivos foi secundário ao aumento do diagnóstico de transtornos de humor nos pacientes internados. As frequências de transtornos de humor que antes eram 8,8\% para as mulheres e 4,0\% para os homens em meados de 90 passou para $25,6 \%$ das mulheres atendidas e 20,8\% dos homens após uma década, assim como as prescrições de antidepressivos, que na mesma época era de 12,7\% e 7,0\%, e passou a ser de $39,1 \%$ e $28,2 \%$ respectivamente.

Em ambos os sexos, observou-se a redução na prescrição de benzodiazepínicos ao longo dos anos, provavelmente pelo avanço de pesquisas a respeito do impacto do uso desta medicação e no risco de dependência entre seus usuários (GRIFFITHS; ATOR, 1980).

Por volta de $30 \%$ das mulheres atendidas pelo serviço de Interconsulta e $25 \%$ 
dos homens foram encaminhados para atendimento psiquiátrico ambulatorial pósalta, sendo uma tendência crescente ao longo dos anos, em especial, na última década, estando, inclusive, de acordo com muitos estudos (PÉREZ; SILVERMAN, 1983; HENGEVELD; ROOYMANS; BERGH, 1984; SCHOFIELD; DOONAN; DALY, 1986; HUYSE; STRAIN; HAMMER, 1990; HALL, 1994; GALA et al., 1999; GRANT; MELLER; UREVIG, 2001). Observou-se, também, que houve um aumento progressivo de encaminhamentos pós-alta para outros profissionais da saúde mental, tais como psicólogos e terapeutas ocupacionais, o que pode estar relacionado com a expansão da rede de assistência extra-hospitalar defendida pela Política Nacional de Saúde Mental, promovendo, assim, o aumento de serviços oferecidos ao longo dos anos.

\subsection{ASPECTOS RELACIONADOS AOS PROFISSIONAIS DE SAÚDE} E AOS INTERCONSULTORES

Apesar da importância da boa comunicação entre médicos e pacientes estar bem esclarecida no contexto da saúde, cerca da metade dos pacientes internados no HCFMRP-USP não foi avisada pelos clínicos a respeito da visita do interconsultor, sendo esta tendência, inclusive, mantida na última década. Este acontecimento também foi reportado em outros estudos, porém com frequências em torno de 30\% (PÉREZ; SILVERMAN, 1983; GALA et al., 1999).

Desconsiderando casos em que os pacientes se encontravam em condições excepcionais, como coma ou em delírio, esta tendência poderia sugerir que ainda existam entraves na comunicação entre o médico e o paciente, em especial, a 
respeito de possíveis tratamentos psiquiátricos, pois poderia causar recusa ou preocupação por parte do paciente (GALA et al., 1999). Contudo, estudos como o de Steinberg et al. (1980, apud NEEHALL; PSYCH; BEHARRY, 1993) e Wise et al. (1985), relataram que a maioria dos pacientes se mostrou muito receptiva ao atendimento psiquiátrico, inclusive atribuindo à tal experiência um caráter benéfico para si e útil para o próprio médico clínico. O próprio fato de o paciente ser comunicado antes a respeito da visita da Psiquiatria foi considerado como aspecto positivo pelos mesmos e, segundo Wise et al. (1985), evitaria que os pacientes tivessem uma atitude ambivalente perante o papel do psiquiatra no hospital geral.

Outro aspecto que merece atenção foi a grande parcela de pacientes que estava sendo seguida pelos interconsultores, porém teve alta hospitalar sem que tais tivessem conhecimento, vindo estes a descobrir somente no momento da reavaliação. A falta de conhecimento da alta hospitalar foi de aproximadamente $43 \%$ considerando todos os casos, sendo que, no período de 2006 a 2010, mesmo a menor frequência deste acontecimento (que foi de $26 \%$ dos casos) foi bem superior ao relatado na literatura, que variou de 5 a $13 \%$ de todos os casos atendidos pela Interconsulta (MILLAN et al., 1986; HUYSE; STRAIN; HAMMER, 1990; MAGDALENO JR; BOTEGA, 1991; CLARKE; SMITH, 1995).

Contudo, é importante ressaltar que houve muita omissão a respeito desses dois aspectos investigados, o que impossibilita generalizar tais achados para o contexto do hospital. 


\subsection{QUALIDADE ESTRUTURAL DO PI E DE SUA RESPOSTA}

De maneira geral, a legibilidade tanto da solicitação psiquiátrica quanto da resposta escrita se manteve estável ao longo dos anos, sendo considerada total ou aceitável em quase todos os documentos. Notou-se apenas um aumento progressivo no uso de siglas para a identificação dos diagnósticos clínicos por parte dos profissionais solicitantes, o que talvez seja reflexo do aumento do fluxo hospitalar e da rotina intensa dos próprios profissionais que, no momento de preencher o documento para a solicitação por atendimento psiquiátrico, tendem a registrar de forma mais sucinta as informações.

A identificação dos profissionais solicitantes e dos interconsultores ocorreu na grande maioria dos casos, o que pode ser considerado um aspecto positivo, pois facilita o próprio contato interpessoal entre os mesmos para maior troca de informações ou reuniões com a equipe solicitante.

Tanto o aspecto geral da solicitação psiquiátrica quanto de sua resposta escrita foram considerados aceitáveis ou bons em mais de $80 \%$ dos casos, o que poderia ser um indicativo positivo na qualidade de comunicação entre os profissionais.

Ao longo dos anos, observou-se uma melhora na comunicação escrita, uma vez que, quando comparadas as décadas de 80 e de 2000, os Pls classificados como bons passaram de 3,2 para 15,1\% e as respostas, de 2,5 para $68,8 \%$. 


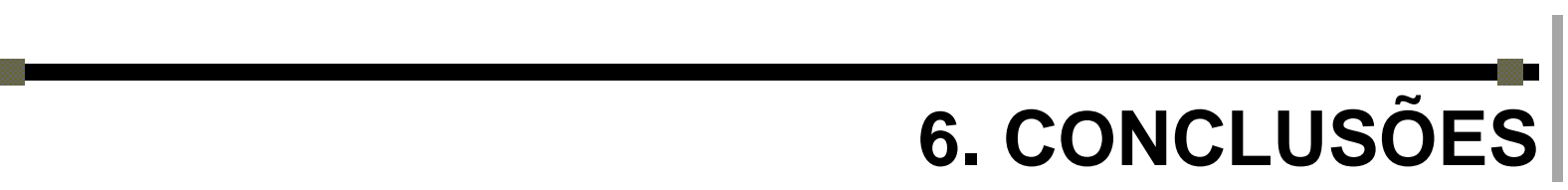


O caráter retrospectivo do presente estudo permitiu analisar aspectos do serviço de Interconsulta, especialmente relacionados ao seu desenvolvimento e funcionamento ao longo dos anos, e confrontá-los com achados da literatura que tiveram apenas retratos parciais a respeito do serviço de Interconsulta inserido no hospital geral, pelo fato de terem restringido os seus períodos de análise.

Muitos estudos atribuíram às baixas taxas de encaminhamento ao serviço diversas razões, entre elas a infraestrutura ainda em desenvolvimento, o não reconhecimento do serviço de Interconsulta como uma unidade inserida no hospital geral e a falha dos clínicos e cirurgiões em reconhecer os transtornos psiquiátricos.

Os achados do presente estudo reforçam que, dentre essas razões, a dificuldade em reconhecer os transtornos psiquiátricos por parte dos clínicos e cirurgiões é um dos fatores mais importantes para as baixas taxas de encaminhamento, especialmente porque, ao longo dos anos, foi evidenciada a melhora na infraestrutura e no funcionamento do serviço de Interconsulta no HCFMRP-USP e também indícios de maior aceitabilidade do serviço pelas clínicas, porém sem grande impacto nas taxas de encaminhamento, que tiveram discreto aumento de 0,7 para 1,0\% em três décadas.

Neste sentido, o uso de instrumentos para rastreamento de condições psiquiátricas por parte das equipes se mostra pertinente, além do treinamento para um reconhecimento mais adequado e rápido das comorbidades psiquiátricas em seus pacientes e também uma postura mais investigativa em relação ao passado dos mesmos. Desta forma, poder-se-ia reduzir o tempo de solicitação o que também poderia reduzir o tempo de internação dos pacientes - que foi mais longo quando comparado com pacientes em geral internados no HCFMRP-USP.

Muitas críticas foram encontradas na literatura a respeito da postura mais resistente dos clínicos e cirurgiões perante os serviços de Interconsulta, principal- 
mente quanto aos benefícios das intervenções psiquiátricas e da reação não favorável do paciente em relação a essa intervenção. Contudo, evidências do presente estudo sugerem mudanças positivas nesse panorama. Mesmo com o aumento de pacientes com quadros cada vez mais complexos devido a múltiplos diagnósticos clínicos concomitantes, os clínicos se mostraram mais atentos a casos em que possivelmente poderiam desencadear comorbidades psiquiátricas, solicitando, assim, o serviço de Interconsulta mais rapidamente a pacientes com determinados quadros clínicos (como, por exemplo, pacientes com doenças endócrinas e metabólicas). Contudo, apresentaram uma postura ainda conservadora quanto a pacientes cujas alterações poderiam ser atribuídas à própria evolução do quadro clínico, solicitando, desta forma, avaliação psiquiátrica mais tardiamente (como o caso, por exemplo, de pacientes com mais de 51 anos, em que alterações poderiam ser atribuídas ao processo de envelhecimento e não propriamente a um transtorno psiquiátrico).

Já o aumento na frequência de solicitações provindas dos cirurgiões ao longo das décadas sugere uma tendência desses especialistas, com o passar dos anos, a estarem mais atentos às alterações psiquiátricas de seus pacientes, o que seria um indicativo de que divulgações a respeito do próprio serviço de Interconsulta causaram um impacto positivo na dinâmica hospitalar.

Outro indicativo deste impacto positivo foi a melhora, ao longo das décadas, da concordância entre as hipóteses diagnósticas feitas pelas equipes que solicitaram assistência do serviço de Interconsulta e os diagnósticos psiquiátricos dados pelos interconsultores, pois pode ser evidência de uma maior aproximação entre a Psiquiatria e outras áreas da Medicina.

Em relação aos pacientes atendidos pelo SISMen, pelo fato do presente estudo ter analisado separadamente mulheres e homens, evidenciaram-se diferenças 
e também algumas semelhanças entre os gêneros.

As mulheres foram mais frequentemente assistidas pelo serviço de Interconsulta Psiquiátrica ao longo de todos os anos, assim como ficaram menos tempo internadas e também tiveram solicitações psiquiátricas realizadas em um menor intervalo de tempo após a admissão hospitalar.

Os transtornos neuróticos, somatoformes e relacionados ao estresse foram os diagnósticos psiquiátricos mais comuns entre as mulheres e homens atendidos pelo SISMen, seguido pelos transtornos de humor e transtornos mentais orgânicos nas mulheres e transtornos mentais orgânicos e transtornos devido ao uso de substâncias nos homens. Em relação ao diagnóstico clínico, foram atendidos com mais frequência mulheres com doenças endócrinas, metabólicas e nutricionais e homens com doenças infecciosas e parasitárias; e casos de múltiplas comorbidades clínicas se tornaram mais frequentes com o passar dos anos.

O PRISMe se mostrou um instrumento muito útil em pesquisa, pois o seu uso promoveu um aumento considerável no fornecimento de informações, inclusive, no registro de particularidades do próprio atendimento que muitas vezes não foram mencionadas nos prontuários dos pacientes. E também seu uso em futuras pesquisas possibilitaria a comparabilidade dos dados obtidos e assim evidenciar as diferenças e semelhanças entre os serviços de Interconsulta no contexto nacional.

Perante os achados do presente estudo, torna-se imprescindível a divulgação desses resultados entre as equipes das diferentes clínicas do HCFMRP-USP para que essas não só tenham conhecimento do trabalho desenvolvido pelo serviço de Interconsulta ao longo dessas três décadas, como também para se conscientizarem de que mudanças são necessárias para poderem oferecer a melhor assistência possível aos pacientes internados no hospital. 

ABUMADINI, M.S.; RAHIM, S.I. Psychiatric admission in a general hospital - patients profile and patterns of service utilization over a decade. Saudi Medical Journal, Arábia Saudita, v.23, n¹, p.44-50, 2002.

AGHANWA, H. Consultation-liaison psychiatry in Fiji. Pacific Health Dialogue, Ilhas do Pacífico, v.9, n¹, p.21-28, 2002.

AGHANWA, H.S.; MORAKINYO, O.; AINA, O.F. Consultation-liaison psychiatry in a general hospital setting in west Africa. East African Medical Journal, África, v.73, $n^{\circ} 2$, p.133-136, 1996.

ALAJA, R.; TIENARI, P.; SEPPA, K.; TUOMISTO, M.; LEPPAVUORI, A.; HUYSE, F.J.; HERZOG, T.; MALT, U.F.; LOBO, A. Patterns of comorbidity in relation to functioning (GAF) among general hospital psychiatric referrals. Acta Psychiatrica Scandinavica, Alemanha, v.99, n², p.135-140, 1999.

ALHAMAD, A.M.; HAWARI, R.A.; MARDINI, D.M.; AL-SABHAN, K.N.; ALSUGHAYIR, M.A.; AL-HAIDAR, F.A.; ABDULLAH, S.A.; AL-HUTHAIL, Y.R.; ASFINA, K.N. Establising a consultation-liaison psychiatric service - impact on clinical indices. Neurosciences, Arabia Saudita, v.9, n4, p.281-286, 2004.

ALHAMAD, A.M.; AL-SAWAF, M.H.; OSMAN, A.A.; IBRAHIM, I.S. Differential aspects of consultation-liaison psychiatry in a Saudi hospital. I: referral pattern and clinical indices. La Revue de Santé de la Méditerranée Orientale, v.12, n³/4, p.316-323, 2006.

ALHUTHAIL, Y.R. Psychiatric consultations and length of hospital stay. Neurosciences, Arabia Saudita, v.13, $n^{\circ} 2$, p.161-164, 2008.

ALHUTHAIL, Y.R. Timing of referral to consultation-liaison psychiatry. International Journal of Health Sciences, Arabia Saudita, v.3, n², p.175-170, 2009.

ALI, S. ; ERNST, C. ; PACHECO, M. ; FRICCHIONE, G. Consultation-liaison psychiatry: how far have we come? Current Psychiatry Reports, Estados Unidos, v.8, n³, p.215-222, 2006.

ALMEIDA-FILHO, N.; MARI, J.J.; COUTINHO, E.S.F.; FRANÇA, J.F.; FERNANDES, J.; ANDREOLI, S.B.; BUSNELLO, E.D. Brazilian multicentric study of psychiatric morbidity: methodological features and prevalence estimates. British Journal of Psychiatry, Londres, v.171, p.524-529, 1997. 
ANDERSON, R.J.; FREEDLAND, K.R.; CLOUSE, R.E.; LUSTMAN, P.J. The prevalence of comorbid depression in adults with diabetes. Diabetes Care, Estados Unidos, v.24, $n^{\circ} 6$, p.1069-1078, 2001.

ANDRADE, L.H.S.G.; LÓLIO, C.A.; GENTIL, V.; LAURENTI, R. Epidemiologia dos transtornos mentais em uma área definida de captação da cidade de São Paulo. Revista de Psiquiatria Clínica (São Paulo), São Paulo, v.26, n5, p.257-261, 1999.

ANDRADE, L.H.S.G.; WANG, Y.P.; ANDREONI, S.; SILVEIRA, C.M.; ALEXANDRINO-SILVA, C.; SIU, E.R.; NISHIMURA, R.; ANTHONY, J.C.; GATTAZ, W.F.; KESSLER, R.C.; VIANA, M.C. Mental disorders in megacities: findings from the São Paulo Megacity Mental Health Survey, Brazil. PLoS ONE, São Francisco e Cambridge, v.7, $\mathrm{n}^{\circ} 2, \mathrm{p} .1-11,2012$.

ANDREOLI, P.B.A.; PELUSO, E.T.; ANDREOLI, S.B.; MARTINS, L.A.N. Padronização e informatização de dados em serviços de interconsulta médicopsicológica de um hospital geral. Revista da Associação Brasileira de Psiquiatria - Asociación Psiquiatrica de La America Latina, São Paulo, v.18, n³, p.89-94, 1996.

ARAYA, R.; ROJAS, G.; FRITSCH, R.; ACUÑA, J.; LEWIS, G. Common mental disorders in Santiago, Chile: prevalence and sociodemographic correlates. British Journal of Psychiatry, Londres, v.178, p.228-233, 2001.

ARBABI, M.; GHODSI, Z.; MAHDANIAN, A.; NOORMOHAMMADI, N.; SHALILEH, K.; DARVISH, F.; ASHRAFINIA, N.; CHAMS, C. Mental health in patients with pemphigus: an issue to worth consideration. Indian Journal of Dermatology, Índia, v.56, n॰5, p.541-545, 2011.

ARBABI, M.; LAGHAYEEPOOR, R.; GOLESTAN, B.; MAHDANIAN, A.; NEJATISAFA, A.; TAVAKKOLI, A.; IZADIAN, E.S.; MOHAMMADI, M.R. Diagnoses, requests and timing of 503 psychiatric consultations in two general hospitals. Acta Medica Iranica, Irã, v.50, n¹, p.53-60, 2012.

ARRIBAS, V.R; IBÁÑEZ, M.L.; MARTÍNEZ, E.S.; BENAVENTE, C.V.; GARCÍA, A.A.; GAMARRA, J.L.B. Evaluación de la calidad de comunicación entre niveles asistenciales mediante el documento interconsulta. Revista Atencion Primaria, Espanha, v.26, n¹0, p.681-684, 2000.

BALHARA, Y.P.S. Diabetes and psychiatric disorders. Indian Journal of Endocrinology and Metabolism, Índia, v.15, n4, p.274-283, 2011. 
BALINT, M. The doctor, his patients and the illness. $2^{\mathrm{a}}$ Edição. Nova lorque: International Universities Press, 1973.

BÉROD, A.C.; KLAY, M.; SANTOS-EGGIMANN, B.; PACCAUD, F. Anxiety, depressive or cognitive disorders in rehabilitation patients: effect on length of stay. American Journal of Physical Medicine and Rehabilitation, Estados Unidos, v.79. $n^{\circ} 3$, p.266-277, 2000.

BIJL, R.V.; GRAAF, R.; HIRIPI, E.; KESSLER, R.C.; KOHN, R.; OFFORD, D.R.; USTUN, T.B.; VICENTE, B.; VOLLEBERGH, W.A.M.; WALTERS, E.E.; WITTCHEN, H.U. The prevalence of treated and untreated mental disorders in five countries. Health Affairs, Washington, v.22, n³, p.122-133, 2003.

BOLAND, R.J.; DIAZ, S.; LAMDAN, R.M.; RAMCHANDANI, D.; McCARTNEY, J.R. Overdiagnosis of depression in the general hospital. General Hospital Psychiatry, Nova lorque, v.18, n¹, p.28-35, 1996.

BOTEGA, N.J.; PEREIRA, W.A.; GARCIA JR, C.; ZOMIGNANI, M.A. Psychiatric morbidity among medical in-patients: a standardized assessment (GHQ-12 and CISR) using lay interviewers in a Brazilian hospital. Social Psychiatry and Psychiatric Epidemiology, Estados Unidos, v.30, n³, p.127-131, 1995.

BOTEGA, N.J. Prática psiquiátrica no hospital geral: interconsulta e emergência. 2a Edição. Porto Alegre: Artmed Editora, 2006.

BOTEGA, N.J. AZEVEDO, R.C.S., MAURO, M.L.F.; MITSUUSHI, G.N.; FANGER, P.C.; LIMA, D.D.; GASPAR, K.C.; SILVA, V.F. Factors associated with suicide ideation among medically and surgically hospitalized patients. General Hospital Psychiatry, Nova lorque, v.32, n4, p.396-400, 2010.

BOURGEOIS, J.A.; KREMEN, W.S.; SERVIS, M.E.; WEGELIN, J.A.; HALES, R.E. The impact of psychiatric diagnosis on length of stay in a university medical center in the managed care era. Psychosomatics, Virginia, v.46, n5, p.431-439, 2005.

BOURGEOIS, J.A.; HILTY, D.M.; WEGELIN, J.A.; HALES, R.E. Cognitive-disorder diagnoses in inpatient psychosomatic-medicine consultations: associations with age and length of stay. Psychosomatics, Virginia, v.47, n5, p.414-420, 2006. 
BOURGEOIS, J.A.; WEGELIN, J.A.; SERVIS, M.E.; HALES, R.E. Psychiatric diagnoses of 901 inpatients seen by consultation-liaison psychiatrists at an Academic Medical Center in a managed care environment. Psychosomatics, Virginia, v.46, n¹, p.47-57, 2005.

BOURGEOIS, J.A.; WEGELIN, J.A. Lagtime in psychosomatic medicine consultations for cognitive-disorders patients: association with length of stay. Psychosomatics, Virginia, v.50, n6, p.622-625, 2009.

BRESSI, S.K.; MARCUS, S.C.; SOLOMON, P.L. The impact of psychiatric comorbidity on general hospital length of stay. Psychiatric Quarterly, Holanda, v.77, $\mathrm{n}^{\circ} 3$, p.203-209, 2006.

BROWN, A.; COOPER, F. The impact of a liaison psychiatry service on patterns of referral in a general hospital. British Journal of Psychiatry, Londres, v.150, p.8387, 1987.

BUSNELLO, E.D.; PEREIRA, M.O.; KNAPP, W.P. Morbidade psiquiátrica na população urbana de Porto Alegre. Jornal Brasileiro de Psiquiatria, Rio de Janeiro, v.41, $\mathrm{n}^{\circ} 10$, p.507-512, 1992.

CARR, V.J.; LEWIN, T.J.; WALTON, J.M.; FAEHRMANN, C.; REID, A.L.A. Consultation-liaison psychiatry in general practice. Australian and New Zealand Journal of Psychiatry, Sidney, v.31, n¹, p.85-94, 1997.

CARVALHO, T.F.R.; LIMA, M.G.; PONDÉ, M.P.; CAETANO, D. Diagnóstico em Interconsulta Psiquiátrica - experiência de uma pesquisa realizada no $\mathrm{HC}$ UNICAMP. Jornal Brasileiro de Psiquiatria, Rio de Janeiro, v.42, n³, p.157-160, 1993.

CASSORLA, R.M.S. Dificuldades no lidar com aspectos emocionais da prática médica: estudo com médicos no início de grupos Balint. Revista da Associação Brasileira de Psiquiatria - Asociación Psiquiatrica de La America Latina, São Paulo, v.16, n¹, p.18-24, 1994.

Censo Demográfico 2010 do Instituto Brasileiro de Geografia e Estatística. Disponível em: < http://www.ibge.gov.br/censo2010/>. Acesso em: maio de 2012.

CHANDARANA, P.C.; CONLON, P.; STEINBERG, N. The evaluation of a consultation-liaison service. General Hospital Psychiatry, Nove lorque, v.10, n5, 
p.378-381, 1988.

CHRISTODOULOU, C.; FINETI, K.; DOUZENIS, A.; MOUSSAS, G.; MICHOPOULOS, I.; LYKOURAS, L. Transfers to psychiatry through the consultationliaison psychiatry service: 11 years of experience. Annals of General Psychiatry, Inglaterra, v.7, $n^{\circ} 10$, sem número de página (page number not for citation purposes), 2008.

CLARKE, D.M.; SMITH, G.C. Consultation-liaison psychiatry in general medical units. Australian and New Zealand Journal of Psychiatry, Sidney, v.29, n`3, p.424-432, 1995.

COELHO, F.M.C. Prevalência de transtornos mentais comuns e fatores associados em adultos da cidade de Pelotas. 2006. 79 f. Dissertação (Mestrado em Saúde e Comportamento) - Universidade Católica de Pelotas, Pelotas, 2006.

COELHO, F.M.C.; PINHEIRO, R.T.; HORTA, B.L.; MAGALHÃES, P.V.S.; GARCIAS, C.M.M.; SILVA, C.V. Common mental disorders and chronic non-communicable diseases in adults: a population-based study. Cadernos de Saúde Pública, Rio de Janeiro, v.25, n¹, p.59-67, 2009.

COLLINS, D.; DIMSDALE, J.E.; WILKINS, D. Consultation-liaison psychiatry utilization patterns in different cultural groups. Psychosomatic Medicine, Flórida, v.54, n², p.240-245, 1992.

COSSIDENTE, A.; SARTI, M. Psychiatric syndromes with dermatologic expression. Clinics in Dermatology, Estados Unidos, v.2, no.4, p.201-220, 1984.

CRAIG, T.J. An epidemiologic study of a psychiatric liaison service. General Hospital Psychiatry, Nova lorque, v.4, n², p.131-137, 1982.

CREED, F.; GUTHRIE, E.; BLACK, D.; TRANMER, M. Psychiatric referrals within the general hospital: comparison with referrals to general practitioners. British Journal of Psychiatry, Londres, v.162, p.204-211, 1993.

DALGALARRONDO, P. Repensando a internação psiquiátrica: a proposta das unidades de internação psiquiátrica de hospitais gerais. 1990. 310 f. Dissertação (Mestrado em Medicina) - Faculdade de Ciências Médicas, Universidade Estadual de Campinas, Campinas, 1990. 
DE JONGE, P.; HUYSE, F.J.; RUINEMANS, G.M.F.; STIEFEL, F.C.; LYONS, J.S.; SLAETS, J.P.J. Timing of psychiatric consultations - the impact of social vulnerability and level of psychiatric dysfunction. Psychosomatics, Virginia, v.41, $n^{\circ} 6$, p.505-511, 2000.

Departamento de DST, AIDS e Hepatites Virais do Ministério da Saúde. Disponível em: < http://www.aids.gov.br/pagina/historia-da-aids>. Acesso em: maio de 2012.

DESAN, P.H.; ZIMBREAN, P.C.; WEINSTEIN, A.J.; BOZZO, J.E.; SLEDGE, W.H. Proactive psychiatric consultation services reduce length of stay for admissions to an inpatient medical team. Psychosomatics, Virginia, v.52, nº6, p.513-520, 2011.

DEVASAGAYAM, D.; CLARKE, D. Changes to inpatient consultation-liaison psychiatry service delivery over a 7-year period. Australasian Psychiatry, Estados Unidos, v.16, n6, p.418-422, 2008.

DHAVALE, H.S.; BARVE, R.G. Psychiatric referral pattern in general hospital. Journal of Postgraduate Medicine, India, v.36, n²4, p.199-202, 1990.

DHOSSCHE, D.M.; LORANT, Z. Psychiatric consultations in a southern university hospital. Southern Medical Journal, Estados Unidos, v.95, n4, p.446-449, 2002.

DIEFENBACHER, A. Implementation of a psychiatric consultation service - a singlesite observational study over a 1-year-period. Psychosomatics, Virginia, v.42, $n^{\circ} 5$, p.404-410, 2001.

DIEFENBACHER, A.; STRAIN, J.J. Consultation-liaison psychiatry: stability and change over 10-year-period. General Hospital Psychiatry, Nove lorque, v.24, $n^{\circ} 4$, p.249-256, 2002.

DOONGAJI, D.R.; NADKARNI, R.P.; BATHAWDEKAR, M.L. Psychiatric referrals in two general hospitals. Journal of Postgraduate Medicine, India, v.35, $n^{\circ} 3$, p.171177, 1989.

FAVA, G.A.; PAVAN, L. Consultation psychiatry in na italian general hospital - a report on 500 referrals. General Hospital Psychiatry, Nove lorque, v.2, $n^{\circ} 1$, p.3540, 1980.

FIDO, A.A.; MUGHAISSED, A.A. Consultation-liaison psychiatry in a Kuwaiti general 
hospital. International Journal of Social Psychiatry, v.35, n³, p.274-279, 1988.

FIGUEIREDO, G.R. A evolução do hospício no Brasil. 1996. 238 f. Tese (Doutorado em Medicina) - Escola Paulista de Medicina, Universidade Federal de São Paulo, São Paulo, 1996.

FORLENZA, O.V.; VIEIRA FILHO, A.H.G. Pertubações mentais associadas a doenças clínicas: diagnóstico, prevalência e considerações neurobiológicas. Jornal Brasileiro de Psiquiatria, Rio de Janeiro, v.46, n², p.89-96, 1997.

FULOP, G.; STRAIN, J.J.; VITA, J.; LYONS, J.S.; HAMMER, J.S. Impact of psychiatric comorbidity on length of hospital stay for medical/surgical patients: a preliminary report. The American Journal of Psychiatry, Estados Unidos, v.144, n7, p.878-882, 1987.

FURLANETTO, L.M.; SILVA, R.V.; BUENO, J.R. The impact of psychiatric comorbidity on length of stay of medical inpatients. General Hospital Psychiatry, Nova lorque, v.25, n¹, p.14-19, 2003.

FURLANETTO, L.M.; STEFANELLO, B. Suicidal ideation in medical inpatients: psychosocial and clinical correlates. General Hospital Psychiatry, Nova lorque, v.33, $n^{\circ} 6$, p.572-578, 2011.

GALA, C.; RIGATELLI, M.; BERTOLINI, C.; RUPOLO, G.; GABRIELLI, F.; GRASSI, L. A multicenter investigation of consultation-liaison psychiatry in Italy. General Hospital Psychiatry, Nova lorque, v.21, n4, p.310-317, 1999.

GELFAND, R.; KIELY, W.F. Psychiatric consultation to a general hospital medical evaluation service. General Hospital Psychiatry, Nova lorque, v.2, n¹, p.56-60, 1980.

GISPERT, R.; RAJMIL, L.; SCHIAFFINO, A.; HERDMAN, M. Sociodemographic and health-related correlates of psychiatric distress in a general population. Social Psychiatry and Psychiatric Epidemiology, Berlim, v.38, p.677-683, 2003.

GRANT, J.E.; MELLER, W.; UREVIG, B. Changes in psychiatric consultations over then years. General Hospital Psychiatry, Nova lorque, v.23, n5, p.261-265, 2001. 
GRIFFITHS, R.R.; ATOR, N.A. Benzodiazepine self-administration in animals and humans - a comprehensive literature review. National Institute on Drug Abuse Research Monographs, Estados Unidos, v.33, p.22-36, 1980.

HALES, R.E.; POLLY, S.; BRIDENBAUGH, H.; ORMAN, D. Psychiatric consultations in a military general hospital - a report on 1065 cases. General Hospital Psychiatry, Nova lorque, v.8, n³, p.173-182, 1986.

HALL, D.J. A psychiatric liaison service in a general hospital referrals and their appropriateness. Scottish Medical Journal, Inglaterra, v.39, n5, p.141-144, 1994.

HANDRINOS, D.; McKENZIE, D.; SMITH, G.C. Timing of referral to a consultationliaison psychiatry. Psychosomatics, Virginia, v.39, n², p.311-317, 1998.

HANSEN, M.S.; FINK, P.; FRYDENBERG, M.; OXHOJ, M.L.; SONDERGAARD, L.; MUNK-JORGENSEN, P. Mental disorders among internal medical inpatients prevalence, detection and treatment status. Journal of Psychosomatic Research, v.50, n4, p.199-204, 2001.

HATTORI, T. Consultation psychiatry in a Japanese general hospital: patients referred to psychiatric consultation. Folia Psychiatrica et Neurologica Japônica, v.39, p.115-120, 1985.

HAWRO, T.; KRUPINSKA-KUN, M.; RABE-JABLONSKA, J.; SYSAJEDRZEJOWSKA, A.; ROBAK, E.; BOGACZEWICZ, J.; WOZNIACKA, A. Psychiatric disorders in patients with systemic lupus erythematosus: association of anxiety disorder with shorter disease duration. Rheumatology International, Estados Unidos, v.31, n¹0, p.1387-1391, 2011.

HENGEVELD, M.W.; ROOYMANS, H.G.M.; BERGH, R.V.V.D. Psychiatric consultations in a dutch university hospital: a report on 1814 referrals compared with a literature review. General Hospital Psychiatry, Nova lorque, v.6, n4, p.271-279, 1984

HOLDEN, J.D.; HUGHES, I.A.; TREE, A. Benzodiazepine prescribing and withdrawal for 3234 patients in 15 general practices. Family Practice, Estados Unidos, v.11, n4, p.358-362, 1994.

HOLMES, A.; HANDRINOS, D.; THEOLOGUS, E.; SALZBERG, M. Australasian Psychiatry, Estados Unidos, v.19, n³, p.254-258, 2011. 
HOSAKA, T.; AOKI, T.; WATANABE, T.; OKUYAMA, T.; KUROSAWA, H. Comorbidity of depression among physically ill patients and its effect on the length of hospital stay. Psychiatry and Clinical Neurosciences, Japão, v.53, n4, p.491-495, 1999.

HUYSE, F.J.; HERZOG, T.; LOBO, A.; MALT, U.F.; OPMEER, B.C.; STEIN, B.; DE JONGE, P.; DIJCK, R.V.; CREED, F.; CRESPO, M.D.; CARDOSO, G.; GUIMARAES-LOPES, R.; MAYOU, R.; MOFFAERT, M.V.; RIGATELLI, M.; SAKKAS, P.; TIENARI, P. Consultation-liaison psychiatric service delivery: results from a European study. General Hospital Psychiatry, Nova lorque, v.23, $n^{\circ} 3$, p.124-132, 2001.

HUYSE, F.J.; LYONS, J.S.; STRAIN, J.J. Evaluating psychiatric consultations in the general hospital. General Hospital Psychiatry, Nova lorque, v.14, n6, p.363-369, 1992.

HUYSE, F.J.; STRAIN, J.J.; HAMMER, J.S. Interventions in consultation-liaison psychiatry - part I: patterns of recommendations. General Hospital Psychiatry, Nova lorque, v.12, n4, p.213-220, 1990.

KERR-CORRÊA, F.; SILVA, B.C.M. Avaliação do ensino de psiquiatria pela análise dos pedidos de interconsulta. Jornal Brasileiro de Psiquiatria, Rio de Janeiro, v.34, $\mathrm{n}^{\circ} 4$, p.247-252, 1985.

KESSLER, R.C.; McGONAGLE, K.A.; ZHAO, S.; NELSON, C.B.; HUGHES, M.; ESHLEMAN, S.; WITTCHEN, H.; KENDLER, K.S. Lifetime and 12-month prevalence of DSM-IIIR Psychiatric Disorders in the United States. Archives of General Psychiatry, Chicago, v.51, n¹, p.8-19, 1994.

KESSLER, R.C.; BERGLUND, P.A.; BRUCE, M.L.; KOCH, J.R.; LASKA, E.M.; LEAF, P.J.; MANDERSCHEID, R.W.; ROSENHECK, R.A.; WALTERS, E.E.; WANG, P.S. The prevalence and correlates of untreated serious mental illness. Health Services Research Journal, Chicago, v.36, n6, p.987-1007, 2001.

KING, M.; NAZARETH, I.; LEVY, G.; WALKER, C.; MORRIS, R.; WEICH, S.; BELLÓN-SAAMEÑO, J.A.; MORENO, B.; SVAB, I.; ROTAR, D.; RIFEL, J.; MAAROOS, H.I.; ALUOJA, A.; KALDA, R.; NEELEMAN, J.; GEERLINGS, M.I.; XAVIER, M.; ALMEIDA, M.C.; CORREA, B.; TORRES-GONZALEZ, F. Prevalence of common mental disorders in general practice attendees across Europe. British Journal of Psychiatry, Londres, v.192, p.362-367, 2008. 
KISHI, Y.; MELLER, W.H.; KATHOL, R.G.; SWIGART, S.E. Factors affecting the relationship between the timing of psychiatric consultation and general hospital length of stay. Psychosomatics, Virginia, v.45, n6, p.470-476, 2004.

KISHI, Y.; MELLER, W.H.; KATO, M.; THURBER, S.; SWIGART, S.E.; OKUYAMA, T.; MIKAMI, K.; KATHOL, R.G. HOSAKA, T.; AOKI, T. A comparison of psychiatric consultation-liaison services between hospitals in the United States and Japan. Psychosomatics, Virginia, v.48, n6, p.517-522, 2007.

KOOPMANS, G.T.; DONKER, M.C.H.; RUTTEN, F.H.H. Length of hospital stay and health services use of medical inpatients with comorbid noncognitive mental disorders: a review of the literature. General Hospital Psychiatry, Nove lorque, v.27, n¹, p.44-56, 2005.

KORTEN, A.; HENDERSON, S. The australian national survey of mental health and well-being: common psychological symptoms and disablement. British Journal of Psychiatry, Londres, v.177, p.325-330, 2000.

KUHN, W.F.; BELL, R.A.; FRIERSON, R.L.; LIPPMANN, S.B. Consultative psychiatry in both private and public general hospitals. General Hospital Psychiatry, Nove lorque, v.8, n4, p.236-240, 1986.

LARANJEIRA, R.; PINSKY, I.; ZALESKI, M.; CAETANO, R.I. Levantamento Nacional sobre os padrões de consumo de álcool na população brasileira. São Paulo: Centro Brasileiro de Informações sobre Drogas Psicotrópicas, Escola Paulista de Medicina; 2007.

LEO, R.J.; SHERRY, C.; JONES, A.W. Referral patterns and recognition of depression among African-american and Caucasian patients. General Hospital Psychiatry, Nove lorque, v.20, n³, p.175-182, 1998.

LEUNG, C.M.; CHAN, K.K.; CHENG, K.K. Psychiatric morbidity in a general medical ward - Hong Kong's experience. General Hospital Psychiatry, Nove lorque, v.14, n³, p.196-200, 1992.

Levantamento domiciliar sobre o uso de drogas psicotrópicas no Brasil, 2005, da Secretaria Nacional Antidrogas. Disponível em: <http://www.obid.senad.gov.br/>. Acesso em: maio de 2012.

LIMA, M.C.P. Transtornos mentais comuns e uso de álcool na população 
urbana de Botucatu. 2004. 221 f. Tese (Doutorado em Ciências) - Faculdade de Medicina, Universidade de São Paulo, São Paulo, 2004.

LIMA, M.C.P.; SOARES, B.G.O.; MARI, J.J. Saúde e doença mental em Pelotas, RS: dados de um estudo populacional. Revista de Psiquiatria Clínica (São Paulo), São Paulo, v.26, n5, p.225-235, 1999.

LIN, E.H.B.; KORFF, M.V. Mental disorders among persons with diabetes - results from the World Mental Health Surveys. Journal of Psychosomatic Research, v.65, $\mathrm{n}^{\circ} 6, \mathrm{p} .571-580,2008$.

LIPOWSKI, Z.J. Review of consultation psychiatry and psychosomatic medicine - II. Clinical aspects. Psychosomatic Medicine, Flórida, v.29, n¹, p.201-224, 1967.

LIPOWSKI, Z.J.; WOLSTON, E.J. Liaison psychiatry: referral patterns, and their stability over time. American Journal of Psychiatry, Estados Unidos, v.138, $\mathrm{n}^{\circ} 12$, p.1608-1611, 1981.

LLORENTE, M.D.; URRUTIA, V. Diabetes, psychiatric disorders and the metabolic effects of antipsychotic medications. Clinical Diabetes, Estados Unidos, v.24, $\mathrm{n}^{\circ} 1$, p.18-24, 2006.

LOBO, A.; HUYSE, F.J.; HERZOG, T.; MALT, U.; OPMEER, B.C. The ECLW Collaborative study II: patient registration form (PRF) instrument, training and reliability. European Consultation/Liaison Work group. Journal of Psychosomatic Research, v.40, n², p.143-156, 1996.

LOEWENSTEIN, R.J.; SHARFSTEIN, S.S. Psychiatric consultations at the NIH. General Hospital Psychiatry, Nova lorque, v.5, n², p.83-87, 1983.

LUCAS, B.; DOYLE, H. Thirty years of in-patient consultation-liaison psychiatry at Guy's. Psychiatric Bulletin, Inglaterra, v.19, p.631-634, 1995.

LUDERMIR, A.B.; MELO FILHO, D.A. Condições de vida e estrutura ocupacional associadas a transtornos mentais comuns. Revista de Saúde Pública, São Paulo, v.36, n², p.213-221, 2002.

LYONS, J.S.; HAMMER, J.S.; STRAIN, J.J.; FULOP, G. The timing of psychiatric consultation in the general hospital and length of hospital stay. General Hospital 
Psychiatry, Nova lorque, v.8, n³, p.159-162, 1986.

MAGDALENO, JR., R.; BOTEGA, N.J. Interconsulta psiquiátrica no hospital geral universitário: um ano no Hospital das Clínicas da UNICAMP. Jornal Brasileiro de Psiquiatria, Rio de Janeiro, v.40, n², p.95-98, 1991.

MAIA, A.C.C.O.; BRAGA, A.A.; BROUWERS, A.; NARDI, A.E. SILVA, A.C.O. Prevalence of psychiatric disorders in patients with diabetes types 1 and 2 . Comprehensive Psychiatry, Estados Unidos, 2012. No prelo.

MALHOTRA, S,; MALHOTRA, A. Liaison psychiatry in na indian general hospital. General Hospital Psychiatry, Nova lorque, v.6, n², p.266-270, 1984.

MARAGNO, L.; GOLDBAUM, M.; GIANINI, R.J.; NOVAES, H.M.D.; CÉSAR, C.L.G. Prevalência de transtornos mentais comuns em populações atendidas pelo Programa Saúde da Família (QUALIS) no município de São Paulo. Cadernos de Saúde Pública, Rio de Janeiro, v.22, n8, p.1639-1648, 2006.

MAYOU, R. What should British consultation-liaison psychiatry be doing? General Hospital Psychiatry, Nova lorque, v.13, n4, p.261-266, 1991.

MAYOU, R.; HAWTON, K. Psychiatric disorder in the general hospital. British Journal of Psychiatry, Londres, v.149, p.172-190, 1986.

MAYOU, R.; SIMKIN, S.; COBB, A. Use of psychiatric services by patients referred to a consultation unit. General Hospital Psychiatry, Nova lorque, v. 16, n5, p.354-357, 1994.

McKEGNEY, F.P.; McMAHON, T.; KING, J. The use of DSM-III in a general hospital consultation-liaison service. General Hospital Psychiatry, Nova lorque, v.5, $n^{\circ} 2$, p.115-121, 1983.

MEDEIROS, D. Tabagismo e transtorno mental comum na população de São Paulo: um estudo a partir do Inquérito de Saúde no Município de São Paulo (ISACAPITAL). 2010. 158 f. Dissertação (Mestrado em Saúde Pública) - Faculdade de Saúde Pública, Universidade de São Paulo, São Paulo, 2010.

MILLAN, L.R.; MIGUEL FILHO, E.C.; LIMA, M.G.A.; FRÁGUAS JR, R.; GIMENES, R. Psiquiatria no hospital geral: experiência de um ano. Revista de Psiquiatria 
Clínica, São Paulo, v.13, n¹/4, p.33-38, 1986.

MORGADO, A.F.; COUTINHO, E.S.F. Dados de epidemiologia descritiva de transtornos mentais em grupos populacionais do Brasil. Cadernos de Saúde Pública, Rio de Janeiro, v.1, n³, p.327-347, 1985.

NAKABAYASHI, T.I.K.; GUERRA, K.A.; SOUZA, R.M.; LOUREIRO, S.R.; CONTEL, J.O.; CABRERA, C.C.; HALLAK, J.E.C.; OSÓRIO, F.L.; LEAL, C.G.; RUFINO, A.C.T.B.F.; CRIPPA, J.A.S. Comparação entre solicitações psiquiátricas de dois hospitais gerais universitários brasileiros: uso do protocolo de registro de Interconsulta em Saúde Mental. Cadernos de Saúde Pública, Rio de Janeiro, v.26, n6, p.1246-1260, 2010.

NAKAO, M.; SATO, M.; NOMURA, K.; YANO, E. Benzodiazepine prescription and length of hospital stay at a Japanese university hospital. BioPsychoSocial Medicine, Japão, v.3, n¹0, 2009.

NARROW, W.E.; RAE, D.S.; ROBINS, L.N.; REGIER, D.A. Revised prevalence estimates of mental disorders in the United States. Archives of General Psychiatry, Chicago, v.59, n², p.115-123, 2002.

NEEHALL, J.; BEHARRY, N. The pattern of in-patient psychiatric referrals in a general hospital. West Indian Medical Journal, Jamaica, v.42, n4, p.155-157, 1993.

ORMONT, M.A.; WEISMAN, H.W.; HELLER, S.S.; NAJARA, J.E.; SHINDLEDECKER, R.D. The timing of psychiatric consultation requests - utilization, liaison and diagnostic considerations. Psychosomatics, Virginia, v.38, n¹, p.38-44, 1997.

OZKAN, S.; YUCEL, B.; TURGAY, M.; GUREL, Y. The development of psychiatric medicine at Istanbul Faculty of Medicine and evaluation of 889 psychiatric referrals. General Hospital Psychiatry, Nova lorque, v. 17, n³, p.216-223, 1995.

PARADA, B.V.; RIOSECO, P.; SALDIVIA, S.; KOHN, R.; TORRES, S. Estudio chileno de prevalencia de patología psiquiátrica: DSM-IIIR/CIDI. Revista Médica de Chile / Sociedad Médica de Santiago de Chile, Santiago, v.130, n5, p.527-536, 2002

PARADISI, A.; SAMPOGNA, F.; PIETRO, C.; CIANCHINI, G.; DIDONA, B.; FERRI, 
R.; ABENI, D.; TABOLLI, S. Quality-of-life assessment in patients with pemphigus using a minimun set of evaluation tools. Journal of the American Academy of Dermatology, Estados Unidos, v.60, n², p.261-269, 2009.

PEH, L.H.; TAY, W.K. Psychiatric referral pattern in a general hospital. Singapore Medical Journal, Singapura, v.31, n¹, p.42-45, 1990.

PEREZ, E.L.; SILVERMAN, M. Utilization pattern of a canadian psychiatric consultation service. General Hospital Psychiatry, Nova lorque, v.5, n`3, p.185190, 1983.

REBOLLEDO, M.M.; GANGAS, A.M.N.; LAVIN, M.O.; DELGADO, M.C. Psiquiatria de enlace em Concepcion. Revista de Psiquiatria Santiago do Chile, Chile, v.12, n॰3/4, p.190-194, 1995.

REGIER, D.A.; BOYD, J.H.; BURKE, J.D.; RAE, D.S.; MYERS, J.K.; KRAMER, M.; ROBINS, L.N.; GEORGE, L.K.; KARNO, M.; LOCKE, B.Z. One month prevalence of mental disorders in the United States. Archives of General Psychiatry, Chicago, v.45, n¹1, p.977-986, 1988.

REICHENHEIM, M.E.; HARPHAM, T. Maternal mental health in a squatter settlement in Rio de Janeiro. British Journal of Psychiatry, Londres, v.159, p.683-690, 1991.

RIEDER, E.; TAUSK, F. Psoriasis, a model of dermatologic psychosomatic disease: psychiatric implications and treatments. International Journal of Dermatology, Estados Unidos, v.51,n¹, p.12-26, 2012.

RIES, R.K.; KLEINMAN, A.; BOKAN, J.A.; SCHUCKIT, M.A. Psychiatric consultationliaison service - patients, requests and functions. General Hospital Psychiatry, Nova lorque, v.2, n³, p.204-212, 1980.

ROTHENHÄUSLER, H.B.; EHRENTRAUT, S.; KAPFHAMMER, H.P. Changes in patterns of psychiatric referral in a German general hospital: results of a comparison of two 1-year surveys 8 years apart. General Hospital Psychiatry, Nova lorque, v.23, $n^{\circ} 4$, p.205-214, 2001.

RUSSO, P.A.J.; ILCHEF, R.; COOPER, A.J. Psychiatric morbidity in psoriasis: a review. Australasian Journal of Dermatology, Nova Zelândia, v.45, n³, p.155161, 2004. 
SALVO, L.; CASTRO, J. Psiquiatria de enlace en um hospital general. Revista de Psiquiatría y Salud Mental, Espanha, v.20, n4, p.223-230, 2003.

SAMPOGNA, F.; TABOLLI, S.; ABENI, D. The impact of changes in clinical severity on psychiatric morbidity in patients with psoriasis: a follow-up study. British Journal of Dermatology, Inglaterra, v.157, n³, p.508-513, 2007.

SARAVAY, S.M.; LAVIN, M. Psychiatric comorbidity and length of stay in the general hospital: a critical review of outcome studies. Psychosomatics, Virginia, v.35, $n^{\circ} 3$, p.233-252, 1994.

SARAVAY, S.M.; POLLACK, S.; STEINBERG, M.D.; WEINSCHEL, B.; HABERT, M. Four-year follow-up of the influence of psychological comorbidity on medical rehospitalization. The American Journal of Psychiatry, Estados Unidos, v.153, n`3, p.397-403, 1996.

SCHELLHORN, S.E.; BARNHILL, J.W.; RAITERI, V.; LO FASO, V.; FERRANDO, S.J. A comparison of psychiatric consultation between geriatric and non-geriatric medical inpatients. International Journal of Geriatric Psychiatry, Inglaterra, v.24, $\mathrm{n}^{\circ} 10$, p.1054-1061, 2009.

SCHOFIELD, A.; DOONAN, H.; DALY, R.J. Liaison psychiatry in an irish hospital: a survey of a year's experience. General Hospital Psychiatry, Nova lorque, v.8, n`2, p.119-122, 1986.

Secretaria Estadual de Saúde: Direção Regional de Saúde de Ribeirão Preto. Ribeirão Preto (SP); 1997.

SELTZER, A. Prevalence, detection and referral of psychiatric morbidity in general medical patients. Journal of the Royal Society of Medicine, Inglaterra, v.82, $\mathrm{n}^{\circ} 7$, p.410-412, 1989.

SHAVITT, R.G.; BUSATTO FILHO, G.; MIGUEL FILHO, E.C. Interconsulta psiquiátrica: conceito e evolução. Revista Paulista de Medicina, São Paulo, v.107, $\mathrm{n}^{\circ} 2$, p.108-112, 1989.

SHEEHAN, D.; LECRUBIER, Y.; SHEEHAN, K.H.; AMORIM, P.; JANAVS, J.; WEILLER, E.; HERGUETA, T.; BAKER, R.; DUNBAR, G.C. The Mini International Neuropsychiatric Interview (MINI): The Development and Validation of a Structured 
Diagnostic Psychiatric Interview for DSM-IV and ICD-10. Journal of Clinical Psychiatry, Estados Unidos, v.59, n59, p.22-33, 1998.

SILVA, N.G.; OLIVEIRA, A.G.B.; IDE P.H. Demandas de atendimento psiquiátrico em um hospital universitário. Revista Gaúcha de Enfermagem, Porto Alegre, v.32, $n^{\circ} 3,531-538,2011$.

SILVERSTONE, P.H. Prevalence of psychiatric disorders in medical inpatients. Journal of Nervous and Mental Disease, Baltimore, v.184, n¹, p.43-51, 1996.

SMAIRA, S.I. Transtornos psiquiátricos e solicitações de interconsulta psiquiátrica em Hospital Geral: um estudo de caso controle. 1998. Tese (Doutorado em Saúde Mental) - Faculdade de Medicina de Ribeirão Preto, Universidade de São Paulo, Ribeirão Preto, 1999.

SMAIRA, S.I.; KERR-CORRÊA, F.; CONTEL, J.O.B. Psychiatric disorders and psychiatric consultation in a general hospital: a case-control study. Revista Brasileira de Psiquiatria, São Paulo, v.25, n¹, p.18-25, 2003.

SOBEL, S.N.; MUNITZ, H.; KARP, L. Psychiatric consultations in two israeli general hospitals. General Hospital Psychiatry, Nova lorque, v.10, n4, p.298-304, 1988.

SOUZA, J.R.P. Consultoria psiquiátrica na Santa Casa de Campo Grande. Jornal Brasileiro de Psiquiatria, Rio de Janeiro, v.44, n³, p.123-128, 1995.

SPINELLI, M.A.; TOLEDO, M.L.; CANTINELLI, F. Psiquiatria de Interconsulta no Hospital Geral: comunicação inicial de uma experiência. Revista da Associação Médica Brasileira, São Paulo, v.42, n³, p.175-184, 1996.

SRINIVASAN, K.; BABU, R.K.; APPAYA, P.; SUBRAHMANYAM, H.S. A study of inpatient referral patterns to a general hospital psychiatry unit in India. General Hospital Psychiatry, Nova lorque, v.9, n5, p.372-375, 1987.

STOJANOVICH, L.; ZANDMAN-GODDARD, G.; PAVLOVICH, S.; SIKANICH, N. Psychiatric manifestations in systemic lupus erythematosus. Autoimmunity Reviews, v.6, n6, p.421-426, 2007.

TABOLLI, S.; MOZZETTA, A.; ANTINONE, V.; ALFANI, S.; CIANCHINI, G.; ABNI, D. The health impact of pemphigus vulgaris and pemphigus foliaceus assessed using 
the Medical Outcomes Study 36-item short form health survey questionnaire. British Journal of Dermatology, Inglaterra, v.158, n5, p.1029-1034, 2008.

Tábuas de Mortalidade, 1980 e 2010, do Instituto Brasileiro de Geografia e Estatística. Disponível em: < http://www.ibge.gov.br/>. Acesso em: maio de 2012.

TAPIA, P.; EVA, P.; ORTIZ, L. Programa de psiquiatria de enlace e interconsulta psiquiatrica en un hospital general. Revista Chilena de Neuro-Psiquiatria, Chile, v.35, n², p.197-201, 1997.

TENNEN, G.B.; RUNDELL, J.R.; STEVENS, S.R. Mortality in medical-surgical inpatients referred for psychiatric consultation. General Hospital Psychiatry, Nova lorque, v.31, n4, p.341-346, 2009.

TERRONI, L.M.N.; SILVA, G.V.; ESTEVÃO, G. Álcool e drogas no hospital geral: subdiagnóstico. Temas (São Paulo), São Paulo, v.33, n64/65, p.54-61, 2003.

TOREM M.; SARAVAY, S.K.; STEINBERG, H. Psychiatric liaison: Benefits of an "active" approach. Psychosomatics, Virginia, v.2, n9, p.598-611, 1979.

TORO, J.S.; LIZAMA, M.S.; SEGUEL, P.M. Interconsultas psiquiatricas en un hospital geral. Revista de Psiquiatria Clínica, Santiago do Chile, v.31, n², p.91-98, 1994.

TSOI, W.F.; KOK, L.P. Liaison psychiatry - referral pattern in a general hospital. Singapore Medical Journal, Singapura, v.24, n5, p.269-275, 1983.

VALDÉS, M.; PABLO, J.; CAMPOS, R.; FARRÉ, J.M.; GIRÓN, M.; LOZANO, M.; AIBAR, C.; GARCÍA-CAMBA, E.; CALVO, A.M.; CARRERAS, S.; STEIN, B.; HUYSE, F.; HERZOG, T.; LOBO, A. El proyecto multinacional europeo y multicêntrico español de mejora de calidad asistencial en psiquiatria de enlace en el hospital general: el perfil clínico en España. Medicina Clinica, Espanha, v.115, n¹8, p.690-694, 2000.

VAZ, F.J.; SALCEDO, M.S. A model for evaluating the impact of consultation-liaison psychiatry activities on referral patterns. Psychosomatics, Virginia, v.37, n`3, p.289298, 1996.

VECHI, L. G. latrogenia e exclusão social: a loucura como objeto do discurso científico no Brasil. Revista Estudos de Psicologia, São Paulo, v.9, n³, p.489-495, 
2004.

VEGA, W.A.; KOLODY, B.; AGUILAR-GAXIOLA, S.; ALDERETE, E.; CATALANO, R.; CARAVEO-ANDUAGA, J. Lifetime prevalence of DSM-IIIR psychiatric disorders among urban and rural mexican americans in California. Archives of General Psychiatry, Chicago, v.55, n॰9, p.771-778, 1998.

VIANA, M.C.; TEIXEIRA, M.G.; BERALDI, F.; BASSANI, I.S.; ANDRADE, L.H. São Paulo Megacity Mental Health Survey - a population-based epidemiological study of psychiatric morbidity in the São Paulo metropolitan area: aims, design and field implementation. Revista Brasileira de Psiquiatria, São Paulo, v.31, n4, p.375-386, 2009.

VINCENTE, B.; KOHN, R.; RIOSECO, P.; SALDIVIA, S.; LEVAV, I.; TORRES, S. Lifetime and 12-month prevalence of DSM-IIIR disorders in the Chile psychiatric prevalence study. American Journal of Psychiatry, Estados Unidos, v.163, $\mathrm{n}^{\circ} 8$, p.1362-1370, 2006.

WANCATA, J.; BENDA, N.; WINDHABER. J.; NOWOTNY, M. Does psychiatric comorbidity increase the length of stay in general hospitals? General Hospital Psychiatry, Nova lorque, v.23, $n^{\circ 1}$, p.08-14, 2001.

WEICH, S.; LEWIS, G.; JENKINS, S.P. Income inequality and the prevalence of common mental disorders in Britain. British Journal of Psychiatry, Londres, v.178, p.222-227, 2001.

WEKKING, E.M. Psychiatric symptoms in systemic lupus erythematosus: an update. Psychosomatic Medicine, Flórida, v.55, n², p.219-228, 1993.

WORLD MENTAL HEALTH SURVEY CONSORTIUM. Prevalence, severity and unmet need for treatment of mental disorders in the World Health Organization World Mental Health Surveys. Journal of the American Medical Association, Estados Unidos, v.291, n²1, p.2581-2590, 2004.

WILKINSON, P.; BOLTON, J.; BASS, C. Older patients referred to a consultationliaison psychiatry clinic. International Journal of Geriatric Psychiatry, Inglaterra, v.16, $n^{\circ} 1$, p.100-105, 2001.

WISE, T.N.; MANN, L.S.; DOVE, H.W.; PLUCHIK, E.; KIERNAN, K.W. Patient's perceptions of psychiatric consultations. Comprehensive Psychiatry, Estados 
Unidos, v.26, n6, p.554-557, 1985.

YASSINI, S.M.; YASSINI, S.; YAZDI, F.M.; POORMOVAHED, Z.; KHOLASEZADEH, G. Evaluation of psychiatric consultations in Yazd Shahid Sadughi general hospital. Procedia - Social and Behavioral Sciences, v.30, p.1561-1564, 2011.

ZIGMOND, A.S.; SNAITH, R.P. The hospital anxiety and depression scale. Acta Psychiatrica Scandinavica, Dinamarca, v.67, p.361-370, 1983.

ZUO, C.; YANG, L.; CHU, C.C. Patterns of psychiatric consultation in a chinese general hospital. American Journal of Psychiatry, Estados Unidos, v.142, $\mathrm{n}^{\circ}$, p.1092-1094, 1985. 


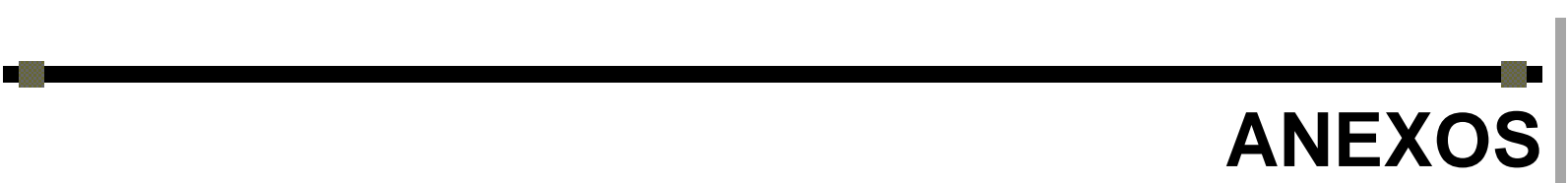


$\begin{array}{llll}\text { Setor: } & \text { (1) Psiquiatria (1) Psicologia (2)Terapia Ocupacional }\end{array}$

\section{DADOS DEMOGRÁFICOS}

Nome do Paciente (Iniciais):

Idade:

Estado civil:

Vive com:

Procedência Cor ou raça (IBGE):

Situação laboral:

(0) Autônomo

(1) Empregado informalmente (free lancer)

(2) Empregado formalmente

(3) Cuidando do lar

(4) Estudante

(5) Desempregado

(6) Inativo (Aposentado por invalidez - incapaz)

(7) Inativo (Aposentado por tempo de serviço)

(8) Afastado

(9) Outros

(1) Sozinho(a) (1) Com cônjuge
Registro No:
anos
Sexo:
(0) $F$ (1) $M$

(1) Solteiro (1) Casado/Amasiado

(2) Separado/Desquitado

(3) Viúvo

(9) ?

(4) Com os pais (5) Com parente(s)

(2) Só, com filho(a)(s) (3) Com cônjuge e filhos

(D) Ribeirão Preto (1) Estado de SP

(2) Outro estado (3) Outro país

(1) Branca (1) Preta (2) Parda (3) Amarela (4) Índio

Escolaridade: anos
(0) Analfabeto
(1) Ensino fundamental incompleto
(2) Ensino fundamental completo
(3) Ensino médio incompleto
(4) Ensino médio completo
(5) Ensino superior incompleto
(6) Ensino superior completo
(7) Mais de uma faculdade/ Pós-graduação

\section{DADOS DO PEDIDO DE INTERCONSULTA}

Tipo de pedido:

Solicitação:

(0) Urgência (plantão)

(0) Verbal

(1) Escrita

(1) Regular

(2) Ambos
(2) Ligação

Clínica solicitante:

Está registrado o nome do solicitante?: $\quad$ (1) $\mathrm{N}$ (1) $\mathrm{S}$

Função do Solicitante: (0) Médico residente/Aprimorando

$$
\text { (5) Terapeuta Ocupacional (6) Enfermeiro/Auxiliar }
$$

(1) Médico assistente (2) Docente

(3) Aluno/Doutorando

(4) Psicólogo

Data do Pedido de Interconsulta:

Legibilidade do pedido:

(0) Total (1) Parcial (2) llegível

Está descrito o motivo da solicitação?: $\quad$ (1) $\mathrm{N}$ (1) $\mathrm{S}$

Motivo MAIS IMPORTANTE do pedido (Se citado):

(0) Risco suicida

(1) Sintomas psiquiátricos presentes

(2) Sintomas físicos mal definidos/origem psicológica?

(3) Doença de etiologia associada a fatores psicossociais

(4) Abuso de psicotrópicos /substâncias psicoativas

(5) Avaliação quanto ao uso de psicotrópicos
(6) Psicodiagnóstico
(7) Problemas quanto a cooperação no tratamento/ adesão/manejo
(8) Aval para procedimentos mutilantes/ de risco/ sem consentimento formal
(9) Antecedentes psiquiátricos
(10) Atendimento ao familiar
(11) Ociosidade/internação longa

12 Outros

0 solicitante manifesta expectativa para 0 atendimento?:

O solicitante descreveu o diagnóstico clínico?: Se SIM qual(is)(múltiplos):

A.
(0) $\mathrm{N}$
(1) $S$
(1) $\mathrm{N}$ (1) $\mathrm{S}$

B.

C.

O solicitante redigiu o possível diagnóstico psiquiátrico?: Se SIM qual(is)(múltiplos) (CID X e por extenso):

$\begin{array}{ll}\text { (0) } \mathrm{N} & \text { (1) } \mathrm{S} \\ \text { a). } \mathrm{F} . & \text { Nome } \\ \text { b). } \mathrm{F} . & \text { Nome } \\ \text { c). } \mathrm{F} & \text { Nome }\end{array}$




\section{AVALIAÇÃO E DIAGNÓSTICO}

Data da Resposta da Interconsulta:

Paciente com alta antes da avaliação

0 paciente foi informado da consulta?

(1) N (1) $S$ (2) Óbito (3) Alta a pedido

Assistência em saúde mental antes da internação:

(1) $N$ (1) $S$

Se SIM qual(is)(múltiplos):

(0) Tratamento psiquiátrico ambulatorial prévio

(a) $\mathrm{N}$ (1) $\mathrm{S}$

(1) Tratamento psiquiátrico ambulatorial atual

(4) Psicofarmacoterapia

(2) Semi-internação

(3) Internação psiquiátrica prévia (Se $\underline{\mathrm{SIM}}$, quantas)

(5) Psicoterapia

(6) Terapia Ocupacional

Risco Suicida Atual: $\quad$ (1) $N$ (1) $S$

Tentativas anteriores (1) $N$ (1) $S$

(Se $\underline{\text { SIM}}$, quantas)

$O$ paciente tem condições de informar sobre si? (1) $N$ (1) $S$ Se NÃO, quem foi o informante:

Diagnóstico psiquiátrico (CID X e por extenso): Se SIM qual(is)(múltiplos):

a). F.

b). F.

c). F.

(9) Não Aplicável

Nome

Nome

Nome

Diagnóstico Somático Principal (por extenso):

Medicação psicotrópica atualmente em uso e prescrita antes da avaliação do interconsultor? (1) N (1) $S$

Se SIM, qual(is)? (incluir a dose - nome genérico):

A.

B.

C.

\section{CONDUTA E DESFECHO}

Medicação prescrita pelo interconsultor?:

(1) $\mathrm{N}$ (1) $\mathrm{S}$

Se SIM, qual(is)? (incluir a variação da dose): $A$.

B. $\overline{\text { C. }}$

Plano de tratamento (Múltiplos):
(0) Atendimento individual
(5) Sugestão/ prescrição de psicofármacos
(1) Atendimento grupal
(2) Atendimento de familiares
(6) Sugestão de exames/ outras avaliações/ outros profissionais
(3) Orientação à equipe
(7) Orientação a outras instituições
(8) Encaminhamento(s) especializado(s). Se $\underline{\text { SIM}}$, qual(is)

(4) Orientação aos familiares

Profissionais contatados até a alta (múltiplos): (0) Médico residente/Aprimorando

(3) Aluno/Doutorando

(4) Psicólogo

(5) Terapeuta Ocupacional

(6) Enfermeiro/Auxiliar

(1) Médico assistente

(8) Outros

Foi feito reunião com a equipe solicitante?

(1) $N$ (1) $S$

Se SIM, quantas

$O$ paciente recebeu alta médica antes de o interconsultor ser comunicado? (1) $N$ (1) $S$ (2) Óbito (3) Alta a pedido

$\mathrm{O}$ interconsultor recomendou seguimento em saúde mental posterior? (1) $\mathrm{N}$ (1) $\mathrm{S}$
Se SIM, qual(is)?
(0) Psiquiátrico
(1) Psicoterápico
(2) Terapia Ocupacional

\section{0 caso foi discutido com supervisor? \\ (1) $\mathrm{N}$ \\ (1) $S$ \\ (9) Não Aplicável}

Número total de atendimentos (incluindo a primeira avaliação):

Data da internação:

Data da alta: Número de dias internado: 


\section{APROVAÇÃO PELO COMITÊ DE ÉTICA EM PESQUISA DO HCFMRP-USP}

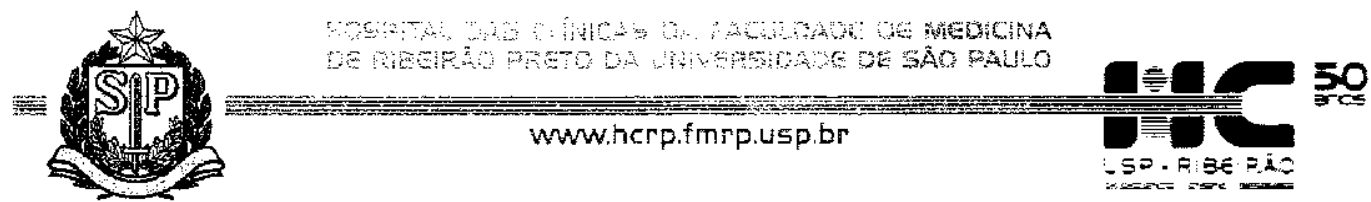

Ribeirão Preto, 07 de fevereiro de $200 \bar{x}$

Oficio $\mathrm{n}^{\circ} 324 / 2007$

CEP/SPC

Prezada Senhora,

O projeto de pesquisa intitulado:

“CARACTERIZAÇÃO DO PADRÃO DE SOLICITAÇÕES PSIQUIÁTRICAS EM UM HOSPITAL GERAL: ESTABILIDADE E MUDANÇAS EM UM PERÍODO DE 25 ANOS DE UM SERVIÇO DE INTERCONSULTA", foi analisado pelo Comitê de Ética em Pesquisa, em sua $240^{a}$ Reunião Ordinária realizada em 05/02/2007, e enquadrado na categoria: APROVADO, de acordo com o Processo HCRP $\mathrm{n}^{\circ} 14139 / 2006$. Lembramos que devem ser encaminhados a este CEP relatórios semestrais e relatório final da pesquitsa.

Atenciosamente.

PROF. DR. SÉRGIO PEREIRA DA CUNHA

Coordenador do Comitê de Ética em

Pesquisa do HCRP e da FMRP-USP

Ilustrissima Senhora

TATIANA IURIKO KAWASAKI NAKABAYASHI

PROF. DR. JOSÉ ALEXANDRE DE SOUZA CRIPPA (Orientador)

Depto. de Neurologia, Psiquiatria e Psicologia Médica - Saúde Mental 


\section{DEPARTAMENTO DE NEUROLOGIA, PSIQUIATRIA E PSICOLOGIA MÉDICA \\ HOSPITAL DAS CLÍNICAS \\ FACULDADE DE MEDICINA DE RIBEIRÃO PRETO UNIVERSIDADE DE SÃO PAULO}

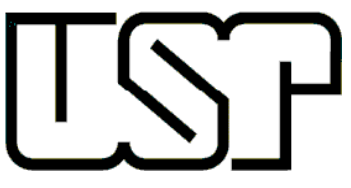

Ribeirão Preto, 13 de novembro de 2006.

Prezado Professor Doutor Sérgio Pereira da Cunha,

O projeto de pesquisa intitulado: “Caracterização do padrão de solicitações psiquiátricas em um hospital geral: estabilidade e mudanças em um período de 30 anos de um serviço de interconsulta", elaborado por Tatiana luriko Kawasaki Nakabayashi com orientação do Prof. Dr. José Alexandre de Souza Crippa, será realizado mediante análise dos prontuários dos pacientes que estiveram internados no Hospital das Clínicas da Faculdade de Medicina de Ribeirão Preto no período entre 1981 a 2007, portanto, solicita-se a dispensa do Termo de Consentimento Livre e Esclarecido para a realização desta pesquisa.

Atenciosamente,

Tatiana luriko Kawasaki Nakabayashi

Bacharel em Psicologia

Prof. Dr. José Alexandre de Souza Crippa

Professor Doutor do Departamento de Neurologia,

Psiquiatria e Psicologia Médica da Faculdade de Medicina de Ribeirão Preto da Universidade de São Paulo 


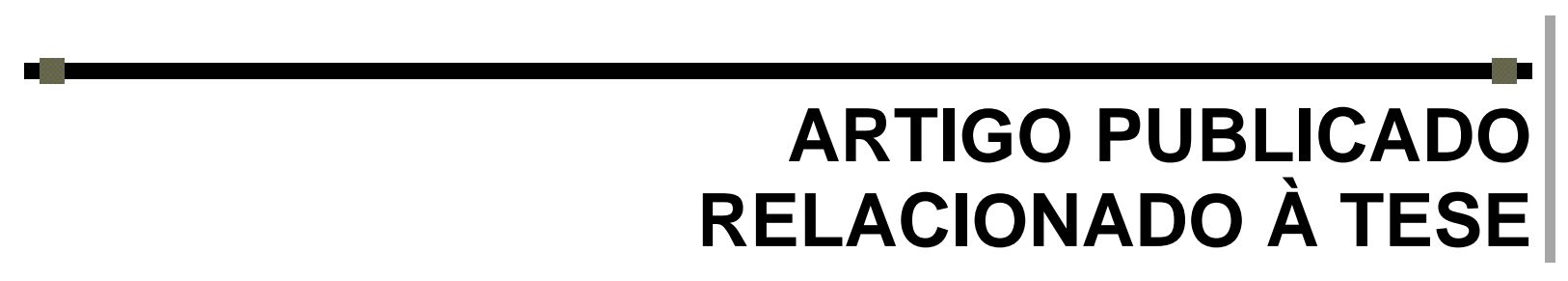




\section{Comparação entre solicitações psiquiátricas de dois hospitais gerais universitários brasileiros: uso do protocolo de registro de interconsulta em saúde mental}

\author{
A comparison of consultative psychiatric services \\ in two Brazilian university hospitals using a \\ standardized protocol for recording liaison \\ consultations
}

\author{
Tatiana Iuriko Kawasaki Nakabayashi 1 \\ Karen Aguirres Guerra 2 \\ Roberto Molina de Souza 1 \\ Sonia Regina Loureiro 1 \\ José Onildo Betioli Contel 1 \\ Catalina Camas Cabrera 1 \\ Jaime Eduardo Cecílio Hallak 1 \\ Flávia Lima Osório 1 \\ Cybele Garcia Leal 1 \\ Armanda Carla T. Brandão Fragata Rufino 2 \\ José Alexandre de Souza Crippa ${ }^{1}$
}

\title{
Introdução
}

1 Faculdade de Medicina de Ribeirão Preto, Universidade de São Paulo, Ribeirão Preto, Brasil.

2 Universidade Federal de Santa Catarina, Florianópolis, Brasil.

Correspondência T. I. K. Nakabayashi Hospital das Clínicas, Faculdade de Medicina de Ribeirão Preto, Universidade de São Paulo. Av. Bandeirantes 3900 , Ribeirão Preto, $S P$ 14040-901, Brasil. tatiana_nakabayashi@terra. com.br

\begin{abstract}
The objective of the present report was to compare consultative psychiatric services in two Brazilian university hospitals and to evaluate the applicability of a standardized protocol (PRISMe) for recording psychiatric liaison consultations. Analyses of psychiatric consultations and the attached protocol were performed. 541 consecutive liaison consultations were included in the final sample (438 consecutive consultations from the Federal university hospital in São Paulo and 103 from the Federal university hospital in Santa Catarina). In both hospitals, the majority of patients were female, married, white, and 31 to 60 years of age. Depression and adjustment and personality disorders were the most common psychiatric diagnoses, which could explain the higher referral of female patients. The results are consistent with the Brazilian and international literature, and the differences between the two hospitals could be related to both logistical differences between the consultative psychiatric services and the socioeconomic contexts. The findings confirm the applicability of the PRISMe and suggest that systematization of clinical and demographic information is important for future comparative studies.
\end{abstract}

Psychiatry; Mental Health; Diagnosis
Ao longo dos anos, pôde-se identificar um aumento na valorização dos serviços de interconsulta nos hospitais gerais ${ }^{1}$. A importância desse investimento reside no fato de que parece ocorrer uma elevada morbidade psiquiátrica em pacientes internados nessas instituições 2. A partir da década de 1980, houve um aumento significativo na produção de conhecimento na área, sendo publicados muitos trabalhos a respeito da interconsulta e da psiquiatria no hospital geral 3,4,5,6,7,8,9,10

Entretanto, a maioria dos trabalhos publicados na área usou protocolos individuais para obtenção dos dados, o que dificulta a comparabilidade e generalização dos resultados. Igualmente, nenhum dos estudos nacionais procurou comparar diferentes serviços de interconsulta. Isto seria particularmente importante, com a utilização de instrumento padronizado, na realização de futuros estudos multicêntricos na área, como os desenvolvidos pelo European Consultation-Liaison Workgroup for General Hospital Psychiatry and Psychosomatics (ECLW) 11,12,13,14,15,16.

Assim, o presente estudo visou, durante o período de implementação e uso de um Protocolo de Registro de Interconsulta em Saúde Mental (PRISMe): (i) obter informações clínicodemográficas dos pacientes cujos pedidos de interconsulta foram solicitados aos serviços de Interconsulta Psiquiátrica do Hospital das Clíni- 
cas da Faculdade de Medicina de Ribeirão Preto, da Universidade de São Paulo (HCFMRP-USP), e do Hospital Universitário Professor Polydoro Ernani de São Thiago, da Universidade Federal de Santa Catarina (HU-UFSC); (ii) descrever as clínicas solicitantes, função do profissional solicitante, motivo de solicitação, diagnóstico clínico e possível diagnóstico psiquiátrico; (iii) descrever a avaliação, conduta e desfecho propostos pelo interconsultor, destacando os diagnósticos psiquiátricos, as intervenções farmacoterapêuticas, o plano de tratamento e encaminhamento; e (iv) analisar os padrões atuais de uso do serviço de Interconsulta Psiquiátrica, considerando o tempo de internação, o tempo de solicitação e o tempo de resposta do pedido de interconsulta.

\section{Método}

Foram considerados todos os Pedidos de interconsulta consecutivos para os serviços de Interconsulta Psiquiátrica realizados no HCFMRPUSP (entre agosto de 2005 a dezembro de 2007, período em que foi implementado o protocolo) e no HU-UFSC (entre janeiro a dezembro de 2007) aos pacientes internados nas enfermarias de tais hospitais.

\section{Desenvolvimento do PRISMe}

O PRISMe foi elaborado com base no Patient Registration Form (PRF) do ECLW 12. Por ser um instrumento estruturado, este protocolo possibilita coletar informações descritivas a respeito do planejamento, andamento e avaliação do serviço de interconsulta.

\section{Procedimento de coleta de dados}

Cada instituição contou com uma pesquisadora responsável pelo levantamento dos dados mediante análise dos registros nos pedidos de interconsulta e no PRISMe. Nos casos nos quais ocorreu ausência de informações, foi realizada a consulta dos prontuários dos pacientes nos serviços de arquivo médico.

\section{Caracterização dos locais de estudo}

O HCFMRP-USP é um hospital geral universitário de nível assistencial terciário de acordo com o Sistema Único de Saúde (SUS). Esta instituição oferece serviços de alta tecnologia e procedimentos médicos especializados e é considerada referência para uma área do interior do Estado de São Paulo que engloba cerca de 1.200.000 habitantes (Direção Regional de Saúde de Ribeirão Preto,
Secretaria Estadual de Saúde. http://www.ribei raopreto.sp.gov.br/cerest/index.php?pagina=/ cerest/il6cidades.htm, acessado em Jan/2009).

As enfermarias possuem 692 leitos distribuídos em 580 leitos gerais, 23 leitos particulares, 36 leitos de Hospital-Dia e 53 leitos de Unidade de Terapia Intensiva. Estas instalações estão distribuídas entre diversas clínicas, incluindo Cirurgia e Clínica Médica, entre outros. É importante ressaltar que a Unidade de Emergência (UE) do HCFMRP-USP é uma instalação localizada no centro do Município de Ribeirão Preto, enquanto que o hospital é localizado no campus da universidade, sendo, portanto, duas instituições distintas. Os casos mais urgentes são atendidos na UE e, após a estabilização do quadro do paciente, são encaminhados ao HCFMRP-USP caso necessitem de um atendimento mais complexo.

O HU-UFSC é uma instituição de referência para todo o Estado de Santa Catarina, abrangendo cerca de 5.900.000 habitantes (Instituto Brasileiro de Geografia e Estatística. http://www. ibge.gov.br/home/estatistica/populacao/con tagem2007/contagem_final/tabela1_1_22.pdf, acessado em Jan/2009). Este hospital é responsável por atendimentos nos três níveis assistenciais do SUS.

A estrutura do HU-UFSC é baseada em quatro áreas: Clínica Médica, Clínica Cirúrgica, Pediatria e Tocoginecologia, além da Emergência. O número total de leitos é de 247.

Para o cálculo da taxa de encaminhamento, foram excluídos os leitos das clínicas que contaram com psiquiatra em sua equipe interna nos períodos considerados para este estudo.

Foi utilizada a 10a revisão da Classificação Internacional de Doenças (CID-10) 17 para definir e categorizar os diagnósticos clínicos e psiquiátricos.

A realização da pesquisa foi aprovada pelos comitês de ética de ambos os hospitais.

\section{Análise dos dados}

Foi realizada a análise estatística para estabelecer as freqüências das variáveis e foi empregado teste do qui-quadrado para verificar a associação entre as variáveis. O coeficiente de concordância kappa foi aplicado para verificar a concordância entre as variáveis categóricas. O nível de significância estabelecido foi $\mathrm{p} \leq 0,05$. E o programa SAS/STAT (SAS Inst., Cary, Estados Unidos) foi usado para a análise. 


\section{Resultados}

Número de solicitações e taxa de encaminhamento

No HCFMRP-USP, foram realizados 543 pedidos de interconsulta para a Psiquiatria dos quais foram excluídos 105 (19,3\%) por não apresentarem o PRISMe preenchido, restando 438 pedidos. No HU-UFSC, foram feitos 110 pedidos de interconsulta e excluídos sete $(6,4 \%)$, restando 103 . O número total de pedidos de interconsulta inclusos na amostra final foi 541.

No HU-UFSC, de janeiro a dezembro de 2007, foram realizadas 9.603 internações nas enfermarias do hospital. Assim, a taxa de encaminhamento para o serviço de interconsulta psiquiátrica foi de 1,1\%. Já, no HCFMRP-USP, para se calcular a taxa de encaminhamento, foram considerados apenas os pedidos de interconsulta realizados no mesmo período estabelecido para o HU-UFSC em relação às internações ocorridas ( $\mathrm{n}=23.056)$. Foram realizados 219 pedidos de interconsulta, tendo, assim, uma taxa de encaminhamento para este serviço de interconsulta psiquiátrica de $0,9 \%$.

\section{Dados sócio-demográficos}

Não foi encontrada diferença estatística significativa entre os pacientes atendidos nos dois hospitais no que diz respeito ao sexo $(\mathrm{p}=0,54)$, à faixa etária $(\mathrm{p}=0,58)$, à cor $\mathrm{e} / \mathrm{ou}$ etnia $(\mathrm{p}=0,68)$ e ao estado civil $(p=0,47)$. De modo geral, foram atendidos com freqüência pacientes do sexo feminino, entre 21 a 60 anos, caucasianos e casados.

Foram encontradas diferenças relacionadas à procedência dos pacientes $(\mathrm{p}<0,01)$, às pessoas com quem (ou onde) os pacientes conviviam ( $\mathrm{p}<$ $0,01)$, à situação laboral $(\mathrm{p}<0,01)$ e à escolaridade $(p=0,02)$. Os pacientes que foram atendidos no HCFMRP-USP procederam, em grande maioria, de cidades do Estado de São Paulo ( $\mathrm{n}=224$; $52,3 \%$ ) enquanto que, no HU-UFSC, os pacientes atendidos procederam majoritariamente da própria cidade de Florianópolis ( $\mathrm{n}=60 ; 59,4 \%$ ). Apesar dos pacientes, em ambos os hospitais, residirem com seus cônjuges e filhos com maior freqüência, no HU-UFSC, essa parcela foi mais elevada ( $n=40 ; 41,2 \%$ ) que em Ribeirão Preto ( $n=$ $120 ; 29,2 \%)$.

Em ambos os hospitais, a inatividade por invalidez/afastamento e o cuidado com o lar foram as situações mais alegadas entre os pacientes assistidos. Porém, no HU-UFSC, o emprego formal foi mais freqüente $(n=13 ; 13,1 \%)$ quando comparado com o HCFMRP-USP ( $\mathrm{n}=27 ; 6,3 \%)$.
A respeito da escolaridade, no HCFMRP-USP, os pacientes tinham o ensino fundamental incompleto em $49,1 \%$ ( $n=186$ ) dos casos, enquanto que, no HU-UFSC, essa freqüência foi menor (n=26; 32,1\%) (Tabela 1).

\section{Clínicas solicitantes}

No HCFMRP-USP, a Clínica Médica foi responsável por 33,3\% $(\mathrm{n}=146)$ das solicitações e a Nutrologia, por $11 \%(\mathrm{n}=48)$. Por outro lado, no HU-UFSC, a grande maioria $(n=70 ; 67,9 \%)$ dos pedidos de interconsulta foram solicitados pela Clínica Médica e 9,7\% (n=10), da Emergência.

\section{Profissionais solicitantes}

Foram evidenciadas diferenças significativas quanto à função dos profissionais solicitantes $(p<0,01)$. No HU-UFSC, os pedidos de interconsulta foram solicitados basicamente pelos residentes ( $\mathrm{n}=81 ; 79,4 \%$ ) e pelos médicos assistentes ( $n=20 ; 19,6 \%)$, enquanto que, no HCFMRP-USP, além dos residentes $(\mathrm{n}=359$; $82,7 \%)$ e dos assistentes ( $n=12 ; 2,7 \%)$, também solicitaram pedidos de interconsulta psicólogos ( $\mathrm{n}=39 ; 9 \%)$, doutorandos $(\mathrm{n}=22 ; 5,1 \%)$ e terapeutas ocupacionais $(n=2 ; 0,5 \%)$.

Tanto em Ribeirão Preto quanto em Florianópolis, a presença de sintomas psiquiátricos foi considerada, pelos profissionais solicitantes, como o motivo principal para a solicitação de avaliação do interconsultor ( $\mathrm{n}=209 ; 47,8 \%$, e $\mathrm{n}=$ 37; 36,6\%, respectivamente). Porém, em Florianópolis, destaca-se que o risco suicida motivou $37,6 \%(n=38)$ dos pedidos de interconsulta, sendo o motivo mais freqüente e significativamente mais comum $(\mathrm{p}<0,01)$ do que em Ribeirão Preto ( $\mathrm{n}=27 ; 6,2 \%)$ (Tabela 2$)$.

\section{Diagnósticos clínicos e psiquiátricos}

Não foi encontrada diferença estatística entre os serviços quanto ao diagnóstico psiquiátrico fornecido pelo interconsultor $(\mathrm{p}=0,25)$. Porém, quanto ao diagnóstico clínico, foi observada diferença particularmente quanto à condição "outros" ( $\mathrm{p}<0,01)$ (Tabela 2). Os diagnósticos psiquiátricos mais freqüentemente realizados pelos psiquiatras foram referentes ao episódio depressivo, aos transtornos de adaptação e aos transtornos de personalidade, sendo que estas condições psiquiátricas foram mais freqüentes em pacientes de 31 a 60 anos de idade $(\mathrm{p}<0,01)$.

Não foi evidenciada associação entre o diagnóstico psiquiátrico e o clínico em Florianópolis ( $\mathrm{p}=0,12)$. Entretanto, em Ribeirão Preto, foram encontradas associações entre episódio depres- 


\section{Tabela 1}

Dados sócio-demográficos referentes aos pacientes atendidos pelos serviços de interconsulta psiquiátrica do Hospital das Clínicas da Faculdade de Medicina de Ribeirão Preto da Universidade de São Paulo (HCFMRP-USP) e do Hospital Universitário Professor Polydoro Ernani de São Thiago, da Universidade Federal de Santa Catarina (HU-UFSC).

\begin{tabular}{|c|c|c|c|}
\hline Variáveis & HCFMRP-USP (\%) & HU-UFSC (\%) & Valor de $p$ \\
\hline \multicolumn{4}{|l|}{ Sexo } \\
\hline Feminino & $273(62,5)$ & $61(59,2)$ & 0,54 \\
\hline Masculino & $164(37,5)$ & $42(40,8)$ & \\
\hline \multicolumn{4}{|l|}{ Faixa etária (anos) } \\
\hline Até 14 & $17(3,9)$ & - & 0,58 \\
\hline $15-20$ & $36(8,3)$ & $8(8,0)$ & \\
\hline $21-30$ & $71(16,3)$ & $15(15,0)$ & \\
\hline $31-40$ & $76(17,4)$ & $22(22,0)$ & \\
\hline $41-50$ & $93(21,3)$ & $25(25,0)$ & \\
\hline $51-60$ & $68(15,6)$ & $15(15,0)$ & \\
\hline $61-70$ & $49(11,2)$ & $10(10,0)$ & \\
\hline Acima de 71 & $26(6,0)$ & $5(5,0)$ & \\
\hline \multicolumn{4}{|l|}{ Raça/Etnia } \\
\hline Branca & $337(77,8)$ & $84(82,4)$ & 0,68 \\
\hline Parda & $50(11,6)$ & $8(7,8)$ & \\
\hline Preta & $45(10,4)$ & $10(9,8)$ & \\
\hline Amarela & $1(0,2)$ & - & \\
\hline \multicolumn{4}{|l|}{ Estado civil } \\
\hline Casado/União consensual & $216(50,1)$ & $60(58,3)$ & 0,47 \\
\hline Solteiro & $114(26,5)$ & $21(20,4)$ & \\
\hline Separado/Desquitado & $65(15,1)$ & $15(14,6)$ & \\
\hline Viúvo & $36(8,4)$ & $7(6,8)$ & \\
\hline \multicolumn{4}{|l|}{ Procedência } \\
\hline Estado de São Paulo/Estado de Santa & $224(52,3)$ & $41(40,6)$ & $<0,01$ \\
\hline \multicolumn{4}{|l|}{ Catarina } \\
\hline Ribeirão Preto/Florianópolis & $170(39,7)$ & $60(59,4)$ & \\
\hline Outros estados & $34(7,9)$ & - & \\
\hline \multicolumn{4}{|l|}{ Vive com/onde } \\
\hline Cônjuge e filhos & $120(29,2)$ & $40(41,2)$ & $<0,01$ \\
\hline Pais & $90(21,9)$ & $12(12,4)$ & \\
\hline Cônjuge & $70(17,0)$ & $15(15,5)$ & \\
\hline Só e com filhos & $56(13,6)$ & $10(10,3)$ & \\
\hline Parentes & $33(8,0)$ & $3(3,1)$ & \\
\hline Sozinho & $32(7,8)$ & $8(8,3)$ & \\
\hline Em instituição & $5(1,2)$ & $2(2,1)$ & \\
\hline Amigos & $3(0,7)$ & $3(3,1)$ & \\
\hline Outros & $2(0,5)$ & $4(4,1)$ & \\
\hline \multicolumn{4}{|l|}{ Situação laboral } \\
\hline Inativo(a) por invalidez & $117(27,2)$ & $32(32,3)$ & $<0,01$ \\
\hline Cuidando do lar & $112(26,1)$ & $19(19,2)$ & \\
\hline Desempregado & $51(11,9)$ & $9(9,1)$ & \\
\hline Autônomo & $42(9,8)$ & $3(3,0)$ & \\
\hline Estudante & $39(9,1)$ & $3(3,0)$ & \\
\hline Aposentado (tempo de serviço) & $33(7,7)$ & $10(10,1)$ & \\
\hline Empregado(a) formalmente & $27(6,3)$ & $13(13,1)$ & \\
\hline Empregado(a) informalmente & $8(1,9)$ & $10(10,1)$ & \\
\hline Outros & $1(0,2)$ & - & \\
\hline
\end{tabular}

(continua) 
Tabela 1 (continuação)

\begin{tabular}{lccc}
\hline Variáveis & HCFMRP-USP (\%) & HU-UFSC (\%) & Valor de $\mathbf{p}$ \\
\hline Escolaridade & & & \\
$\quad$ Analfabeto & $35(9,3)$ & $6(7,4)$ & 0,02 \\
Ensino fundamental incompleto & $151(40,1)$ & $20(24,7)$ & \\
Ensino fundamental completo & $47(12,5)$ & $6(7,4)$ & \\
Ensino médio incompleto & $56(14,9)$ & $22(27,2)$ \\
Ensino médio completo & $63(16,7)$ & $5(6,2)$ \\
Ensino superior incompleto & $8(2,1)$ & $3(3,7)$ & \\
Ensino superior completo & $15(4,0)$ & - \\
Mais de uma faculdade & $2(0,5)$ & \\
\hline
\end{tabular}

Tabela 2

Dados referentes aos motivos de solicitação psiquiátrica alegados pelos profissionais solicitantes, diagnósticos psiquiátricos fornecidos pelos interconsultores e os diagnósticos somáticos dos pacientes internados.

\begin{tabular}{|c|c|c|c|}
\hline Variáveis & HCFMRP-USP (\%) & HU-UFSC (\%) & Valor de $p$ \\
\hline \multicolumn{4}{|l|}{ Motivos de solicitação } \\
\hline Sintomas psiquiátricos presentes & $209(47,8)$ & $37(36,6)$ & $<0,01$ \\
\hline Antecedentes psiquiátricos & $72(16,5)$ & - & \\
\hline Sintomas físicos mal definidos & $41(9,4)$ & $8(7,9)$ & \\
\hline Risco suicida & $27(6,2)$ & $38(37,6)$ & \\
\hline Avaliação quanto ao uso de psicotrópicos & $24(5,5)$ & $3(3,0)$ & \\
\hline Outros & $64(14,7)$ & $15(14,9)$ & \\
\hline \multicolumn{4}{|l|}{ Diagnóstico psiquiátrico } \\
\hline Episódio depressivo & $130(19,1)$ & $35(20,4)$ & 0,25 \\
\hline Transtornos de adaptação & $107(15,7)$ & $19(11,1)$ & \\
\hline Transtornos de personalidade & $73(10,7)$ & $21(12,2)$ & \\
\hline Delirium * & $43(6,3)$ & $8(4,7)$ & \\
\hline Outros transtornos mentais ** & $40(5,9)$ & $5(2,9)$ & \\
\hline Outros & $288(42,3)$ & $84(48,8)$ & \\
\hline \multicolumn{4}{|l|}{ Diagnóstico somático } \\
\hline Doenças infecciosas e parasitárias & $90(15,4)$ & $12(8,3)$ & $<0,01$ \\
\hline Doenças do sistema circulatório & $76(13,0)$ & $20(13,9)$ & \\
\hline $\begin{array}{l}\text { Doenças endócrinas, metabólicas e } \\
\text { nutricionais }\end{array}$ & $76(13,0)$ & $15(10,4)$ & \\
\hline Doenças do aparelho digestivo & $61(10,4)$ & $7(4,9)$ & \\
\hline Neoplasias & $50(8,6)$ & $7(4,9)$ & \\
\hline Outros & $232(39,7)$ & $83(57,6)$ & \\
\hline
\end{tabular}

HCFMRP-USP: Hospital das Clínicas da Faculdade de Medicina de Ribeirão Preto da Universidade de São Paulo; HU-UFSC: Hospital Universitário Professor Polydoro Ernani de São Thiago da Universidade Federal de Santa Catarina.

* Não induzido por substâncias psicoativas;

** Devido à lesão e disfunção cerebral ou doença física.

sivo e transtornos de adaptação com algumas condições médicas gerais $(p<0,01)$, como, por exemplo, doenças infecciosas, parasitárias e relacionadas ao sistema circulatório (Tabela 3).
Os diagnósticos psiquiátricos se mostraram associados ao sexo do paciente $(\mathrm{p}<0,01)$ sendo que a maioria das condições psiquiátricas, com destaque para os transtornos de personalidade 
( $\mathrm{n}=73 ; 77,6 \%)$ e os episódios depressivos ( $\mathrm{n}=$ $103 ; 62,4 \%$ ), acometeu mais pacientes do sexo feminino.

Foi realizada, também, uma análise de concordância entre as hipóteses de diagnóstico psiquiátrico fornecidas pelos profissionais solicitantes e os diagnósticos dados pelos interconsultores após a avaliação dos pacientes. Aproximadamente metade ( $\mathrm{n}=164 ; 48,5 \%$ ) dos diagnósticos fornecidos pelos solicitantes e pelos interconsultores coincidiram.

\section{Antecedentes psiquiátricos e ideação suicida}

No HU-UFSC, apesar dos antecedentes psiquiátricos não terem sido um aspecto motivador para solicitação de pedido de interconsulta, foram solicitadas mais avaliações para pacientes com história psiquiátrica prévia, comparado ao HCFMRP-USP. No HU-UFSC, 72,9\% ( $\mathrm{n}=102$ ) dos pacientes assistidos já tinham sido submetidos a tratamentos psiquiátricos ou psicoterapia, enquanto que, em Ribeirão Preto, esse número foi significativamente menor $(\mathrm{n}=261 ; 52,3 \%)$ $(\mathrm{p}<0,01)$.

Os pacientes do HU-UFSC apresentaram mais ideação suicida no momento da avaliação ( $\mathrm{p}=0,01)$ e mais tentativas prévias de suicídio $(\mathrm{p}<0,01)$ quando comparados com os pacientes atendidos no HCFMRP-USP.

\section{Planos de tratamento e prescrição de medicações psicotrópicas}

Os planos de tratamento propostos pelos interconsultores incluíram atendimentos individuais em mais do que $1 / 3$ dos casos avaliados e prescrição de psicofármacos em torno de $27 \%$ ( $n=70$ no HU-UFSC; $\mathrm{n}=244$ no HCFMRP-USP). Ressalta o fato de que no HU-UFSC, foi maior a freqüência de pacientes que não estavam submetidos a tratamento psicofarmacológico até o momento da avaliação do interconsultor e, após a visita, passaram a fazê-lo $(\mathrm{p}=0,01)$. Do mesmo modo, ocorreu a necessidade de novos exames e de avaliações de outros profissionais segundo a opinião do interconsultor $(\mathrm{p}<0,01)$.

Dados referentes aos diagnósticos somáticos e psiquiátricos (fornecidos pelos interconsultores) dos pacientes assistidos.

\begin{tabular}{|c|c|c|c|c|c|c|c|c|c|}
\hline \multirow[t]{3}{*}{ Diagnóstico psiquiátrico } & \multicolumn{9}{|c|}{ Diagnóstico somático } \\
\hline & \multicolumn{3}{|c|}{$\begin{array}{c}\text { Doenças infecciosas } \\
\text { e parasitárias }\end{array}$} & \multicolumn{2}{|c|}{$\begin{array}{c}\text { Doenças do sistema } \\
\text { circulatório }\end{array}$} & \multicolumn{2}{|c|}{$\begin{array}{c}\text { Doenças do aparelho } \\
\text { digestivo }\end{array}$} & \multicolumn{2}{|c|}{$\begin{array}{l}\text { Doenças endócrinas, } \\
\text { metabólicas e nutricionais }\end{array}$} \\
\hline & $\begin{array}{l}\text { HCFMRP- } \\
\text { USP (\%) }\end{array}$ & & $\begin{array}{l}U- \\
C(\%)\end{array}$ & $\begin{array}{l}\text { HCFMRP- } \\
\text { USP (\%) }\end{array}$ & $\begin{array}{c}\mathrm{HU}- \\
\text { UFSC (\%) }\end{array}$ & $\begin{array}{l}\text { HCFMRP- } \\
\text { USP (\%) }\end{array}$ & $\begin{array}{c}\mathrm{HU}- \\
\text { UFSC (\%) }\end{array}$ & $\begin{array}{l}\text { HCFMRP- } \\
\text { USP (\%) }\end{array}$ & $\begin{array}{c}\mathrm{HU}- \\
\text { UFSC (\%) }\end{array}$ \\
\hline Episódio depressivo & $19(26,8)$ & \multicolumn{2}{|c|}{$1(12,5)$} & $14(28,6)$ & $1(7,7)$ & $6(15,0)$ & $1(16,7)$ & $13(25,0)$ & $4(40,0)$ \\
\hline Outros transtornos mentais * & $11(15,5)$ & \multicolumn{2}{|c|}{-} & $1(2,0)$ & $3(23,1)$ & - & - & $2(3,9)$ & - \\
\hline Transtornos de personalidade & $7(9,9)$ & \multicolumn{2}{|c|}{-} & $3(6,1)$ & $2(15,4)$ & $3(7,5)$ & $2(33,3)$ & $4(7,7)$ & - \\
\hline Transtornos de adaptação & $6(8,5)$ & \multicolumn{2}{|c|}{$2(25,0)$} & $4(8,2)$ & - & $11(27,5)$ & $1(16,7)$ & $5(9,6)$ & $1(10,0)$ \\
\hline Delirium ** & $4(5,6)$ & \multicolumn{2}{|c|}{-} & $9(18,4)$ & $2(15,4)$ & $3(7,5)$ & $1(16,7)$ & $1(1,9)$ & - \\
\hline Outros & $24(33,8)$ & \multicolumn{2}{|c|}{$5(62,5)$} & $18(36,7)$ & $5(38,5)$ & $17(42,5)$ & $1(16,7)$ & $27(51,9)$ & $5(50,0)$ \\
\hline \multirow[t]{3}{*}{ Diagnóstico psiquiátrico } & \multicolumn{6}{|c|}{ Diagnóstico somático } & \multicolumn{3}{|c|}{ Valor de $p$} \\
\hline & \multicolumn{4}{|c|}{ Neoplasias } & \multicolumn{2}{|c|}{ Outros } & \multirow{2}{*}{\multicolumn{2}{|c|}{ HCFMRP-USP }} & \\
\hline & HCFMRP-US & & HU-L & $C(\%)$ & MRP-USP (\%) & HU-UFSC (\%) & & & HU-UFSC \\
\hline Episódio depressivo & $6(15,0)$ & \multicolumn{3}{|c|}{$3(42,9)$} & $27(17,3)$ & $17(23,9)$ & \multicolumn{2}{|c|}{$<0,01$} & 0,12 \\
\hline Outros transtornos mentais * & - & \multicolumn{3}{|c|}{-} & $11(7,1)$ & $2(2,8)$ & & & \\
\hline Transtornos de personalidade & $2(5,0)$ & \multicolumn{3}{|c|}{-} & $12(7,7)$ & $9(12,7)$ & & & \\
\hline Transtornos de adaptação & $19(47,5)$ & \multicolumn{3}{|c|}{-} & $30(19,2)$ & $2(8,5)$ & & & \\
\hline Delirium ** & $3(7,5)$ & \multicolumn{3}{|c|}{-} & $10(6,4)$ & $4(5,6)$ & & & \\
\hline Outros & $10(25,0)$ & \multicolumn{3}{|c|}{$4(57,1)$} & $66(42,3)$ & $33(46,5)$ & & & \\
\hline
\end{tabular}

HCFMRP-USP: Hospital das Clínicas da Faculdade de Medicina de Ribeirão Preto da Universidade de São Paulo; HU-UFSC: Hospital Universitário Professor

Polydoro Ernani de São Thiago da Universidade Federal de Santa Catarina.

* Devido à lesão e disfunção cerebral ou doença física;

** Não induzido por substâncias psicoativas. 
Não foram verificadas diferenças significativas entre o HCFMRP-USP e o HU-UFSC em relação às classes de medicações psicotrópicas em uso pelo paciente no momento da avaliação $(\mathrm{p}=$ 0,59 ) nem quanto às prescritas pelo interconsultor $(p=0,09)$. As classes mais utilizadas antes da avaliação do interconsultor em Ribeirão Preto e Florianópolis foram os benzodiazepínicos ( $\mathrm{n}=$ $132 ; 39,8 \%$, e $n=28 ; 29,5 \%$, respectivamente), os antidepressivos ISRS ( $\mathrm{n}=67 ; 20,2 \%$, e $\mathrm{n}=26$; $27,4 \%$ ) e os antipsicóticos típicos ( $n=52 ; 15,7 \%$, e $n=18 ; 19 \%$ ). Por outro lado, as classes mais prescritas pelos interconsultores foram os antidepressivos ISRS ( $\mathrm{n}=104 ; 31 \%$, e $\mathrm{n}=39 ; 34,2 \%$ ), os benzodiazepínicos ( $\mathrm{n}=88 ; 26,2 \%$, e $\mathrm{n}=30$; 26,3\%) e os antipsicóticos típicos ( $\mathrm{n}=63 ; 18,8 \%$, e $\mathrm{n}=21 ; 18,4 \%$ ).

Após a visita do interconsultor, grande parte dos pacientes que já estava submetida a um tratamento psicofarmacológico teve sua classe medicamentosa suspensa ou substituída (coeficiente de concordância kappa =0,04). Os pacientes cujas prescrições envolviam benzodiazepínicos tiveram suas classes medicamentosas suspensas ou alteradas em 73,5\% $(n=50)$ dos casos. Já aqueles que utilizavam antipsicóticos típicos tiveram suas prescrições suspensas ou alteradas em $65,4 \%(n=17)$ e aqueles que utilizavam antidepressivos ISRS tiveram suas classes medicamentosas alteradas em aproximadamente metade dos casos $(n=15)$.

Encaminhamento, comunicação da avaliação psiquiátrica e alta hospitalar

Após a alta hospitalar, foram realizados encaminhamentos para cerca de $1 / 3$ dos pacientes atendidos no HU-UFSC, e apenas para $16 \%$ ( $\mathrm{n}=70$ ) dos pacientes no HCFMRP-USP ( $\mathrm{p}<$ 0,01 ). Dos encaminhamentos feitos, $76,5 \%$ ( $\mathrm{n}=$ 26) dos casos do HU-UFSC e $42,8 \%(n=30)$ do HCFMRP-USP foram realizados para o ambulatório de Psiquiatria $(\mathrm{p}<0,01)$.

\section{Tempo de internação}

Em relação ao tempo de internação (período decorrido, em dias, entre a internação até a alta hospitalar), os pacientes permaneceram, no máximo, dez dias internados em 40,6\% ( $n=41)$ dos casos no HU-UFSC, e em 35,5\% ( $\mathrm{n}=127$ ), no HCFMRP-USP. Somente $14,9 \%(\mathrm{n}=15)$ dos pacientes no HU-UFSC, e $12,3 \%$ ( $\mathrm{n}=44$ ) no HCFMRP-USP, permaneceram mais do que 51 dias internados.

No HU-UFSC, foi evidenciada associação entre o tempo de internação e os principais diagnósticos clínicos dos pacientes ( $\mathrm{p}<0,01$ ), enquanto que, no HCFMRP-USP, foi encontrada associação entre o tempo de internação e os principais diagnósticos psiquiátricos dos pacientes $(\mathrm{p}<0,01)$ (Tabela 4).

Em 77,3\% $(n=75)$ dos casos no HU-UFSC e $73,8 \%$ ( $n=285$ ) no HCFMRP-USP, os pedidos de interconsulta foram realizados em até dez dias após a internação do paciente, sendo que as clínicas que mais requeriram em tal período foram as Clínicas Médicas para ambos os hospitais. Em somente $4,1 \%(\mathrm{n}=4)$ dos casos no HU-UFSC e $5,7 \%(n=22)$ no HCFMRP-USP, as solicitações foram feitas 51 dias ou mais decorridos da internação do paciente no hospital.

\section{Tempo de solicitação}

Não foram evidenciadas associações entre o tempo de solicitação (tempo decorrido entre a data de internação e a data do pedido de interconsulta) e as faixas etárias dos pacientes ( $\mathrm{p}=$ 0,12 ), os motivos de solicitação dos pedidos de interconsulta $(\mathrm{p}=0,10)$ ou os possíveis diagnósticos psiquiátricos fornecidos nos pedidos de interconsulta $(p<0,19)$ (Tabela 5). Foram encontradas somente associações relacionadas aos diagnósticos clínicos dos pacientes em ambos os hospitais $(\mathrm{p}<0,01)$ (Tabela 6).

No HU-UFSC, o tempo de solicitação foi menor para pacientes com enfermidades relacionadas ao aparelho circulatório, sendo solicitados a esses pacientes pedidos de interconsulta em até dez dias após a internação, enquanto que o período mais estendido (acima de 40 dias) foi para pacientes acometidos por doenças infecciosas e endócrinas, metabólicas e nutricionais $(\mathrm{p}<0,01)$. No HCFMRP-USP, os pedidos de interconsulta para pacientes com doenças infecciosas, endócrinas, metabólicas e nutricionais foram solicitados em até dez dias após a internação. Para aqueles pacientes que tiveram solicitação realizada após 50 dias de internação, os mais freqüentes foram pacientes com doenças no aparelho digestivo $(\mathrm{p}<0,01)$.

Em $72 \%(n=72)$ dos casos no HU-UFSC e em $65,7 \%$ ( $\mathrm{n}=260$ ) no HCFMRP-USP, os pacientes receberam até três atendimentos durante o período de internação. Nos dois hospitais, não foram encontradas evidências de associação entre a quantidade de atendimentos realizados pelo interconsultor e as enfermidades clínicas dos pacientes ou seus diagnósticos psiquiátricos.

\section{Tempo de resposta}

Para averiguar a existência de fatores que pudessem influenciar no tempo de resposta (tempo decorrido entre a data do pedido de interconsul- 
Tabela 4

Dados referentes ao tempo de internação (duração da internação do paciente na enfermaria), aos diagnósticos somáticos dos pacientes internados e os diagnósticos psiquiátricos fornecidos pelos interconsultores.

\begin{tabular}{|c|c|c|c|c|c|c|c|c|}
\hline \multirow[t]{3}{*}{ Diagnóstico } & \multicolumn{8}{|c|}{ Tempo de internação (em dias) } \\
\hline & \multicolumn{2}{|c|}{ Até 10} & \multicolumn{2}{|c|}{$11-20$} & \multicolumn{2}{|c|}{$21-30$} & \multicolumn{2}{|c|}{$31-40$} \\
\hline & $\begin{array}{l}\text { HCFMRP- } \\
\text { USP (\%) }\end{array}$ & $\begin{array}{c}\text { HU- } \\
\text { UFSC (\%) }\end{array}$ & $\begin{array}{l}\text { HCFMRP- } \\
\text { USP (\%) }\end{array}$ & $\begin{array}{c}\mathrm{HU}- \\
\text { UFSC (\%) }\end{array}$ & $\begin{array}{l}\text { HCFMRP- } \\
\text { USP (\%) }\end{array}$ & $\begin{array}{c}\mathrm{HU}- \\
\text { UFSC (\%) }\end{array}$ & $\begin{array}{l}\text { HCFMRP- } \\
\text { USP (\%) }\end{array}$ & $\begin{array}{c}\text { HU- } \\
\text { UFSC (\%) }\end{array}$ \\
\hline \multicolumn{9}{|l|}{ Somático } \\
\hline Doenças infecciosas e parasitárias & $27(16,4)$ & $1(2,4)$ & $23(15,7)$ & $1(3,3)$ & $14(19,2)$ & $2(7,1)$ & - & - \\
\hline Doenças do sistema circulatório & $25(15,2)$ & $1(2,4)$ & $11(7,5)$ & $5(16,7)$ & $10(13,7)$ & $9(32,1)$ & $4(28,6)$ & $2(28,6)$ \\
\hline Doenças do aparelho digestivo & $18(10,9)$ & $2(4,9)$ & $16(10,9)$ & $1(3,3)$ & $8(11,0)$ & $1(3,6)$ & - & - \\
\hline \multicolumn{9}{|l|}{ e nutricionais } \\
\hline Neoplasias & $15(9,1)$ & - & $14(9,5)$ & $1(3,3)$ & $4(5,5)$ & $2(7,1)$ & $2(14,3)$ & - \\
\hline Outros & $64(38,8)$ & $37(90,2)$ & $66(44,9)$ & $19(63,3)$ & $27(37,0)$ & $11(39,3)$ & $4(28,6)$ & $2(28,6)$ \\
\hline \multicolumn{9}{|l|}{ Psiquiátrico } \\
\hline Episódio depressivo & $38(21,2)$ & $12(20,7)$ & $23(13,8)$ & $5(16,1)$ & $18(19,6)$ & $5(15,2)$ & $6(31,6)$ & $1(10,0)$ \\
\hline Transtornos de adaptação & $22(12,3)$ & $5(8,6)$ & $25(15,0)$ & $4(12,9)$ & $14(15,2)$ & $3(9,1)$ & $5(26,3)$ & $1(10,0)$ \\
\hline Transtornos de personalidade & $21(11,7)$ & $10(17,2)$ & $23(13,8)$ & - & $9(9,8)$ & $5(15,2)$ & $2(10,7)$ & $2(20,0)$ \\
\hline Delirium * & $9(5,0)$ & $1(1,7)$ & $14(8,4)$ & $1(3,2)$ & $4(4,4)$ & $3(9,1)$ & $1(5,3)$ & - \\
\hline Outros transtornos mentais ** & $6(3,4)$ & $1(1,7)$ & $9(5,4)$ & $1(3,2)$ & $12(13,0)$ & $2(6,1)$ & - & $1(10,0)$ \\
\hline Outros & $83(46,4)$ & $29(50,0)$ & $73(43,7)$ & $20(64,5)$ & $35(38,0)$ & $15(45,5)$ & $5(26,3)$ & $5(50,0)$ \\
\hline \multirow[t]{3}{*}{ Diagnóstico } & \multicolumn{5}{|c|}{ Tempo de internação (em dias) } & \multicolumn{3}{|c|}{ Valor de $p$} \\
\hline & \multicolumn{3}{|c|}{$41-50$} & \multicolumn{2}{|c|}{ Acima de 51} & & & \\
\hline & $\begin{array}{l}\text { HCFMRP- } \\
\text { USP (\%) }\end{array}$ & UF & (\%) & $\begin{array}{l}\text { HCFMRP- } \\
\text { USP (\%) }\end{array}$ & $\begin{array}{c}\text { HU- } \\
\text { UFSC (\%) }\end{array}$ & HCFM & P-USP & HU-UFSC \\
\hline \multicolumn{9}{|l|}{ Somático } \\
\hline Doenças infecciosas e parasitárias & $5(23,8)$ & & & $4(7,6)$ & $7(24,1)$ & & & $<0,01$ \\
\hline Doenças do sistema circulatório & $2(9,5)$ & & & $10(18,9)$ & $3(10,3)$ & & & \\
\hline Doenças do aparelho digestivo & - & & & $5(9,4)$ & $1(3,5)$ & & & \\
\hline $\begin{array}{l}\text { Doenças endócrinas, metabólicas } \\
\text { e nutricionais }\end{array}$ & $5(23,8)$ & & & $8(15,1)$ & $6(20,7)$ & & & \\
\hline Neoplasias & $2(9,5)$ & & & $1(1,9)$ & $4(13,8)$ & & & \\
\hline Outros & $7(33,3)$ & & $0,0)$ & $25(47,2)$ & $8(27,6)$ & & & \\
\hline \multicolumn{9}{|l|}{ Psiquiátrico } \\
\hline Episódio depressivo & $8(25,8)$ & & ,0) & $14(20,3)$ & $9(34,6)$ & $<0$ & & 0,61 \\
\hline Transtornos de adaptação & - & & ,0) & $15(21,7)$ & $3(11,5)$ & & & \\
\hline Transtornos de personalidade & $2(6,5)$ & & ,0) & $6(8,7)$ & $2(7,7)$ & & & \\
\hline Delirium * & - & & $, 0)$ & $7(10,1)$ & $1(3,9)$ & & & \\
\hline Outros transtornos mentais ** & $5(16,1)$ & & & - & - & & & \\
\hline Outros & $16(51,6)$ & & $, 0)$ & $27(39,1)$ & $11(42,3)$ & & & \\
\hline
\end{tabular}

HCFMRP-USP: Hospital das Clínicas da Faculdade de Medicina de Ribeirão Preto da Universidade de São Paulo; HU-UFSC: Hospital Universitário Professor Polydoro Ernani de São Thiago da Universidade Federal de Santa Catarina.

* Não induzido por substâncias psicoativas;

** Devido à lesão e disfunção cerebral ou doença física. 
Tabela 5

Dados referentes ao tempo de solicitação (tempo decorrido entre a data de internação e a data do pedido de interconsulta), os motivos de solicitação e as hipóteses de diagnósticos psiquiátricos fornecidos alegados pelo profissional solicitante.

\begin{tabular}{|c|c|c|c|c|c|c|c|}
\hline & \multicolumn{6}{|c|}{ Tempo de solicitação (em dias) } & \multirow[t]{2}{*}{ Valor de $\mathrm{p}$} \\
\hline & Até $10(\%)$ & $11-20(\%)$ & $21-30(\%)$ & $31-40(\%)$ & $41-50(\%)$ & Acima de 51 (\%) & \\
\hline \multicolumn{8}{|l|}{ Faixa etária (anos) * } \\
\hline Até 14 & $11(3,1)$ & $1(1,5)$ & - & $1(7,7)$ & - & $2(7,7)$ & 0,12 \\
\hline $15-20$ & $33(9,4)$ & $5(7,6)$ & - & $3(23,1)$ & - & $1(3,9)$ & \\
\hline $21-30$ & $58(16,6)$ & $10(15,2)$ & $1(4,8)$ & $2(15,4)$ & $1(25,0)$ & $6(23,1)$ & \\
\hline $31-40$ & $73(20,9)$ & $7(10,6)$ & $1(4,8)$ & $1(7,7)$ & - & $4(15,4)$ & \\
\hline $41-50$ & $73(20,9)$ & $14(21,2)$ & $9(42,9)$ & $3(23,1)$ & $1(25,0)$ & $5(19,2)$ & \\
\hline $51-60$ & $52(14,9)$ & $11(16,7)$ & $2(9,5)$ & $2(15,4)$ & $2(50,0)$ & $3(11,5)$ & \\
\hline $61-70$ & $32(9,1)$ & $12(18,2)$ & $5(23,8)$ & - & - & $5(19,2)$ & \\
\hline Acima de 71 & $18(5,1)$ & $6(9,1)$ & $3(14,3)$ & $1(7,7)$ & - & - & \\
\hline \multicolumn{8}{|l|}{ Motivos de solicitação } \\
\hline Sintomas psiquiátricos presentes & $50(14,3)$ & $7(10,5)$ & $2(9,5)$ & - & - & $2(8,0)$ & 0,10 \\
\hline Risco suicida & $18(5,1)$ & $3(4,5)$ & $1(4,8)$ & - & $1(25,0)$ & $1(4,0)$ & \\
\hline Antecedentes psiquiátricos & $55(15,7)$ & $5(7,5)$ & $1(4,8)$ & - & $1(25,0)$ & - & \\
\hline Sintomas físicos mal definidos & $34(9,7)$ & $7(10,5)$ & $1(4,8)$ & $3(23,1)$ & - & $1(4,0)$ & \\
\hline Avaliação quanto ao uso de psicotrópicos & $144(41,1)$ & $34(50,8)$ & $11(52,4)$ & $10(76,9)$ & $2(50,0)$ & $14(56,0)$ & \\
\hline Outros & $49(14,0)$ & $11(16,4)$ & $5(23,8)$ & - & - & $7(28,0)$ & \\
\hline \multicolumn{8}{|l|}{ Hipótese de diagnóstico psiquiátrico * } \\
\hline Episódio depressivo & $78(30,0)$ & $15(33,3)$ & $5(38,5)$ & $1(16,7)$ & $1(50,0)$ & $8(47,1)$ & 0,19 \\
\hline Transtornos de personalidade & $10(3,9)$ & $1(2,2)$ & - & - & - & - & \\
\hline Delirium ** & $10(3,9)$ & - & - & - & - & - & \\
\hline Transtornos de adaptação & $4(1,5)$ & - & $2(15,4)$ & - & - & - & \\
\hline 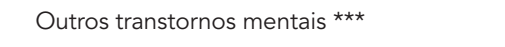 & $1(0,4)$ & $2(4,4)$ & - & - & - & - & \\
\hline Outros & $157(60,4)$ & $27(60,0)$ & $6(46,2)$ & $5(83,3)$ & $1(50,0)$ & $9(52,9)$ & \\
\hline
\end{tabular}

\footnotetext{
* Não foi evidenciada diferença significativa entre os dois hospitais ( $p=0,54$ para faixa etária; $p=0,25$ para hipótese de diagnóstico psiquiátrico);

** Não induzido por substâncias psicoativas;

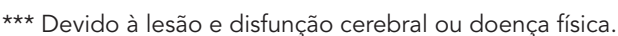

ta e a resposta do interconsultor), foram investigadas associações entre algumas variáveis referentes à solicitação do pedido de interconsulta, à faixa etária e aos diagnósticos psiquiátricos $\mathrm{e}$ clínicos.

Não foi encontrada nenhuma associação entre o tempo de resposta e a legibilidade do pedido de interconsulta $(p=0,30)$; manifestação de expectativa por atendimento por parte do profissional solicitante $(p=0,52)$; e identificação e registro do nome desse último $(\mathrm{p}=0,97)$. A legibilidade do pedido de interconsulta foi considerada totalmente legível em 77,8\% $(n=421)$ de todas as solicitações avaliadas, a manifestação de expectativa esteve presente em $74,3 \%(n=402)$ dos pedidos de interconsulta e, em 91,1\% ( $\mathrm{n}=$ 493) das solicitações, a identificação do profissional foi fornecida.
Também não foram evidenciadas associações entre o tempo de resposta e as faixas etárias dos pacientes atendidos $(\mathrm{p}=0,71)$ ou os motivos de solicitação de interconsulta psiquiátrica $(p=0,08)$. O atendimento do interconsultor foi realizado no mesmo dia da solicitação ou no dia seguinte em mais do que $70 \%$ dos casos em todas as faixas etárias (em pacientes com até 14 anos de idade, esse número foi de $82,3 \%$ ). Isto ocorreu independentemente dos motivos alegados (os pedidos que enfatizaram a avaliação quanto ao uso de psicotrópicos foram atendidos em $85,2 \%$ dentro desse prazo).

No HU-UFSC, não foram encontradas associações do tempo de resposta com os diagnósticos psiquiátricos $(\mathrm{p}=0,83)$ e clínicos $(\mathrm{p}=0,42)$. Entretanto, no HCFMRP-USP, foi evidenciada somente associação entre o tempo de resposta e os diagnósticos clínicos ( $\mathrm{p}<0,01$; enquanto que a 
Dados referentes ao tempo de solicitação (tempo decorrido entre a data de internação e a data do pedido de interconsulta) e os diagnósticos somáticos dos pacientes internados.

\begin{tabular}{|c|c|c|c|c|c|c|c|c|}
\hline \multirow[t]{3}{*}{ Diagnóstico somático } & \multicolumn{8}{|c|}{ Tempo de solicitação (em dias) } \\
\hline & \multicolumn{2}{|c|}{ Até 10} & \multicolumn{2}{|c|}{$11-20$} & \multicolumn{2}{|c|}{$21-30$} & \multicolumn{2}{|c|}{$31-40$} \\
\hline & $\begin{array}{l}\text { HCFMRP- } \\
\text { USP (\%) }\end{array}$ & $\begin{array}{c}\text { HU- } \\
\text { UFSC (\%) }\end{array}$ & $\begin{array}{l}\text { HCFMRP- } \\
\text { USP (\%) }\end{array}$ & $\begin{array}{c}\text { HU- } \\
\text { UFSC (\%) }\end{array}$ & $\begin{array}{l}\text { HCFMRP- } \\
\text { USP (\%) }\end{array}$ & $\begin{array}{c}\mathrm{HU}- \\
\text { UFSC (\%) }\end{array}$ & $\begin{array}{l}\text { HCFMRP- } \\
\text { USP (\%) }\end{array}$ & $\begin{array}{c}\text { HU- } \\
\text { UFSC (\%) }\end{array}$ \\
\hline Doenças infecciosas e parasitárias & $55(15,3)$ & $2(2,1)$ & $19(22,1)$ & $2(12,5)$ & - & $1(10,0)$ & - & $4(66,7)$ \\
\hline $\begin{array}{l}\text { Doenças endócrinas, metabólicas } \\
\text { e nutricionais }\end{array}$ & $50(13,9)$ & $6(6,4)$ & $6(7,0)$ & $4(25,0)$ & $4(21,0)$ & $2(20,0)$ & $1(8,3)$ & - \\
\hline Doenças do sistema circulatório & $41(11,4)$ & $13(13,8)$ & $16(18,6)$ & $4(25,0$ & $6(31,6)$ & $1(10,0)$ & $2(16,7)$ & - \\
\hline Doenças do aparelho digestivo & $36(10,0)$ & $4(4,3)$ & $5(5,8)$ & - & $3(15,8)$ & - & - & $1(16,7)$ \\
\hline Neoplasias & $29(8,1)$ & $3(3,2)$ & $5(5,8)$ & - & $2(10,5)$ & - & $3(25,0)$ & - \\
\hline Outros & $148(41,3)$ & $66(70,2)$ & $35(40,7)$ & $6(37,5)$ & $4(21,1)$ & $6(60,0)$ & $6(50,0)$ & $1(16,7)$ \\
\hline \multirow[t]{3}{*}{ Diagnóstico somático } & \multicolumn{5}{|c|}{ Tempo de solicitação (em dias) } & \multicolumn{3}{|c|}{ Valor de $p$} \\
\hline & \multicolumn{3}{|c|}{$41-50$} & \multicolumn{2}{|c|}{ Acima de 51} & \multirow{2}{*}{\multicolumn{2}{|c|}{ HCFMRP-USP }} & \multirow[b]{2}{*}{ HU-UFSC } \\
\hline & $\begin{array}{l}\text { HCFMRP- } \\
\text { USP (\%) }\end{array}$ & \multicolumn{2}{|c|}{ UFSC (\%) } & $\begin{array}{l}\text { HCFMRP- } \\
\text { USP (\%) }\end{array}$ & $\begin{array}{c}\text { HU- } \\
\text { UFSC (\%) }\end{array}$ & & & \\
\hline Doenças infecciosas e parasitárias & - & \multicolumn{2}{|c|}{$3(33,3)$} & $3(11,1)$ & - & \multicolumn{2}{|c|}{$<0,01$} & $<0,01$ \\
\hline $\begin{array}{l}\text { Doenças endócrinas, metabólicas } \\
\text { e nutricionais }\end{array}$ & - & \multicolumn{2}{|c|}{$3(33,3)$} & $1(3,7)$ & - & & & \\
\hline Doenças do sistema circulatório & $1(16,7)$ & \multicolumn{2}{|c|}{-} & - & - & & & \\
\hline Doenças do aparelho digestivo & $2(33,3)$ & \multicolumn{2}{|c|}{-} & $4(14,8)$ & - & & & \\
\hline Neoplasias & - & \multicolumn{2}{|c|}{$1(11,1)$} & $2(7,4)$ & - & & & \\
\hline Outros & $3(50,0)$ & \multicolumn{2}{|c|}{$2(22,2)$} & $17(63,0)$ & - & & & \\
\hline
\end{tabular}

HCFMRP-USP: Hospital das Clínicas da Faculdade de Medicina de Ribeirão Preto da Universidade de São Paulo; HU-UFSC: Hospital Universitário Professor Polydoro Ernani de São Thiago da Universidade Federal de Santa Catarina.

associação com os diagnósticos psiquiátricos obteve $\mathrm{p}=0,67$ ), o que indicaria uma tendência do interconsultor a responder mais rapidamente ao pedido de interconsulta segundo os diagnósticos clínicos. Dos pedidos que foram respondidos em até um dia, 15,8\% eram pedidos de interconsulta realizados para pacientes com doenças infecciosas e parasitárias, 13,8\% para pacientes com doenças do aparelho circulatório e 12,3\% para pacientes com doenças endócrinas, metabólicas ou nutricionais.

\section{Discussão}

Do nosso conhecimento, não foi realizado nenhum estudo comparativo entre dois hospitais gerais universitários brasileiros com a utilização de um protocolo padronizado, o que atribui ao presente estudo um caráter inédito e pioneiro.

\section{Características sócio-demográficas}

Com maior freqüência, foi solicitado atendimento para pacientes caucasianos, o que também foi observado em estudos nacionais anteriores 3,8 . Igualmente de acordo com a maioria de trabalhos prévios 3,18,19,20, foram atendidos predominantemente pacientes entre 21 a 60 anos e pacientes casados ou com união consensual 4,6,19,20. A maioria das solicitações foi feita para pacientes do sexo feminino, o que também está de acordo com os resultados da literatura na área 8,16,18,19,20. Tal predominância do sexo feminino pode estar relacionada ao fato de que os possíveis transtornos psiquiátricos motivadores de solicitação (por exemplo, transtorno de adaptação e depressão) se mostraram freqüentes em pacientes deste sexo 21,22,23 e também pode estar relacionada, segundo Botega 1, a um aspecto cultural manifestado pelo sexo feminino: maior capacidade de comunicar suas inquietudes psicológicas e ansiedade. 
Em ambas as cidades pesquisadas, a inatividade por invalidez (ou afastamento do trabalho) foi a situação laboral mais freqüentemente alegada, o que poderia estar relacionado à condição de saúde marcada pela gravidade ou cronicidade do quadro clínico dos pacientes. Este fato também foi evidenciado em outros estudos 20 . Já o cuidado com a casa foi também uma das situações laborais mais freqüentes, o que poderia estar relacionado ao fato de que a maioria da amostra foi do sexo feminino.

Foi encontrada diferença significativa entre a procedência dos pacientes atendidos no HU-UFSC e no HCFMRP-USP. Pacientes atendidos no HCFMRP-USP procederam, em grande maioria, de municípios do Estado de São Paulo enquanto que, no HU-UFSC, freqüentemente, foram atendidos pacientes da própria cidade de Florianópolis. Uma possível explicação para este achado é o fato do HCFMRP-USP ser um hospital universitário predominantemente de nível assistencial terciário, cujo atendimento é livre a qualquer paciente da rede de saúde pública que necessite de serviços de alta complexidade e procedimentos médicos especializados. Sendo assim, são atendidos pacientes de todo o Estado de São Paulo e também de outros estados do país. Por outro lado, o HU-UFSC é responsável por oferecer atendimentos nos três níveis assistenciais e, desta forma, indivíduos da própria cidade têm maior acesso à instituição por meio da rede de saúde local, o que elevaria a freqüência de pacientes provenientes da própria cidade de Florianópolis.

Dados referentes ao reduzido nível de escolaridade dos pacientes atendidos pela interconsulta psiquiátrica do HCFMRP-USP representam uma realidade característica do hospital: a maioria dos pacientes assistidos não possui condições econômicas e sociais favoráveis, e muitos deles provêm de uma região caracterizada pela agroindústria canavieira cujos trabalhos rurais são muito freqüentes. Vale ressaltar também que o HCFMRP-USP realiza muito poucos atendimentos particulares e de outros convênios, portanto, assiste indivíduos desprovidos de maiores recursos econômicos, fato que normalmente está relacionado diretamente com o nível de escolaridade. Em relação ao HU-UFSC, segundo dados obtidos no Instituto Brasileiro de Geografia e Estatística (http://tabnet.datasus.gov.br/cgi/ idb2008/matriz.htm, acessado em Jan/2009), a Região Sul do Brasil apresenta o maior índice de desenvolvimento humano, o que poderia explicar o maior nível de escolaridade dos pacientes assistidos no HU-UFSC.

\section{Diagnósticos clínicos e psiquiátricos}

A depressão foi o diagnóstico psiquiátrico mais freqüente entre os pacientes atendidos pelo serviço de interconsulta de ambos os hospitais, o que está de acordo com a maioria dos trabalhos realizados nesta área 18,20,24,25,26. Outros estudos também encontraram freqüências relevantes de transtornos de adaptação 6,8,24,25,26 e transtornos de personalidade 24,26 nos pacientes assistidos pela interconsulta psiquiátrica.

Acerca da associação encontrada entre os diagnósticos psiquiátricos e o sexo dos pacientes, assim como relatado em outros estudos 27,28 , a depressão mostrou ser mais prevalente no sexo feminino, o que poderia estar relacionado ao funcionamento hormonal e sua influência no bem-estar psíquico e emocional da mulher ao longo de sua vida. Estudos acerca da relação entre gênero e transtornos de personalidade consideraram que alguns tipos de transtornos (por exemplo, borderline em mulheres 29 , e anti-social e narcisista em homens ${ }^{30}$ ) podem estar relacionados ao sexo, porém, devido a possíveis limitações metodológicas, esses aspectos necessitariam de maiores investigações.

A associação entre o diagnóstico psiquiátrico e o clínico foi evidenciada somente nos dados referentes ao HCFMRP-USP. Não foi verificada nenhuma destas associações no HU-UFSC, provavelmente pelo fato do tamanho da amostra ser reduzido.

No HCFMRP-USP, o episódio depressivo mostrou ser condição freqüente em pacientes acometidos por doenças do aparelho circulatório, doenças infecciosas e parasitárias, e doenças endócrinas, metabólicas e nutricionais assim como relatado por Teng et al. 32 . Também foi encontrada evidência de associação entre os transtornos de adaptação e as neoplasias e enfermidades relacionadas ao sistema digestivo, o que poderia estar relacionado à condição de hospitalização e gravidade da doença, além da sabida relação entre estas condições e aspectos relacionados à maior morbidade, mortalidade e prejuízo na qualidade de vida.

\section{Clínicas solicitantes}

Assim como encontrado em outros estudos 6,19,20,32, a Clínica Médica foi a responsável pelo maior número de solicitações e também a que solicitou mais precocemente pedidos de interconsulta aos pacientes internados de ambos os hospitais. Isso pode ser explicado pelo fato de a clínica médica abarcar o maior número de especialidades, o que aumentaria sua freqüência como clínica solicitante. No HCFMRP-USP, a 
Nutrologia também se destacou entre as clínicas mais solicitantes devido à maior atenção voltada aos transtornos alimentares e, possivelmente, à ausência de uma equipe específica em Saúde Mental para essa clientela no hospital. Já, no HU-UFSC, como a Emergência não é uma unidade separada da instituição (como no caso do HCFMRP-USP), de fato seria de se esperar que muitas solicitações fossem feitas a seus pacientes, uma vez que são atendidos em condições de crise (muitas solicitações tiveram como motivo principal o risco suicida, sendo que a presença de ideação suicida e tentativas prévias de suicídio foram evidenciadas em mais de $20 \%$ dos casos avaliados pelos interconsultores).

A baixa freqüência de atendimentos a pacientes com histórico psiquiátrico no HCFMRPUSP pode estar relacionada à infra-estrutura da rede assistencial à saúde do Município de Ribeirão Preto e região. Desta forma, pacientes com enfermidades clínicas e psiquiátricas (ou com recidivas) passíveis de tratamento ambulatorial são assistidos no nível ambulatorial e centros de atenção psicossocial (CAPS) da rede municipal (diferentemente do HU-UFSC, que oferece assistência nos três níveis de atenção e o acesso é facilitado aos pacientes).

\section{Profissionais solicitantes}

Diferenças nas infra-estruturas dos serviços de interconsulta entre os dois hospitais podem explicar as variabilidades encontradas quanto aos profissionais solicitantes. A equipe profissional do HU-UFSC é composta por apenas médicos assistentes, residentes e um número mínimo de psicólogos contratados, o que poderia explicar a concentração de pedidos de interconsulta feitos por essas duas primeiras categorias. No HCFMRP-USP, houve maior distribuição entre os profissionais solicitantes, pois são oferecidos programas de aprimoramento, especialização e estágios em diversas áreas da saúde. Do mesmo modo, o hospital conta com uma equipe assistencial à Saúde Mental constituída por diversas categorias de profissionais, tais como alunos da Faculdade de Medicina de Ribeirão preto da própria universidade, terapeutas ocupacionais, psicólogos e estagiários, além dos residentes e dos médicos assistentes.

As taxas de encaminhamento verificadas no HCFMRP-USP e no HU-UFSC (em torno de 1\%) estão de acordo com as descritas na literatura nacional ${ }^{1}$, apesar de que ainda inferiores a de outros países como os Estados Unidos e a Inglaterra ${ }^{1}$. Sabe-se que a prevalência de transtornos psiquiátricos em hospitais gerais de modo geral, e universitários em particular, pode chegar até
50\% das internações. Daí pode-se especular que há uma enorme demanda reprimida para atendimento psiquiátrico nestes hospitais estudados.

\section{Tempo de internação}

As diferenças encontradas acerca do tempo de internação no HU-UFSC e no HCFMRP-USP parecem também estar relacionadas à própria infra-estrutura das instituições. A estabilização do quadro clínico, independente da presença e evolução do quadro psiquiátrico, mostrou ser preditora do tempo de internação do paciente - o que também justificaria os freqüentes encaminhamentos realizados após a alta hospitalar para os pacientes com transtornos psiquiátricos. No HCFMRP-USP, apesar da demanda por atendimento também ser elevada, a presença e evolução de transtornos psiquiátricos mostrou ser influente no tempo de internação. Como a instituição possui várias equipes multiprofissionais em Saúde Mental que atuam em ligação, a assistência aos pacientes com enfermidades clínicas que apresentam transtornos psiquiátricos é facilitada - o que poderia resultar no número reduzido de encaminhamentos realizados após a alta hospitalar quando comparado ao HU-UFSC.

\section{Tempo de solicitação e diagnóstico clínico}

Não foram encontradas diferenças significativas quanto ao tempo de solicitação em ambos os hospitais e este se mostrou associado aos diagnósticos clínicos. No HU-UFSC, foram solicitados mais rapidamente pedidos de interconsulta para pacientes internados com doenças do aparelho circulatório e tardiamente para aqueles com doenças infecciosas e endócrinas, metabólicas e nutricionais. Por outro lado, no HCFMRP-USP, pacientes com doenças infecciosas, endócrinas, metabólicas e nutricionais tiveram pedidos de interconsulta solicitados rapidamente e aqueles com doenças no aparelho digestivo tiveram solicitações realizadas tardiamente (após 50 dias de internação). Dessa forma, pode-se dizer que o diagnóstico clínico influiu diferentemente no tempo de solicitação do PI em relação aos dois hospitais estudados.

Para exemplificar essa dinâmica, pode-se citar que no HU-UFSC, cujos pacientes com doenças infecciosas, parasitárias, endócrinas, metabólicas, nutricionais e neoplasias tiveram um tempo de internação prolongado (acima de 51 dias), provavelmente devido às complicações clínicas, à recorrente necessidade de intervenções e à demora na estabilização dos quadros clínicos. As solicitações dos pedidos de interconsulta daqueles com comprometimento endócrino, 
metabólico e nutricional ou com neoplasias foram realizadas precocemente (em até dez dias após a internação) enquanto que os pacientes com doenças infecciosas e parasitárias tiveram solicitações de pedidos de interconsulta realizadas tardiamente (após um mês de internação). Esse fato pode ser atribuído pelo caráter emergencial das condições dos pacientes acometidos por doenças endócrinas, metabólicas e, especialmente, nutricionais, uma vez que muitos deles apresentaram quadros agudos de desnutrição ou disfunção que exigiram intervenção rápida e multiprofissional. No caso de pacientes com neoplasias, a gravidade do quadro costuma ser peculiar e qualquer alteração psiquiátrica requer uma avaliação mais precisa. Já a condição dos pacientes acometidos por doenças infecciosas e parasitárias, em especial àqueles com HIV/AIDS, foi caracterizada pela cronicidade do quadro e complicações ao longo do desenvolvimento da doença, o que justificaria a solicitação tardia de pedidos de interconsulta.

\section{Tempo de resposta e diagnóstico clínico}

Evidências apontam que o tempo de resposta está relacionado ao diagnóstico clínico do paciente, o que indicaria uma tendência do interconsultor a responder mais rapidamente aos pedidos de interconsulta segundo os diagnósticos clínicos dos pacientes. Pacientes com doenças infecciosas, parasitárias, endócrinas, metabólicas, nutricionais e relacionadas ao aparelho circulatório foram atendidas em até um dia após a realização dos pedidos de interconsulta.

Atendimentos realizados pelo interconsultor

Como não foram encontradas evidências que influenciassem o número de atendimentos feitos pelo interconsultor, como por exemplo o diagnóstico clínico ou psiquiátrico do paciente, pode-se entender que este número esteja relacionado à disponibilidade de atendimento por parte do mesmo.

\section{Planos de tratamento e prescrição de psicotrópicos}

A conduta adotada pelos interconsultores em relação ao plano de tratamento foi em acordo com a recomendada na literatura atual. Atendimentos individuais com interface terapêutica e prescrição de psicofármacos foram condutas freqüentemente sugeridas em diversos serviços de interconsulta psiquiátrica 3,18,25 assim como observado nos hospitais envolvidos no presente estudo.
Em relação às classes de medicação psicotrópica prescritas, notou-se uma homogeneidade na conduta dos profissionais de ambos os hospitais. Isto pode ser atribuído às informações amplamente divulgadas acerca dos benefícios da utilização de benzodiazepínicos, antidepressivos ISRS e antipsicóticos típicos no tratamento de transtornos psiquiátricos.

Quanto às diferenças nas medicações benzodiazepínicas prescritas, as diferenças encontradas podem estar relacionadas ao acesso, seja do hospital ou do paciente, a tais medicações na rede pública de Ribeirão Preto e de Florianópolis.

Aspectos relacionados aos médicos clínicos, aos profissionais de saúde e aos interconsultores

Na maior parte dos pedidos de interconsulta não foi descrita uma hipótese para o possível diagnóstico psiquiátrico. Entretanto, a maioria dos pedidos de interconsulta mencionou presença de distintos sintomas psiquiátricos para justificar a solicitação.

Médicos clínicos mostraram certa falta de familiaridade quanto à adequação de medicações psicotrópicas em possíveis casos psiquiátricos. Este fato pode estar relacionado à elevada suspensão ou troca dos psicotrópicos em uso após a avaliação dos interconsultores (entre 50\% e 65\% dos casos).

\section{Limitações do estudo}

Algumas limitações do presente estudo podem ser apontadas. Em relação ao tamanho da amostra, pode-se dizer que foi relativamente pequena, especialmente no HU-UFSC. As diferenças na infra-estrutura dos dois serviços e dos contextos regionais nos quais estão inseridos também são aspectos a serem mencionados. Outras limitações foram o razoável número de perdas por ausência do PRISMe anexado ao pedido de interconsulta e a impossibilidade de seguimento pós-alta dos pacientes. É importante ressaltar, também, que os diagnósticos psiquiátricos não foram confirmados por instrumentos validados e padronizados (Structured Clinical Interview for DSM - SCID - ou Composite International Diagnostic Interview - CIDI -, por exemplo).

\section{Conclusão}

Os achados do presente estudo estão de acordo com a literatura nacional e internacional e as diferenças encontradas em relação à clientela as- 
sistida, às clínicas e profissionais solicitantes e ao tempo de internação podem ser atribuídas à infra-estrutura (estrutura física e equipe profissional atuante) das instituições e aos contextos sócio-econômicos particulares nos quais estão inseridos. Porém, apesar dessas diferenças, as atitudes e condutas adotadas tanto pelos profissionais de saúde quanto pelos interconsultores em ambos os hospitais foram homogêneas e condizentes com o difundido na literatura.

\section{Resumo}

O objetivo do presente estudo foi comparar pedidos de interconsulta psiquiátrica realizados para dois hospitais gerais universitários brasileiros e avaliar a aplicabilidade de um protocolo de registro de interconsulta psiquiátrica (PRISMe). Foi realizada análise dos pedidos de interconsulta, do PRISMe anexado a eles e o número total de pedidos de interconsulta incluídos na amostra foi 541 (438 pedidos de interconsulta do HCFMRP-USP e 103 pedidos de interconsulta do $H U$-UFSC). Observou-se maior freqüência de solicitação para pacientes do sexo feminino, caucasianos, entre 31 a 60 anos e casados. Os diagnósticos psiquiátricos mais freqüentes foram depressão, transtornos de adaptação e de personalidade. Os resultados estão de acordo com a literatura nacional e internacional e as diferenças encontradas podem ser atribuídas às diferenças na infra-estrutura das instituições e nos contextos sócio-econômicos nos quais estão inseridas. Achados do presente estudo demonstram a aplicabilidade do PRISMe e sugerem que podem facilitar a sistematização da obtenção de achados clínico-demográficos e a comparabilidade entre as diferenças.
Os achados no presente estudo são pertinentes e podem auxiliar no aprimoramento dos serviços de interconsulta de ambos os hospitais.

Por fim, a aplicabilidade de um protocolo de registro, em especial o PRISMe, se mostrou viável e seu uso, promissor. Assim, pode-se dizer que futuros estudos com maior período de avaliação e maior número de serviços seriam particularmente necessários e oportunos.

\section{Colaboradores}

T. I. K. Nakabayashi e J. A. S. Crippa participaram da concepção, projeto, análise e interpretação dos dados, redação do artigo e revisão crítica relevante do conteúdo intelectual. A. C. T. B. F. Rufino contribuiu com a concepção, projeto, análise e interpretação dos dados e revisão crítica relevante do conteúdo intelectual. J. E. C. Hallak, F. L. Osório, S. R. Loureiro, C. G. Leal, J. O. B. Contel, C. C. Cabrera e K. A. Guerra participaram da concepção e projeto; revisão crítica relevante do conteúdo intelectual. R. M. Souza participou da análise e interpretação dos dados.

\section{Agradecimentos}

T. I. K. Nakabayashi é bolsista da Fundação de Amparo à Pesquisa do Estado de São Paulo (FAPESP). J. A. S. Crippa e S. R. Loureiro recebem bolsa de produtividade em pesquisa do Conselho Nacional de Desenvolvimento Científico e Tecnológico (CNPq). Este trabalho teve apoio parcial da Fundação de Apoio ao Ensino, Pesquisa e Assistência (FAEPA) do HCFMRP-USP.

Psiquiatria; Saúde Mental; Diagnóstico 


\section{Referências}

1. Botega NJ. Prática psiquiátrica no hospital geral: interconsulta e emergência. 2a Ed. Porto Alegre: Editora Artmed; 2006

2. Mayou R, Hawton K. Psychiatric disorder in the general hospital. Br J Psychiatry 1986; 149:172-90.

3. Kerr-Corrêa F, Silva BCM. Avaliação do ensino de psiquiatria pela análise dos pedidos de interconsulta. J Bras Psiquiatr 1985; 34:247-52.

4. Millan LR, Miguel Filho EC, Lima MGA, Fráguas Jr. R, Gimenes R. Psiquiatria no hospital geral: experiência de um ano. Rev Psiquiatr Clín 1986; 13:33-8.

5. Shavitt RG, Busatto Filho G, Miguel Filho EC. Interconsulta psiquiátrica: conceito e evolução. Rev Paul Med 1989; 107:108-12.

6. Magdaleno Jr. R, Botega NJ. Interconsulta psiquiátrica no hospital geral universitário: um ano no Hospital das Clínicas da UNICAMP. J Bras Psiquiatr 1991; 40:95-8.

7. Souza JRP. Consultoria psiquiátrica na Santa Casa de Campo Grande. J Bras Psiquiatr 1995; 44:123-8.

8. Andreoli PBA, Peluso ET, Andreoli SB, Martins LAN. Padronização e informatização de dados em serviços de interconsulta médico-psicológica de um hospital geral. Rev ABP-APAL 1996; 18:89-94.

9. Spinelli MA, Toledo ML, Cantinelli F. Psiquiatria de interconsulta no Hospital Geral: comunicação inicial de uma experiência. Rev Assoc Med Bras 1996; 42:175-84.

10. Smaira SI. Transtornos psiquiátricos e solicitações de interconsulta psiquiátrica em Hospital Geral: um estudo de caso controle [Dissertação de Mestrado]. Ribeirão Preto: Universidade de São Paulo; 1998.

11. Huyse FJ, Herzog T, Malt UF, Lobo A. The European Consultation-Liaison Workgroup (ECLW) collaborative study I: general outline. Gen Hosp Psychiatry 1996; 18:44-55.

12. Lobo A, Huyse FJ, Herzog T, Malt UF, Opmeer BC. The ECLW collaborative study II: patient registration form (PRF) instrument, training and reliability. J Psychosom Res 1996; 40143-56.

13. Alaja R, Seppä K, Sillanaukee P, Tienari P, Huyse FJ, Herzog T, et al. Psychiatric referrals associated with substance use disorders: prevalence and gender differences. Alcohol Clin Exp Res 1997; 21:620-6.

14. Alaja R, Tienari P, Seppä K, Tuomisto M, Leppävuori A, Huyse FJ, et al. Patterns of comorbity in relation to functioning (GAF) among general hospital psychiatric referrals. Acta Psychiatr Scand 1999; 99:135-40.

15. Huyse FJ, Herzog T, Lobo A, Malt UF, Opmeer BC, Stein B, et al. European consultation-liaison psychiatric services: the ECLW collaborative study. Acta Psychiatr Scand 2000; 101:360-6.

16. Huyse FJ, Herzog T, Lobo A, Malt UF, Opmeer BC, Stein B, et al. European consultation-liaison services and their user populations: the European consultation-liaison workgroup collaborative study. Psychosomatics 2000; 41:330-8.
17. Organização Mundial da Saúde. Classificação estatística internacional de doenças e problemas relacionados à saúde. 10a revisão. São Paulo: Universidade de São Paulo; 1997.

18. Lipowski ZJ, Wolston EJ. Liaison psychiatry: referral patterns and their stability over time. Am J Psychiatry 1981; 138:1608-11.

19. Gala C, Rigatelli M, De Bertolini C, Rupolo G, Gabrielli F, Grassi L. A multicenter investigation of consultation-liaison psychiatric in Italy. Gen Hosp Psychiatry 1999; 21:310-7.

20. Kishi Y, Meller WH, Kathol RG, Swigart SE. Factors affecting the relationship between the timing of psychiatric consultation and general hospital length of stay. Psychosomatics 2004; 45:470-6.

21. Shevitz SA, Silberfarb PM, Lipowski ZJ. Psychiatric consultation in general hospital: a report of 1000 referrals. Dis Nerv Syst 1976; 37:295-300.

22. Theme-Filha MM, Szwarcwald CL, Souza-Junior PRB. Socio-demographic characteristics, treatment coverage, and self-rated health of individuals who reported six chronic diseases in Brazil, 2003. Cad Saúde Pública 2005; 21 Suppl:S43-53.

23. Vinberg M, Kessing LV. Risk factors for development of affective disorders. Ugeskr Laeger 2007; 169:1434-6.

24. Brown A, Cooper F. The impact of a liaison psychiatry service on patterns of referral in a general hospital. Br J Psychiatry 1987; 150:83-7.

25. Fido AA, Al Mughaiseeb A. Consultation liaison psychiatric in a Kuwaiti general hospital. Int J Soc Psychiatry 1989; 35:274-9.

26. Lyketsos CG, Dunn G, Kaminsky MJ, Breakey WR. Medical comorbidity in psychiatric inpatients - relation to clinical outcomes and hospital length of stay. Psychosomatics 2002; 43:24-30.

27. Andrade LHSG, Viana MC, Silveira CM. Epidemiologia dos transtornos psiquiátricos na mulher. Rev Psiquiatr Clín 2006; 33:43-54.

28. Justo LP, Calil HM. Depressão - o mesmo acometimento para homens e mulheres? Rev Psiquiatr Clín 2006; 33:74-9.

29. Johnson DM, Shea MT, Yen S, Battle CL, Zlotnick C, Sanislow CA, et al. Gender differences in borderline personality disorder: findings from the collaborative longitudinal personality disorders study. Compr Psychiatry 2003; 44:284-92.

30. Golomb M, Fava M, Abraham M, Rosenbaum JF. Gender differences in personality disorders. Am J Psychiatry 1995; 152:579-82.

31. Teng CT, Humes EC, Demetrio FN. Depressão e comorbidades clínicas. Rev Psiquiatr Clín 2005; 32:149-59.

32. Alhamad AM, Al-Sawaf MH, Osman AA, Ibrahim IS. Differential aspects of consultation-liaison psychiatry in a Saudi hospital. I: referral pattern and clinical indices. East Mediterr Health J 2006; 12:316-23.

Recebido em 27/Mar/2009

Versão final reapresentada em 17/Nov/2009

Aprovado em 01/Abr/2010 